\title{
Variations in coral reef net community calcification and aragonite saturation state on local and global scales
}

\author{
By \\ Whitney Nicole Bernstein \\ B.S., University of California, Berkeley, 2008 \\ Submitted in partial fulfillment of the requirements for the degree of \\ Doctor of Philosophy \\ at the \\ MASSACHUSETTS INSTITUTE OF TECHNOLOGY \\ and the \\ WOODS HOLE OCEANOGRAPHIC INSTITUTION
}

September 2013

\section{(C) 2013 Whitney Nicole Bernstein \\ All rights reserved.}

The author hereby grants to MIT and WHOI permission to reproduce and to distribute publicly paper and electronic copies of this thesis document in whole or in part in any medium now known or hereafter created.

Signature of Author

Joint Program in Oceanography/Applied Ocean Science and Engineering Massachusetts Institute of Technology and Woods Hole Oceanographic Institution August 9, 2013

Certified by

Dr. Konrad A. Hughen

Thesis Supervisor

Accepted by

Dr. Elizabeth Kujawinski

Chair, Joint Committee for Chemical Oceanography

Woods Hole Oceanographic Institution 


\title{
Variations in coral reef net community calcification and aragonite saturation state on local and global scales
}

by

\section{Whitney Nicole Bernstein}

Submitted to the Department of Marine Chemistry and Geochemistry, Massachusetts Institute of Technology - Woods Hole Oceanographic Institution Joint Program in Oceanography/Applied Ocean Science and Engineering on August 9, 2013

in partial fulfillment of the requirements for the degree of Doctor of Philosophy

\begin{abstract}
Predicting the response of net community calcification (NCC) to ocean acidification $(\mathrm{OA})$ and declining aragonite saturation state $\left(\Omega_{\mathrm{a}}\right)$ requires a thorough understanding of controls on NCC. The diurnal control of light and net community production (NCP) on NCC confounds the underlying control of $\Omega_{\mathrm{a}}$ on NCC and must be averaged out in order to predict the general response of NCC to OA. I did this by generating a general NCC- $\Omega_{a}$ correlation based on data from 15 field and mesocosm studies around the globe. The general relationship agrees well with results from mesocosm experiments. This general relationship implies that NCC will transition from net calcification to net dissolution at a $\Omega_{\mathrm{a}}$ of $1.0 \pm 0.6$ and predicts that NCC will decline by $50 \%$ from 1880 to 2100 , for a reef of any percent calcifier cover and short reef water residence time. NCC will also decline if percent calcifier cover declines, as evidenced by estimates of NCC in two Caribbean reefs having declined by an estimated $50-90 \%$ since 1880 . The general NCC- $\Omega_{a}$ relationship determined here, along with changes in percent calcifier cover, will be useful in predicting changes in NCC in response to OA and for refining models of reef water $\Omega_{\mathrm{a}}$.
\end{abstract}

Thesis Supervisor: Konrad A. Hughen

Title: Associate Scientist, Woods Hole Oceanographic Institution 


\section{Acknowledgements}

This thesis represents a half decade of work for which there is a village of people to thank. First and foremost, I thank my committee, Konrad Hughen, Chris Langdon, Steve Lentz, Dan McCorkle, and Ed Boyle. I deeply appreciate all the time and advice you dedicated to this project through committee meetings and numerous informal meetings in between. Your contribution has greatly enriched my learning experience throughout graduate school.

Konrad Hughen, my thesis adviser, is a veritable fountain of enthusiasm and scientific curiosity. Above all, I appreciate him allowing me to pursue the research that interested me, even if it did not fall neatly within his expertise or funding portfolio. He is open-minded and flexible and is a creative problem solver. Also, Konrad is deeply dedicated to the success of the lab group - he is even willing to answer the phone at midnight to help me troubleshoot the inductively coupled plasma atomic emission spectrometer! Finally, I am so grateful for him including me in many adventures in the Red Sea and Micronesia. These were experiences of a lifetime that I will never forget and always cherish.

I am also deeply grateful to Chris Langdon, effectively my second adviser and mentor. Chris, I am still astonished at your willingness to take me under your wing and include me in your research plans. Your openness to an impromptu proposal at the ASLO poster session led to a collaboration and mentorship that profoundly changed the path of my thesis and my intellectual journey along the way. I deeply appreciate the scenic drives, long suppers, and many phone calls when we discussed science from the minutia of theory and data to the big picture questions of what this all really means to you, me and society.

When learning how to conduct my own field work, my first mistake was thinking I could do it all myself. So I am extremely grateful to Craig Marquette for coming to the rescue during my first field campaign. I am so fortunate that he was on our field trip and available to help me handle the gear and sample the water. Of all the people that have helped me in the field, he made the caps the tightest! From that point onward, I actively sought out field assistants. I am very grateful to all the people who generously volunteered their time and energy to assist me in the field: Steve Lentz, Chris Langdon, James Churchill, Pedro De La Torre, William Decarvalho, Jessica Masterman, Chip Young, Ryan Moyer, Melissa Meléndez Oyola, Evan D'Alessandro, Jeff Demott, Jorge Corredor and the students at University of Puerto Rico at Mayagüez. William so patiently trouble-shot the YSI and the the CTD. He was also enthusiastic about swimming or floating across the reef for each transect, even with the cumbersome CTD load. Pedro brought a wonderful sense of humor and comical note to the group. He was also incredibly helpful at remember details and he was so swift with the Niskin casts excellent! Jess is a careful listener and is always thinking of ways to improve the effort, rather than simply following instructions. She always helped me remember or account for things that I may have overlooked. She also is very thorough and helped with the entire job, all the way to the end. Chip is a true right hand man. He is always ready, willing 
and eager to help and is always thinking and trouble shooting. I feel so fortunate to have had the pleasure of working with so many wonderful, joyful and inspirational people.

I also received tremendous support from many people in both Dan McCorkle's laboratory and Chris Langdon's laboratory. I am especially appreciative of Carolina Mor, Rebecca Belastock, and Elizabeth Bonk for teaching, guiding, and assisting me in the laboratory in so many ways and for being such a joy to work with during long lab days. Dan and Chris, thank you for generously providing these laboratory resources and facilities to me.

Among the countless people who have helped me along the way are Tom Farrar for providing files of surface irradiance and wind speed, Sanjay Tiwari and David Glover for helping me learn MATLAB, Vicke Starczak for help with statistics, Jill Duzan at Falmouth Hospital for helping me take x-ray images of coral cores, and Rachel Stanley for helping me better understand my calculations for air-sea gas exchange. I thank Jim Falter, Emily Shaw, Katie Shamberger, and Jack Silverman for kindly sharing their original hourly net community calcification rates from their published studies. So many others have helped too, so if I neglected to name you here, please know that you are in my mind and I am thankful for your help.

I appreciate the hospitality of the University of Puerto Rico at Mayaguiez, the Univeristy of Miami at Broad Key, Dream Divers and the King Abdullah University of Science and Technology. These institutions have provided essential support that is invaluable to the success of each field excursion. The Dream Divers crew members, especially Ray Nan, were incredibly helpful in all aspects of the research activities.

The administrative support of at WHOI is unparalleled and has made this a home for me and my class mates: in APO Julia Westwater, Marsha Gomes, Tricia Gebbie, Leanora Fraser, Michelle McCafferty, Christine Charette, Jim Yoder, and Meg Tivey; chemistry education coordinator Mark Kurz; in MC\&G Jeff Seewald, Sheila Clifford and Donna Mortimer. Many thanks to the JP's tireless champion at MIT, Ed Boyle, for continuing to look out for our welfare at MIT. Thanks to Ronni Schwartz for helping us navigate the resources at MIT.

I would like to express a special thanks to Jim Yoder. Jim has connected me with so many opportunities to enrich my educational and intellectual experience during graduate school and to prepare me for success in my career afterward. The opportunity to participate in his NNOCCI project was pivotal. Following that experience, I presented several creative ways to further enrich my experience and those of my peers - namely the Broader Impacts Group and Synergy and related activities. I am deeply appreciative of Jim's open-mindedness and his tremendous support of these new ideas.

I am immensely appreciative of my incredible family and friends - mom, dad, Kathryn, Jim, Russell, Chelsea, Megan, Kalina, Alice, Sarah, Lizzie, Johanna, Jennifer, Maria, and many others. Having been with me from the beginning or having come into my life along the way, each of these individuals made an important contribution toward enriching my overall experience in graduate school.

Above all, I am indebted to Frédéric Jaffre. Thank you for helping me with everything this thesis entailed - the happy days, the hungry days, the tough days, and the days of triumph. This thesis is as much yours as it is mine. I dedicate this thesis to you. 
This research was supported by WHOI Coastal Ocean Institute Student Research Award, MIT EAPS Student Research Award, WHOI Academic Program Office Ocean Ventures Fund, MIT Student Assistance Fund and MIT Houghton Fund. Additional research funds were provided by OCE1031288, WHOI Access to the Sea 27500040 and WHOI Access to the Sea-Special Call 25110104 to K.A.Hughen; NSF OCE0628406 and NOAA's Coral Reef Conservation Program Atlantic Ocean Acidification Test Bed project funding to C. Langdon; King Abdullah University of Science and Technology USA 00002 and KSA 00011 to S.J. Lentz; and King Abdullah University of Science and Technology to D. McCorkle.

I was supported throughout this graduate program by the NSF Graduate Research Fellowship Program, WHOI Ocean Life Insitute, WHOI Academic Program Office funds, and NSF-DUE-1043405 (PI James Yoder).

This material is based upon work supported under a National Science Foundation Graduate Research Fellowship. Any opinions, findings, conclusions or recommendations expressed in this publication are those of the author(s) and do not necessarily reflect the views of the National Science Foundation. 


\section{Table of Contents}

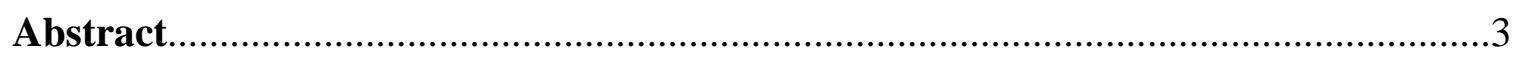

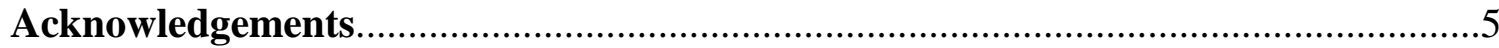

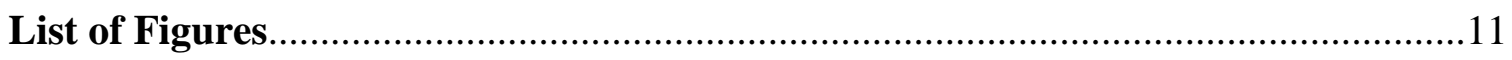

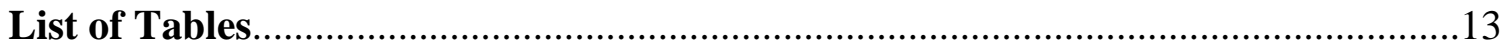

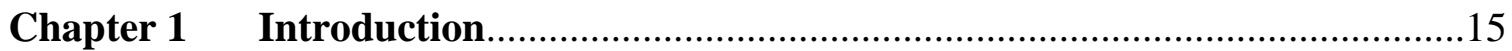

Chapter 2 Environmental controls on daytime net community calcification on a

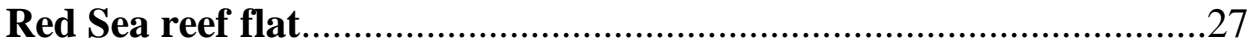

Figures and Tables....................................................................5

Supplementary Tables...............................................................6 67

Chapter 3 A general relationship to predict the global response of coral reef net community calcification (NCC) to ocean acidification.......................71

Figures and Tables........................................................................91

Supplementary Figures and Tables................................................... 106

Chapter 4 Decline in net community calcification in the Caribbean Region.....117

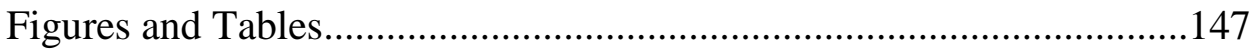

Supplementary Figures and Tables...................................................165

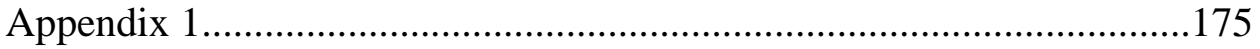

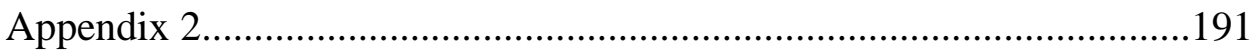

Chapter 5 Conclusions and suggestions for future research............................199 


\section{List of Figures}

\section{Chapter 2}

Figure 1: Sketch of the processes and parameters that influence NCC and NCP

Figure 2: Maps of study site

Figure 3: Temperature and light climatology

Figure 4: Benthic community composition

Figure 5: Diagram of length estimates

Figure 6: Time series of water velocity and depth

Figure 7: NCC versus $\Omega_{\mathrm{a}}$

Figure 8: NCC versus NCP

Figure 9: $\mathrm{NCC}$ and $\mathrm{NCP}$ versus $\left[\mathrm{NO}_{3}{ }^{2-}\right]$

Figure 10: Daytime NCC versus $\Omega_{\mathrm{a}}$ for field and mesocosm studies

Figure 11: $\Omega_{\mathrm{a}}$ versus light levels

Figure 12: Alkalinity versus DIC

\section{Chapter 3}

Figure 1: Daytime NCC rate versus $\Omega_{\mathrm{a}}$ for field and mesocosm studies.

Figure 2: Distribution of the global data amongst the seasons

Figure 3: Geographic distribution of the global data set

Figure 4: NCC versus percent calcifier cover

Figure 5: Global data set of field and mesocosm NCC versus $\Omega_{\mathrm{a}}$

Figure 6: Global data set of field and mesocosm NNCC versus $\Omega_{a}$

Figure 7: $\Omega_{\mathrm{a}}$ versus percent calcifier cover

Figure 8: NCC versus temperature

Figure 9: NCC versus daily-integrated PAR

Figure 10: NCC in 1880 and 2100

Figure S1: Daytime NCC rate versus $\Omega_{\mathrm{a}}$ for field studies only

Figure S2: Daytime NCC rate versus $\Omega_{\mathrm{a}}$ for mesocosm studies only

Figure S3: Daytime NNCC rate versus $\Omega_{\mathrm{a}}$ for field and mesocosm studies

Figure S4: Daytime NNCC rate versus $\Omega_{\mathrm{a}}$ for field studies only

Figure S5: Daytime NNCC rate versus $\Omega_{\mathrm{a}}$ for mesocosm studies only

Figure S6: Global data set of field study NCC versus $\Omega_{\mathrm{a}}$

Figure S7: Global data set of mesocosm study NCC versus $\Omega_{a}$

Figure S8: Global data set of field study NNCC versus $\Omega_{\mathrm{a}}$

Figure S9: Global data set of mesocosm study NNCC versus $\Omega_{\mathrm{a}}$ 


\section{Chapter 4}

Figure 1: Map of study site in La Parguera, Puerto Rico

Figure 2: Map of study site near North Key Largo, Florida

Figure 3: Aerial photograph of Cayo Enrique, Puerto Rico

Figure 4: Benthic Cover at Cayo Enrique, Puerto Rico

Figure 5: Aerial photograph of Evan's Reef, Florida

Figure 6: Benthic Cover at Evan's Reef, Florida

Figure 7: Photograph of the Lagrangian drifter

Figure 8: Hourly NCC rates for each field season at each site

Figure 9: Hourly NCP rates for each field season at each site

Figure S1:Direction of flow at Cayo Enrique

Figure S2: Velocity of flow at Cayo Enrique

Figure S3:YSI Calibration - Broad Key - August

Figure S4:TA-DIC plot - Cayo Enrique - August

Figure S5: TA-DIC plot - Cayo Enrique - December

Figure S6: TA-DIC plot - Broad Key - February

Figure S7: TA-DIC plot - Broad Key - August

Figure S8: Hourly NCC rates with times of transects

Figure S9: Hourly NCP rates with times of transects

\section{Appendix 1}

Figure A1.1: Change in TA and S - Cayo Enrique - August

Figure A1.2: Expanded Axis: Change in TA and S - Cayo Enrique - August

Figure A1.3: YSI salinity data - Cayo Enrique - August - T11-T13

Figure A1.4: Change in TA and S - Cayo Enrique - December

Figure A1.5: Change in TA and S - Broad Key - February

Figure A1.6: YSI salinity data - Broad Key - February - T1

Figure A1.7: Change in TA and S - Broad Key - August

Figure A1.8: YSI salinity data - Broad Key - August - T16

Figure A1.9: YSI salinity data - Broad Key - August - T18

Figure A1.10: Expanded Axis: Change in TA and S - Broad Key - August

Figure A1.11: YSI salinity data - Broad Key - August - T17

Figure A1.12: Expanded Axis: Change in TA and S - Broad Key - August

Figure A1.13: YSI salinity data - Broad Key - August - T32

Figure A1.14: YSI salinity data - Broad Key - August - T26

Figure A1.15: YSI salinity data - Broad Key - August - T29

Figure A1.16: YSI salinity data - Broad Key - August - T20-T21 


\section{Appendix 2}

Figure A2.1: YSI Calibration - Broad Key - February

Figure A2.2: Scatter plot comparing YSI and Winkler-based NCP estimates

Figure A2.3: Bar graph comparing YSI and Winkler-based NCP estimates

Figure A2.4: Comparison of DIC and $\mathrm{O}_{2}$-based NCP estimates $-\mathrm{CE}-\mathrm{Dec}$

Figure A2.5: Comparison of DIC and $\mathrm{O}_{2}$-based NCP estimates $-\mathrm{BK}-\mathrm{Feb}$

\section{List of Tables}

\section{Chapter 2}

Table 1 Summary of measurements and calculated values

Table 2: Average daytime NEC and NCP rates and environmental data for several field and mesocosm studies

Table 3: Statistics and regression data for correlations between NCC, NCP and environmental parameters

Table 4: The net metabolic effect of NCC and NCP on $\Omega_{\mathrm{a}}$

Table S1: Instantaneous NCC and NCP

Table S2: Alkalinity and DIC of the open-ocean end-member

Table S3: Daytime NCC and environmental data and description of data source

\section{Chapter 3}

Table 1: Summary of data extracted from the 14 studies used in this analysis

Table 2: Statistics and regression data for correlations between NCC and environmental parameters

Table 3: Statistics and regression data for correlations between NNCC and environmental parameters

\section{Chapter 4}

Table 1: Summary of measurements and calculated values

Table 2: Precision of TA and DIC measurements

Table 3: Net community calcification rates (NCC) for this study compared to NCC for Kinsey (1982) 


\section{Chapter 1:}

Introduction to controls on net community calcification 
It is critical that the accretion of carbonate material precipitate by calcifying organisms exceed the cumulative erosive and corrosive forces continually deteriorating the reef structure in order for reefs to retain their physical framework and to keep pace with sea level rise and to remain robust and resilient in the face of diverse stressors. The net accretion of biogenic carbonate minerals by calcifying organisms minus the loss of that material by dissolution is called net community calcification (NCC). Because NCC is a biologically mediated mineral precipitation process, it is sensitive to several biologically and chemically relevant parameters, including carbonate saturation state, temperature, light levels, nutrient concentrations, and productivity. Carbonate saturation state is of particular interest because it is presently in rapid decline around the globe due to ocean acidification, the decline in ocean $\mathrm{pH}$ due to dissolution of anthropogenic $\mathrm{CO}_{2}$ into the surface ocean. . The concomitant shift in carbonate speciation - a decline in carbonate saturation state - results in less favorable conditions for carbonate mineral precipitation. In this thesis, I estimated NCC at three sites and assessed short and long term controls on NCC. I proposed a model for predicting the impact of ocean acidification on average NCC around the globe with the aim of informing scientific understanding of how coral reefs will respond to the rapidly changing environment in the future.

\section{Net community calcification}

Calcification is a critical process at coral reefs, promoting high biodiversity by providing the structural support for complex habitats and providing suitable substrate over a large depth gradient (Kleypas and Langdon 2006; Kleypas et al. 2006). Massive corals serve to build the gross reef structure, enabling the entire ecosystem to keep pace with long-term changes in sea level (Kleypas and Langdon 2006; Kleypas et al. 2006) and constantly working against the forces of bio-erosion, dissolution and erosion from waves and storms. Sand, coral rubble, and foraminifera fill in the gaps in the reef framework and coralline algae serve to cement and consolidate the reef foundation (Bjork et al. 1995). Together, these reef building components produce a varied and complex 
habitat that supports some of the most diverse ecosystems on the planet (Kleypas and Langdon 2006; Kleypas et al. 2006).

$\mathrm{NCC}$ is the net result of calcification and dissolution. Calcification is the biogenic precipitation of carbonate mineral by organisms such as corals, coralline algae, bivalves, snails and foraminifera. Because tropical and subtropical surface waters are saturated with respect to $\mathrm{CaCO}_{3}$, most dissolution is metabolically driven. Metabolic dissolution occurs when microbial remineralization of organic matter (respiration) generates $\mathrm{CO}_{2}$, leading to $\mathrm{CaCO}_{3}$ undersaturation in microenvironments within the reef matrix or sediment pore waters (Walter et al. 1993; Ku et al. 1999; Burdige and Zimmerman 2002; Andersson et al. 2007; Burdige et al. 2010). High-magnesium calcite produced by coralline algae is more susceptible to this because it is the more soluble than aragonite and low-magnesium calcite (Morse et al. 2006; Anthony et al. 2008; Jokiel et al. 2008; Kuffner et al. 2008; Martin and Gattuso 2009). Biocorrosion occurs when euendoliths, such as microbes, fungi and algae, penetrate carbonate substrates by dissolving them (Radtke et al. 1997; Tribollet and Golubic 2011). Some organisms, such as sea cucumbers, dissolve carbonate sediments in their digestive tracts (Schneider et al. 2011). Some macroborers use chemical means combined with abrasion to penetrate and erode the substrate. Even small organisms are able to make microenvironments sufficiently acidic to drive dissolution of the carbonate substrate. Together, the net effect of calcification and dissolution by this diverse community of calcifying organisms and erosion agents is a change in alkalinity. Alkalinity declines by two equivalents $/ \mathrm{kg}$ seawater with each mole of $\mathrm{CaCO}_{3}$ formed. Dissolution of $\mathrm{CaCO}_{3}$ restores alkalinity to the seawater in the same proportion. Thus, assuming that the effects of abiotic carbonate precipitation and photosynthesis on alkalinity are negligible, we estimate NCC by measuring the change in alkalinity.

\section{Ocean acidification and aragonite saturation state}

Since the start of the industrial revolution, anthropogenic activities such as the burning of fossil fuels, cement production, and land use changes have redistributed 
significant amounts of carbon from the lithosphere and biosphere to the atmosphere (IPCC 2007). Approximately one quarter of the anthropogenic $\mathrm{CO}_{2}$ emitted to the atmosphere each year is absorbed by the surface ocean and reacts with seawater to form carbonic acid (Canadell et al. 2007). Since the industrial revolution (1800-1994), the oceans absorbed as much as $48 \%$ of the total anthropogenic $\mathrm{CO}_{2}$ emissions (Sabine et al. 2004), resulting in a decline in average global surface ocean $\mathrm{pH}$ of approximately 0.1 units, which equates to a $30 \%$ increase in acidity (i.e. hydrogen ion concentration) (Caldeira and Wickett 2003). Seawater $\mathrm{pH}$ is projected to continue to decline by about 0.3 units by the year 2100 (Caldeira and Wickett 2003).

Because of the profound influence of $\mathrm{pH}$ on the carbonate chemistry of seawater, ocean acidification is expected to significantly impact biogenic calcium carbonate precipitation in the future. Ocean acidification results in a reduction in the concentration of carbonate ion, $\left[\mathrm{CO}_{3}{ }^{2-}\right]$, via the following net reaction: $\mathrm{H}_{2} \mathrm{O}+\left(\mathrm{CO}_{2}\right)_{\mathrm{aq}}+\mathrm{CO}_{3}{ }^{-2} \rightarrow$ $2 \mathrm{HCO}_{3}{ }^{-}$. For the average surface waters in the tropical ocean, as of 1994 ocean acidification had already caused an $11 \%$ decline in $\left[\mathrm{CO}_{3}{ }^{2-}\right]$ relative to preindustrial levels and is projected to cause a $45 \%$ decline in $\left[\mathrm{CO}_{3}{ }^{2-}\right]$ by the year 2011 , if atmospheric $\mathrm{CO}_{2}$ continually increases (Orr et al. 2005). This has negative consequences for calcifying organisms because $\mathrm{CO}_{3}{ }^{2-}$ is an essential ingredient for calcification. This consequence is reflected in the decline in the calcium carbonate saturation state, defined as:

$$
\Omega=\frac{\left[\mathrm{Ca}^{2+}\right]\left[\mathrm{CO}_{3}^{2-}\right]}{K_{s p}^{\prime}}
$$

where $K_{s p}^{\prime}$ is the conditional solubility product for a particular mineral phase of $\mathrm{CaCO}_{3}$ (e.g. calcite, aragonite, high-magnesium calcite). The aragonite saturation state $\left(\Omega_{\mathrm{a}}\right)$ is used exclusively in this thesis because it is the dominant form of $\mathrm{CaCO}_{3}$ precipitated by calcifying reef organisms, particularly corals. High-magnesium calcite is precipitated by calcifying algae, but there is no consensus as to which $K_{s p}^{\prime}$ to use for this mineral because the $K_{s p}^{\prime}$ depends on the proportion of magnesium to calcium in the mineral, and this proportion is not fixed.

$\Omega_{\mathrm{a}}$ provides an indication of whether or not the formation of solid $\mathrm{CaCO}_{3}$ is thermodynamically favored under the specific conditions and chemical composition of 
the system. The concentration of calcium in seawater is large $(\sim 10 \mathrm{mmol} / \mathrm{kg})$ and varies only slightly with salinity, whereas the concentration of carbonate is much smaller $(\sim 0.25$ $\mathrm{mmol} / \mathrm{kg}$ ) and has already decreased by $11 \%$ over the past century due to ocean acidification (Orr et al. 2005). If $\Omega_{\mathrm{a}}$ is less than 1 , then the amounts of each ion are insufficient for the spontaneous formation of aragonite. If $\Omega_{a}$ is greater than 1 , there is a sufficient amount of each ion to favor the formation of aragonite. However, there is a kinetic barrier to the spontaneous precipitation of aragonite (and all carbonate minerals). At the $\Omega_{\mathrm{a}}$ of seawater, aragonite would form very slowly and calcite would be preferred over aragonite without the help of biology. Calcifying organisms employ energetically costly mechanisms in order to overcome the kinetic barrier to aragonite precipitation (Gattuso et al. 1999; Cohen and McConnaughey 2003). It requires less metabolic energy to form aragonite from solutions with higher $\Omega_{\mathrm{a}}$ than from solutions with lower $\Omega_{\mathrm{a}}$. As ocean acidification progresses, the $\Omega_{\mathrm{a}}$ of the surface ocean decreases and we expect it to become increasingly difficult (i.e., energy intensive) for coral reef organisms to calcify.

This hypothesis is supported by numerous controlled culture and mesocosm experiments, suggesting a causal relationship between $\Omega_{\mathrm{a}}$ and NCC (Langdon et al. 2000; Leclercq et al. 2000,2002; Langdon and Atkinson 2005; Andersson et al. 2009; Chan and Connolly 2013). The correlation between $\Omega_{\mathrm{a}}$ and NCC has also been investigated in field studies (Ohde and van Woesik 1999; Silverman et al. 2007; Shamberger et al. 2011; Falter et al. 2012; Shaw et al. 2012; Albright et al. 2013). However, studies of different reefs report relationships between $\mathrm{NCC}$ and $\Omega_{\mathrm{a}}$ that are dissimilar to each other and to controlled mesocosm studies (Pandolfi et al. 2011). In other words, the different studies report different sensitivities of NCC to $\Omega_{\mathrm{a}}$ and report different $\Omega_{\mathrm{a}}$ "thresholds" or transition points below which the reef systems will transition from net calcification to net dissolution.

It is difficult to determine the underlying $N C C-\Omega_{a}$ relationship in field studies because the challenging nature of this type of fieldwork precludes the collection of sufficient data to describe the full variability in coral reef carbonate chemistry and its relation to metabolic rates (Gray et al. 2012; Albright et al. 2013) and because the $\Omega_{\mathrm{a}}$ 
does not vary over as large a range as can be achieved in controlled experiments. Because NCC is biologically controlled, it is also influenced by numerous environmental factors (temperature, light, nutrient concentrations and productivity rates) that can affect the correlation of NCC with $\Omega_{\mathrm{a}}$. Light and NCP may be exercising stronger controls on NCC than $\Omega_{\mathrm{a}}$ causing the NCC- $\Omega_{\mathrm{a}}$ relationship determined in field studies to appear steeper than the underlying relationship actually is (Marubini et al. 2001) (see Chapter 3). Additional detailed field studies are required to better constrain our understanding of how seawater carbonate chemistry relates to NCC.

\section{Objectives of this thesis}

I measured NCC at diverse sites in order to investigate the variability of NCC on short and long timescales and on local and global spatial scales. I had several objectives:

1. To estimate baseline NCC values at three sites. The response of NCC to long term global change can be estimated by comparing future measures of NCC against these baseline values. (Chapters 2 and 4 )

2. Investigate the correlations between $\mathrm{NCC}$ and environmental parameters on short (hours, days) timescale. (Chapter 2)

3. Estimate the change in NCC over long timescales (years-decades). (Chapter 4)

4. Determine a general relationship between NCC and $\Omega_{\mathrm{a}}$ for predicting the response of reefs worldwide to ocean acidification. (Chapter 3)

I estimated baseline NCC value on a platform reef in the Red Sea, a fringing reef in Puerto Rico and a patch reef in the Florida Keys. In the Red Sea, I focused on the correlation between NCC and $\Omega_{\mathrm{a}}$ on short timescales because the ranges in NCC and $\Omega_{\mathrm{a}}$ were sufficiently large to determine a correlation, and the ranges in temperature, light and nutrients during the sampling periods were small (Chapter 2). In Puerto Rico and the Florida Keys, I focused on quantifying a long term change in NCC because there were suitable historical values against which to compare the modern values (Chapter 4). To address the final objective, I synthesized results from previously published studies around 
the globe. I compiled the data from these studies in order to derive a general relationship that shows agreement between disparate field sites, and between field and controlled mesocosm experiments (Chapter 3). This thesis offers a contribution to scientific understanding of local variability and long term changes in NCC, and proposes a solution to the question of how $\mathrm{NCC}$ will respond to future ocean acidification on a global scale (Chapter 5). 


\section{References}

Albright R, Langdon C, Anthony K (2013) Dynamics of seawater carbonate chemistry, production, and calcification of a coral reef flat, Central Great Barrier Reef. Biogeosciences Discussions 10:7641-7676

Andersson AJ, Bates NR, Mackenzie FT (2007) Dissolution of carbonate sediments under rising pCO2 and ocean acidification: observations from Devil's Hole, Bermuda. Aquatic Geochemistry 13:237-264

Andersson AJ, Kuffner IB, Mackenzie FT, Jokiel PL, Rodgers KS, Tan A (2009) Net Loss of $\mathrm{CaCO}(3)$ from a subtropical calcifying community due to seawater acidification: mesocosm-scale experimental evidence. Biogeosciences 6:18111823

Anthony KRN, Kline DI, Diaz-Pulido G, Dove S, Hoegh-Guldberg O (2008) Ocean acidification causes bleaching and productivity loss in coral reef builders. Proceedings of the National Academy of Sciences of the United States of America 105:17442-17446

Bjork M, Mohammad SM, Bjorklund M, Semesi A (1995) Coralline algae, important coral reef builders threatened by pollution. Ambio 24:502-505

Burdige DJ, Zimmerman RC (2002) Impact of sea grass density on carbonate dissolution in Bahamian sediments. Limnology and Oceanography 47:1751-1763

Burdige DJ, Hu X, Zimmerman RC (2010) The widespread occurrence of coupled carbonate dissolution/reprecipitation in surface sediments on the Bahamas Bank. American Journal of Science 310:492-521

Caldeira K, Wickett ME (2003) Oceanography: anthropogenic carbon and ocean $\mathrm{pH}$. Nature 425:365-365

Canadell JG, Le Quéré C, Raupach MR, Field CB, Buitenhuis ET, Ciais P, Conway TJ, Gillett NP, Houghton R, Marland G (2007) Contributions to accelerating atmospheric $\mathrm{CO} 2$ growth from economic activity, carbon intensity, and efficiency of natural sinks. Proceedings of the National Academy of Sciences 104:1886618870

Chan NCS, Connolly SR (2013) Sensitivity of coral calcification to ocean acidification: a meta-analysis. Global Change Biology 19:282-290

Cohen AL, McConnaughey TA (2003) Geochemical perspectives on coral mineralization. Reviews in Mineralogy and Geochemistry 54:151-187

Falter JL, Lowe RJ, Atkinson MJ, Cuet P (2012) Seasonal coupling and de-coupling of net calcification rates from coral reef metabolism and carbonate chemistry at Ningaloo Reef, Western Australia. Journal of Geophysical Research-Oceans 117

Gattuso JP, Allemand D, Frankignoulle M (1999) Photosynthesis and calcification at cellular, organismal and community levels in coral reefs: A review on interactions and control by carbonate chemistry. American Zoologist 39:160-183

Gray SE, DeGrandpre MD, Langdon C, Corredor JE (2012) Short-term and seasonal pH, pCO2and saturation state variability in a coral-reef ecosystem. Global Biogeochemical Cycles 26 
IPCC (2007) Climate change 2007-the physical science basis: Working group I contribution to the fourth assessment report of the IPCC. Cambridge University Press,

Jokiel PL, Rodgers KS, Kuffner IB, Andersson AJ, Cox EF, Mackenzie FT (2008) Ocean acidification and calcifying reef organisms: a mesocosm investigation. Coral Reefs 27:473-483

Kleypas, Langdon (2006) Coral Reefs and Changing Seawater Carbonate Chemistry. In: Phinney J, Hoegh-Guldberg O, Kleypas J, Skirving W, Strong A (eds) Coral Reefs and Climate Change: Science and Management. American Geophysical Union, pp73-110

Kleypas, Feely, Fabry, Langdon, Sabine, Robbins (2006) Impacts of ocean acidification on coral reefs and other marine calcifiers: a guide for future research

Ku T, Walter L, Coleman M, Blake R, Martini A (1999) Coupling between sulfur recycling and syndepositional carbonate dissolution: evidence from oxygen and sulfur isotope composition of pore water sulfate, South Florida Platform, USA. Geochimica et Cosmochimica Acta 63:2529-2546

Kuffner IB, Andersson AJ, Jokiel PL, Rodgers KS, Mackenzie FT (2008) Decreased abundance of crustose coralline algae due to ocean acidification. Nature Geoscience 1:114-117

Langdon C, Atkinson MJ (2005) Effect of elevated pCO(2) on photosynthesis and calcification of corals and interactions with seasonal change in temperature/irradiance and nutrient enrichment. Journal of Geophysical ResearchOceans 110:1-16

Langdon C, Takahashi T, Sweeney C, Chipman D, Goddard J, Marubini F, Aceves H, Barnett H, Atkinson MJ (2000) Effect of calcium carbonate saturation state on the calcification rate of an experimental coral reef. Global Biogeochemical Cycles 14:639-654

Leclercq N, Gattuso JP, Jaubert J (2000) CO2 partial pressure controls the calcification rate of a coral community. Global Change Biology 6:329-334

Leclercq N, Gattuso JP, Jaubert J (2002) Primary production, respiration, and calcification of a coral reef mesocosm under increased $\mathrm{CO} 2$ partial pressure. Limnology and Oceanography 47:558-564

Martin S, Gattuso JP (2009) Response of Mediterranean coralline algae to ocean acidification and elevated temperature. Global Change Biology 15:2089-2100

Marubini F, Barnett H, Langdon C, Atkinson MJ (2001) Dependence of calcification on light and carbonate ion concentration for the hermatypic coral Porites compressa. Marine Ecology Progress Series 220:153-162

Morse JW, Andersson AJ, Mackenzie FT (2006) Initial responses of carbonate-rich shelf sediments to rising atmospheric $\mathrm{pCO}(2)$ and "ocean acidification": Role of high Mg-calcites. Geochimica et Cosmochimica Acta 70:5814-5830

Ohde S, van Woesik R (1999) Carbon dioxide flux and metabolic processes of a coral reef, Okinawa. Bulletin of Marine Science 65:559-576 
Orr JC, Fabry VJ, Aumont O, Bopp L, Doney SC, Feely RA, Gnanadesikan A, Gruber N, Ishida A, Joos F (2005) Anthropogenic ocean acidification over the twenty-first century and its impact on calcifying organisms. Nature 437:681-686

Pandolfi JM, Connolly SR, Marshall DJ, Cohen AL (2011) Projecting Coral Reef Futures Under Global Warming and Ocean Acidification. Science 333:418-422

Radtke G, Hofmann K, Golubic S (1997) A bibliographic overview of micro-and macroscopic bioerosion. Courier Forschungsinstitut Senckenberg 201:307-340

Sabine CL, Feely RA, Gruber N, Key RM, Lee K, Bullister JL, Wanninkhof R, Wong C, Wallace DW, Tilbrook B (2004) The oceanic sink for anthropogenic CO2. Science 305:367-371

Schneider K, Silverman J, Woolsey E, Eriksson H, Byrne M, Caldeira K (2011) Potential influence of sea cucumbers on coral reef $\mathrm{CaCO} 3$ budget: A case study at One Tree Reef. Journal of Geophysical Research: Biogeosciences (2005-2012) 116

Shamberger KEF, Feely RA, Sabine CL, Atkinson MJ, DeCarlo EH, Mackenzie FT, Drupp PS, Butterfield DA (2011) Calcification and organic production on a Hawaiian coral reef. Marine Chemistry 127:64-75

Shaw EC, McNeil BI, Tilbrook B (2012) Impacts of ocean acidification in naturally variable coral reef flat ecosystems. Journal of Geophysical Research-Oceans 117

Silverman J, Lazar B, Erez J (2007) Effect of aragonite saturation, temperature, and nutrients on the community calcification rate of a coral reef. Journal of Geophysical Research-Oceans 112

Tribollet A, Golubic S (2011) Reef Bioerosion: Agents and Processes

Walter LM, Bischof SA, Patterson WP, Lyons TW, O'Nions R, Gruszczynski M, Sellwood B, Coleman M (1993) Dissolution and recrystallization in modern shelf carbonates: evidence from pore water and solid phase chemistry [and discussion]. Philosophical Transactions of the Royal Society of London Series A: Physical and Engineering Sciences 344:27-36 


\title{
Chapter 2:
}

\section{Environmental controls on daytime net community calcification on a}

\author{
Red Sea reef flat ${ }^{1}$
}

\footnotetext{
${ }^{1}$ We intend to submit this chapter for publication with the following author list: W. N. Bernstein, K. A. Hughen, C. Langdon, D. C. McCorkle, S. J. Lentz
} 


\begin{abstract}
Coral growth and carbonate accumulation form the foundation of the coral reef ecosystem. Changes in environmental conditions due to coastal development, climate change, and ocean acidification may pose a threat to carbonate accumulation in the near future. Controlled laboratory studies demonstrate that calcification by corals and coralline algae is sensitive to changes in aragonite saturation state $\left(\Omega_{\mathrm{a}}\right)$, as well as temperature, light, and nutrition. The sensitivity of coral reefs to these parameters must be confirmed and quantified in the natural environment in order to predict how coral reefs will respond to local and global changes, particularly ocean acidification. We estimated the daytime hourly net community metabolic rates, both net community calcification (NCC) and net community productivity (NCP), at Sheltered Reef, an offshore platform reef in the central Red Sea.

Average NCC is $8 \pm 3 \mathrm{mmol} \mathrm{m}^{-2} \mathrm{~h}^{-1}$ in December 2010 and $11 \pm 1 \mathrm{mmol} \mathrm{m}^{-2} \mathrm{~h}^{-1}$ in May 2011, and NCP is $20 \pm 7 \mathrm{mmol} \mathrm{m}^{-2} \mathrm{~h}^{-1}$ in December 2010 and $44 \pm 4 \mathrm{mmol} \mathrm{m}^{-2} \mathrm{~h}^{-1}$ in May 2011. We also monitored a suite of physical and chemical properties to help relate the rates at Sheltered Reef to published rates from other sites. NCC on this reef flat is positively, but weakly, correlated with $\Omega_{\mathrm{a}}$. The positive correlation between NCC and $\Omega_{\mathrm{a}}$ may include metabolic controls on $\Omega_{\mathrm{a}}$ and the simultaneous control of NCP on NCC, in addition to the underlying control of $\Omega_{\mathrm{a}}$ on NCC.
\end{abstract}




\section{Introduction}

Biologically mediated calcification is an essential process on coral reefs. Massive corals build the foundation of the reef, enabling it to keep pace with changes in local sea level (Kleypas and Langdon 2006; Kleypas et al. 2006). Coralline algae, foraminifera, and sand serve as the infill and cement that fortify the reef foundation (Adey 1998; Kleypas and Langdon 2006; Kleypas et al. 2006). Coral colonies of diverse morphologies create the complex habitat that supports the extremely high biodiversity of reef ecosystems (Kleypas and Langdon 2006; Kleypas et al. 2006). Net community calcification (NCC) is the accretion of biogenic carbonate minerals by calcifying organisms minus the loss of that material by dissolution.

The growth of calcifying reef organisms is presently threatened by environmental changes due to climate change and ocean acidification (Kleypas et al. 2006; Pandolfi et al. 2011), in addition to the local stresses imposed by coastal development, harmful fishing practices, invasive species, and disease. Climate change causes warming of the surface ocean and increases the frequency of extreme heat conditions on coral reefs. Controlled laboratory and mesocosm studies as well as field observations have demonstrated that calcification rates of corals tend to increase with temperature until a thermal optimum is reached (Clausen and Roth 1975; Jokiel and Coles 1977; Coles and Jokiel 1978; Lough and Barnes 2000). Prolonged exposure to temperatures surpassing the thermal optimum results in thermal stress, reduced growth and reproduction rates, coral bleaching, and eventually coral death (Coles and Jokiel 1978; Baird and Marshall 2002; Mendes and Woodley 2002).

Ocean acidification $(\mathrm{OA})$ is the process by which anthropogenic $\mathrm{CO}_{2}$ dissolves in the surface ocean and depresses the $\mathrm{pH}$ and carbonate saturation state $(\Omega)$ of the seawater. Results from controlled experiments indicate that a decline in aragonite saturation state $\left(\Omega_{\mathrm{a}}\right)$ negatively impacts coral and algal calcification and NCC (Marubini and Atkinson 1999; Langdon et al. 2000; Leclercq et al. 2000; Marubini et al. 2001; Langdon and Atkinson 2005; Jokiel et al. 2008; Kuffner et al. 2008; Martin and Gattuso 2009). This is presumably because the biologically mediated precipitation of a given mineral is more 
energetically costly when the mineral saturation state in the seawater is depressed, implying that increased energy availability might enhance biologically mediated calcification (Cohen and Holcomb 2009). Experiments have established that calcification in hermatypic scleractinian corals is enhanced by light (Chalker and Taylor 1975; Barnes 1982; Marubini et al. 2001), perhaps because photosynthesis by endosymbiotic algae provides the coral animal with both sugars to help fuel skeletal precipitation and also with the biochemical precursors of the organic matrix underlying the skeletal crystals (Wainwright 1963; Chalker and Taylor 1975; Gattuso et al. 1999; Allemand et al. 2004; Muscatine L 2005). An additional hypothesis is that photosynthesis promotes calcification by consuming $\mathrm{CO}_{2}$ and elevating $\Omega_{\mathrm{a}}$ in the coral microenvironment or the ambient seawater, thereby lowering the energetic barrier to calcification (Goreau and Goreau 1959; Gattuso et al. 1999; Allemand et al. 2004). Recent experiments suggest that nutrient uptake and heterotrophic feeding also impact calcification rates (Marubini and Davies 1996; Houlbreque et al. 2003), and may in fact decrease the sensitivity of calcification to $\Omega_{\mathrm{a}}$ (Langdon and Atkinson 2005; Silverman et al. 2007b,a; Cohen and Holcomb 2009). Although the mechanistic links between light, nutrition and calcification are not yet fully understood, it is clear that both light and nutrition, in addition to temperature and $\Omega_{\mathrm{a}}$, must be considered when investigating the impact of OA on NCC.

While mesocosm studies have demonstrated that NCC changes with $\Omega_{\mathrm{a}}$, confirming this dependence in the natural environment is challenging. The large differences in the correlations observed at different sites has highlighted the need for a deeper understanding of environmental controls on metabolic rates on various timescales before extrapolating correlations globally or over several decades (Pandolfi et al. 2011; Shamberger et al. 2011; Andersson and Gledhill 2013). Each empirical NCC- $\Omega_{\mathrm{a}}$ correlation is influenced by several factors including the relative rates of NCC and net community production (NCP) (Andersson and Gledhill 2013) and contemporaneously variable temperature, light, and nutrition levels (Fig. 1). In order to gain a predictive understanding of how coral reefs world-wide will respond to OA, we must investigate the 
relationships between metabolic rates and environmental conditions in diverse regions, reef settings (e.g., fringing reef or outer shelf reef), and reef zones (e.g. fore-reef, reef flat, lagoon) (Kleypas and Langdon 2006; Atkinson and Cuet 2008).

In this study we estimated NCC and NCP rates on Sheltered Reef, a platform reef on the outer shelf of the Red Sea near Jeddah, Saudi Arabia. The goal of this study is to examine the relationship between NCC and NCP and the physiochemical environment on an hourly timescale, and to compare the results with those from previously published studies in the Red Sea and other regions. A study of NCC in the Red Sea is of particular interest in comparison to similar studies elsewhere, because the Red Sea has relatively high temperature and $\Omega_{\mathrm{a}}$ (Kleypas et al. 1999; Silverman et al. 2007a).

\section{Methods}

\subsection{Study site}

Sheltered Reef (SR) is a small $\left(275 \times 125 \mathrm{~m}^{2}\right)$ platform reef within the Quita Dukais offshore reef platform in the eastern Red Sea, north of Jeddah $\left(21^{\circ} 59^{\prime}\right.$ N, $38^{\circ} 51^{\prime}$ E, Fig. 2). Samples were collected on 7 and 8 December 2010, and 21-23 May 2011. The temperature around Quita Dukais ranges from $25^{\circ} \mathrm{C}$ in February to $31^{\circ} \mathrm{C}$ in August and is about $28^{\circ} \mathrm{C}$ in both December and May (Fig. 3). Light levels are at a minimum in December and reach a maximum in May (Fig. 3). The water is oligotrophic (Table 1).

$\mathrm{SR}$ has rich coral cover on the steep walls and rim. The reef flat is about 1 meter deep and hosts a community consisting of $41 \%$ rhodoliths (free living coralline algal crusts; Foster 2001; Donnan and Moore 2003; Fig. 4b), $28 \%$ algal turf (non-calcifying algae), $15 \%$ crustose coralline algae, $8 \%$ sand, and 5\% live coral (Fig. 4a). The coral present are mainly Stylophora spp., Porites spp., and Platygyra spp..

SR is a particularly interesting site because the community is largely composed of coralline algae. This group of calcifying organisms fulfills many important functional roles in coral reef systems. Crustose coralline red algae serve as a settling cue for juvenile coral recruits (Morse et al. 1994; Birrell et al. 2008). Crustose coralline algae also cement and consolidate the reef foundation, supporting the construction of diverse habitats, 
guarding against erosion, and in some cases serving as the principle driver of carbonate accumulation on reefs (Bjork et al. 1995). A rhodolith bed is a complex three dimensional matrix that provides habitat for numerous associated invertebrates and macroalgae (Foster 2001; Donnan and Moore 2003). Coralline algae may be more susceptible to ocean acidification because they are made of high-magnesium calcite, a more soluble carbonate mineral than aragonite (Morse et al. 2006; Anthony et al. 2008; Jokiel et al. 2008; Kuffner et al. 2008; Martin and Gattuso 2009). This study is one of few that have examined calcification in natural communities dominated by coralline algae (Chisholm 2000).

\subsection{Determination of Metabolic rates}

At SR we estimated daytime NCC and NCP rates using an Eulerian flow respirometry method (Odum 1956; Langdon et al. 2010), in which we compared the alkalinity and dissolved inorganic carbon concentration (DIC) of the upstream open-ocean end-member (grey region, Fig. 2) and the reef flat end-member (white dots, Fig. 2). We used the changes in salinity-normalized alkalinity and salinity-normalized DIC together with estimates of current speeds and reef geometry to calculate NCC and NCP rates, respectively. Normalization to constant salinity (Normalized Alkalinity $=$ Alkalinity $x$ 40/Salinity) removes the effects of evaporation and precipitation on alkalinity and DIC. This should not make a large difference in most reef settings, but we chose to do this because we were confident in our salinity measurements (accuracy $=0.001$ PSU, resolution $0.0002 \mathrm{PSU}$ ), so there was little danger of confounding the results with faulty salinity measurements. By budgeting these two parameters, we are able to estimate the net metabolic rates.

The two reactions of interest are calcification and photosynthesis. Calcification results in the loss of two equivalents of alkalinity and one mole of DIC for each mole of $\mathrm{CaCO}_{3}$ produced:

$$
\mathrm{Ca}^{2+}{ }_{(\mathrm{aq})}+\mathrm{CO}_{3}{ }^{2-}{ }_{(\mathrm{aq})}=>\mathrm{CaCO}_{3(\mathrm{~s})}
$$


while photosynthesis results in a decrease in DIC by one mole and a negligible change in alkalinity $(\triangle \mathrm{ALK}: \triangle \mathrm{DIC}=28: 550$, for photosynthesis on coral reefs (Atkinson and Smith 1983; Atkinson and Falter 2003)) for each mole of organic carbon produced:

$550 \mathrm{CO}_{2}+30 \mathrm{NH}_{4}{ }^{+}+\mathrm{HPO}_{4}{ }^{2-}=\mathrm{C}_{550} \mathrm{H}_{93} \mathrm{O}_{\mathrm{x}} \mathrm{N}_{30} \mathrm{P}+\mathrm{PQ} \cdot 550 \mathrm{O}_{2}+28 \mathrm{H}^{+}$

(Reaction 2)

PQ is photosynthetic quotient or the moles of $\mathrm{O}_{2}$ produced for each mole of $\mathrm{CO}_{2}$ assimilated.

Therefore, the budget for alkalinity describes NCC:

$$
N C C=0.5 \rho_{w} h \frac{\Delta A_{T}}{\Delta t}-0.5 \rho_{w} u h \frac{\Delta A_{T}}{L}
$$

where NCC is the instantaneous net calcification rate $\left(\mathrm{mmol} \mathrm{m}^{-2} \mathrm{~h}^{-1}\right) . \quad \mathrm{NCC}$ is the sum of the rate of change of the TA inventory along the transect plus the advective flux of TA into and out of the transect, assuming the diffusive flux is small (Falter et al. 2008). $\Delta \mathrm{A}_{\mathrm{T}} / \mathrm{L}$ is the change in alkalinity from the open ocean to the reef flat $\left(\mathrm{A}_{\text {Treef }}-\mathrm{A}_{\text {Topen ocean }}\right)$ along the length $(\mathrm{m})$ of reef substrate over which the water passes, $L . \Delta \mathrm{A}_{\mathrm{T}} / \Delta \mathrm{t}$ is the rate of change in average (reef and open ocean) alkalinity as measured between subsequent transects. $\rho_{\mathrm{w}}$ is the density of seawater $\left(\sim 1026 \mathrm{~kg} \mathrm{~m}^{-3}\right), u$ is the speed of the water $\left(\mathrm{m} \mathrm{h}^{-}\right.$ ${ }^{1}$ ), averaged both vertically and over the four minute duration of each hourly velocity measurement, and $\mathrm{h}$ is the depth $(\mathrm{m})$ of the water on top of the reef.

The budget for DIC incorporates the effects of NCP and NCC and gas exchange on DIC:

$$
N C P=\rho_{w} h \frac{\left[\Delta D I C-0.5 \Delta A_{T}\right]}{\Delta t}-\rho_{w} u h \frac{\left[\Delta D I C-0.5 \Delta A_{T}\right]}{L}+F_{A S G E}
$$

where NCP is the instantaneous net productivity $\left(\mathrm{mmol} \mathrm{m}^{-2} \mathrm{~h}^{-1}\right)$. Again, we have assumed that the diffusive flux is small (Falter et al. 2008). The terms in equation 2 are analogous to those in equation 1 , except the change in DIC is corrected by $0.5 \Delta \mathrm{A}_{\mathrm{T}}$ to account for the change in DIC that derives from the calcification process (Reaction 1). $\mathrm{F}_{\mathrm{ASGE}}$ is the flux of carbon due to the air-sea gas exchange of $\mathrm{CO}_{2}$. However, because $\mathrm{CO}_{2}$ equilibrates slowly with the atmosphere this term is negligible (less than $0.35 \mathrm{mmol} \mathrm{m}^{-2} \mathrm{~h}^{-1}$ ) (Wanninkhof 1992; Frankignoulle et al. 1996; Sweeney et al. 2007) and is not included in the calculation.

The uncertainty for NCC and NCP is calculated using the differential method to propagate the uncertainty of all input parameters, $\Delta \mathrm{A}_{\mathrm{T}}, \Delta \mathrm{DIC}, u, \mathrm{~h}, \mathrm{~L}$, addressed 
individually below. This uncertainty for both NCC and NCP is about $24 \%\left(2.5 \mathrm{mmol} \mathrm{m}{ }^{-2}\right.$ $\mathrm{h}^{-1}$ for NCC and $9.6 \mathrm{mmol} \mathrm{m}^{-2} \mathrm{~h}^{-1}$ for NCP (Table S1). The values estimated by this method represent an average over an appreciable area due to lateral mixing of reef waters (Kinsey 1985).

\subsection{Sample collection and analysis}

Water samples for determination of DIC, alkalinity, salinity, and nutrients were collected from the reef-water interface using a hand-held Niskin sampler. We measured DIC and alkalinity using a Marianda VINDTA-3C analysis system, in Dr. Daniel McCorkle’s lab at Woods Hole Oceanographic Institution. Alkalinity was determined by nonlinear curve fitting of data obtained by open-cell titrations, and DIC concentrations were determined by coulometric analysis. Both measurements were standardized using certified reference materials obtained from Dr. A. Dickson at the Scripps Institution of Oceanography. The analytical precision for alkalinity based on replicate samples is $1.2 \mathrm{umol} / \mathrm{kg}(\mathrm{n}=90$ pairs), and for DIC is $3.4 \mathrm{umol} / \mathrm{kg}(\mathrm{n}=90$ pairs). Salinity was measured using a salinometer at WHOI (accuracy $=0.001$ PSU, resolution 0.0002 PSU, Wellwood pers. comm. March 2013).

We sampled the open ocean end-member from the waters surrounding the reef (grey shaded region in Fig. 2c) both in the morning and afternoon on each day. We evaluated spatial variability in the open ocean end-member by collecting water from 1meter depth at three different locations within the open ocean region on each morning of three consecutive days in December. The variability between these locations for alkalinity and DIC was less than the analytical precision of the measurement (Table S2). Therefore, although we always aimed to sample upstream of the reef each morning and afternoon, we assumed the open ocean end-member to be uniform in space.

We sampled on the reef flat at three points along the long axis of the reef (points A, B, C in Fig. 2c) twice per day for two days in December, and four to five times per day for three days in May. To calculated NCC and NCP, we compared the reef flat values to the open ocean values that corresponded most closely to the sampling time of each reef flat end-member. This yielded two to five NCC and NCP estimates at each 
point each day. Samples were collected between the hours of 09:00 hrs and 16:00 hrs. Therefore, NCC and NCP rates were determined during peak sunlight hours.

\subsection{Input parameters}

The calculations of NCC and NCP require input of the water velocity $(u)$, water depth (h), and the distance (L) over which the water traveled over the reef flat. A $2 \mathrm{MHz}$ Nortek AquaDopp Profiler, located at point B (Fig. 2c), sampled the current profile for 4 minutes at hourly intervals with $2.5 \mathrm{~cm}$ vertical resolution, and 1 second temporal resolution. This sampling program was designed for a separate year-long study, and the data were generously provided to us by our colleagues, Drs. Steve Lentz and James Churchill. We understand that this sampling resolution was not ideal for our study and may have introduced aliasing problems. The stokes drift (wave transport) is negligible (pers. comm. S. Lentz, June 2013). Because the water was shallow ( 1m) and the benthic topography was rough, we assumed that the water column was well mixed, and we used the vertically integrated water velocity (analytical error $0.1 \mathrm{~cm} / \mathrm{s}$ ).

The changes in depth were measured using a Seagauge Wave and Tide Recorder (SBE 26plus). The Seagauge was located at the northern end of the reef, so the raw data were corrected by $21 \pm 5 \mathrm{~cm}$ to account for the depth of the Aquadopp relative to the Seagauge. We used the water depth and water velocity at the Aquadopp because the product of depth and velocity is equal everywhere on the reef flat when flow is nondivergent and non-convergent.

The distance over which the water travelled was estimated as the length from the sampling point to the reef edge, following the direction of flow at the sampling time. The reef edge was defined by a GPS track generated by swimming the perimeter of the reef with a hand-held GPS unit (white loop in Fig. 2, black loops in Fig. 5). The distance was calculated from each sampling point to the edge of the reef following the direction of flow described by the velocity measurements. The error in distance was estimated as the difference between subsequent estimates. We estimated a minimum error of $5 \mathrm{~m}$ to account for uncertainties in our knowledge of the exact positions along the reef edge and positions at points A, B, and C. An additional source of uncertainty arises from the fact 
that a given parcel of water may follow a meandering path and may experience changes in speed as it moves across the reef. However, because we did not follow a parcel of water, we were compelled to make the simplest assumption that the water followed a linear path across the reef (Fig. 5). Using the assumption of linear flow yields a minimum estimate of $\mathrm{L}$, and a maximum estimate of metabolic rate.

\subsection{Environmental parameters}

$\Omega_{\mathrm{a}}$, temperature, light, and nutrient (ammonium, nitrate, nitrite) concentrations all influence NCC and NCP (Kleypas and Langdon 2006; Kleypas et al. 2006). In addition, nitrogen fixation, and consumption of dissolved and particulate organic matter, can also be important sources of nutrition for reef communities (Kinsey 1985; Erez 1990; Ribes et al. 2003). Ideally, one would assess the influence of all of the nutritional sources in evaluating controls on metabolic rates. Inorganic concentrations were measured at Oregon State University using a continuous segmented flow system consisting of a Technicon AutoAnalyzer II (SEAL Analytical) and an Alpkem RFA 300 Rapid Flow Analyzer (Alpkem), as described in (Apprill and Rappe 2011). The precisions for nitrite and nitrate+nitrite are $0.02 \mu \mathrm{M}$ and $0.15 \mu \mathrm{M}$, respectively.

$\Omega_{\mathrm{a}}$ was calculated from the measured alkalinity, DIC, temperature, and salinity. Although the reef is primarily composed of coralline algae, which produce high-Mg calcite, we calculated $\Omega$ with respect to aragonite because the $\Omega$ with respect to high-Mg calcite changes with the percentage of $\mathrm{Mg}$ in the mineral and there is no agreement as to which value should be used. Therefore, we used the $\Omega_{\mathrm{a}}$, which is most relevant to the previously published literature. The calculation was carried out using the CO2SYS program (Pierrot 2006), applying the carbonate species dissociation constants of (Mehrbach et al. 1973) as refit by (Dickson and Millero 1987), and the aragonite solubility constant of (Mucci 1983).

Temperature was measured using several tools, including a YSI sonde; a conductivity, temperature, depth (CTD) logger; and numerous Hobo temperature loggers. Incoming short wave radiation (SWR) was measured in Watts $\mathrm{m}^{-2}$ at a nearby 
meteorological tower, located $43 \mathrm{~km}$ away, on the campus of King Abdullah University of Science and Technology (KAUST) (22¹7.823’N, 3905.567’E).

\section{Results}

\subsection{Measurements}

The average PAR from 11:00-13:00 hrs was 1350 $\pm 130 \mathrm{Watt}^{-2}$ in December and 1530 $\pm 660 \mathrm{Watt}^{-2}$ in May (mean \pm stdev) (Table 1). The measured reef flat temperatures were about $29^{\circ} \mathrm{C}$ on the sampling days in both seasons (Table 1). The average reef flat $\Omega_{\mathrm{a}}$ was about 4.6 in both seasons (Table 1 ).

Average nitrate and phosphate concentration were $0.2 \pm 0.0 \mu \mathrm{M}$ and $0.07 \pm 0.04$ $\mu \mathrm{M}$, respectively ( $\mathrm{n}=2$ seasons, see Table 1 for seasonal averages). These values are typical of coral reef systems worldwide (Nitrate typical range: 0.05-0.5 $\mu \mathrm{M}$, Phosphate typical range: 0.05-0.3 $\mu \mathrm{M}$; (Atkinson and Falter 2003).

The input parameters for calculating NCC and NCP were water depth, current speed, and length of reef substrate traversed. Average water depth was just under $1 \mathrm{~m}$ (Fig. 6). The water speed ranged from $0-6 \mathrm{~cm} \mathrm{~s}^{-1}$ and was highly variable (Fig. 6). The lengths of reef over which the water passed ranged from $20 \mathrm{~m}$ to $200 \mathrm{~m}$ (Fig. 5).

\section{$3.1 N C C$ and NCP}

Daytime hourly NCC and NCP were estimated at three points on the reef flat (Fig. 2c, points A, B, C) during each season. The daytime NCC rates ranged from 2 to $19 \mathrm{mmol}$ $\mathrm{m}^{-2} \mathrm{~h}^{-1}$ in Dec and from -2 to $23 \mathrm{mmol} \mathrm{m}^{-2} \mathrm{~h}^{-1}$ in May (Table S1). The daytime NCP rates ranged from 10 to $53 \mathrm{mmol} \mathrm{m}^{-2} \mathrm{~h}^{-1}$ in Dec and from 1 to $72 \mathrm{mmol} \mathrm{m}^{-2} \mathrm{~h}^{-1}$ (Table $\mathrm{S} 1)$. The average daytime NCC for the reef is $8 \pm 3 \mathrm{mmol} \mathrm{m}^{-2} \mathrm{~h}^{-1}$ in Dec and $11 \pm 1$ mmol m $\mathrm{m}^{-2} \mathrm{~h}^{-1}$ in May (Table 1). Integrating over 12-hour days and assuming nighttime NCC around zero, this equates to an NCC of $91 \mathrm{mmol} \mathrm{m}^{-2}$ day $^{-1}$ in Dec and $129 \mathrm{mmol} \mathrm{m}^{-}$

${ }^{2}$ day $^{-1}$ in May. These values are within the range of previously published studies listed in Table 2, and at the extremes of the range $\left(110 \pm 19 \mathrm{mmol} \mathrm{m}^{-2} \mathrm{day}^{-1}\right)$ of the long term "standard performance" for coral/algal flats between 23S and 21N (Kinsey 1983a). 
The average daytime NCP for the reef is $21 \pm 7 \mathrm{mmol} \mathrm{m}^{-2} \mathrm{~h}^{-1}$ in Dec and $44 \pm 4$ $\mathrm{mmol} \mathrm{m} \mathrm{m}^{-2}$ in May (Table 1). These are within the range observed in previously published studies (Table 2 and Table S3).

\subsection{Regressions}

The correlation between NCC and $\Omega_{\mathrm{a}}$ is significant ( $\mathrm{p}=0.05$, Fig. 7, Table 3). However, the variance explained is low $\left(\mathrm{r}^{2}=0.1\right.$, Table 3$)$ due to the large scatter. This indicates that some other variable is exerting a stronger control on NCC so as to obscure the control on $\Omega_{\mathrm{a}}$ on NCC. NCC was most strongly correlated with NCP $\left(\mathrm{r}^{2}=0.71, \mathrm{p}<<0.0001\right.$, Table 3 , Fig. 8). However, one must keep in mind that these values are not truly independent because the change in alkalinity is part of the calculation for both NCC and NCP (Equations 1 and 2). Both NCC and NCP showed a weak but significant correlation with nitrate concentration (Fig. 9). Regressions of both NCC and NCP against light and temperature were weak and insignificant (Table 3).

While temperature, nutrient concentrations and $\Omega_{\mathrm{a}}$ showed similar values in both December and May (Table 1), seasonally averaged light showed a larger difference between the seasons (Table 1, Fig. 3) and is a plausible driver of the difference in NCC and NCP between the sampling seasons. It is plausible that temperature is also a driver of metabolic variability on seasonal timescales, but we were not able to test this because the maximum variability in temperature did not coincide with our sampling seasons (Fig. 3). Long-term studies with higher-resolution (i.e., weekly or monthly) sampling to capture the full intra- and inter-seasonal variability would be required to quantify the relationships between metabolic rates and light, temperature, and nutrient concentrations on a seasonal timescale.

\section{Discussion}

\subsection{Comparison to previously published data}

The NCC and NCP values obtained for SR are within the range of values obtained for coral reefs worldwide (Table 2 and Table S3). The range in average daytime metabolic rates reported over the past three decades appears to be quite large ( 0 to $18 \mathrm{mmol} \mathrm{m} \mathrm{m}^{-2} \mathrm{~h}^{-1}$ 
for NCC, and -2 to $100 \mathrm{mmol} \mathrm{m}^{-2} \mathrm{~h}^{-1}$ for NCP). This large range may be due to differences in $\Omega_{\mathrm{a}}$ or community structure and indeed, when comparing metabolic rates at different reefs, care must be taken to consider the community composition, environmental conditions, and methods used (Kinsey 1985; Atkinson and Cuet 2008).

Previously, only two studies have measured NCC rates in the Red Sea (Barnes and Lazar 1993; Silverman et al. 2007b,a). Both studies took place in the Gulf of Eilat on a reef flat within the Nature Reserve Reef (NRR). Comparing these two studies to one another revealed that NCC decreased from 13.5 to $2.8 \mathrm{mmol} \mathrm{m}^{-2} \mathrm{~h}^{-1}$ over a decade (Silverman et al. 2007a). This decrease in NCC was attributed to the decline in coral cover due to local anthropogenic stress (Silverman et al. 2007a). The values for NCC and NCP in the study at SR fall between those estimated by Barnes and Lazar (1993) and those measured by Silverman et al. (2007b). Although SR has low live coral cover (4\%), it has high cover of coralline algae $(60 \%$, Fig. 4$)$. The coral cover at NRR during the Silverman et al. (2007 a, 2007b) studies was comparable to that at SR (<10\%, Silverman, pers. comm.). Although the abundance of coralline algae at NRR was not reported, it is estimated to be much lower than $60 \%$ (Silverman, pers. comm.). The higher NCC and $\mathrm{NCP}$ at SR relative to the recent values measured at NRR is reasonable considering the higher calcifier cover and higher $\Omega_{\mathrm{a}}$ (Table 2$)$. Slightly warmer temperatures and higher light fluxes at SR may also play a role in the high NCC rates observed. However, it is also plausible that calcifying communities are well-adapted to the average temperature and light regime of their environment. Unless we sampled during times of stress, the average temperature and light levels may not be controlling the difference in NCC at SR and NRR (Table 2). The difference to the two sites is likely due to differences in calcifier cover and $\Omega_{\mathrm{a}}$, and may be related to differences in temperature or light levels.

A number of studies have examined NCC of mixed communities that have abundant coralline algae. In the BIOSPHERE-2 mesocosm studies (Langdon et al. 2000; Langdon et al. 2003) coral cover was low (3\%) and the coralline algae were the main calcifying organisms (as much as $40 \%$ cover, Langdon, pers. comm.); thus the 
community was similar to that of SR. The NCC rates in BIOSPHERE-2 were $10 \pm 0.8$ at $\Omega_{\mathrm{a}}$ of about 5 , which agrees with the rates at SR (Table 2).

A field study by Shamberger et al. (2011) in Kaneohe Bay, Hawaii, yielded higher NCC rates (13 and $\left.16 \mathrm{mmol} \mathrm{m}^{-2} \mathrm{~h}^{-1}\right)$ than we measured at SR ( 8 and $11 \mathrm{mmol} \mathrm{m}^{-2} \mathrm{~h}^{-1}$ ) (Table 2). This difference may be due to the higher coral cover in Kaneohe Bay (20-30\% live coral cover and abundant CCA) compared to the reef flat of SR (4\% live coral cover, $60 \%$ CCA). If the corals in Kaneohe Bay tend to grow faster than CCA, then a higher proportion of corals would yield a higher NCC (Kinsey 1985; Adey 1998). However, as noted by Shamberger et al. (2011), the NCC rate at Kaneohe Bay is surprisingly high given the low $\Omega_{\mathrm{a}}(2.8)$ at that site. It is possible that the calcifying organisms in Kaneohe Bay have a higher nutritional status, or that the community has developed OA-hardy genotypes in order to compensate for lower $\Omega_{\mathrm{a}}$ (Pandolfi et al. 2011; Shamberger et al. 2011). Future studies are needed to resolve the question of how the Kaneohe Bay community calcifies so quickly under such low saturation state conditions.

\subsection{NCC and $\Omega_{a}$ relationship}

The correlation between NCC and $\Omega_{\mathrm{a}}$ at this site and other field sites is considerably steeper than previously published correlations from mesocosm studies, and implies that the reef community will transition from net calcification to net dissolution at a high $\Omega_{\mathrm{a}}$ than implied by the other relationships (Fig. 10). This transition point is referred to as a $\Omega_{\mathrm{a}}$ threshold. The steep slope of most field studies in contrast to shallower slopes of mesocosm studies (Pandolfi et al. 2011) may be due to co-varying controls on NCC on the short timescales (hours, days) of the field studies. In this study, $\Omega_{\mathrm{a}}$ NCP and light levels increase together (Table 3, Fig. 11). An appreciable share of the variability in NCC may be due to its strong correlation with NCP (Table 3, Fig. 8), resulting in a larger range in NCC than if $\Omega_{\mathrm{a}}$ were the only control. This is similar to the findings of Shaw et al. (2012) at Lady Elliot Island, where the sensitivity of NCC to changes in $\Omega_{\mathrm{a}}$ is damped when NCP is taken into account using a multivariate regression. However, in both this study and Shaw et al. (2012), the calculation of NCP involves the 
change in alkalinity, so NCP is not independent of NCC. To truly test for the control of $\mathrm{NCP}$ on NCC, one must calculate NCP from changes in oxygen concentration.

The control of NCC by NCP could derive from cellular or community-level linkages between the processes (Gattuso et al. 1999). On a cellular level, symbiotic algae (zooxanthellae) may consume coral metabolic wastes or substances interfering with aragonite precipitation, or they may increase the local $\Omega_{\mathrm{a}}$ by consuming $\mathrm{CO}_{2}$ (Goreau and Goreau 1959; Simkiss 1964; Crossland and Barnes 1974). Photosynthate may be used to fuel active transport mechanisms in the calcifying space or to synthesize organic molecules that facilitate aragonite precipitation (Wainwright 1963; Chalker and Taylor 1975). On a community level, reef productivity consumes $\mathrm{CO}_{2}$ and raises the $\Omega_{\mathrm{a}}$ of the ambient seawater thereby stimulating NCC (Kinsey 1985; Frankignoulle et al. 1996; Gattuso et al. 1996; Gattuso et al. 1999). Therefore, it is not surprising to find that these two metabolic processes are correlated in this study. ${ }^{2}$

However, it is difficult to explain the variability in both NCC and NCP using temperature, light, nutrients and $\Omega_{\mathrm{a}}$ data collected during this short term study. Many studies have demonstrated a correlation between NCC, NCP and light levels (Frankignoulle et al. 1996; Gattuso et al. 1996; Langdon and Atkinson 2005; Falter et al. 2012; Silverman et al. 2012; Albright et al. 2013). However, these studies estimate NCC and NCP over the full diurnal range. While light may truly be impacting the NCC and NCP rates on the reef, it may be difficult to observe this influence simply because our observations fall between 9:00 hrs and 16:00 hrs, spanning a narrower range in light flux and a period during which the metabolic processes may often be light saturated.

Another possible reason for the lack of apparent correlation between NCC, NCP and light could be the geographic distance between the two data sources. The light data come from a meteorological tower $43 \mathrm{~km}$ away and located on the coast. Conditions in the Red Sea tend to be such that the sky is always hazy but rarely cloudy. The haze could be of different thickness at the offshore field site and at the meteorological tower and the

\footnotetext{
${ }^{2}$ It is important to note that NCP and NCC are not categorically coupled (Langdon et al. 2003; Shamberger et al. 2011).
} 
differences may not be constant in time. The light flux at the meteorological tower may not accurately reflect the light flux at our site. Therefore, it is possible that light is driving the variations in NCC and NCP that are mechanistically coupled on cellular and community levels. Super-imposing these larger potentially light-driven variations onto a small diurnal change in $\Omega_{\mathrm{a}}$ that also fluctuates on a diurnal cycle (Falter et al. 2013) and correlates with light (Fig. 11) would steepen the apparent NCC- $\Omega_{\mathrm{a}}$ correlation.

The lack of correlation with temperature may seem surprising at first because incubation experiments have shown that temperature is an important control on calcification rate (Clausen and Roth 1975; Coles and Jokiel 1978; Reynaud et al. 1999; Marshall and Clode 2004). However, these experiments have primarily focused on single coral species. If calcifying organisms each have a species-specific optimum temperature range, then it is possible for a diverse community calcifying organisms to show little or no sensitivity to temperature over the narrow range observed throughout the middle of a the day (9:00 hrs to 16:00 hrs). A similar case could be made for explaining the lack of relationship between NCP and temperature. Few field studies have investigated the relationship between NCC and temperature. Two field studies related NCC to temperature on seasonal scales, but they attributed any apparent relationship to the thermodynamic influence of temperature on $\Omega_{\mathrm{a}}$ (Silverman et al. 2007a; Shaw et al. 2012). Only one other field study investigated the correlation between NCC and temperature on an hourly basis as we did, and in agreement with our findings, they also found no correlation (Shaw et al. 2012). Therefore, temperature is unlikely to play a role in causing the NCC- $\Omega_{\mathrm{a}}$ relationship to appear steep.

NCC and nitrate concentrations are negatively correlated, in accordance with laboratory studies that have demonstrated the negative affect of increased nutrient concentrations on coral growth, albeit with ranges in concentrations much greater than those observed here (Marubini and Davies 1996; Marubini and Thake 1999; Marubini and Atkinson 1999; Ferrier-Pages et al. 2000; Ferrier-Pagès et al. 2001; Langdon and Atkinson 2005). This is also in agreement with another field study also in the Red Sea and with similar nitrate concentrations (Silverman et al. 2007a). It is possible that nitrate 
concentrations may play some role in controlling the observed and coincident range in $\mathrm{NCC}$ and NCP, but the weak correlations suggest that nitrate concentration is not the primary control. Importantly, many of these studies also found decreased sensitivity of NCC to $\Omega_{\mathrm{a}}$ under high nutrient conditions (Langdon and Atkinson 2005; Silverman et al. 2007a; Cohen and Holcomb 2009). Therefore, the effect of nutrition is unlikely to be the cause of the steep NCC- $\Omega_{a}$ correlations relative to the mesocosm correlations. Nutrition and energetic status in corals are very complex and more research needs to be done to fully understand the role of nutrition.

Finally, in exploring environmental controls on metabolism, we must also consider that metabolism, in turn, is influencing the carbonate chemistry of the seawater ((Anthony et al. 2011; Kleypas et al. 2011; Andersson and Gledhill 2013); Fig. 1). In both seasons, the reef water was depleted in alkalinity and DIC relative to the open ocean water (Fig. 12), indicating that the reef flat is net calcifying and net autotrophic during the daytime. On a property-property plot of salinity normalized alkalinity versus DIC, the data fall directly between the stoichiometric lines for calcification and photosynthesis, indicating that both processes are altering the seawater chemistry. In both seasons, the slope $\left(\Delta \mathrm{A}_{\mathrm{T}} / \Delta \mathrm{DIC}\right)$ was about 0.5 . According to the equation derived by (Suzuki and Kawahata 2003):

$$
\frac{n c p}{n e c}=2 \frac{\Delta D I C}{\Delta A_{T}}-1=2 * \frac{1}{0.5}-1=3 \quad \text { Equation } 3
$$

NCC is roughly $30 \%$ of NCP. This agrees with the ratios of explicitly calculated values for NCC and NCP at SR (Table 1), and drives an increase in $\Omega_{\mathrm{a}}$ (Anthony et al. 2011; Kleypas et al. 2011; Andersson and Gledhill 2013).

When NCP exceeds NCC and there is little change in temperature and salinity (assuming negligible fluxes of carbon to and from the atmosphere), consumption of $\mathrm{CO}_{2}$ due to photosynthesis outweighs the decline in alkalinity due to calcification and drives an increase in reef flat $\Omega_{\mathrm{a}}$ relative to the open ocean end-member (Anthony et al. 2011; Kleypas et al. 2011). This is consistent with the observation that $\Omega_{\mathrm{a}}$ on the reef flat is higher than $\Omega_{\mathrm{a}}$ of the open-ocean end-member in both December and May, while temperature and salinity change very little (Table 4 ). The overall community metabolism 
(NCC:NCP ratio) elevates the $\Omega_{\mathrm{a}}$ of the seawater as it flows over the reef by as much as one unit, creating a positive feedback for calcification (Fig. 12). Thus, the positive correlation between NCC and $\Omega_{\mathrm{a}}$ in this study may reflect both the control of $\Omega_{\mathrm{a}}$ on NCC as well as the metabolic control on $\Omega_{\mathrm{a}}$ (Andersson and Gledhill 2013), and may be steepened by the confounding influence of NCP on NCC. Importantly, controlled laboratory studies provide direct evidence for the control of $\Omega_{\mathrm{a}}$ on NCC by isolating $\Omega_{\mathrm{a}}$ as a variable. Langdon et al. (2000) demonstrated that with weekly sampling over several years, the daily and seasonal variations in temperature, light and nutrient concentrations average out so that the underlying dependence of NCC on $\Omega_{\mathrm{a}}$ emerges (see Fig. 7 in Langdon et al. 2000). This indicates that similar confirmation may be achievable in field studies if data are collected regularly over several years.

\section{Conclusion}

NCC shows a significant positive correlation with $\Omega_{\mathrm{a}}$, although the sensitivity and $\Omega_{\mathrm{a}}$ threshold implied by the relationship is different from several other previously published relationships, particularly those from mesocosm studies. Because NCC is $30 \%$ of NCP, the net daytime metabolic effect is an increase in $\Omega_{\mathrm{a}}$. The positive correlation between NCC and $\Omega_{\mathrm{a}}$ may include both metabolic controls on $\Omega_{\mathrm{a}}$ and simultaneous controls of NCP on NCC, in addition to the underlying control of $\Omega_{a}$ on NCC. The exact equation of the observed NCC- $\Omega_{\mathrm{a}}$ relationship in this study is likely driven by a combination of environmental factors. Averaging of high resolution sampling over several years may allow the underlying $\mathrm{NCC}-\Omega_{\mathrm{a}}$ relationship to emerge. Until then, it is unlikely that a single local relationship is generally applicable on a global scale.

\section{Acknowledgements}

We would like to thank Craig Marquette, James Churchill, Pedro De La Torre, William Decarvalho, Jessica Masterman, Elizabeth Bonk and Rebecca Belastock for assisting in sampling and analysis of samples. We would also like to thank Tom Farrar for providing files of surface irradiance and wind speed. We acknowledge funding and support from King Abdullah University of Science and Technology and the National Science Foundation. 


\section{References}

Adey WH (1998) Coral reefs: Algal structured and mediated ecosystems in shallow, turbulent, alkaline waters. Journal of Phycology 34:393-406

Albright R, Langdon C, Anthony K (2013) Dynamics of seawater carbonate chemistry, production, and calcification of a coral reef flat, Central Great Barrier Reef. Biogeosciences Discussions 10:76417676

Allemand D, Ferrier-Pages C, Furla P, Houlbreque F, Puverel S, Reynaud S, Tambutte E, Tambutte S, Zoccola D (2004) Biomineralisation in reef-building corals: from molecular mechanisms to environmental control. Comptes Rendus Palevol 3:453-467

Andersson AJ, Gledhill D (2013) Ocean Acidification and Coral Reefs: Effects on Breakdown, Dissolution, and Net Ecosystem Calcification. Annual Review of Marine Science 5:321-348

Andersson AJ, Kuffner IB, Mackenzie FT, Jokiel PL, Rodgers KS, Tan A (2009) Net Loss of CaCO(3) from a subtropical calcifying community due to seawater acidification: mesocosm-scale experimental evidence. Biogeosciences 6:1811-1823

Anthony KRN, Kleypas JA, Gattuso JP (2011) Coral reefs modify their seawater carbon chemistry implications for impacts of ocean acidification. Global Change Biology 17:3655-3666

Anthony KRN, Kline DI, Diaz-Pulido G, Dove S, Hoegh-Guldberg O (2008) Ocean acidification causes bleaching and productivity loss in coral reef builders. Proceedings of the National Academy of Sciences of the United States of America 105:17442-17446

Apprill A, Rappe MS (2011) Response of the microbial community to coral spawning in lagoon and reef flat environments of Hawaii, USA. Aquatic Microbial Ecology 62:251-266

Atkinson M, Falter J (2003) Coral Reefs. In: Black KaS, G. (ed) Biogeochemistry of marine systems. CRC Press, Boca Raton, Florida,

Atkinson MJ, Cuet P (2008) Possible effects of ocean acidification on coral reef biogeochemistry: topics for research. Marine Ecology-Progress Series 373:249-256

Baird AH, Marshall PA (2002) Mortality, growth and reproduction in scleractinian corals following bleaching on the Great Barrier Reef. Marine Ecology Progress Series 237:133-141

Baker KS, Frouin R (1987) Relationship between photosynthetically available radiation and total insolation at the surface of the ocean under clear skies. Limnol Oceanogr 32:1370-1377

Barnes DJ (1982) Light Response Curve for calcification in the staghorn coral, Aropora-acuminata. Comparative Biochemistry and Physiology a-Physiology 73:41-45

Barnes DJ, Lazar B (1993) Metabolic performance of a shallow reef patch near Eilat in the Red Sea. Journal of Experimental Marine Biology and Ecology 174:1-13

Birrell CL, McCook LJ, Willis BL, Diaz-Pulido GA (2008) Effects of benthic algae on the replenishment of corals and the implications for the resilience of coral reefs. In: Gibson RN, Atkinson RJA, Gordon JDM (eds) Oceanography and Marine Biology: An Annual Review, Vol 46, pp25

Bjork M, Mohammad SM, Bjorklund M, Semesi A (1995) Coralline algae, important coral reef builders threatened by pollution. Ambio 24:502-505

Chalker BE, Taylor DL (1975) Light-enhanced calcification, and role of oxidative-phosphorylation on calcification of coral Acropora-cervicornis. Proceedings of the Royal Society B-Biological Sciences 190:323-331

Chisholm JRM (2000) Calcification by crustose coralline algae on the northern Great Barrier Reef, Australia. Limnology and Oceanography 45:1476-1484

Clausen CD, Roth AA (1975) Effect of Temperaturea and Temperature Adaptation on Calcification Rate in Hermatypic Coral PocilloporaDamicornis. Marine Biology 33:93-100

Cohen AL, Holcomb M (2009) Why corals care about ocean acidification : uncovering the mechanism. Oceanography 22

Coles SL, Jokiel PL (1978) Synergistic Effects Of Temperature, Salinity, and Light On Hermatypic Coral Montipora-Verrucosa. Marine Biology 49:187-195

Crossland C, Barnes D (1974) The role of metabolic nitrogen in coral calcification. Marine Biology 28:325-332 
Dickson AG, Millero FJ (1987) A comparison of the equilibrium-constants for the dissociation of carbonicacid in seawatr media. Deep-Sea Research Part a-Oceanographic Research Papers 34:1733-1743

Donnan DW, Moore PG (2003) Special issue: International Workshop on 'The conservation and management of maerl' - 23-27 February, 2001 - University Marine Biological Station, Millport, Isle of Cumbrae, Scotland - Introduction. Aquatic Conservation-Marine and Freshwater Ecosystems 13:S1-S3

Erez J (1990) On the importance of food sources in coral-reef ecosystems. In: Elsevier (ed) Ecosystems of the world: Coral Reefs, Amsterdam, pp411-418

Falter JL, Lowe RJ, Atkinson MJ, Cuet P (2012) Seasonal coupling and de-coupling of net calcification rates from coral reef metabolism and carbonate chemistry at Ningaloo Reef, Western Australia. Journal of Geophysical Research-Oceans 117

Falter JL, Lowe RJ, Zhang Z, McCulloch M (2013) Physical and biological controls on the carbonate chemistry of coral reef waters: effects of metabolism, wave forcing, sea level, and geomorphology. Plos One 8:e53303

Falter JL, Lowe RJ, Atkinson MJ, Monismith SG, Schar DW (2008) Continuous measurements of net production over a shallow reef community using a modified Eulerian approach. Journal of Geophysical Research-Oceans 113

Ferrier-Pages C, Leclercq N, Jaubert J, Pelegri SP (2000) Enhancement of pico- and nanoplankton growth by coral exudates. Aquatic Microbial Ecology 21:203-209

Ferrier-Pagès C, Schoelzke V, Jaubert J, Muscatine L, Hoegh-Guldberg O (2001) Response of a scleractinian coral, $<\mathrm{i}>$ Stylophora pistillata $</ \mathrm{i}>$, to iron and nitrate enrichment. Journal of Experimental Marine Biology and Ecology 259:249-261

Foster MS (2001) Rhodoliths: Between rocks and soft places. Journal of Phycology 37:659-667

Frankignoulle M, Gattuso JP, Biondo R, Bourge I, CopinMontegut G, Pichon M (1996) Carbon fluxes in coral reefs .2. Eulerian study of inorganic carbon dynamics and measurement of air-sea $\mathrm{CO} 2$ exchanges. Marine Ecology-Progress Series 145:123-132

Gattuso JP, Allemand D, Frankignoulle M (1999) Photosynthesis and calcification at cellular, organismal and community levels in coral reefs: A review on interactions and control by carbonate chemistry. American Zoologist 39:160-183

Gattuso JP, Pichon M, Delesalle B, Canon C, Frankignoulle M (1996) Carbon fluxes in coral reefs .1. Lagrangian measurement of community metabolism and resulting air-sea $\mathrm{CO} 2$ disequilibrium. Marine Ecology-Progress Series 145:109-121

Goreau TF, Goreau NI (1959) The physiology of skeleton formation in corals. II. Calcium deposition by hermatypic corals under various conditions in the reef. Biological Bulletin 117:239-250

Houlbreque F, Tambutte E, Ferrier-Pages C (2003) Effect of zooplankton availability on the rates of photosynthesis, and tissue and skeletal growth in the scleractinian coral Stylophora pistillata. Journal of Experimental Marine Biology and Ecology 296:145-166

Jokiel PL, Coles SL (1977) Effects Of Temperature on Mortality and growth of Hawaiian Reef Corals. Marine Biology 43:201-208

Jokiel PL, Rodgers KS, Kuffner IB, Andersson AJ, Cox EF, Mackenzie FT (2008) Ocean acidification and calcifying reef organisms: a mesocosm investigation. Coral Reefs 27:473-483

Kinsey DW (1983a) Standards of performance in coral reef primary production and carbon turnover. Perspectives on Coral Reefs Australian Institute of Marine Science

Kinsey DW (1985) Metabolism, Calcification and Carbon Production. Proceedings 5th International Coral Reef Symposium 4:505-526

Kleypas, Langdon (2006) Coral Reefs and Changing Seawater Carbonate Chemistry. In: Phinney J, HoeghGuldberg O, Kleypas J, Skirving W, Strong A (eds) Coral Reefs and Climate Change: Science and Management. American Geophysical Union, pp73-110

Kleypas, Feely, Fabry, Langdon, Sabine, Robbins (2006) Impacts of ocean acidification on coral reefs and other marine calcifiers: a guide for future research

Kleypas JA, McManus JW, Menez LAB (1999) Environmental limits to coral reef development: Where do we draw the line? American Zoologist 39:146-159 
Kleypas JA, Anthony KRN, Gattuso JP (2011) Coral reefs modify their seawater carbon chemistry - case study from a barrier reef (Moorea, French Polynesia). Global Change Biology 17:3667-3678

Kuffner IB, Andersson AJ, Jokiel PL, Rodgers KS, Mackenzie FT (2008) Decreased abundance of crustose coralline algae due to ocean acidification. Nature Geoscience 1:114-117

Langdon, Gattuso, Andersson (2010) Measurements of calcifi cation and dissolution of benthic organisms and communities. Guide to best practices for ocean acidifi cation research and data reporting Chapter 13:213-232

Langdon C, Atkinson MJ (2005) Effect of elevated $\mathrm{pCO}(2)$ on photosynthesis and calcification of corals and interactions with seasonal change in temperature/irradiance and nutrient enrichment. Journal of Geophysical Research-Oceans 110:1-16

Langdon C, Takahashi T, Sweeney C, Chipman D, Goddard J, Marubini F, Aceves H, Barnett H, Atkinson MJ (2000) Effect of calcium carbonate saturation state on the calcification rate of an experimental coral reef. Global Biogeochemical Cycles 14:639-654

Langdon C, Broecker WS, Hammond DE, Glenn E, Fitzsimmons K, Nelson SG, Peng TH, Hajdas I, Bonani G (2003) Effect of elevated CO2 on the community metabolism of an experimental coral reef. Global Biogeochemical Cycles 17

Leclercq N, Gattuso JP, Jaubert J (2000) CO2 partial pressure controls the calcification rate of a coral community. Global Change Biology 6:329-334

Lough JM, Barnes DJ (2000) Environmental controls on growth of the massive coral Porites. Journal of Experimental Marine Biology and Ecology 245:225-243

Marshall AT, Clode P (2004) Calcification rate and the effect of temperature in a zooxanthellate and an azooxanthellate scleractinian reef coral. Coral Reefs 23:218-224

Martin S, Gattuso JP (2009) Response of Mediterranean coralline algae to ocean acidification and elevated temperature. Global Change Biology 15:2089-2100

Marubini F, Davies PS (1996) Nitrate increases zooxanthellae population density and reduces skeletogenesis in corals. Marine Biology 127:319-328

Marubini F, Atkinson M (1999) Effects of lowered $\mathrm{pH}$ and elevated nitrate on coral calcification. Marine Ecology-Progress Series 188:117-121

Marubini F, Thake B (1999) Bicarbonate addition promotes coral growth. Limnology and Oceanography 44:716-720

Marubini F, Barnett H, Langdon C, Atkinson MJ (2001) Dependence of calcification on light and carbonate ion concentration for the hermatypic coral Porites compressa. Marine Ecology Progress Series 220:153-162

Mehrbach C, Culberso.Ch, Hawley JE, R.M. P (1973) Measurement of apparent dissociation-constants of carbonic-acid in seawater at atmospheric-pressure. Limnology and Oceanography 18:897-907

Mendes JM, Woodley JD (2002) Effect of the 1995-1996 bleaching event on polyp tissue depth, growth, reproduction and skeletal band formation in Montastraea annularis. Marine Ecology Progress Series 235:93-102

Morse DE, Morse ANC, Raimondi PT, Hooker N (1994) Morphogen-based chemical flypaper for Agaricia-humulis coral larvae. Biological Bulletin 186:172-181

Morse JW, Andersson AJ, Mackenzie FT (2006) Initial responses of carbonate-rich shelf sediments to rising atmospheric $\mathrm{pCO}(2)$ and "ocean acidification": Role of high $\mathrm{Mg}$-calcites. Geochimica et Cosmochimica Acta 70:5814-5830

Mucci A (1983) The solubility of calcite and aragonite in seawater at various salinities, temperatures, and one atmosphere total pressure. American Journal of Science 283:780-799

Muscatine L GC, Land L, Jaubert J, Cuif JP, Allemand D (2005) Stable isotopes of organic matrix from coral skeleton. Proc National Academies of Science USA 102:1525-1530

Odum HT (1956) Primary production in flowing waters. Limnology and Oceanography 1:102-117

Pandolfi JM, Connolly SR, Marshall DJ, Cohen AL (2011) Projecting Coral Reef Futures Under Global Warming and Ocean Acidification. Science 333:418-422

Pierrot DEL, and D. W. R. Wallace. (2006) MS Excel Program Developed for CO2 System Calculations. ORNL/CDIAC-105a 
Reynaud VS, Gattuso JP, Cuif JP, Jaubert J, Juillet-Leclerc A (1999) A novel culture technique for scleractinian corals: application to investigate changes in skeletal delta $\mathrm{O}-18$ as a function of temperature. Marine Ecology-Progress Series 180:121-130

Ribes M, Coma R, Atkinson MJ, Kinzie RA (2003) Particle removal by coral reef communities: picoplankton is a major source of nitrogen. Marine Ecology-Progress Series 257:13-23

Shamberger KEF, Feely RA, Sabine CL, Atkinson MJ, DeCarlo EH, Mackenzie FT, Drupp PS, Butterfield DA (2011) Calcification and organic production on a Hawaiian coral reef. Marine Chemistry 127:64-75

Shaw EC, McNeil BI, Tilbrook B (2012) Impacts of ocean acidification in naturally variable coral reef flat ecosystems. Journal of Geophysical Research-Oceans 117

Silverman J, Lazar B, Erez J (2007a) Effect of aragonite saturation, temperature, and nutrients on the community calcification rate of a coral reef. Journal of Geophysical Research-Oceans 112

Silverman J, Lazar B, Erez J (2007b) Community metabolism of a coral reef exposed to naturally varying dissolved inorganic nutrient loads. Biogeochemistry 84:67-82

Silverman J, Kline D, Johnson L, Rivlin T, Schneider K, Erez J, Lazar B, Caldeira K (2012) Carbon turnover rates in the One Tree Island reef: A 40-year perspective. Journal of Geophysical Research: Biogeosciences (2005-2012) 117

Simkiss K (1964) Phosphates as crystal poisons of calcification. Biological Reviews 39:487-504

Suzuki A, Kawahata H (2003) Carbon budget of coral reef systems: an overview of observations in fringing reefs, barrier reefs and atolls in the Indo-Pacific regions. Tellus 2:428-444

Sweeney C, Gloor E, Jacobson AR, Key RM, McKinley G, Sarmiento JL, Wanninkhof R (2007) Constraining global air-sea gas exchange for $\mathrm{CO} 2$ with recent bomb C-14 measurements. Global Biogeochemical Cycles 21

Wainwright SA (1963) Skeletal organization in the coral, Pocillopora damicornis. Quarterly Journal of Microscopical Science 3:169-183

Wanninkhof R (1992) Relationship between wind-speed and gas-exchange over the ocean. Journal of Geophysical Research-Oceans 97:7373-7382

Watanabe A, Kayanne H, Hata H, Kudo S, Nozaki K, Kato K, Negishi A, Ikeda Y, Yamano H (2006) Analysis of the seawater $\mathrm{CO} 2$ system in the barrier reef-lagoon system of Palau using total alkalinity-dissolved inorganic carbon diagrams. Limnology and Oceanography 51:1614-1628 


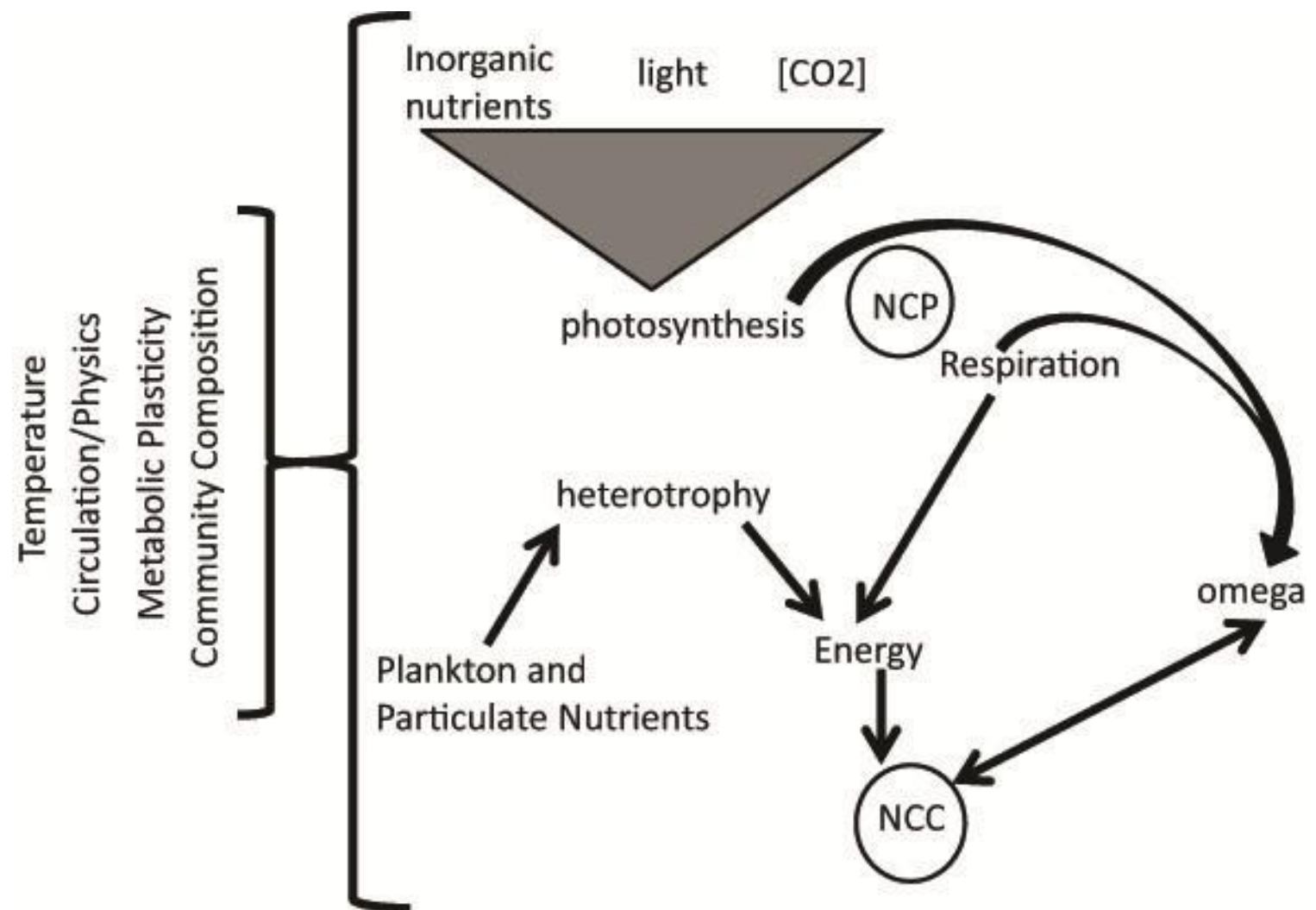

Figure 1 A sketch summarizing the influence of various processes and parameters on one another. Inorganic nutrient concentrations, light and the amount of carbon available, $\left[\mathrm{CO}_{2}\right]$, influence photosynthesis. NCP is the net result of photosynethesis and respiration and impacts $\Omega_{\mathrm{a}}$, which in turn influences NCC. Energy to fuel NCC is derived from heterotrophy by the polyp and respiration of sugars produced by endosymbionts. All of the relationships between all of the processes and parameters are influenced by the temperature, the circulation physics, the community composition and the metabolic plasticity of the organisms comprising the community. 


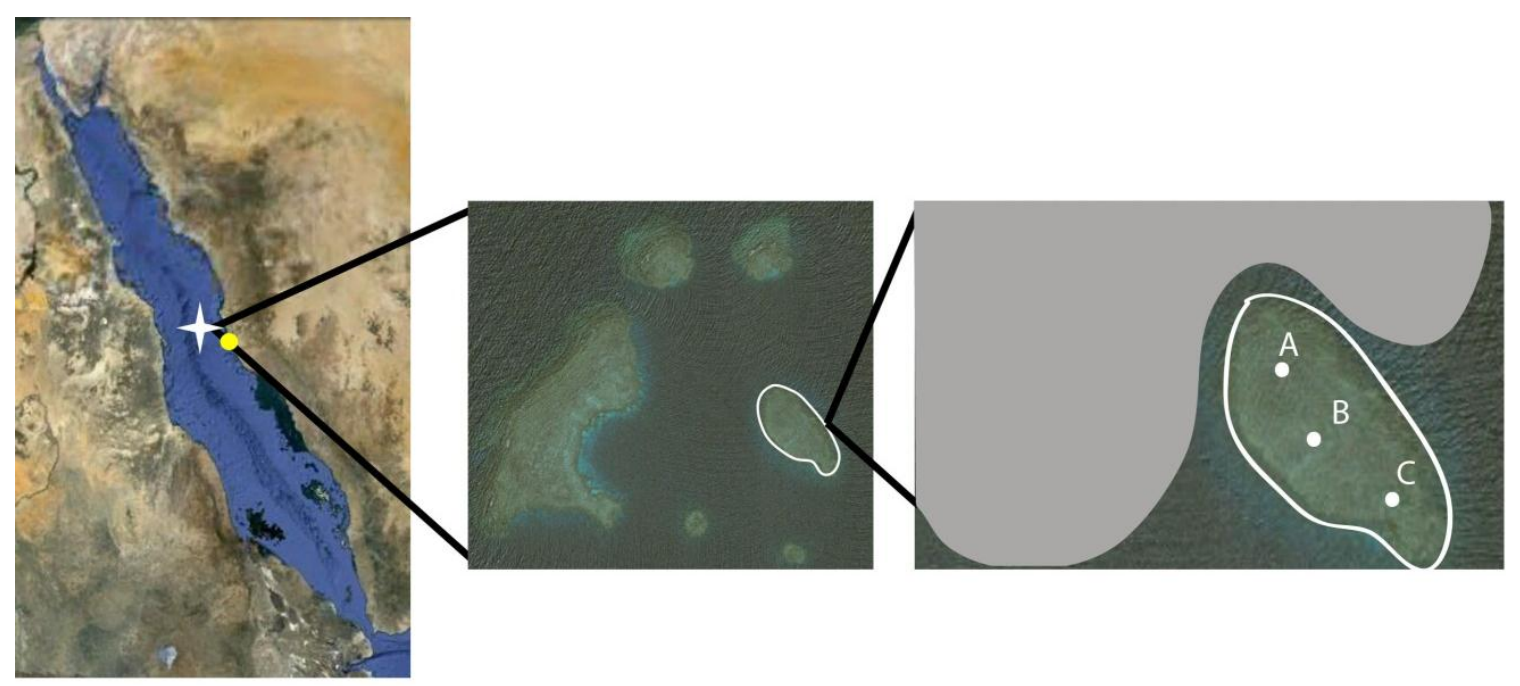
(a) Red Sea
(b) Quita Dukais Reef System
(c) Sheltered Reef

Figure 2 Sheltered Reef $\left(21^{\circ} 59^{\prime} \mathrm{N}, 38^{\circ} 51^{\prime} \mathrm{E}\right)$ is a small $\left(275 \times 125 \mathrm{~m}^{2}\right)$ offshore platform reef within the Quita Dukais reef system (white star in (a), also show in (b)), in the central Red Sea, near Jeddah (yellow circle in (a)). The open ocean samples were collected from within the grey-shaded region (c). Reef flat samples were collected at the three points (A, B and C), twice per day for two days in December and 4-5 times per day for three days in May. (Images from Google Earth). 


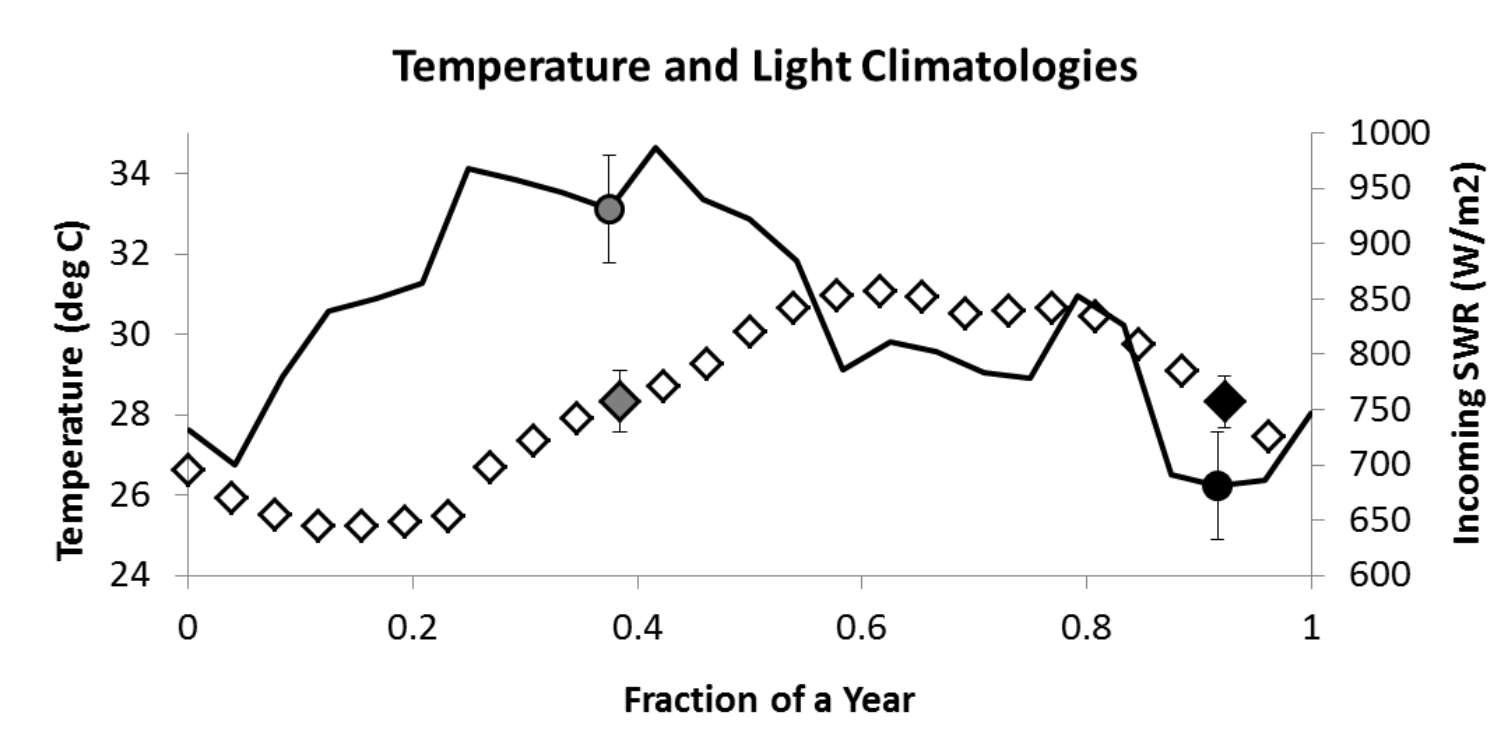

Figure 3 The temperature climatology (diamonds) indicates that the average temperature (deg C) in late May (grey diamond) and early Dec (black diamond) are the same. The light climatology (black line) shows that the monthly average mid-day (between 11:00 and 13:00) flux of incoming short wave radiation $\left(\mathrm{SWR}, \mathrm{W} \mathrm{m}^{-2}\right.$ ) is highest in May (grey circle) and lowest in December (black circle). The temperature climatology is based on AVHRR (v5, 4km gridsize) sea surface temperature data from 1985 to 2009. The light climatology is based on data from the meteorlogical tower located on KAUST campus $\left(22^{\circ} 17.823^{\prime} \mathrm{N}, 39^{\circ} 05.567^{\prime} \mathrm{E}\right)$, November 2009 to March 2012 . Error bars are standard deviation. 


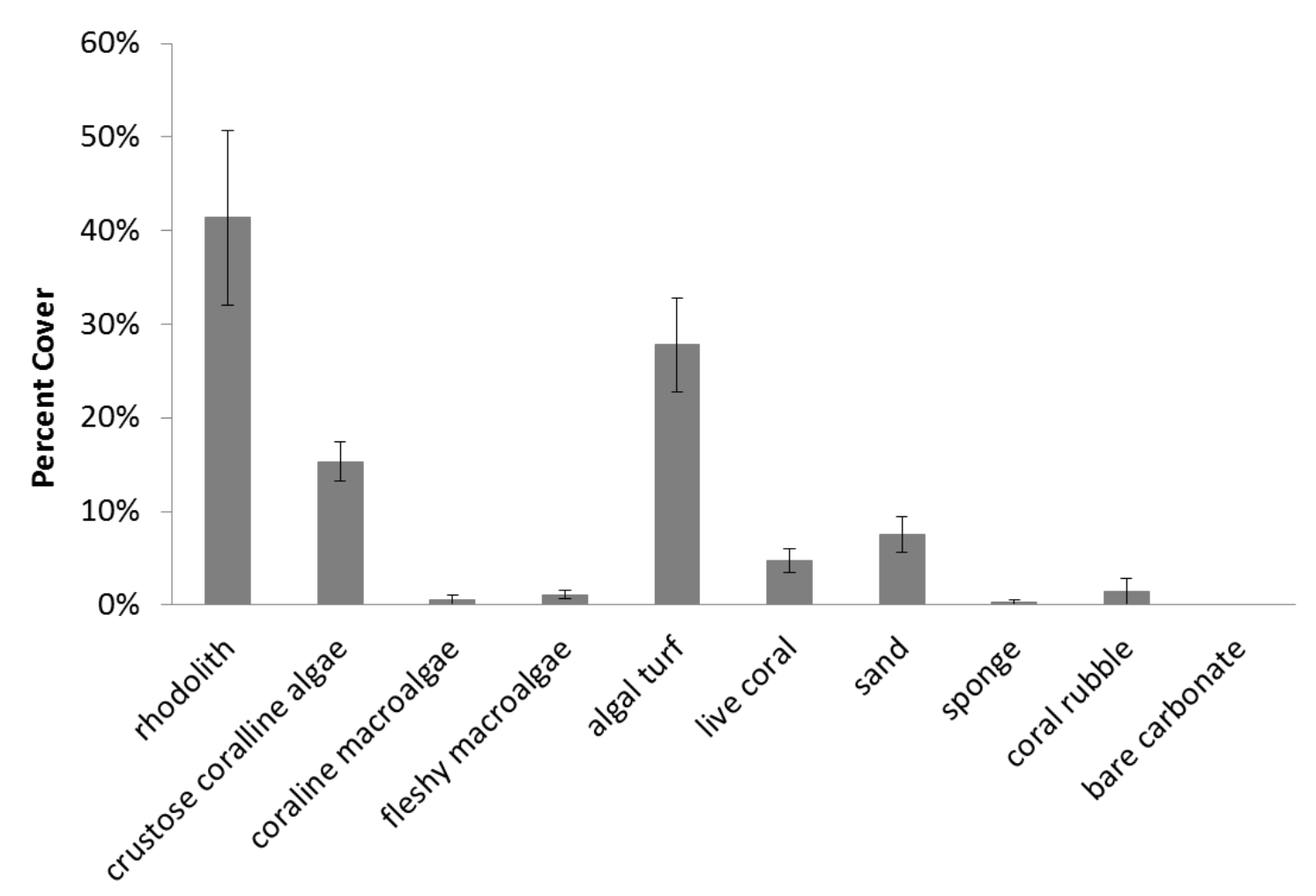

(a)

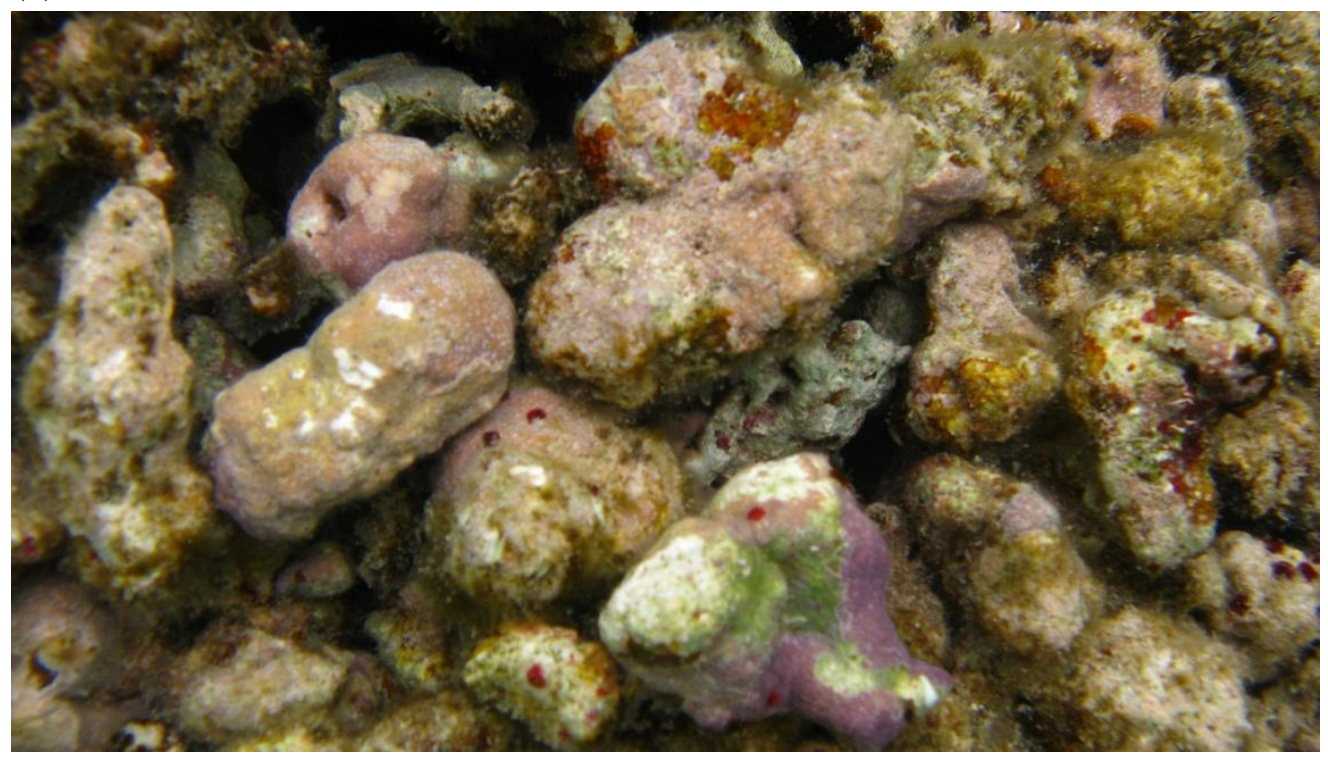

(b)

Figure 4 The community (a) at SR is composed primarily of coralline algae, in both the encrusting form and the free-living rhodolith form (b). The corals present were predominiantly Stylophora spp., Porites spp., and Platygyra spp. Benthic data were collected using the line-intercept method over four randomly placed $50 \mathrm{~m}$ transects. 

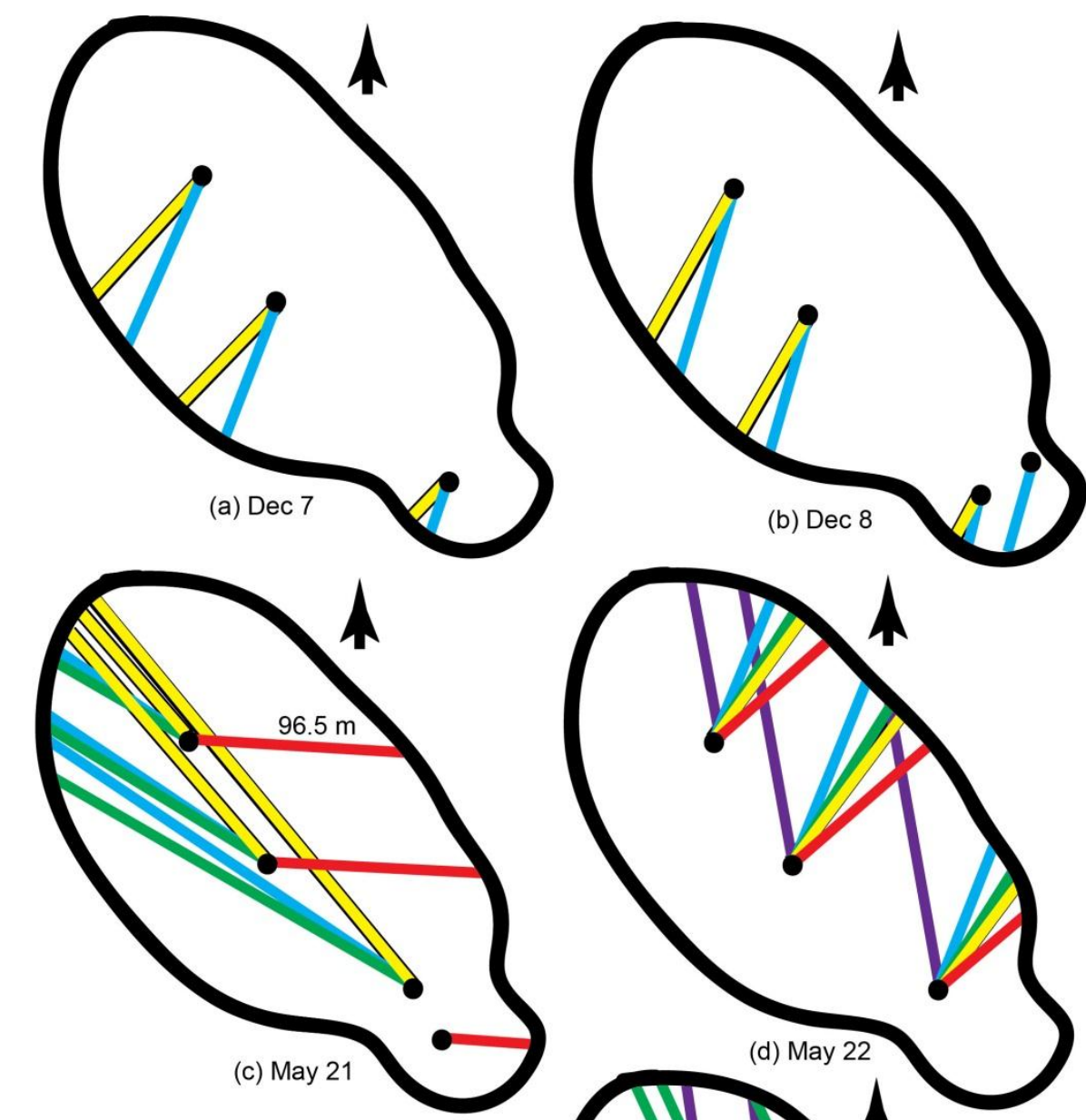

(d) May 22
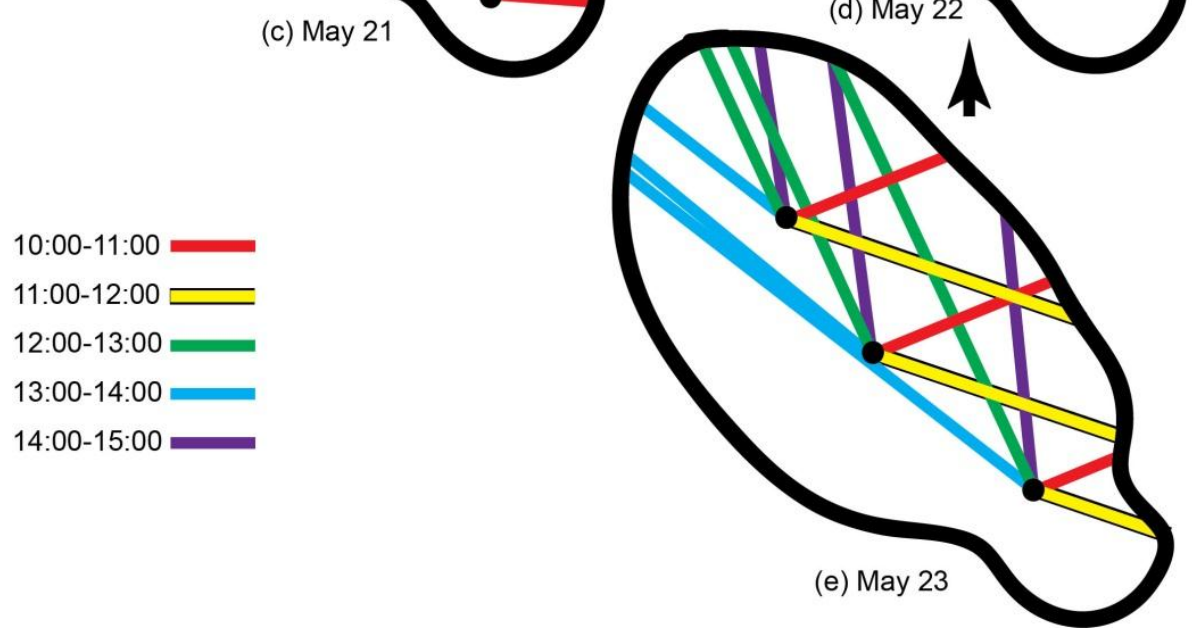

Figure 5 The length (L) of reef that the water traversed was determined by calculating the distance between each sampling waypoint and the GPS track (black line) defined by swimming the perimeter of the reef with a handheld GPS in tracking mode. The colors indicate the relative time of day according to the key. The arrows indicate northerly direction. The distance for one transect on May 21 is indicated for scale. 


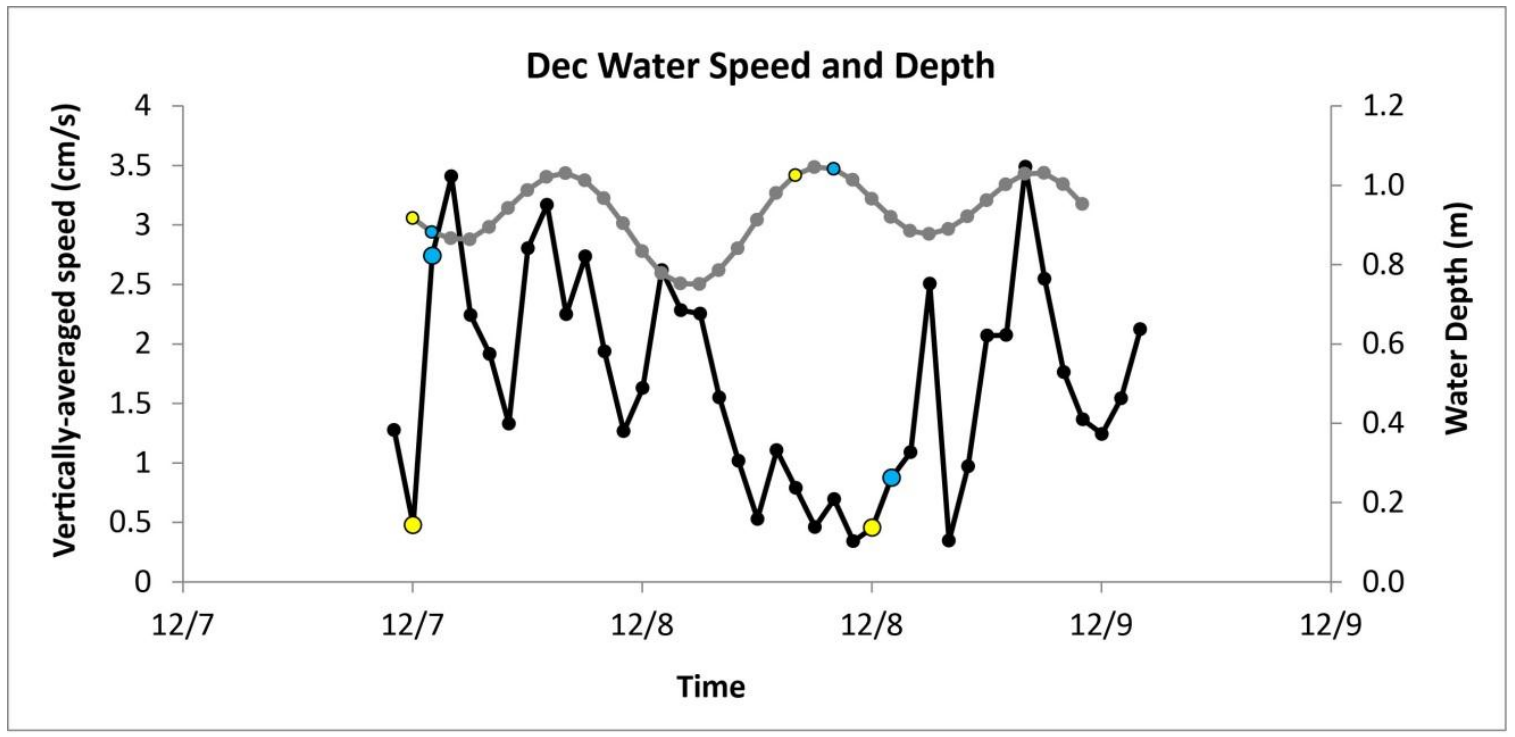

(a)

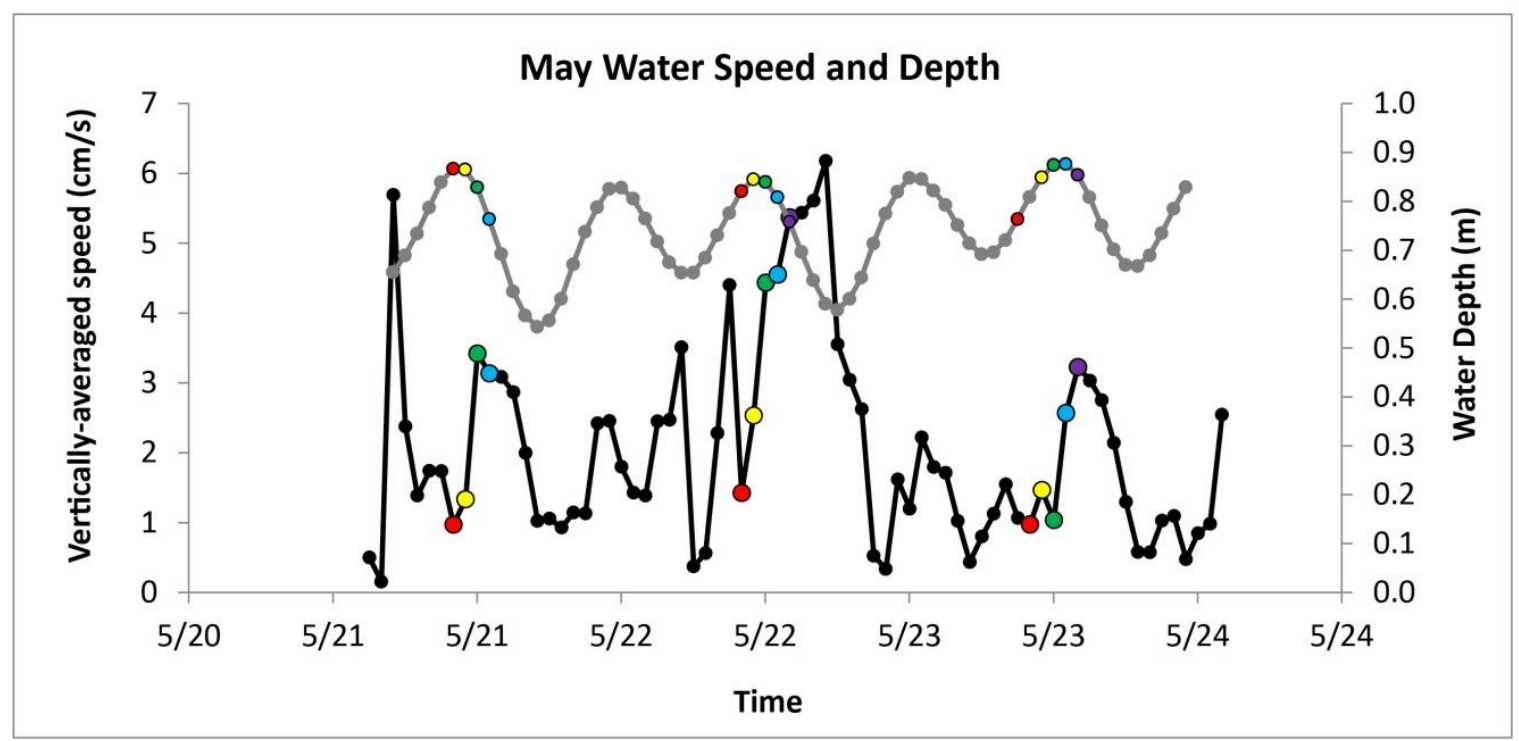

(b)

Figure 6 Depth (grey) and water speed (black) in December (a) and May (b). The colors indicate relative time of day for water samples and resulting flux estimates: Red (10:0011:00), Yellow (11:00-12:00), Green (12:00-13:00), Blue (13:00-14:00), Purple (14:0015:00), as in Fig. 5. The water depth was slightly below 1 meter in both December and May. The vertically-averaged speed of the water column was quite variable. 


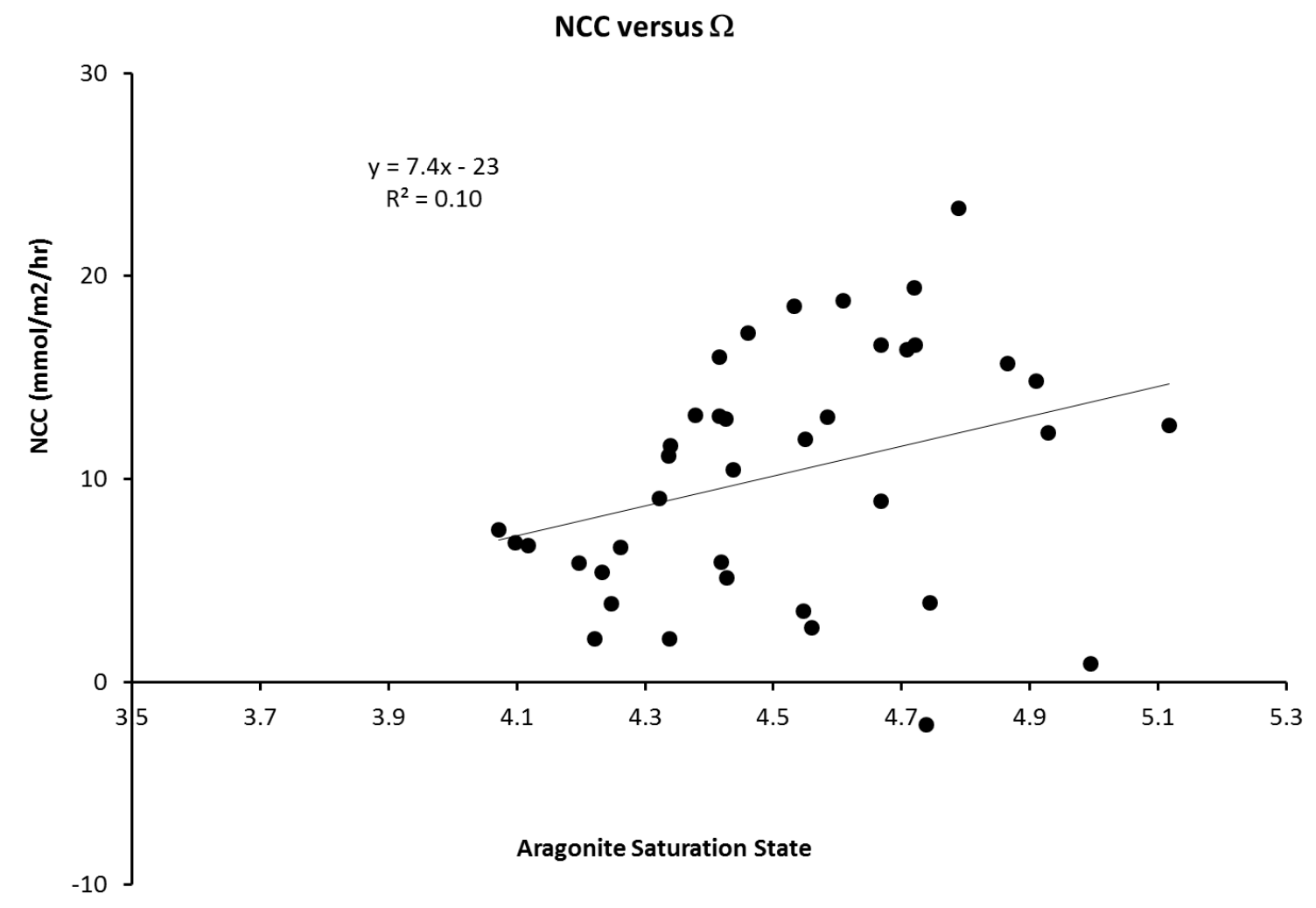

Figure 7 NCC versus $\Omega_{a}$ is significant $(\mathrm{p}=0.05)$ but weak. See Table 3 for regression data and statistics. 


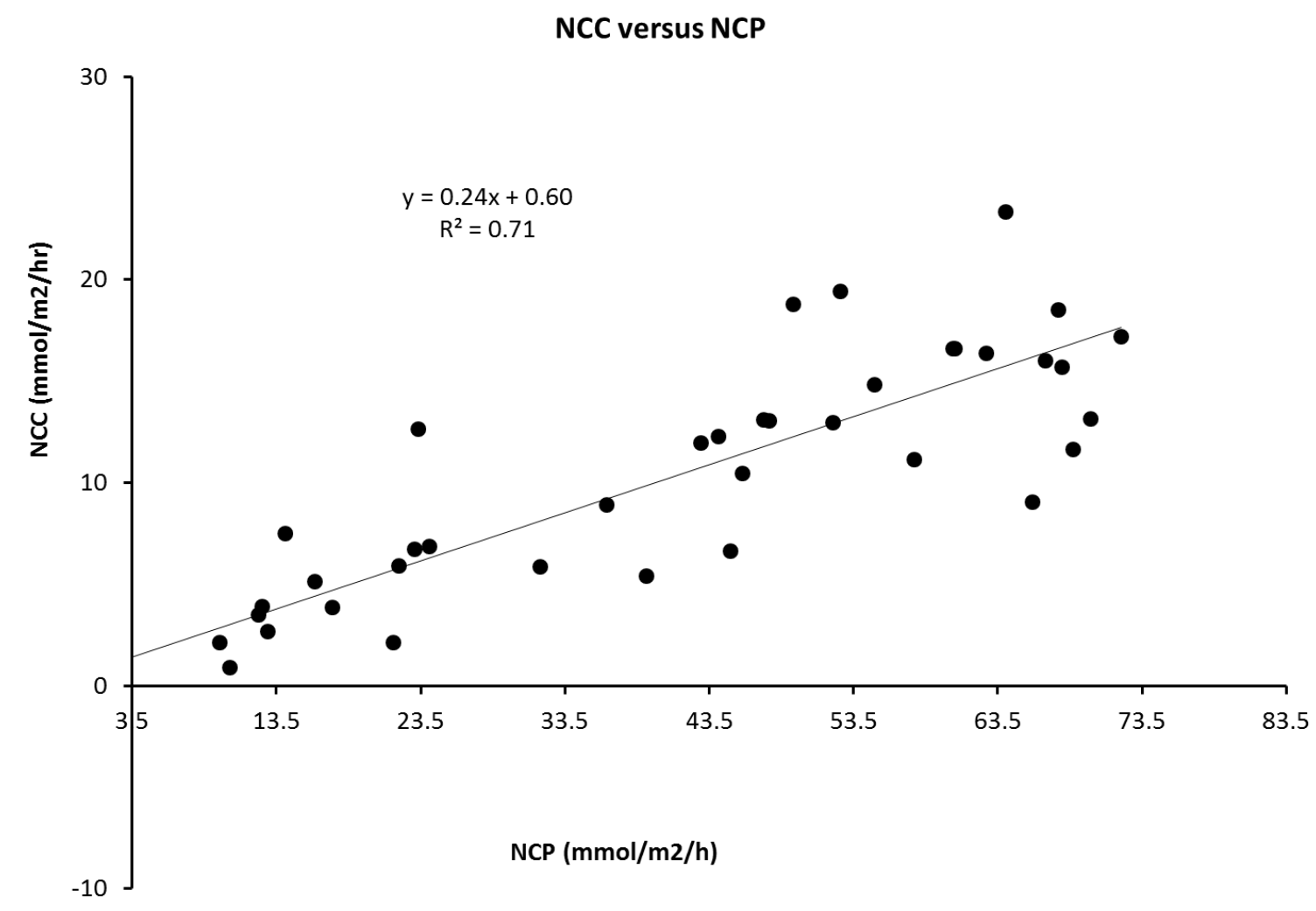

Figure 8 NCC correlates strongly with NCP $(\mathrm{p}=1 \mathrm{e}-11)$. See Table 3 for regression data and statistics. 


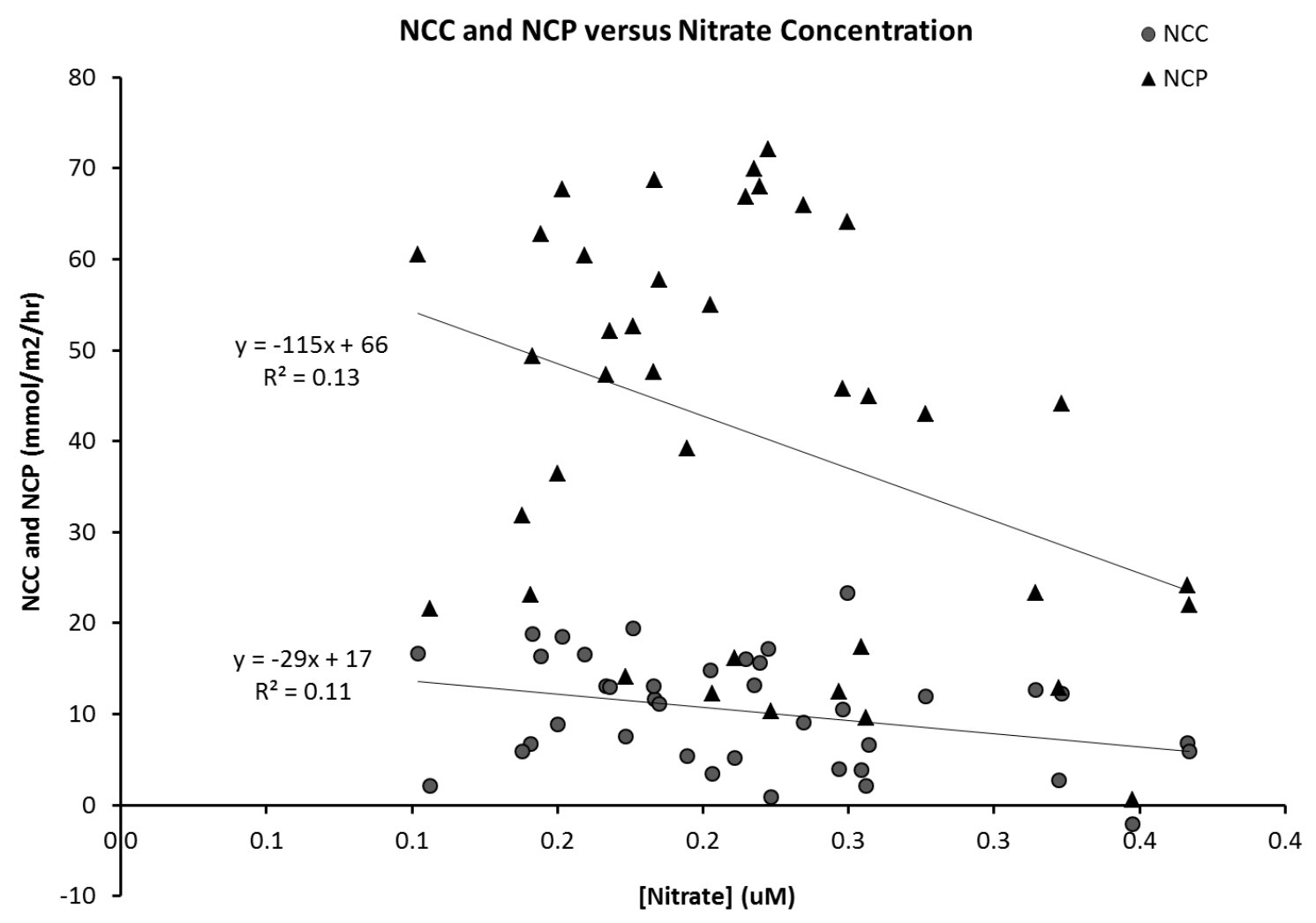

Figure $9 \mathrm{NCC}$ and $\mathrm{NCP}$ both correlate weakly with $\left[\mathrm{NO}_{3}{ }^{2-}\right]$ but the correlations are significant ( $\mathrm{p}=0.05$ and 0.04 respectively). 


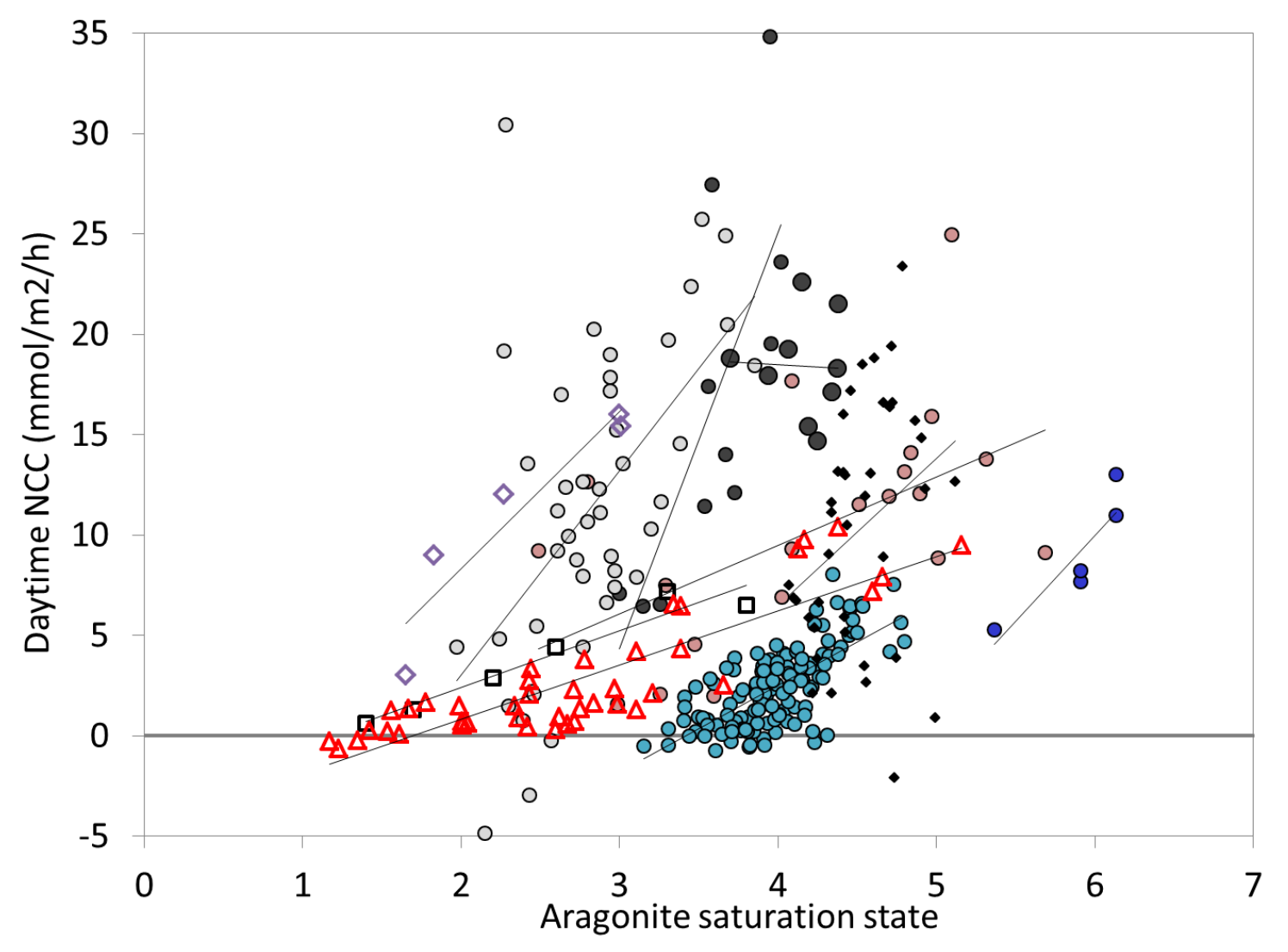

Figure 10 Daytime NCC rate (mmol m-2 h-1) versus $\Omega_{\mathrm{a}}$ for field (solid circles) and mesocosm studies (open symbols). The slopes and $\mathrm{x}$-intercept values ( $\Omega_{\mathrm{a}}$ thresholds) are dissimilar between studies. Hourly daytime data from this study (small black diamonds), original hourly daytime data from Ningaloo Reef (Falter et al. 2012) (small black circles for summer and large black circles for winter), Lady Elliot Island (Shaw et al. 2012) (pink circles), Kaneohe Bay (Shamberger et al. 2011) (box model data, grey circles), and the Gulf of Eilat (Silverman et al. 2007a) (light blue circles) were obtained by personal communication with the authors. Hourly data from the Ryukyu Islands (dark blue circles) are from Table 4 of (Watanabe et al. 2006). And hourly data from mesocosm experiments are from Table 1 of (Andersson et al. 2009)(black squares), from the first two sets of experimental runs in Table 3 of (Langdon and Atkinson 2005) (purple diamonds), and from Table 4 of (Langdon et al. 2000) (red triangles, reported diurnal data divided by 12 hours in a day to estimate daytime hourly rates). Horizontal grey line marks transition from net calcification to net dissolution. 


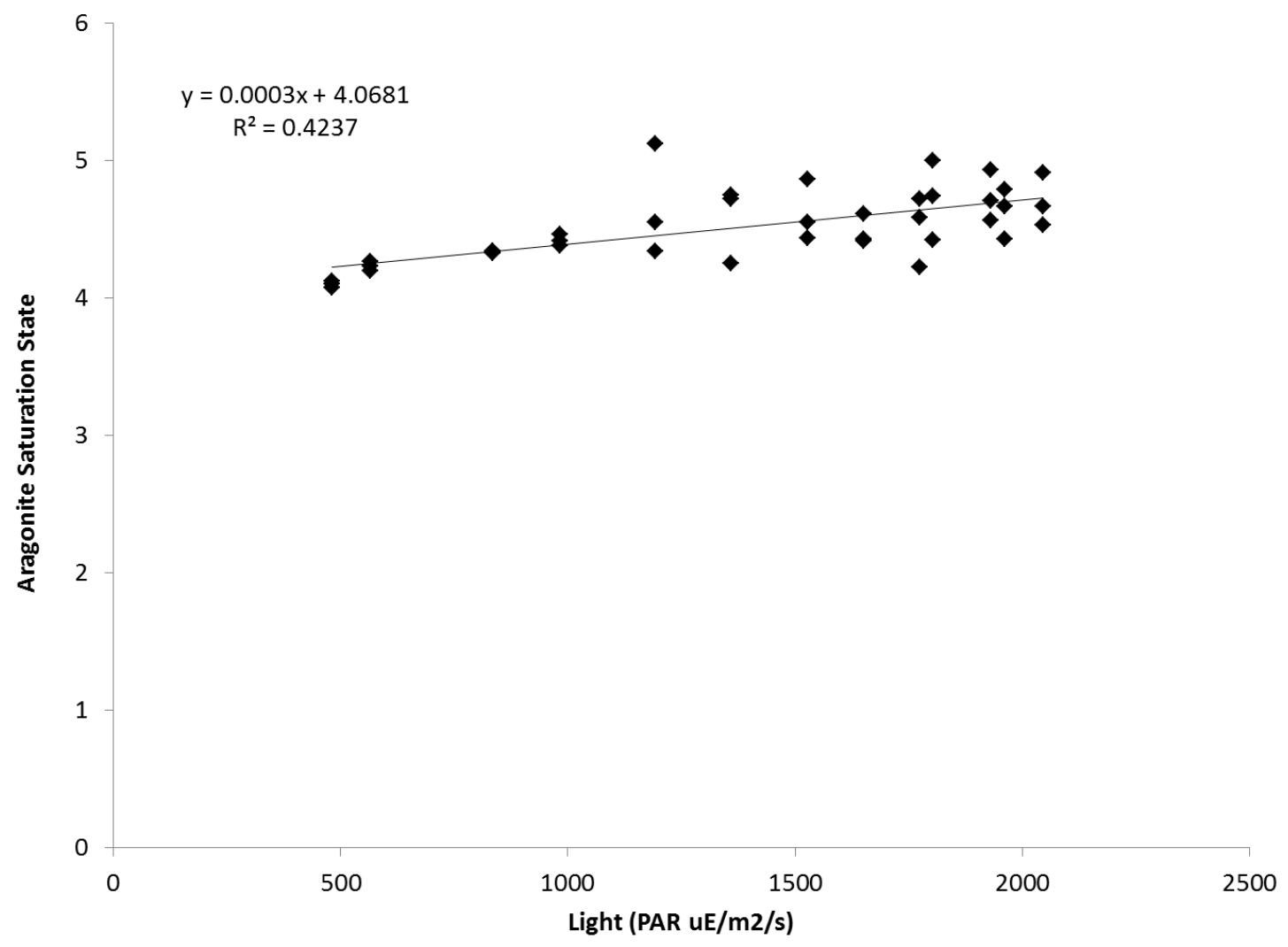

Figure $11 \Omega_{\mathrm{a}}$ and light levels are significantly correlated, $\mathrm{p}=7 \mathrm{e}-6$. 

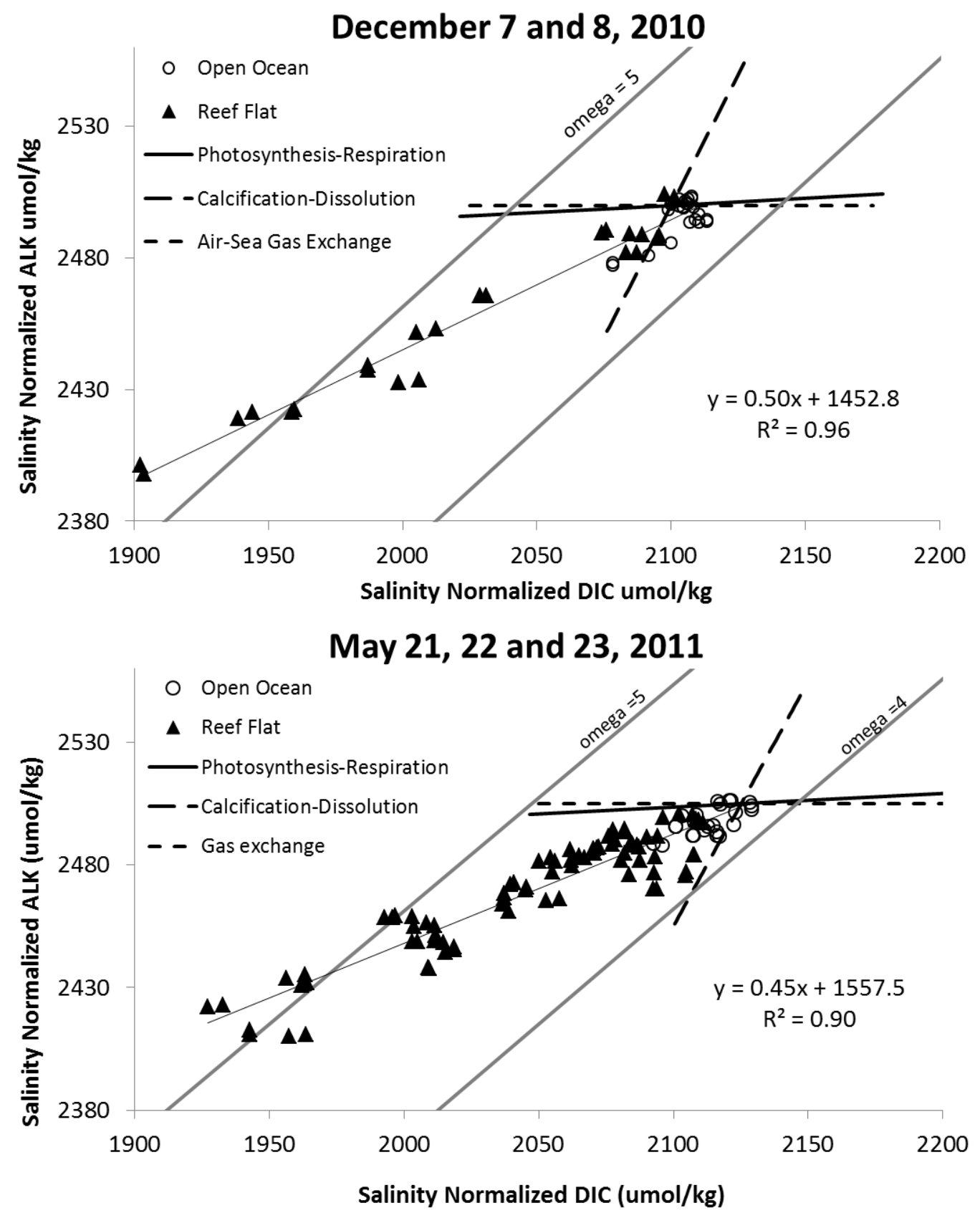

Figure 12 The reef samples (black triangles) generally exhibit depletion in salinity normalized alkalinity and DIC relative to the open ocean end-member (open circles). This pattern is an indication of positive NCP and NCC. Isopleths for $\Omega_{\mathrm{a}}=4$ and $\Omega_{\mathrm{a}}=5$ are plotted in grey and were calculated using CO2sys $(\mathrm{T}=29, \mathrm{~S}=39.1)$. The overall NCC:NCP ratio $\sim 0.28$ creates a positive feedback for calcification, i.e. during the day. The combination of NCC and NCP elevates the $\Omega_{\mathrm{a}}$ by almost one unit. 


\section{Table 1}

During the December and May field seasons we captured maximum and minimum levels in incoming short wave radiation $\left(\mathrm{PAR}, \mu \mathrm{E} \mathrm{m}^{2} \mathrm{~s}^{-1}\right)^{1}$. Nitrate and phosphate concentrations $(\mu \mathrm{M})$, temperature $(\mathrm{C}), \Omega_{\mathrm{a}}{ }^{2}, \mathrm{pCO}_{2}(\mu \mathrm{atm})^{2}$ and $\mathrm{pH}^{2}$ were similar in December and May. Values listed as mean \pm standard deviation, except NCC and NCP values $\left(m m o l ~ m^{-2} \mathrm{~h}^{-1}\right)$ listed with standard error.

\begin{tabular}{|c|cccccccccc|}
\hline & $\mathrm{n}$ & $\mathrm{Temp}$. & $\Omega_{\mathrm{a}}{ }^{1}$ & $\mathrm{pCO}_{2}{ }^{1}$ & $\mathrm{pH}^{1}$ & $\mathrm{PAR}^{2}$ & {$\left[\mathrm{NO}_{3}\right]$} & {$\left[\mathrm{PO}_{4}\right]$} & $\mathrm{NCC}$ & $\mathrm{NCP}$ \\
\hline Dec & 12 & 29.6 & 4.6 & 340 & 8.10 & 1350 & 0.2 & 0.04 & 8 & 21 \\
& & \pm 0.3 & \pm 0.3 & \pm 50 & \pm 0.05 & \pm 130 & \pm 0.1 & \pm 0.03 & \pm 3 & \pm 7 \\
May & 42 & 28.4 & 4.5 & 340 & 8.10 & 1530 & 0.2 & 0.1 & 11 & 44 \\
Average & & \pm 0.6 & \pm 0.3 & \pm 40 & \pm 0.03 & \pm 660 & \pm 0.2 & \pm 0.03 & \pm 1 & \pm 4 \\
of Dec & 2 & 29.0 & 4.6 & 340 & 8.10 & 1440 & 0.2 & 0.07 & 9 & 33 \\
\& May & & \pm 0.9 & \pm 0.1 & \pm 2 & \pm 0.00 & \pm 130 & \pm 0.0 & \pm 0.04 & \pm 2 & \pm 12 \\
\hline
\end{tabular}

${ }^{1}$ Average of short wave radiation flux was integrated from 11:00-13:00 on the three sampling days. The flux of photosynthetically available radiation is estimated as $43 \%$ of total incoming radiative energy flux (Baker and Frouin 1987) which is divided by 0.21 (Onsetcomp.com) to convert $\mathrm{W} \mathrm{m}^{-2}$ to $\mu$ Einsteins $\mathrm{m}^{-2} \mathrm{~s}^{-1}$.

${ }^{2}$ Calculated from alkalinity and DIC using the CO2SYS program (Pierrot 2006), applying the total $\mathrm{pH}$ scale (mol/kg-SW), the carbonate species dissociation constants of Mehrbach et al. (1973) as refit by Dickson and Millero (1987), and the aragonite solubility constant of Mucci (1983). 
Table 2

Average daytime NEC and NCP rates $\left(\mathrm{mmol} \mathrm{m}^{-2} \mathrm{~h}^{-1}\right)$ and environmental data for several field and mesocosm studies. (See table S4 for details on each data source).

\begin{tabular}{|c|c|c|c|c|c|c|c|c|c|c|c|c|c|c|c|c|}
\hline 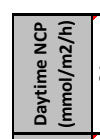 & $\vec{\nabla}$ & $\frac{\pi}{2}$ & $\frac{5}{2} \frac{\pi}{2} \frac{\pi}{2}$ & $\stackrel{m}{m} \underset{\sim}{\stackrel{F}{m}}$ & $\frac{\pi}{2} \frac{\pi}{2} \frac{\pi}{2}$ & $\Rightarrow=$ & 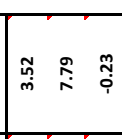 & 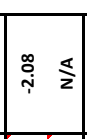 & 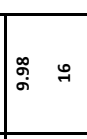 & 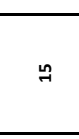 & $\therefore$ & ঃ & $\frac{s}{z} \frac{\pi}{z}$ & of & $\frac{5}{2} \frac{\pi}{2}$ & \\
\hline & & 20 & & $\hat{g}$ & $m$ & 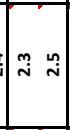 & $\mid$\begin{tabular}{c}
0 \\
\hdashline
\end{tabular} & $\left|\begin{array}{lll}0 & \overrightarrow{0}\end{array}\right|$ & $\stackrel{2}{0} \approx$ & $\stackrel{\mathscr{N}}{\infty}$ & $\stackrel{n}{m}$ & רֶ, & 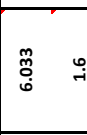 & & 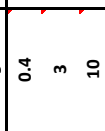 & \\
\hline 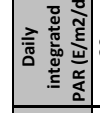 & $0 m$ & 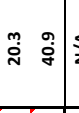 & $\Sigma \Sigma$ & 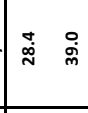 & $\frac{\pi}{2}$ & 至: & 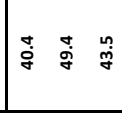 & 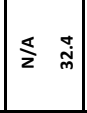 & $\frac{\pi}{2} \frac{\pi}{2}$ & 尊 & $\tilde{\tilde{g}}$ & พับ & $\frac{\pi}{2} \frac{\pi}{2}$ & & 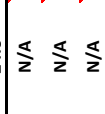 & $\frac{1}{2}=\frac{5}{2}$ \\
\hline 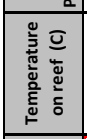 & $\stackrel{\infty}{\infty}$ & & $\mid$ & 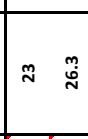 & $\pi \approx$ & $\stackrel{\infty}{\sim} \underset{\sim}{\sim}$ & 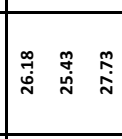 & 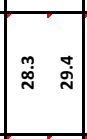 & 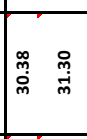 & $\stackrel{m}{N}$ & $\vec{N}$ & $\approx$ & $\stackrel{n}{\stackrel{n}{i}} \stackrel{m}{i}$ & $\stackrel{n}{\approx}$ & 品 & 至 \\
\hline 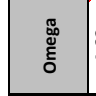 & $\underset{q}{q}:$ & 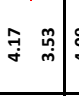 & 索享高 & N & 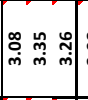 & 然 & 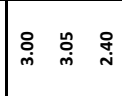 & 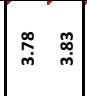 & 总 & $\overrightarrow{\dot{m}}$ & 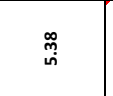 & 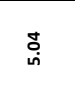 & $\stackrel{m}{m}$ & 年 & $\stackrel{\leftrightarrow}{\rightarrow}$ & \\
\hline 密 & ปّ & & 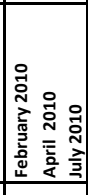 & 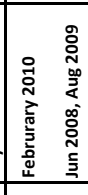 & 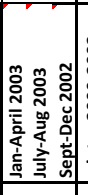 & ح్̃ & 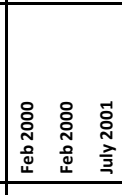 & 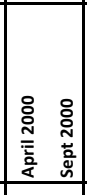 & 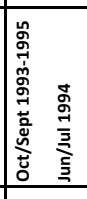 & 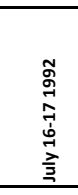 & 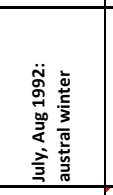 & 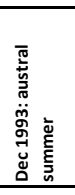 & 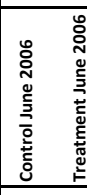 & 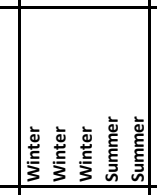 & 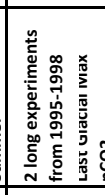 & \\
\hline : & 50 & $\therefore: 5$ & 898 & $\approx 2$ & $\pi \approx \pi$ & $\therefore=$ & $\approx \approx \approx$ & $\because=$ & 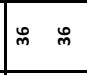 & 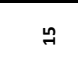 & 2 & 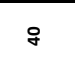 & 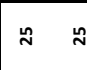 & 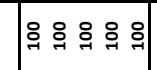 & 898 & 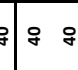 \\
\hline 童 & 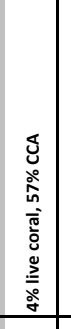 & 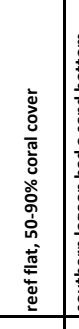 & 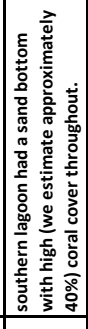 & 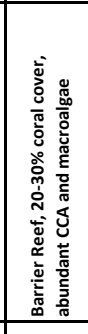 & 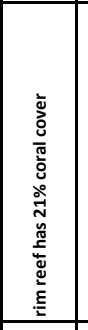 & 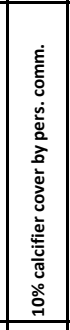 & 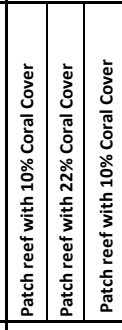 & 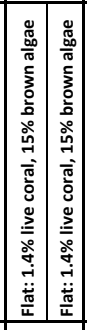 & 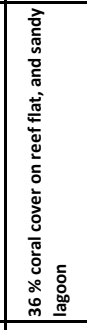 & 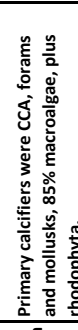 & 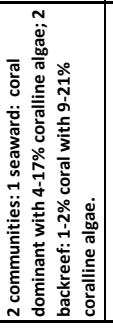 & 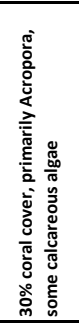 & 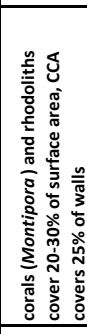 & 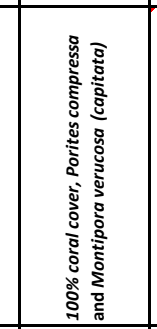 & 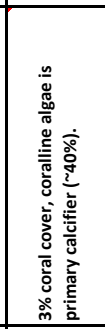 & $\frac{a}{\partial}$ \\
\hline & & | & & & & & 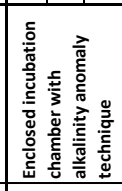 & 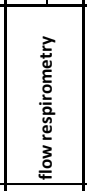 & 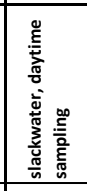 & & & & & & 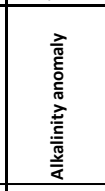 & \\
\hline & 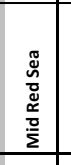 & 巡 & 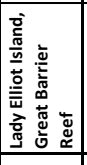 & 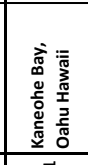 & 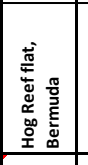 & 5 & 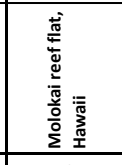 & 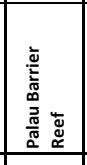 & 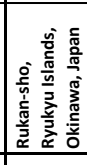 & & & 藍 & 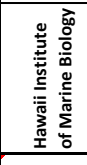 & 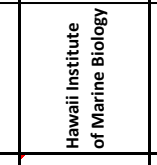 & & \\
\hline & 䓂 & בָּ & 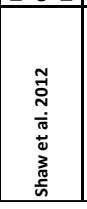 & 节 & 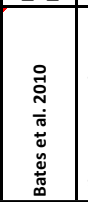 & 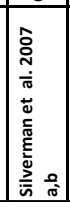 & 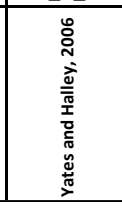 & 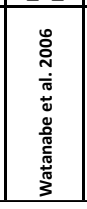 & 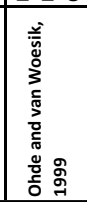 & & & & & క్ & & \\
\hline
\end{tabular}


Table 3

Statistics for regressions between metabolic rates (NCC and NCP) and temperature, PAR, $\Omega_{\mathrm{a}}$, and nitrate concentration. The regressions are weak (low $\mathrm{r}^{2}$ ) and all are insignificant (p-value $>0.05$ ) except for NCC versus $\Omega \mathrm{a}$ and $\mathrm{NCC}$ and NCP versus $\left[\mathrm{NO}_{3}{ }^{2-}\right]$.

\begin{tabular}{|c|c|c|c|c|c|c|c|c|}
\hline & $\mathrm{p}$ & $\mathrm{r}^{2}$ & slope & slope err. & $\mathrm{p}$ & $\mathrm{r}^{2}$ & slope & slope err. \\
\hline & \multicolumn{4}{|c|}{ Temperature } & \multicolumn{4}{|c|}{ PAR } \\
\hline $\mathrm{NCC}$ & 0.7 & 0.003 & -0.5 & 1 & 0.1 & 0.06 & 0.003 & 0.002 \\
\hline \multirow[t]{2}{*}{$\mathrm{NCP}$} & 0.1 & 0.06 & -8 & 5 & 0.7 & 0.004 & 0.003 & 0.007 \\
\hline & \multicolumn{4}{|c|}{$\Omega_{\mathrm{a}}$} & \multicolumn{4}{|c|}{$\left[\mathrm{NO}_{3}\right]$} \\
\hline $\mathrm{NCC}$ & 0.05 & 0.10 & 7 & 4 & 0.04 & 0.11 & -29 & 13 \\
\hline \multirow[t]{2}{*}{$\mathrm{NCP}$} & 0.5 & 0.01 & 8 & 13 & 0.02 & 0.13 & -115 & 48 \\
\hline & $\mathrm{p}$ & $r^{2}$ & slope & slope err. & & & & \\
\hline NCC versus NCP & $1 \mathrm{e}-11$ & 0.71 & 0.24 & 0.02 & & & & \\
\hline$\Omega_{\mathrm{a}}$ versus PAR & $7 e-06$ & 0.4 & 0.0003 & $6 e-05$ & & & & \\
\hline
\end{tabular}


Table 4

The net metabolic effect of NCC and NCP results in elevated $\Omega_{\mathrm{a}}$ on the reef flat.

Temperature (C) and salinity (psu) change very little from open-ocean to reef flat. (mean \pm standard error).

\begin{tabular}{|c|c|c|c|c|c|c|}
\hline & $\begin{array}{c}\Omega_{\mathrm{a}} \\
\text { Open Ocean }\end{array}$ & $\begin{array}{c}\Omega_{\mathrm{a}} \\
\text { Reef Flat }\end{array}$ & $\begin{array}{l}\text { Temperature } \\
\text { Open Ocean }\end{array}$ & $\begin{array}{c}\text { Temperature } \\
\text { Reef Flat }\end{array}$ & $\begin{array}{c}\text { Salinity } \\
\text { Open Ocean }\end{array}$ & $\begin{array}{c}\text { Salinity } \\
\text { Reef Flat }\end{array}$ \\
\hline $\mathrm{D}$ & $4.23 \pm 0.02$ & $4.6 \pm 0.3$ & $29.30 \pm 0.02$ & $29.61 \pm 0.26$ & $39.21 \pm 0.01$ & $39.24 \pm 0.01$ \\
\hline May & -0.02 & & 27.5 & 28.3 & $39.09 \pm$ & 39.0 \\
\hline $\begin{array}{l}\text { Average of } \\
\text { Dec \& May }\end{array}$ & 4.14 & 4.6 & $28.13 \pm 0.71$ & $28.98 \pm 0.88$ & 0.05 & $39.14 \pm 0.01$ \\
\hline
\end{tabular}




\section{Supplementary Tables}

Table S1 Instantaneous NCC and NCP in mmol m${ }^{-2} \mathrm{~h}^{-1}$. 'se' is standard analytical error. Colors correspond the times of sampling transects in Fig. 5. Actual transect times are indicated in gray. Sequential transects were averaged when adding the advection and time-dependent terms, resulting in a new time assignment as indicated in black and illustrated by each data set straddling the color bars for each transect.

\begin{tabular}{|c|c|c|c|c|c|c|c|}
\hline Day & Time & Color & Point & NCC & se & NCP & se \\
\hline \multirow{3}{*}{ 7-Dec-10 } & & Yellow & A & 13 & 3 & 23 & 5 \\
\hline & $4: 52$ & & B & 3 & 2 & 12 & 12 \\
\hline & & Blue & C & 2 & 5 & 10 & 5 \\
\hline \multirow{4}{*}{ 8-Dec-10 } & & Yellow & A & 4 & 1 & 12 & 5 \\
\hline & \multirow[t]{2}{*}{$4: 13$} & & B & 19 & 3 & 53 & 15 \\
\hline & & & C & 4 & 1 & 17 & 3 \\
\hline & $13: 10$ & Blue & & & & & \\
\hline
\end{tabular}

* The advection terms for NCC and NCP at point A at 13:25 on Dec 7 are more than four standard deviations above the means (60 and $177 \mathrm{mmol} \mathrm{m-2} \mathrm{h-1).} \mathrm{The} \mathrm{advection} \mathrm{data} \mathrm{are}$ non-normally distributed with these outliers included, but distributions are normal with these outliers excluded. The lowest NCC advection value ( $-5 \mathrm{mmol} \mathrm{m}-2 \mathrm{~h}-1)$ also occurs at the same time, but at point $\mathrm{C}$. By conditional logic it is unlikely for this to randomly occurr on the exact same date and time as the anomalously highest value. Also, it is unlikely that such high rate of net dissolution would occur in the very middle of the day when all of the other data from all other times exhibit positive net calcification. For these reasons, I suspect something was amiss with the sample at point $\mathrm{C}$ of the second transect on Dec 7 , and I exclude this value as well. The text describes results excluding the 2 outliers for advection terms for NCC and the single outlier for NCP.

\begin{tabular}{|c|c|c|c|c|c|c|c|}
\hline Day & Time & Color & Point & NCC & se & NCP & se \\
\hline \multirow{10}{*}{ 21-May-11 } & 10:20 & Bd & & & & & \\
\hline & & & A & 5.1 & 0.1 & 16.2 & 0.2 \\
\hline & \multirow{3}{*}{$111: 20$} & \multirow{3}{*}{ Yellow } & B & 19 & 3 & 49 & 8 \\
\hline & & & C & 13 & 4 & 47 & 10 \\
\hline & & & A & 13 & 4 & 52 & 21 \\
\hline & \multirow{3}{*}{$\begin{array}{r}3: 36 \\
12: 20\end{array}$} & \multirow{3}{*}{ Green } & B & 9 & 2 & 36 & 9 \\
\hline & & & C & 23 & 11 & 64 & 27 \\
\hline & & & A & 19 & 1 & 68 & 2 \\
\hline & \multirow[t]{2}{*}{$2: 27$} & \multirow[b]{2}{*}{ Blue } & B & 17 & 3 & 61 & 4 \\
\hline & & & c & 15 & 4 & 55 & 8 \\
\hline \multirow{13}{*}{ 22-May-11 } & \multirow[t]{2}{*}{ 10:20 } & \multirow{2}{*}{ Red } & & & & & \\
\hline & & & A & 7 & 1 & 24 & 17 \\
\hline & \multirow{3}{*}{$\begin{array}{r}4: 09 \\
11: 20\end{array}$} & \multirow{3}{*}{ Yellow } & B & 8 & 1 & 14 & 8 \\
\hline & & & C & 7 & 2 & 23 & 17 \\
\hline & & & A & 6.6 & 0.4 & 45 & 16 \\
\hline & \multirow{3}{*}{$\begin{array}{r}: 18 \\
12: 25\end{array}$} & \multirow{3}{*}{ Green } & B & 6 & 1 & 32 & 14 \\
\hline & & & C & 5 & 1 & 39 & 7 \\
\hline & & & A & 12 & 4 & 69 & 9 \\
\hline & \multirow[t]{3}{*}{$4: 26$} & \multirow{3}{*}{ Blue } & B & 11 & 4 & 58 & 13 \\
\hline & & & C & 9 & 4 & 66 & 13 \\
\hline & & & A & 13 & 2 & 70 & 2 \\
\hline & \multirow{2}{*}{$\begin{aligned} 5: 20 \\
14: 50\end{aligned}$} & \multirow[b]{2}{*}{ Purple } & B & 17 & 1 & 72 & 3 \\
\hline & & & C & 16 & 1 & 67 & 10 \\
\hline \multirow{13}{*}{ 23-May-11 } & 10:00 & \multirow{2}{*}{ Red } & & & & & \\
\hline & & & A & 13 & 2 & 48 & 4 \\
\hline & \multirow[t]{3}{*}{$3: 49$} & \multirow{3}{*}{ Yellow } & B & 17 & 3 & 60 & 15 \\
\hline & & & C & 2.11 & 0.02 & 22 & 5 \\
\hline & & & A & 3 & 3 & 13 & 9 \\
\hline & \multirow[t]{3}{*}{$7: 45$} & \multirow{3}{*}{ Green } & B & 12 & 4 & 44 & 16 \\
\hline & & & C & 16 & 4 & 63 & 5 \\
\hline & & & A & 6 & 2 & 22 & 9 \\
\hline & \multirow[t]{3}{*}{$8: 20$} & \multirow{3}{*}{ Blue } & B & -2.1 & 0.1 & 1 & -2 \\
\hline & & & C & 0.89 & 0.04 & 10 & 3 \\
\hline & & & $\bar{A}$ & 10 & 2 & 46 & 10 \\
\hline & \multirow[t]{2}{*}{$6: 38$} & & B & 12 & 3 & 43 & 9 \\
\hline & & Purple & C & 16 & 7 & 68 & 31 \\
\hline
\end{tabular}




\section{Table S2}

The open-ocean end-member was chemically homogeneous. Each value for alkalinity $(\mu \mathrm{eq} \mathrm{kg})$ and DIC $\left(\mu \mathrm{mol} \mathrm{kg}{ }^{-1}\right)$ is an average of 2 replicate samples from the same Niskin bottle. The standard deviations for the sets of three Niskins each day indicate that the open ocean end-member was chemically uniform.

\begin{tabular}{|c|c|c|c|c|c|c|c|}
\hline & 6-Dec & 7-Dec & 8-Dec & & 6-Dec & 7-Dec & 8-Dec \\
\hline TA \#1 & 2494.5 & 2500.1 & 2497.0 & DIC \#1 & 2101.0 & 2104.9 & 2108.5 \\
\hline TA \#2 & 2495.2 & 2501.8 & 2493.8 & DIC \#2 & 2102.8 & 2103.6 & 2111.7 \\
\hline TA \#3 & 2496.4 & 2501.6 & 2494.0 & DIC \#3 & 2099.3 & 2106.3 & 2110.0 \\
\hline Average & 2495.4 & 2501.2 & 2494.9 & Average & 2101.0 & 2104.9 & 2110.0 \\
\hline Std Dev & 0.94 & 0.94 & 1.77 & Std Dev & 1.72 & 1.33 & 1.59 \\
\hline$\%$ Std Dev & $0.04 \%$ & $0.04 \%$ & $0.07 \%$ & $\%$ Std Dev & $0.08 \%$ & $0.06 \%$ & $0.08 \%$ \\
\hline
\end{tabular}


Table S3 Same as Table 2, with the addition of details regarding how data were sourced.

\begin{tabular}{|c|c|c|c|c|c|c|c|c|c|c|c|c|c|c|c|c|}
\hline 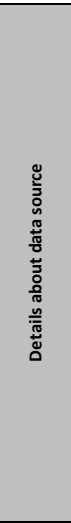 & 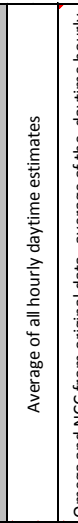 & 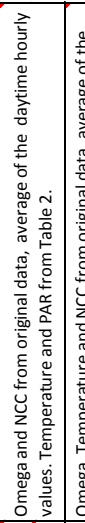 & 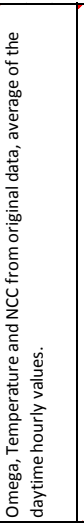 & 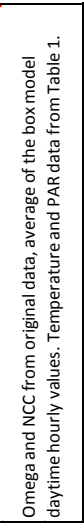 & 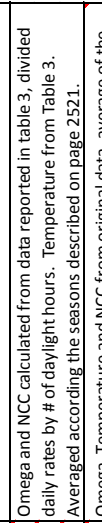 & 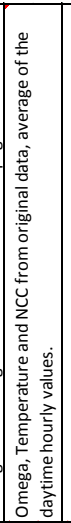 & 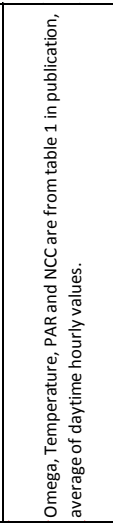 & 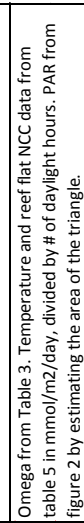 & 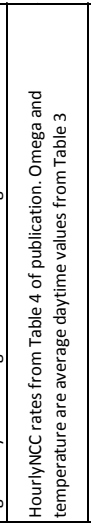 & 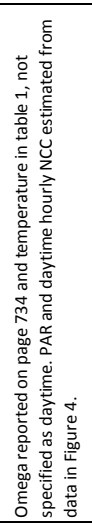 & 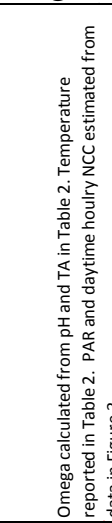 & & 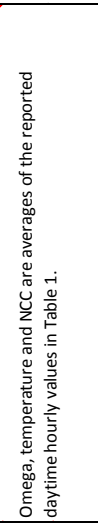 & 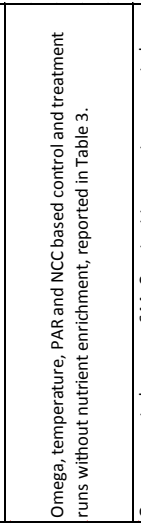 & 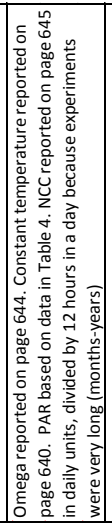 & 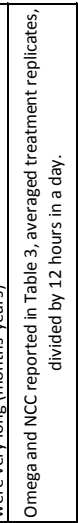 \\
\hline 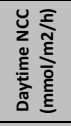 & $\infty=\infty$ & $\infty$\begin{tabular}{ll}
$\infty$ & 0 \\
\hdashline & 0
\end{tabular} & 4 & ڤे & 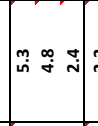 & $\stackrel{n}{\sim} \stackrel{n}{\sim}$ & 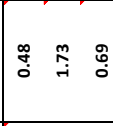 & $\begin{array}{ll}0 \\
0\end{array}$ & $\grave{i} \approx$ & $\underset{\sim}{\mathscr{N}}$ & $\stackrel{n}{\underset{m}{m}}$ & $\stackrel{\mathscr{n}}{\pi}$ & $\stackrel{0}{\circ}$ & & of & \\
\hline & 0 用 & 丞 & $\frac{\pi}{2}$ & 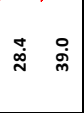 & $\frac{\frac{s}{2}}{2} \frac{s}{2}$ & 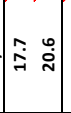 & 字索 & $\frac{\Sigma}{z} \underset{j}{~}$ & $\begin{array}{ll}\frac{\pi}{2} & \frac{\pi}{2}\end{array}$ & 品 & $\tilde{\mathscr{y}}$ & $\stackrel{\sim}{\tilde{g}}$ & $\frac{5}{z}$ & : & 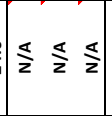 & \\
\hline 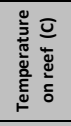 & $\stackrel{m}{\sim} \approx$ & $\hat{\sim} \vec{i}$ & 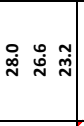 & $\approx \quad \stackrel{m}{i}$ & $\vec{\sim} \approx \AA$ & 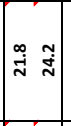 & 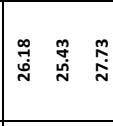 & $\stackrel{\infty}{\sim} \underset{\sim}{~}$ & 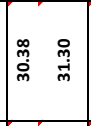 & $\mathrm{N}$ & $\stackrel{4}{n}$ & $\stackrel{N}{N}$ & $\stackrel{m}{\stackrel{m}{*}}$ & 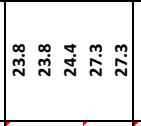 & 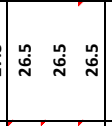 & \\
\hline 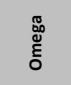 & 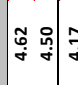 & $f \stackrel{m}{m}$ & 果 & $\vec{i} \underset{\tilde{N}}{\hat{\omega}}$ & 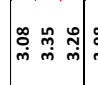 & 命 & 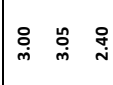 & $\stackrel{\infty}{\infty} \underset{m}{\infty}$ & 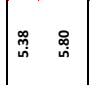 & $\overrightarrow{\dot{m}}$ & in & "मे & $\stackrel{\infty}{\infty}$ & $\vec{m}$ & 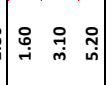 & 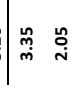 \\
\hline 莺 & 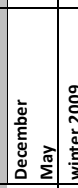 & 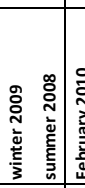 & 递安高 & 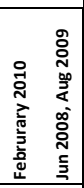 & 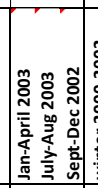 & 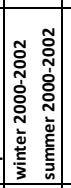 & 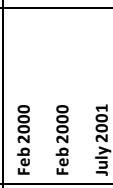 & 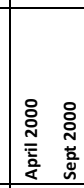 & 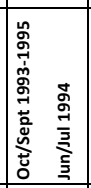 & 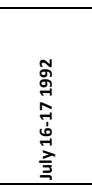 & 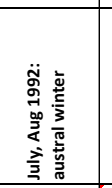 & 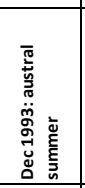 & 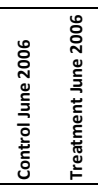 & & 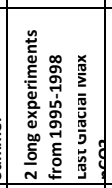 & 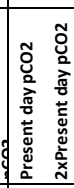 \\
\hline u & $5:=$ & $\therefore: 8$ & 888 & $\stackrel{2}{\sim} \quad \mathscr{N}$ & $\pi \vec{\pi} \pi$ & $\therefore \circ$ & 욱 & ه & 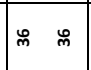 & $\cong$ & 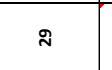 & - & $\approx \approx$ & ¿ & 88 & \\
\hline 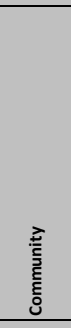 & 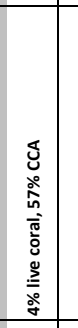 & 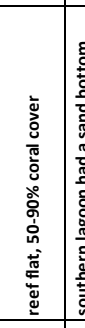 & 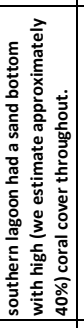 & 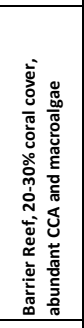 & 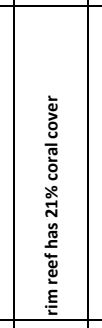 & 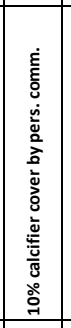 & 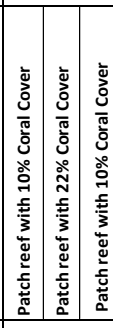 & 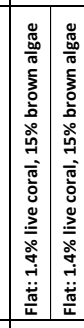 & 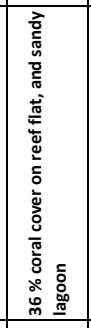 & 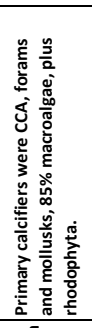 & 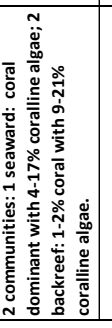 & 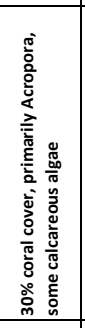 & 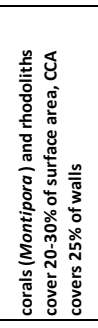 & 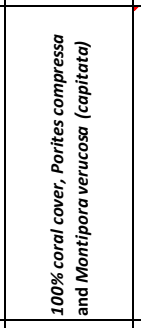 & 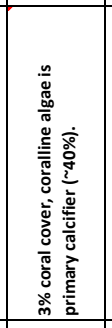 & 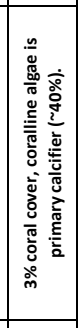 \\
\hline & 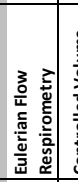 & 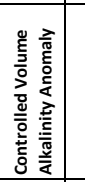 & 离 & 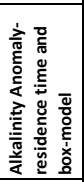 & 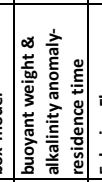 & 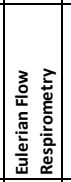 & 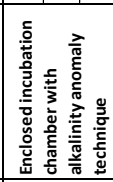 & 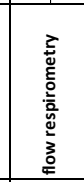 & 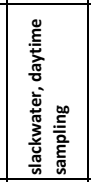 & 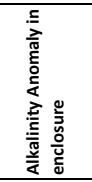 & 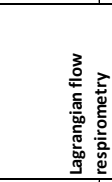 & & $\frac{\overline{\bar{\alpha}}}{\bar{\alpha}}$ & 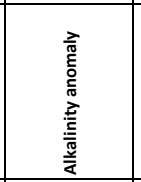 & 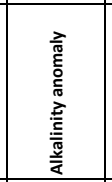 & \\
\hline . & 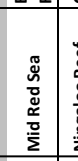 & 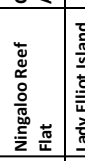 & 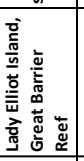 & 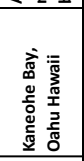 & 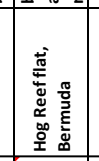 & 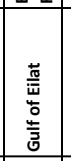 & 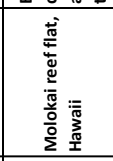 & 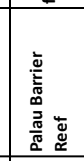 & 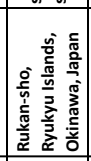 & ฐू & 离 & 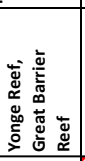 & 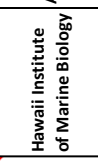 & 害 & 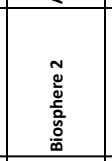 & \\
\hline & 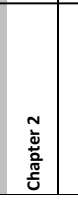 & 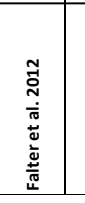 & 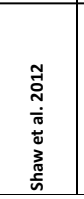 & 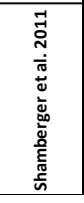 & 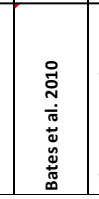 & 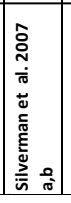 & 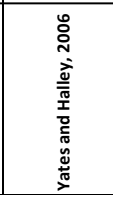 & 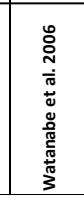 & 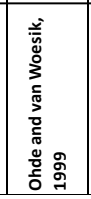 & 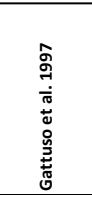 & & & $\begin{array}{l}\text { 苛 } \\
\overline{0} \\
\overline{0}\end{array}$ & 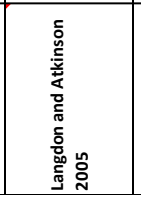 & 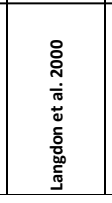 & \\
\hline
\end{tabular}




\section{Chapter 3:}

\section{A general relationship to predict the global response of coral reef net community calcification (NCC) to ocean acidification ${ }^{1}$}

\footnotetext{
${ }^{1}$ We intend to submit this chapter for publication with the following author list: W. N. Bernstein, K. A. Hughen, C. Langdon
} 


\begin{abstract}
Accurately predicting the response of coral reefs to ocean acidification is essential for developing management strategies for these important communities. However, a single equation predicting the general response of net community calcification rate (NCC) to ocean acidification in the field has proven elusive. Due to ecological and environmental differences between reef communities and the confounding influence of irradiance and organic metabolism on NCC and aragonite saturation state $\left(\Omega_{\mathrm{a}}\right)$, different reefs exhibit relationships between $\mathrm{NCC}$ and $\Omega_{\mathrm{a}}$ that are dissimilar to each other and to controlled mesocosm studies. Here, we estimate a global relationship between NCC and $\Omega_{\mathrm{a}}$ by compiling average hourly daytime NCC, $\Omega_{\mathrm{a}}$, light and temperature data from 15 field and mesocosm studies around the world. The correlation of average hourly daytime NCC and $\Omega_{\mathrm{a}}$ suggests that reefs will transition from net calcification to net dissolution at a $\Omega_{\mathrm{a}}$ of $1.0 \pm 0.6$. This transition point is often called the $\Omega_{\mathrm{a}}$ threshold. The analysis suggests a sensitivity of about $2.2 \pm 0.4 \mathrm{mmol} \mathrm{CaCO}_{3} \mathrm{~m}^{-2} \mathrm{~h}^{-1}$ per unit change $\Omega_{\mathrm{a}}$ for a reef with about $30 \%$ calcifier cover. The sensitivity determined by this analysis can be more generally understood as a predicted 50\% decline in NCC from 1880 to 2100 for a reef of any percent calcifier cover and short reef water residence time. This predicted decline agrees well with predictions based on mesocosm studies. The ability to generally predict the response of reefs world-wide to ocean acidification is crucial for national and international decision-makers to account for the effects of this global threat.
\end{abstract}




\section{Introduction}

Central to an investigation into how ocean acidification will affect coral reef net community calcification rate (NCC) are two questions involving the correlation between NCC and aragonite ${ }^{2}$ saturation state $\left(\Omega_{\mathrm{a}}\right)$ :

(1) What is the sensitivity of NCC to $\Omega_{\mathrm{a}}$, i.e., what is the slope of the relationship between NCC and $\Omega_{\mathrm{a}}$ ?

(2) What is the $\Omega_{\mathrm{a}}$ "threshold" at which a community will transition from net calcification to net dissolution on an inter-annual timescale, i.e., what is the $\mathrm{x}$ intercept of that relationship?

Previously, mesocosm experiments under controlled conditions have investigated correlations between NCC and $\Omega_{\mathrm{a}}$ (Langdon et al. 2000; Leclercq et al. 2000; Langdon 2002; Leclercq et al. 2002; Langdon and Atkinson 2005; Andersson et al. 2009). Numerous field studies have also quantified this correlation for natural systems (Ohde and van Woesik 1999; Silverman et al. 2007; Shamberger et al. 2011; Falter et al. 2012; Shaw et al. 2012). However, there is considerable heterogeneity between community responses to changing $\Omega_{\mathrm{a}}$ (Pandolfi et al. 2011; Shamberger et al. 2011; Andersson and Gledhill 2013) (Figures 1 and S1-S5). NCC- $\Omega_{\mathrm{a}}$ correlations based on field studies tend to have steeper slopes than those based on mesocosm studies (Figures 1 and S1-S2). One of the major distinguishing factors between studies at different sites is the ratio of calcifying substrate to non-calcifying substrate. However, the variability in relationships and tendency for steeper slopes for field studies relative to mesocosm studies persists even after normalizing the data for percent calcifier cover (Figures 1 and S1-S5, see methods for details on normalization). It appears that each correlation is unique to each site and that no single relationship should be applied in a general capacity (Shamberger et al. 2011). However, there remains important information to be gleaned from short term studies. Here, we synthesize information from numerous previous studies and look for a general pattern using an approach that is based on three hypotheses:

\footnotetext{
${ }^{2} \Omega \mathrm{a}$ is the mineral saturation state of aragonite, a carbonate mineral that is more soluble than calcite. Corals deposit aragonite and coralline algae deposit high-Mg calcite, a carbonate mineral that is more soluble than aragonite.
} 
(1) Results from short term local field studies tend to yield steeper slopes due to the confounding effects of light and net community productivity (NCP, the net result of photosynthesis and respiration) which co-vary with $\Omega_{\mathrm{a}}$ on the diurnal timescale.

(2) The controls of light, NCP, and temperature are weaker when considering average NCC and average environmental conditions over long (seasonal-annual) timescales and large (global) spatial scales.

(3) Coral reefs in waters with high average $\Omega_{\mathrm{a}}$ have a higher long term average NCC than reefs elsewhere in waters with lower $\Omega_{\mathrm{a}}$. We hypothesize that short term field studies yield steeper slopes of $\mathrm{NCC}-\Omega_{\mathrm{a}}$ correlations than mesocosm studies in part due to the confounding effects of co-varying controls on NCC over the diurnal cycle. NCC can vary by as much as $300-500 \%$ over the diurnal cycle (Frankignoulle et al. 1996; Gattuso et al. 1996; Langdon and Atkinson 2005; Falter et al. 2012; Silverman et al. 2012; Albright et al. 2013). $\Omega_{\mathrm{a}}$ usually covaries with light over a range of 0.5-1.5 units (Yates and Halley 2006; Shamberger et al. 2011; Albright et al. 2013; Falter et al. 2013) due to diurnal patterns in NCP, which usually outweigh the effects of NCC on the carbonate chemistry of the seawater (Albright et al. 2013; Andersson and Gledhill 2013) (see Chapter 2). If an appreciable share of the variability in NCC is due to a dependence on light, then the observed response in NCC may be larger than if only $\Omega_{\mathrm{a}}$ increased and light were held constant. Specifically, the full diurnal range of NCC plotted against the small dynamic range of $\Omega_{\mathrm{a}}$ would yield a steeper slope than the true $\mathrm{NCC}-\Omega_{\mathrm{a}}$ relationship. $\mathrm{NCC}$ and irradiance may be correlated on the diurnal cycle by way of the influence of light on photosynthesis, where endsymbiont photosynthesis provides energy for calcification by the host coral and increases the local $\Omega_{\mathrm{a}}$, and community productivity increases the ambient $\Omega_{\mathrm{a}}$ (Goreau and Goreau 1959; Wainwright 1963; Chalker and Taylor 1975; Gattuso et al. 1999). Therefore, NCP is another important confounding variable on hourly to diurnal timescales. 
There are no studies to date demonstrating the relationship between NCC and temperature on the hourly or diurnal scale (Shaw et al. 2012)and Chapter 2. However, there are several long term incubation experiments have shown that calcification rate varies between 12 and 24\% per degree C (Clausen and Roth 1975; Coles and Jokiel 1978; Reynaud et al. 1999; Marshall and Clode 2004). Temperature typically varies by about 0.2 to 2 degrees (Frankignoulle et al. 1996; Gattuso et al. 1996; Kawahata et al. 1997; Yates and Halley 2006; Andersson et al. 2009; Gray et al. 2012; Albright et al. 2013), although it can range as much as 5 degrees (Davis et al. 2011). A typical diurnal change of $1 \mathrm{C}$ would result in only a $12-24 \%$ change in NCC which is small relative to the change in NCC driven by diurnal fluctuations in PAR. Therefore, temperature fluctuations over the normal diurnal temperature range may play less of a role in confounding the NCC- $\Omega_{\mathrm{a}}$ relationship.

Nutritional status also influences NCC. However, most studies that have investigated the interaction between some measure of nutrition and $\Omega_{\mathrm{a}}$ have found that increased nutritional levels reduce the sensitivity of NCC to $\Omega_{\mathrm{a}}$ (Langdon and Atkinson 2005; Silverman et al. 2007; Cohen and Holcomb 2009). Therefore, the effect of nutrition is unlikely to be the cause of the steep $\mathrm{NCC}-\Omega_{\mathrm{a}}$ correlations relative to the mesocosm correlations. Nutrition and energetic status in corals are very complex and more research needs to be done to fully understand the role of nutrition. NCP, and by extension light which is intimately related to NCP, are the most likely causes of steeper slopes in field studies.

In the field, it is difficult to deconvolve the effects of light, NCP, and $\Omega_{\mathrm{a}}$ on NCC. One could sample regularly at the same light level, say mid-day, over a very long period of time (full annual cycle or longer), but it is unlikely that one will observe the same range in $\Omega_{\mathrm{a}}$ as can be achieved with controlled manipulations in mesocosm studies, thus limiting the applicability of the resulting correlation to a narrow dynamic range in $\Omega_{\mathrm{a}}$. Shaw et al. (2012) took a different approach by developing a multivariate regression that uses both $\Omega_{\mathrm{a}}$ and NCP to describe the variability in NCC. They found that $\Omega_{\mathrm{a}}$ alone describes $32 \%$ of the variability in NCC, with a sensitivity of $3.53 \mathrm{mmol} \mathrm{m}^{-2} \mathrm{~h}^{-1}$ per unit 
$\Omega_{\mathrm{a}}$ but that after accounting for the effects of NCP, this sensitivity declines to $2.14 \mathrm{mmol}$ $\mathrm{m}^{-2} \mathrm{~h}^{-1}$ per unit $\Omega_{\mathrm{a}}$ (multivariate regression describing $53 \%$ of the variability in NCC) (Shaw et al. 2012). This implies that the control of NCP on NCC confounds the NCC- $\Omega_{\mathrm{a}}$ relationship in such a way as to increase the apparent sensitivity, in agreement with our first hypothesis. After accounting for this additional control, they arrived at a relationship that agrees quite well with from mesocosm studies, predicting a decline in NCC of roughly 55\% from 1880 to 2100 (Langdon et al. 2000; Langdon and Atkinson 2005, Shaw et al. 2012). Note that the approach of Shaw et al. (2012) could be improved by deriving NCP from changes in oxygen concentration so that NCP and NCC would be truly independent.

In contrast to field studies, researchers studying NCC in mesocosm studies can manipulate $\Omega_{\mathrm{a}}$ over a large range and can use a combination of high sampling density, experimental design, and increased variable control to deconvolve the effects of irradiance, temperature, NCP and $\Omega_{\mathrm{a}}$ on NCC (Langdon et al. 2000). One way in which mesocosm studies have been able to isolate the effects of $\Omega_{\mathrm{a}}$ is by estimating NCC regularly over several years and averaging out the variability in factors that control NCC on shorter timescales, thereby revealing the underlying relationship between NCC and $\Omega_{\mathrm{a}}$. This approach was demonstrated by the BIOSPHERE 2 mesocosm study, in which observations spanning a total of five years were used to average out the short-term fluctuations in light and nutrient concentrations, revealing a strong underlying relationship between NCC and $\Omega_{\mathrm{a}}$ (Langdon et al. 2000). It is difficult to do this with field studies without extensive manpower and instrumentation resources over several years. Instead, we adopted this averaging approach, but applied it to previously published studies from around the globe.

\section{Methods}

We assembled NCC, $\Omega_{\mathrm{a}}$, temperature, and photosynthetically active radiation (PAR) data collected in short-term field studies, and averaged data from each study on a seasonal timescale. We examined data from 11 field studies and four mesocosm studies in which 
NCC and $\Omega_{\mathrm{a}}$ were measured repeatedly over days or weeks. All four seasons are represented by this data set (Figure 2, Table 1). The 15 studies were conducted in diverse regions around the globe (Atlantic, Pacific, Indian Ocean, and Red Sea) extending from $24^{\circ} \mathrm{S}$ to $32^{\circ} \mathrm{N}$ (Figure 3, Table 1 ).

This retrospective approach is challenging because the data were not collected by the same method, with the same sampling density, or over the same duration. An inherent assumption in generating a data set of average values is that each study sampled at sufficient density and across a sufficiently large breadth of environmental conditions to capture the true mean value of that field season. In comparing these data points, we are also assuming that all methods are equally valid. With these assumptions and challenges in mind, care was taken to ensure that the data from the 14 studies were as comparable as possible. Although average diurnal NCC would be ideal for this analysis, we systematically focused on daytime hourly NCC because nighttime measurements were not made during all studies. We determined the average daytime hourly NCC rates for each study by either extracting the value directly from the report, estimating the value from the reported data, or calculating the value using original published data (see Table 1 for details).

One average NCC value was determined for each field season, distinct mesocosm treatment, or independent in situ incubation. For example, two distinct in situ incubations conducted by Yates and Halley (2006) in February 2000 on patch reef communities of different percent coral cover were considered independently (Table 1). Further, if a season was sampled multiple times over more than one year in any given study we pooled the data into a single value for that season. For example, Shamberger et al. (2011) sampled Kaneohe Bay in June 2008 and again in August 2009. These data were considered together to determine an average summer value for that site (Table 1).

Ideally, each site would be sampled evenly throughout the year for several years. The implicit assumption in our method is that the results from each short term study are representative of the typical conditions and NCC rates for each site. The uncertainty introduced by this assumption is not known, but is likely smaller than the differences 
between seasonal averages at each site. We chose not to average separate seasons into an annual average for each site as this would require the assumption that each year was sufficiently well sampled to determine an annual average. Instead we plotted seasonal averages as separate points and observed that averages from the same field site but different seasons tend to cluster together (Watanabe et al. 2006; Yates and Halley 2006; Silverman et al. 2007; Falter et al. 2012; Shaw et al. 2012). This gives an indication of where an annual average for each site may fall and also lends insight into the maximum uncertainty in each seasonal average beyond the standard error for each study.

The purpose of averaging large data sets in this way is to overcome the effects of diurnal fluctuations in controls (light, temperature, nutrients and NCP) on NCC. These factors may still exercise control on NCC on a seasonal and global basis, a possibility which we investigate and address in the discussion. This process of reducing highresolution data into seasonal averages for each site resulted in 36 data points that constitute the global data set.

For each average NCC value, we extracted the corresponding average daytime temperature, $\Omega_{\mathrm{a}}$ and daily-integrated photosynthetically active radiation levels (PAR) by the same methods described above. If light flux was reported as $\mathrm{W} \mathrm{m}^{2}$, PAR was estimated as $43 \%$ of total incoming radiative energy flux (Baker and Frouin 1987) and W $\mathrm{m}^{2}$ was converted to $\mu$ Einsteins $\mathrm{m}^{-2} \mathrm{~s}^{-1}$ by dividing by 0.21 (Onsetcomp.com). PAR data were integrated from sunrise to sunset. Light data were not available for all studies (see Table 1 for details). Nutrient data were not reported systematically in previous publications and so could not be collected in a consistent manner from study to study.

As a first approximation of percent calcifier cover $(\% \mathrm{CC})$ for each field site and mesocosm we took the sum of the percent cover of coral and coralline algae, weighted equally. We chose the simplest assumption because there are not sufficient data to account for the different groups of calcifying organisms and their relative rates of calcification. It is important to note that not all studies have thoroughly quantified percent cover of coral and coralline algae, so the estimates compiled in this study are based quantitative and semi-quantitative data for which the uncertainty is not known. Future 
studies should carefully quantify the percent cover of major calcifying species to improve comparisons between studies.

All correlations in this study are generated by standard linear regression.

\section{Results}

$\%$ CC explains $27 \%$ of the variance in the global NCC dataset $(\mathrm{p}<<0.001$, Table 2, Figure 4). This was expected because when calcifying organisms are more abundant, more calcification will occur during a given time interval. Additionally, with decreased benthic cover of calcifying substrate, there may be increased opportunity for bioeroders to colonize the carbonate substrate - relict corals, rubble, or sand - and drive up levels of metabolic dissolution, resulting in lower NCC.

The control of \% CC on NCC must be accounted for when investigating the control of $\Omega_{\mathrm{a}}$ (or any other environmental variable) on the global data set. We normalized the NCC rates the average \%CC among the 15 studies (29\%) to compute a normalized net community calcification (NNCC).

$$
\text { NNCC }=\text { NCC } \frac{\text { Average } \% C C}{\text { site specific } \% C C}=\text { NCC } \frac{29 \%}{\% C C}
$$

Note that normalization affects the resulting slope of the correlation between NNCC and $\Omega_{\mathrm{a}}$. The choice of \%CC to which we normalized is arbitrary, therefore we chose to normalize all the NCC data to the average \% CC in order to have the most generally applicable NNCC and $\Omega_{\mathrm{a}}$ slope possible (Figures 5 and 6, and S6-S9). However, predictions of changes in NCC for reefs with \%CC different from $29 \%$ could by computed by multiplying the predicted NNCC by the ratio of $\% \mathrm{CC}$ to $29 \%$.

Also note that the correlation between $\Omega_{\mathrm{a}}$ and $\% \mathrm{CC}$ for field studies is significant, but it is positive and weak (Figure $7, \mathrm{r}^{2}=0.18, \mathrm{p}=0.04$ ). One may have expected to see a negative correlation between $\Omega_{\mathrm{a}}$ and \%CC because calcification draws down $\Omega_{\mathrm{a}}$. However, the carbonate chemistry of reef water is usually controlled by NCP rather than NCC and the extent to which reef metabolism alters $\Omega_{\mathrm{a}}$ on long timescales depends on the geometry and flushing rate of each reef (Falter et al. 2013). Nonetheless, average $\Omega_{\mathrm{a}}$ and \%CC cannot be fully deconvolved when generating or utilizing a correlation between 
NCC and $\Omega_{\mathrm{a}}$ as we do in this study, because both a prediction for $\Omega_{\mathrm{a}}$ and a prediction for $\% \mathrm{CC}$ are required in order to predict the average NCC of any given reef.

After normalizing the global data set, we correlated NNCC with the corresponding $\Omega_{\mathrm{a}}$, temperature, and PAR to evaluate the environmental controls on the global data set (Table 3, Figures 6, 7, 8, S8, S9). Regression analysis of this global data set reveals a statistically significant general relationship between NNCC and $\Omega_{\mathrm{a}}$ (Figures 6, S8, S9, Table 3), and no statistically significant relationship between NNCC and temperature or PAR (Figures 8, 9, Table 3).

\section{Discussion}

\subsection{The NNCC- $\Omega_{a}$ relationship}

In addition to minimizing confounding influences from local environmental variability, this approach circumvents the limited range of $\Omega_{\mathrm{a}}$ in local field studies by leveraging large regional differences in $\Omega_{\mathrm{a}}$, thus allowing the estimation of a general "threshold" $\Omega_{\mathrm{a}}$ value and a tool for predicting the decline in NCC with ocean acidification.

Although the correlation of NNCC versus $\Omega_{\mathrm{a}}$ is significant $\left(\mathrm{r}^{2}=0.26, \mathrm{p}=0.001\right.$;

Figure 6), the $\Omega_{\mathrm{a}}$ "threshold" (the value at which the reef is transitions from net calcification to net dissolution) implied by the regression is low $(0.2 \pm 1.1$, Table 3$)$ relative to the thermodynamic "threshold" of $\Omega_{\mathrm{a}}=1$ and the results of mesocosm studies (Table 3). The data for Shamberger et al. (2011) (grey circles) fall away from the regression line by as many as 5.6 standard errors from the trend line. In their study, Shamberger et al. (2011) noted the NCC values were anomalously high given the low saturation state at that site and hypothesize that heterotrophic feeding may play a role in maintaining high calcification rates. Excluding these data from the global regression yields a considerably stronger correlation that is also significant $\left(\mathrm{r}^{2}=0.55, \mathrm{p}<<0.0001\right.$; Table 3; Figure 6).

\subsection{Evaluating the influence of irradiance, NCP, and temperature}


We do not expect this relationship to suffer from the systematic influence of confounding variables, irradiance, NCP and temperature in the same way as the short term data shown in Figure 1 because these variables do not systematically covary with $\Omega_{\mathrm{a}}$ on long timescales or large spatial scales in the same way that they tend to do on the diurnal scale. Average PAR depends on latitude and turbidity of the water, so does not necessarily covary with average NCC or $\Omega_{\mathrm{a}}$ in a systematic way. Average NCP, although related to PAR, also depends on the abundance of autotrophs in the reef and does not necessarily systematically covary with average PAR or $\Omega_{\mathrm{a}}$ on large spatial scales. An earlier compilation of published data showed that daily NCP and NCC are strongly correlated within sites (short term) but not between sites (Kinsey 1985; Gattuso et al. 1999). Average temperature is controlled by a combination of irradiance, local hydrography and reef geometry (Davis et al. 2011). Although temperature affects $\Omega_{\mathrm{a}}$, it does not necessarily covary with average long term $\Omega_{\mathrm{a}}$, which is controlled by a combination of biological and physical parameters as well as the geometry of the reef (Falter et al. 2013). This is not to say that temperature and PAR and NCP do not affect average $\Omega_{\mathrm{a}}$ and NCC but rather that it seems these effects, along with uncertainties in the community composition, average NCC, average $\Omega_{\mathrm{a}}$ and nutritional status, contribute to the noise of the NNCC- $\Omega_{\mathrm{a}}$ relationship rather than influencing the slope because these variables do not covary on large spatial scales and long temporal scales.

To explicitly test the hypothesis that average temperature and average PAR have a weaker influence on average NCC, we investigated the correlations of NCC and NNCC with temperature and PAR and found them to be weak and insignificant (Tables 2 and 3, Figures 8 and 9). It was not possible to test a correlation with nutrients, because so few nutrient concentrations were measured and data were not collected in a consistent manner between studies. The lack of correlation of NCC and NNCC with temperature and PAR may suggest that reef communities are adapted to the average local temperature and light regime of their environment.

\subsection{Comparing the general relationship with mesocosm studies}


$\Omega_{\mathrm{a}}$ describes $55 \%$ of the global variability in NNCC (Table 3; Figure 6). The global relationship implies a $\Omega_{\mathrm{a}}$ "threshold" of $1.0 \pm 0.6$ (Table 3 ), which agrees with the thermodynamic "threshold" $\left(\Omega_{\mathrm{a}}=1\right)$ and is not statistically different from the $\Omega_{\mathrm{a}}$ "thresholds" determined by the controlled mesocosm studies (Table 3). The slope of 2.1 $\pm 0.3 \mathrm{mmol} \mathrm{m} \mathrm{h}^{-2}$ per unit $\Omega_{\mathrm{a}}$, which is a measure of sensitivity of NNCC to $\Omega_{\mathrm{a}}$, is similar to the slopes from mesocosm studies by Langdon et al. (2000) and Langdon and Atkinson (2005) (all normalized to 29\% calcifier cover, Table 3). Mesocosm experiments by Andersson et al. (2009) exhibited slightly higher sensitivity (see Andersson et al. $2009, n=12$, Table 3). The influence of irradiance on the diurnal timescale may have not been fully removed for these diurnal incubation experiments, in contrast to the longer experiments of Langdon et al. (2000) and the strictly mid-day experiments of Langdon and Atkinson (2005). The slope for Andersson et al. (2009) decreases when the influence of light is removed by considering only the daytime averages $(n=2$, Table 3$)$. Nevertheless, the slope for the global relationship falls within the range of slopes suggested by controlled mesocosm experiments (Table 3), lending confidence that this approach may be successfully estimating a general relationship between NNCC and $\Omega_{\mathrm{a}}$.

\subsection{Applications of the general relationship}

The general relationship derived here may be used to improve models of reef carbonate chemistry and to predict how average NCC will change as ocean acidification progresses. To predict changes in NCC, we must predict how $\Omega_{\mathrm{a}}$ will change in the future and make an assumption or prediction for how \% CC will change as well. Presently, global models predict changes in open ocean $\Omega_{\mathrm{a}}$ (Kleypas et al. 1999; Caldeira and Wickett 2003), but models the predict concomitant changes in reef water $\Omega_{\mathrm{a}}$ are still nascent (Falter et al. 2013). In one recent simulation study for a model reef, NCC was constrained to equal daily integrated rates and was not described as a function of the changing $\Omega_{\mathrm{a}}$ (Falter et al. 2013). The general relationship derived here could be used to introduce a feedback in which the NCC responds to the changing $\Omega_{\mathrm{a}}$ due to ocean acidification forcing in the model reef. This would improve the predictions for changing reef water $\Omega_{\mathrm{a}}$ in conjunction with changing open ocean $\Omega_{\mathrm{a}}$. 
In the absence of such improved reef water predictions, we assume that the longterm (months to years) reef water $\Omega_{\mathrm{a}}$ equals the open ocean $\Omega_{\mathrm{a}}$ and use predictions for the open ocean end-member to predict changes in NCC. The simulation mentioned here demonstrated that this assumption is good for small reefs with flushing times on the order of days. Kleypas et al. (1999) estimated the $\Omega_{\mathrm{a}}$ in 1880 to be $4.6 \pm 0.2$ and that in 2100 to be $2.8 \pm 0.2$. Using these values and the relationship predicted here (based on data normalized to $29 \% \mathrm{CC}$ ), we predict that by 2100 , average NCC will be $50 \%$ lower than the preindustrial value (Figure 10a). The percent decline would be the same, even if we had normalized the data to $100 \%$ CC (Figure10b), but the absolute values would be different of course, because they would be NCC values for reefs of different \%CC. Nonetheless, the relationship normalized to $29 \%$ calcifier cover predicts the same absolute values for a $100 \% \mathrm{CC}$ reef as the relationship normalized to $100 \% \mathrm{CC}$ (Figures $10 \mathrm{a}$ and $\mathrm{b}$ ). Working this out is simply a trivial exercise of mathematics. The important message is that making these predictions in changing NCC involves both a predicted change in average $\Omega_{\mathrm{a}}$ and a predicted change in $\% \mathrm{CC}$ (or an assumption that $\% \mathrm{CC}$ does not change).

\subsection{Sources of uncertainty and suggestions for future research}

The relationship stemming from this global dataset is an approximation that can be improved with additional studies conducted in a consistent manner to facilitate intercomparison. With an $\mathrm{r}^{2}$ of 0.55 , this relationship is still somewhat noisy. With further investigation and additional studies, we may better understand the origin of the noise, and derive a relationship with reduced noise. This may require collecting sufficient data to develop a relationship based on annual averages of daily rates rather than seasonal averages of hourly rates. In order to better define the relationship at the extremes of $\Omega_{\mathrm{a}}$, further studies of NCC where $\Omega_{\mathrm{a}}$ is low (or high) should be prioritized. Accompanying these studies with more detailed quantification of benthic cover would also improve the results and better define the slope and threshold of the NNCC- $\Omega_{\mathrm{a}}$ relationship.

Future research should investigate the outliers at Kaneohe Bay to better understand how this community calcifies so rapidly at low $\Omega_{\mathrm{a}}$. Addition of new studies 
to this analysis may also lead to the identification of other outliers. Investigating why outliers do not agree with the others is always an opportunity to gain new insights and understanding.

There is also the question of whether or not this relationship, based on data collected over the past two decades will be relevant to reefs of the future. The approach proposed here accounts for changes in \%CC. So if a stressor other than ocean acidification only changes the \% $\mathrm{CC}$ but not the rates of calcification or dissolution, then the relationship between NNCC and $\Omega_{\mathrm{a}}$ would remain unchanged. If the stressor other than ocean acidification resulted in a change in NCC that is equal for all reefs, then we would expect the entire relationship to be offset from the current relationship. A simple example would be if global warming affected all reefs equally. However, if that stressor applied a differential pressure to reef NCC globally in a way that is systematic with respect to $\Omega_{\mathrm{a}}$, for example if reefs that exist at low $\Omega_{\mathrm{a}}$ are more or less susceptible to the effects of warming than reefs at high $\Omega_{\mathrm{a}}$, then we would expect the slope of the relationship to change. For example, the slope would increases if reefs at low $\Omega_{\mathrm{a}}$ are energetically taxed and therefore more susceptible to warming. On the other hand, the slope would decrease if reefs that tend to have higher $\Omega_{\mathrm{a}}$ are typically those with longer reef water residence time and therefore experience more frequent or extreme thermal stress. Finally, if the stressor applied a differential pressure to reef NCC globally in a way that is independent of $\Omega_{a}$, then we would expect this to increase the noise of the relationship and shift the slope and intercept in an unpredictable way. An example of this final scenario could be changing populations of bioeroders that affect dissolution rates, irrespective of $\Omega_{\mathrm{a}}$. Further research into the consequences of diverse stressors is required to predict how the general relationship developed here might be different in the future. 


\section{Conclusion}

Using previously published data average $\mathrm{NCC}, \Omega_{\mathrm{a}}$ and $\% \mathrm{CC}$, we developed a general relationship that can be used to predict changes in average NCC in the future and to improve simulations of carbonate chemistry in model reefs. It should be noted that this relationship does not necessarily describe the NNCC- $\Omega_{a}$ relationship on short time scales at any one location. However, given an average $\Omega_{\mathrm{a}}$ and $\% \mathrm{CC}$ for a reef, this general relationship could be used to predict the long-term average NCC at any site. The relationship derived here suggests that due to ocean acidification alone, average NCC in the year 2100 will be $50 \%$ lower than the preindustrial value. This means that coral reefs will be less effective at keeping up with changes in sea level rise and the forces of physical and biological erosion. The decline in average NCC could manifest as increased seasonal periods of negative NCC (dissolution), or spatial patchiness of dissolving versus calcifying reef communities. The decline in NCC and overall reef health will likely be exacerbated by additional stressors such as warming, disease and pollution. To better predict future changes in NCC, we could further investigate the interactions between multiple stressors and the synergistic effects on reef health and growth.

\section{Acknowledgements}

We would like to acknowledge support from WHOI Ocean Life Institute and the WHOI Johnson Fund for W. Bernstein, the National Science Foundation (NSFOCE1031288KAH) for K. Hughen, and NOAA Coral Reefs Conservation Program Atlantic Ocean Acidification Test Bed project for C. Langdon. We thank Jim Falter, Emily Shaw, Katie Shamberger, and Jack Silverman for kindly sharing their original hourly net community calcification rates from their published studies. 


\section{References}

Albright R, Langdon C, Anthony K (2013) Dynamics of seawater carbonate chemistry, production, and calcification of a coral reef flat, Central Great Barrier Reef. Biogeosciences Discussions 10:7641-7676

Andersson AJ, Gledhill D (2013) Ocean Acidification and Coral Reefs: Effects on Breakdown, Dissolution, and Net Ecosystem Calcification. Annual Review of Marine Science 5:321-348

Andersson AJ, Kuffner IB, Mackenzie FT, Jokiel PL, Rodgers KS, Tan A (2009) Net Loss of $\mathrm{CaCO}(3)$ from a subtropical calcifying community due to seawater acidification: mesocosm-scale experimental evidence. Biogeosciences 6:18111823

Baker KS, Frouin R (1987) Relationship between photosynthetically available radiation and total insolation at the surface of the ocean under clear skies. Limnol Oceanogr 32:1370-1377

Bates NR, Amat A, Andersson AJ (2010) Feedbacks and responses of coral calcification on the Bermuda reef system to seasonal changes in biological processes and ocean acidification. Biogeosciences 7:2509-2530

Caldeira K, Wickett ME (2003) Oceanography: anthropogenic carbon and ocean $\mathrm{pH}$. Nature 425:365-365

Chalker BE, Taylor DL (1975) Light-enhanced calcification, and role of oxidativephosphorylation on calcification of coral Acropora-cervicornis. Proceedings of the Royal Society B-Biological Sciences 190:323-331

Clausen CD, Roth AA (1975) Effect of Temperaturea and Temperature Adaptation on Calcification Rate in Hermatypic Coral PocilloporaDamicornis. Marine Biology 33:93-100

Cohen AL, Holcomb M (2009) Why corals care about ocean acidification : uncovering the mechanism. Oceanography 22

Coles SL, Jokiel PL (1978) Synergistic Effects Of Temperature, Salinity, and Light On Hermatypic Coral Montipora-Verrucosa. Marine Biology 49:187-195

Davis K, Lentz S, Pineda J, Farrar J, Starczak V, Churchill J (2011) Observations of the thermal environment on Red Sea platform reefs: a heat budget analysis. Coral Reefs 30:25-36

Falter JL, Lowe RJ, Atkinson MJ, Cuet P (2012) Seasonal coupling and de-coupling of net calcification rates from coral reef metabolism and carbonate chemistry at Ningaloo Reef, Western Australia. Journal of Geophysical Research-Oceans 117

Falter JL, Lowe RJ, Zhang Z, McCulloch M (2013) Physical and biological controls on the carbonate chemistry of coral reef waters: effects of metabolism, wave forcing, sea level, and geomorphology. Plos One 8:e53303

Frankignoulle M, Gattuso JP, Biondo R, Bourge I, CopinMontegut G, Pichon M (1996) Carbon fluxes in coral reefs .2. Eulerian study of inorganic carbon dynamics and measurement of air-sea CO2 exchanges. Marine Ecology-Progress Series $145: 123-132$ 
Gattuso JP, Allemand D, Frankignoulle M (1999) Photosynthesis and calcification at cellular, organismal and community levels in coral reefs: A review on interactions and control by carbonate chemistry. American Zoologist 39:160-183

Gattuso JP, Pichon M, Delesalle B, Canon C, Frankignoulle M (1996) Carbon fluxes in coral reefs .1. Lagrangian measurement of community metabolism and resulting air-sea CO2 disequilibrium. Marine Ecology-Progress Series 145:109-121

Gattuso JP, Payri CE, Pichon M, Delesalle B, Frankignoulle M (1997) Primary production, calcification, and air-sea $\mathrm{CO} 2$ fluxes of a macroalgal-dominated coral reef community (Moorea, French Polynesia). Journal of Phycology 33:729-738

Goreau TF, Goreau NI (1959) The physiology of skeleton formation in corals. II. Calcium deposition by hermatypic corals under various conditions in the reef. Biological Bulletin 117:239-250

Gray SEC, DeGrandpre MD, Langdon C, Corredor JE (2012) Short-term and seasonal $\mathrm{pH}, \mathrm{pCO}(2)$ and saturation state variability in a coral-reef ecosystem. Global Biogeochemical Cycles 26

Kawahata H, Suzuki A, Goto K (1997) Coral reef ecosystems as a source of atmospheric CO2: evidence from PCO2 measurements of surface waters. Coral Reefs 16:261266

Kinsey DW (1985) Metabolism, Calcification and Carbon Production. Proceedings 5th International Coral Reef Symposium 4:505-526

Kleypas JA, Buddemeier RW, Archer D, Gattuso J-P, Langdon C, Opdyke BN (1999) Geochemical consequences of increased atmospheric carbon dioxide on coral reefs. Science 284:118-120

Langdon C (2002) Review of experimental evidence for effects of CO2 on calcification of reef-builders. Ministry of Environment Indonesian Institute of Sciences, Bali, Indonesia:pp. 1091-1098

Langdon C, Atkinson MJ (2005) Effect of elevated pCO(2) on photosynthesis and calcification of corals and interactions with seasonal change in temperature/irradiance and nutrient enrichment. Journal of Geophysical ResearchOceans 110:1-16

Langdon C, Takahashi T, Sweeney C, Chipman D, Goddard J, Marubini F, Aceves H, Barnett H, Atkinson MJ (2000) Effect of calcium carbonate saturation state on the calcification rate of an experimental coral reef. Global Biogeochemical Cycles 14:639-654

Leclercq N, Gattuso JP, Jaubert J (2000) CO2 partial pressure controls the calcification rate of a coral community. Global Change Biology 6:329-334

Leclercq N, Gattuso JP, Jaubert J (2002) Primary production, respiration, and calcification of a coral reef mesocosm under increased $\mathrm{CO} 2$ partial pressure. Limnology and Oceanography 47:558-564

Marshall AT, Clode P (2004) Calcification rate and the effect of temperature in a zooxanthellate and an azooxanthellate scleractinian reef coral. Coral Reefs 23:218-224

Ohde S, van Woesik R (1999) Carbon dioxide flux and metabolic processes of a coral reef, Okinawa. Bulletin of Marine Science 65:559-576 
Pandolfi JM, Connolly SR, Marshall DJ, Cohen AL (2011) Projecting Coral Reef Futures Under Global Warming and Ocean Acidification. Science 333:418-422

Reynaud VS, Gattuso JP, Cuif JP, Jaubert J, Juillet-Leclerc A (1999) A novel culture technique for scleractinian corals: application to investigate changes in skeletal delta O-18 as a function of temperature. Marine Ecology-Progress Series 180:121-130

Shamberger KEF, Feely RA, Sabine CL, Atkinson MJ, DeCarlo EH, Mackenzie FT, Drupp PS, Butterfield DA (2011) Calcification and organic production on a Hawaiian coral reef. Marine Chemistry 127:64-75

Shaw EC, McNeil BI, Tilbrook B (2012) Impacts of ocean acidification in naturally variable coral reef flat ecosystems. Journal of Geophysical Research-Oceans 117

Silverman J, Lazar B, Erez J (2007) Effect of aragonite saturation, temperature, and nutrients on the community calcification rate of a coral reef. Journal of Geophysical Research-Oceans 112

Silverman J, Kline D, Johnson L, Rivlin T, Schneider K, Erez J, Lazar B, Caldeira K (2012) Carbon turnover rates in the One Tree Island reef: A 40-year perspective. Journal of Geophysical Research: Biogeosciences (2005-2012) 117

Wainwright SA (1963) Skeletal organization in the coral, Pocillopora damicornis. Quarterly Journal of Microscopical Science 3:169-183

Watanabe A, Kayanne H, Hata H, Kudo S, Nozaki K, Kato K, Negishi A, Ikeda Y, Yamano H (2006) Analysis of the seawater CO2 system in the barrier reef-lagoon system of Palau using total alkalinity-dissolved inorganic carbon diagrams. Limnology and Oceanography 51:1614-1628

Yates KK, Halley RB (2006) CO32- concentration and pCO(2) thresholds for calcification and dissolution on the Molokai reef flat, Hawaii. Biogeosciences $3: 357-369$ 


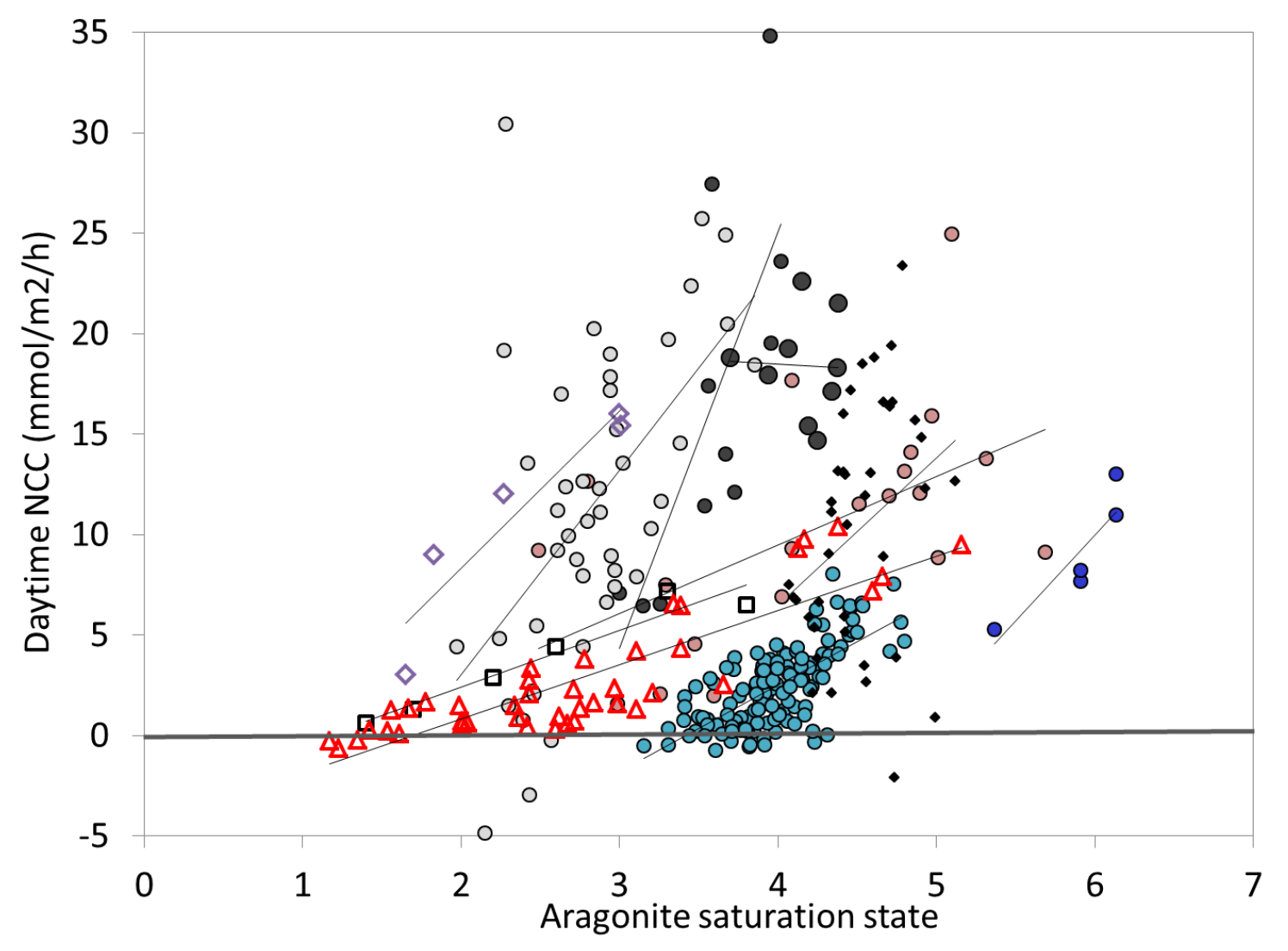

Figure 1 Daytime NCC rate (mmol m $\mathrm{m}^{-2}$ ) versus $\Omega_{\mathrm{a}}$ for field (solid circles) and mesocosm studies (open symbols). The slopes and $\mathrm{x}$-intercept values $\left(\Omega_{\mathrm{a}}\right.$ thresholds) are dissimilar between studies. Original hourly daytime data from Ningaloo Reef (Falter et al. 2012) (small black circles for summer and large black circles for winter), Lady Elliot Island (Shaw et al. 2012) (pink circles), Kaneohe Bay (Shamberger et al. 2011) (box model data, grey circles), and the Gulf of Eilat (Silverman et al. 2007) (light blue circles) were obtained by personal communication with the authors. Unpublished were included from the Red Sea (black diamonds, Chapter 2 of this thesis). Hourly data from the Ryukyu Islands (dark blue circles) are from Table 4 of (Ohde and van Woesik 1999). And hourly data from mesocosm experiments are from Table 1 of (Andersson et al. 2009) (black squares), from the first two sets of experimental runs in Table 3 of (Langdon and Atkinson 2005) (purple diamonds), and from Table 4 of (Langdon et al. 2000) (red triangles, reported diurnal data divided by 12 hours in a day to estimate daytime hourly rates). Horizontal grey line marks transition from net calcification to net dissolution. See Figures S1 and S2 for field and mesocosm studies plotted separately. See Figures S3-S5 for these correlations after accounting for community composition. 


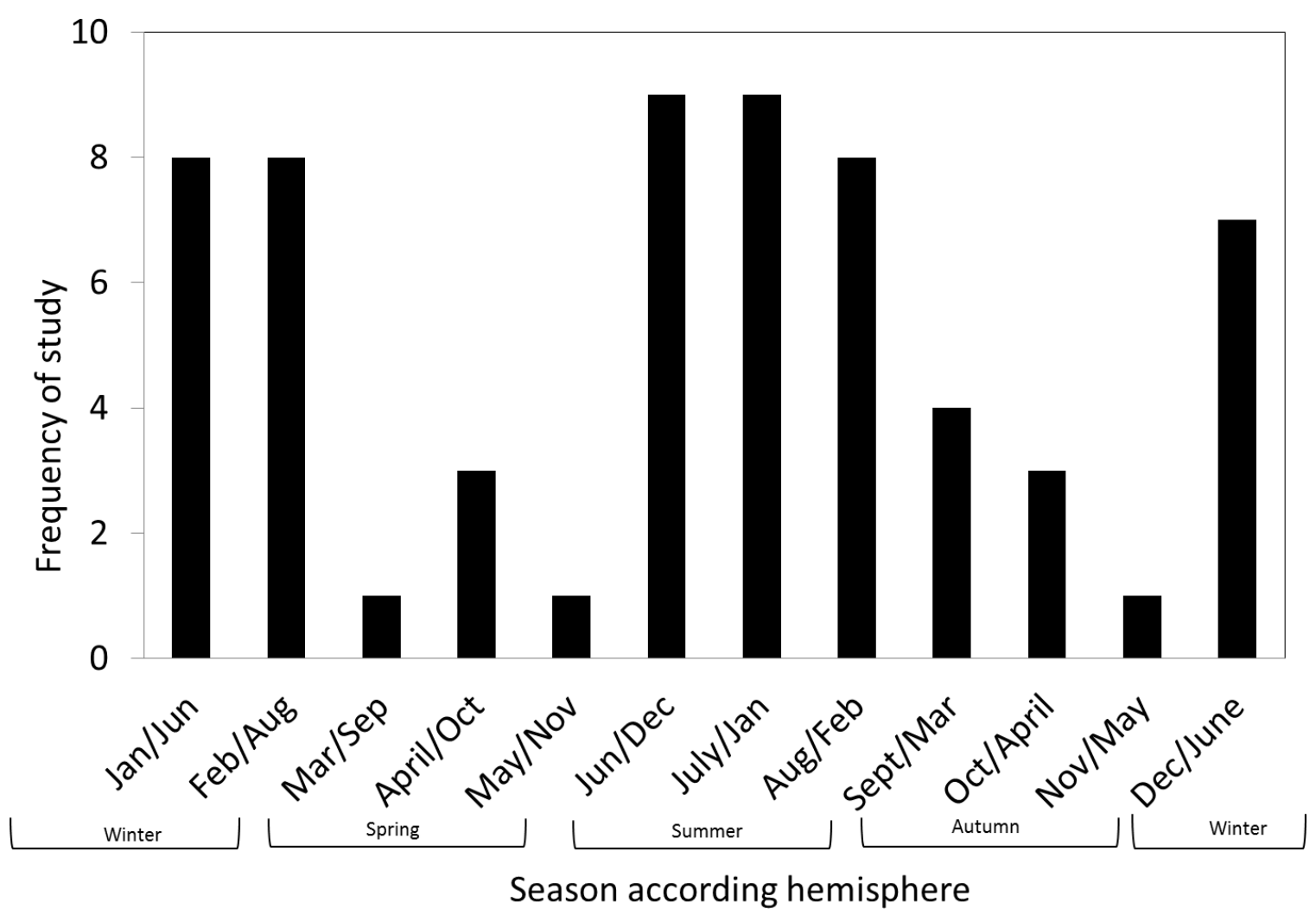

Figure 2 The studies considered in this analysis span all four seasons, with an emphasis on summer and winter. Months are listed as northern hemisphere/southern hemisphere. 


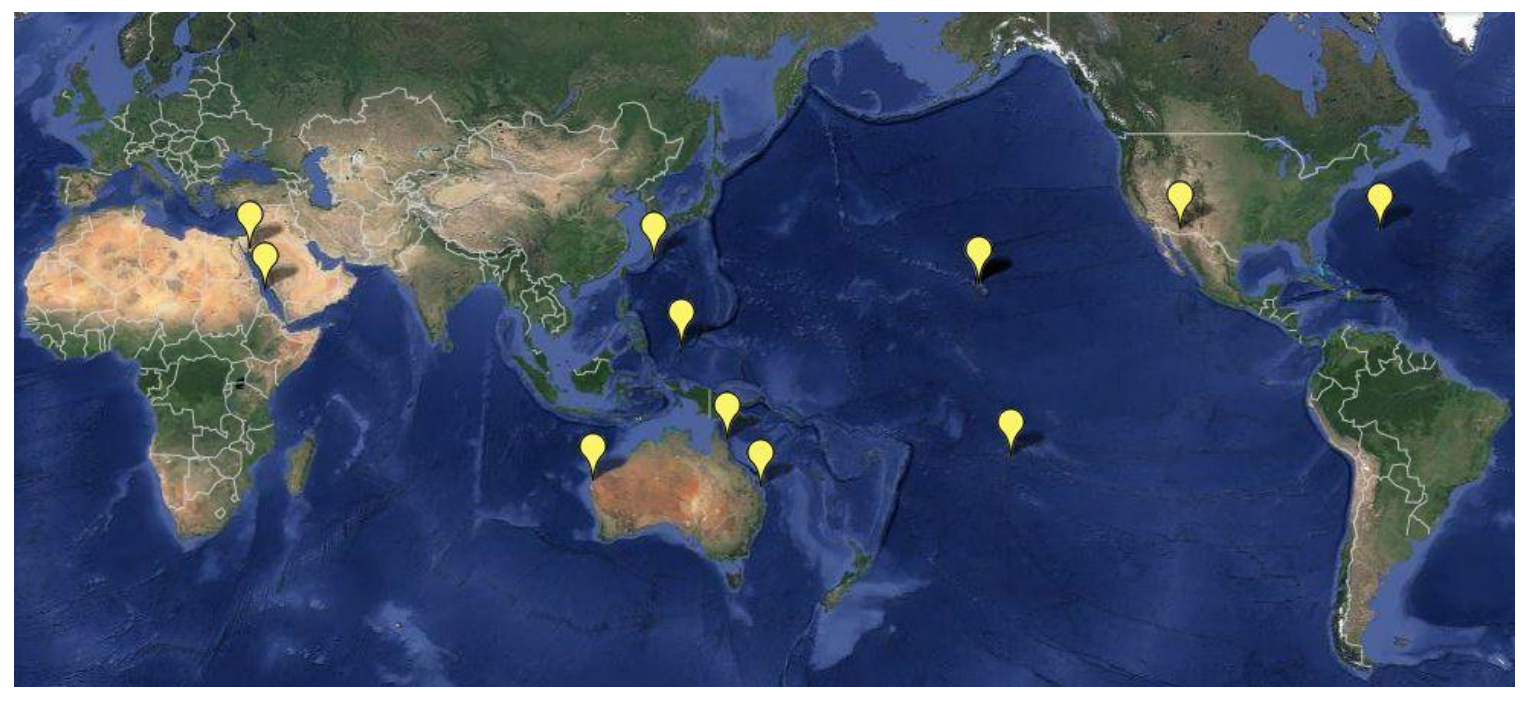

Figure 3 The study sites considered in this analysis (yellow symbols) are distributed around the globe at tropical latitudes. 


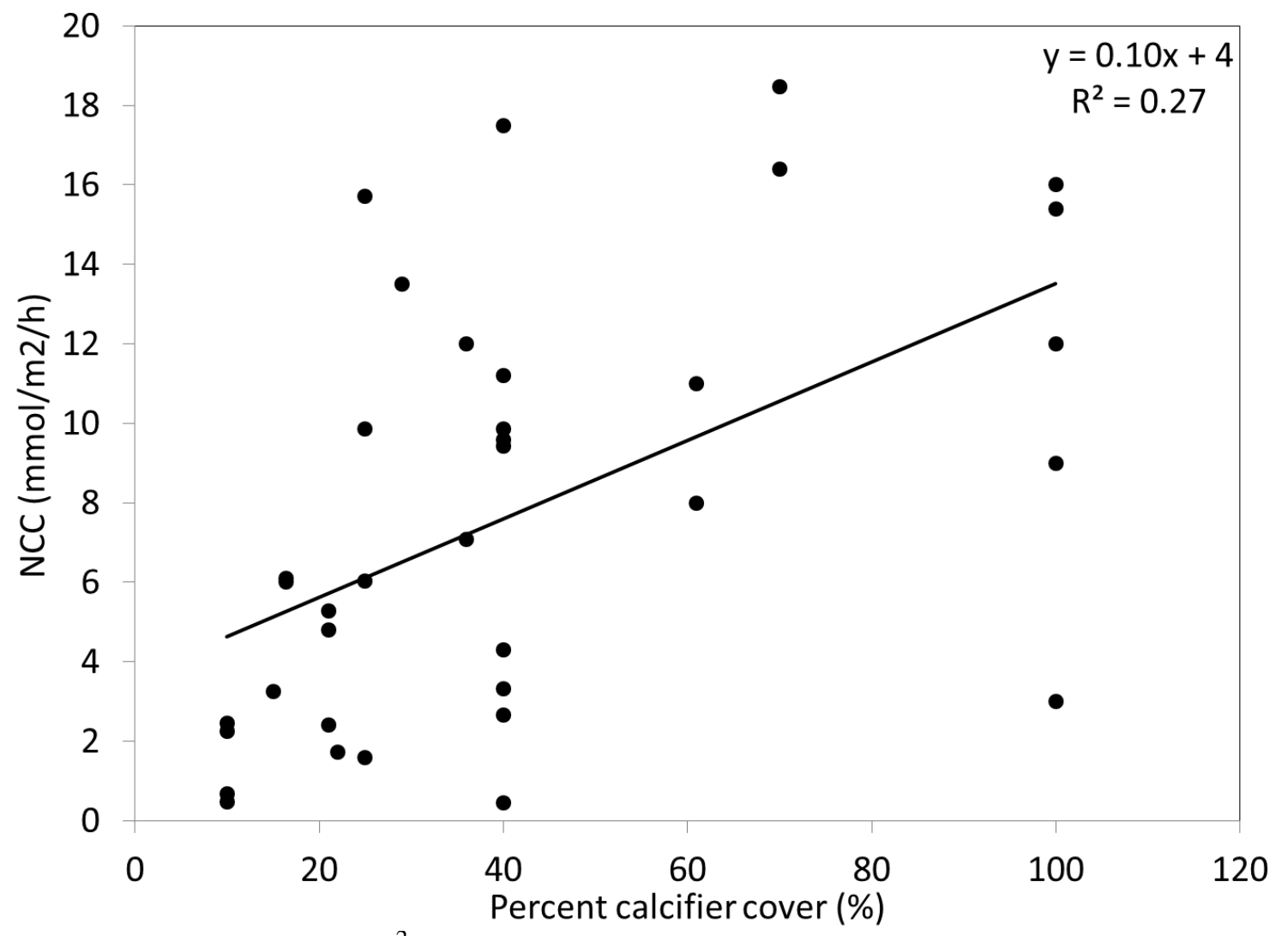

Figure 4 NCC correlates $\left(r^{2}=0.27, p=0.001\right)$ with percent calcifier cover $(\% C C)$ estimates that are extracted from the literature. See Table 1 for details. 


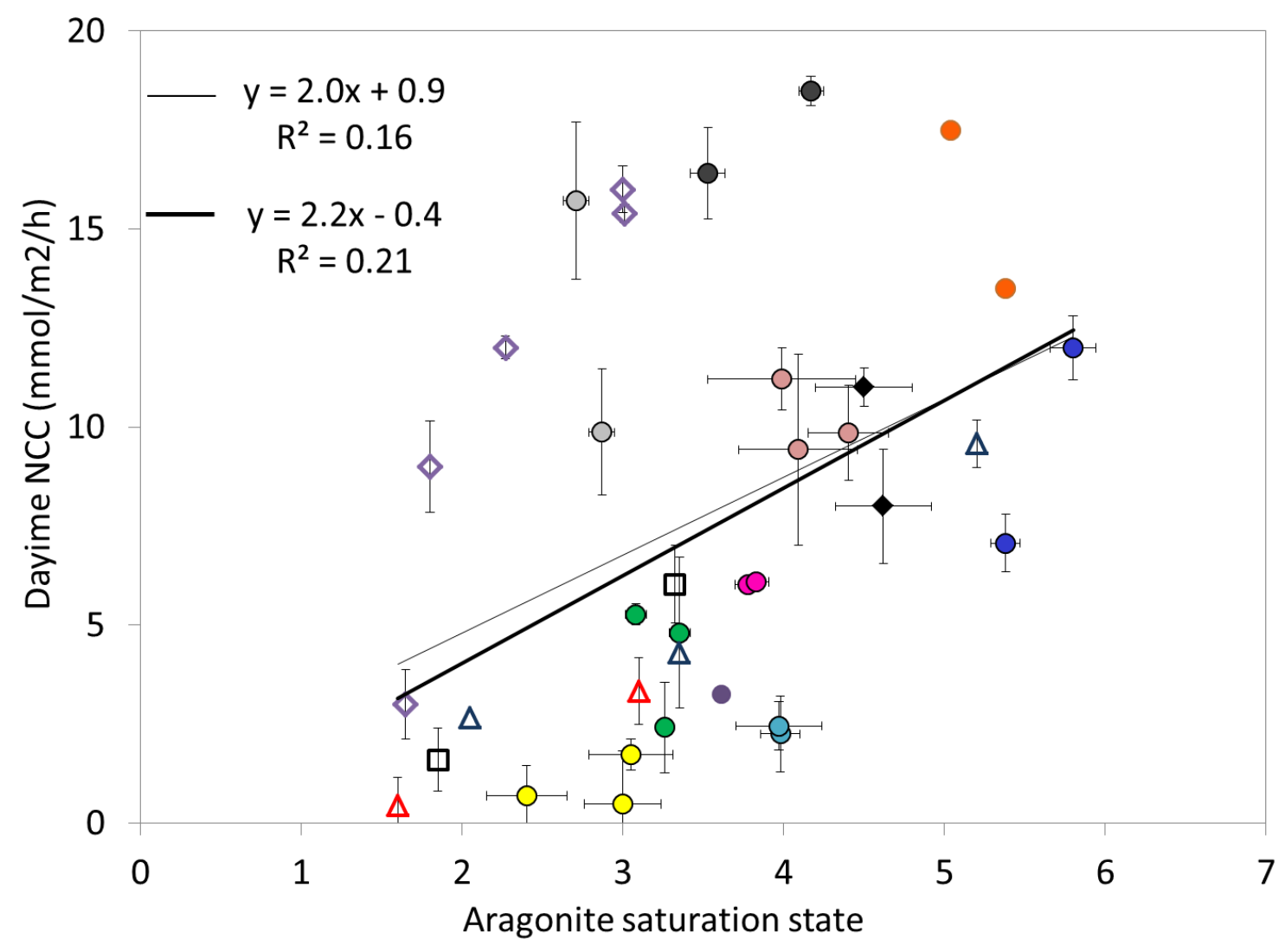

Figure 5 The global data set of field and mesocosm NCC versus $\Omega_{\mathrm{a}}$ before accounting for \%CC at each site. The thin black line is the regression based on all data points (Table 3 ). Heavy black line shows the regression with two outliers removed (grey circles, (Shamberger et al. 2011) (Table 3). Error bars are shown for one standard error, except for (Gattuso et al. 1996; Gattuso et al. 1997) because standard errors were not available. Details concerning the origin of data and the calculation of NCC values are presented in Table 1. Colors and symbols are the same as in Figure1 with the addition of several studies that reported only average values: (Bates et al. 2010) (green circles), (Watanabe et al. 2006) (fuchsia circles), (Yates and Halley 2006) (yellow circles), (Gattuso et al. 1996; Gattuso et al. 1997) (orange and purples circles respectively), and (Langdon 2002) (blue triangles). (See Figures S6 and S7 for field and mesocosm studies plotted separately). 


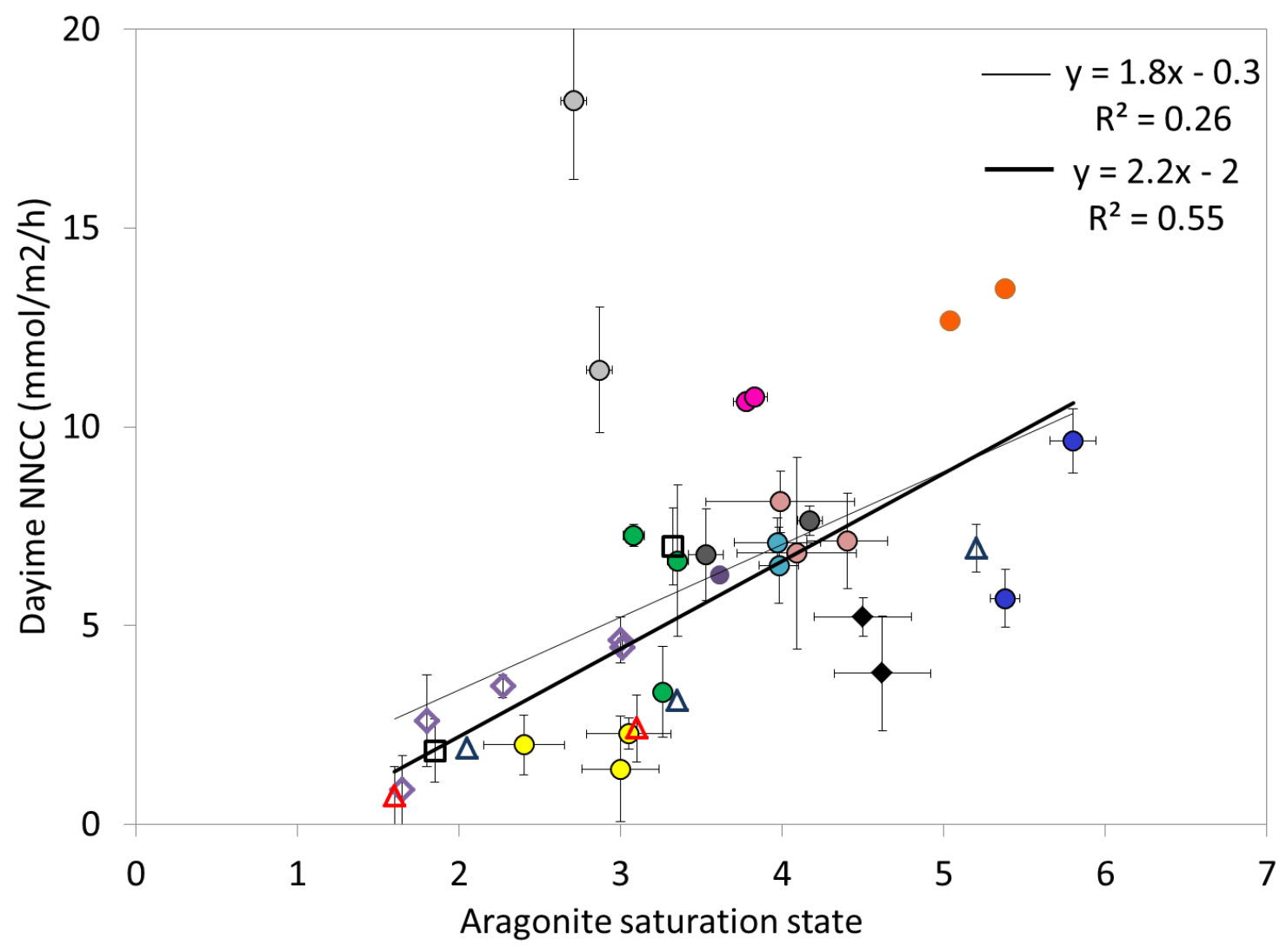

Figure 6 Same as Figure 5, after normalizing for \%CC to arrive at NNCC (29\%CC). The global data set of field and mesocosm NNCC correlates strongly with $\Omega_{\mathrm{a}}$. (See Figures S8 and S9 for field and mesocosm studies plotted separately.) 


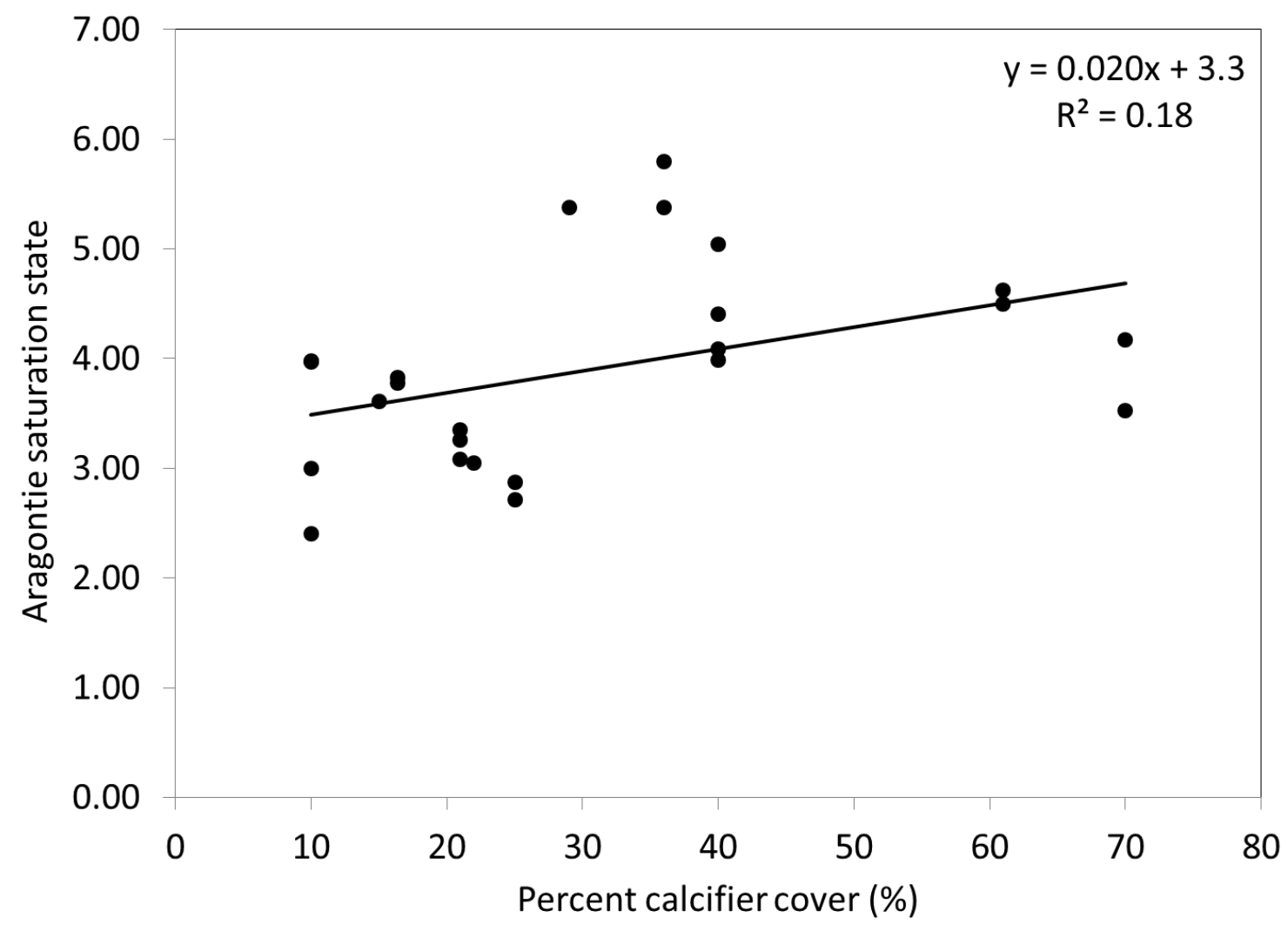

Figure $7 \Omega_{\mathrm{a}}$ correlates weakly with percent calcifier cover $(\% \mathrm{CC}) . \mathrm{n}=24, \mathrm{p}=0.04$. Here we plot only field studies because we are looking for a natural response of $\Omega_{\mathrm{a}}$ to $\% \mathrm{CC}$ or vice versa, and in a mesocosm both of these are set by the researcher. 


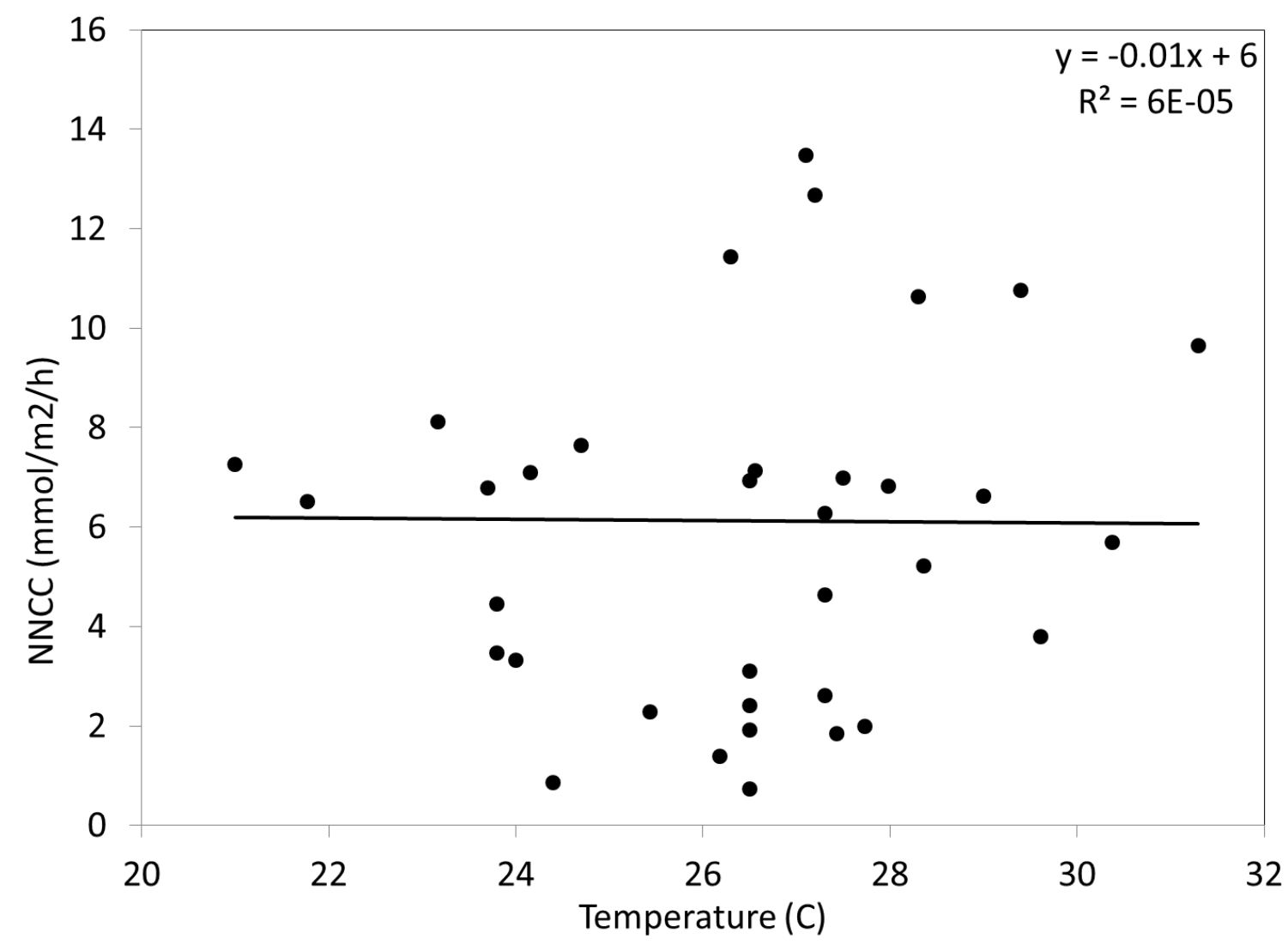

Figure 8 Average NNCC for each study versus average temperature (C) for each study $(\mathrm{p}=1)$. 


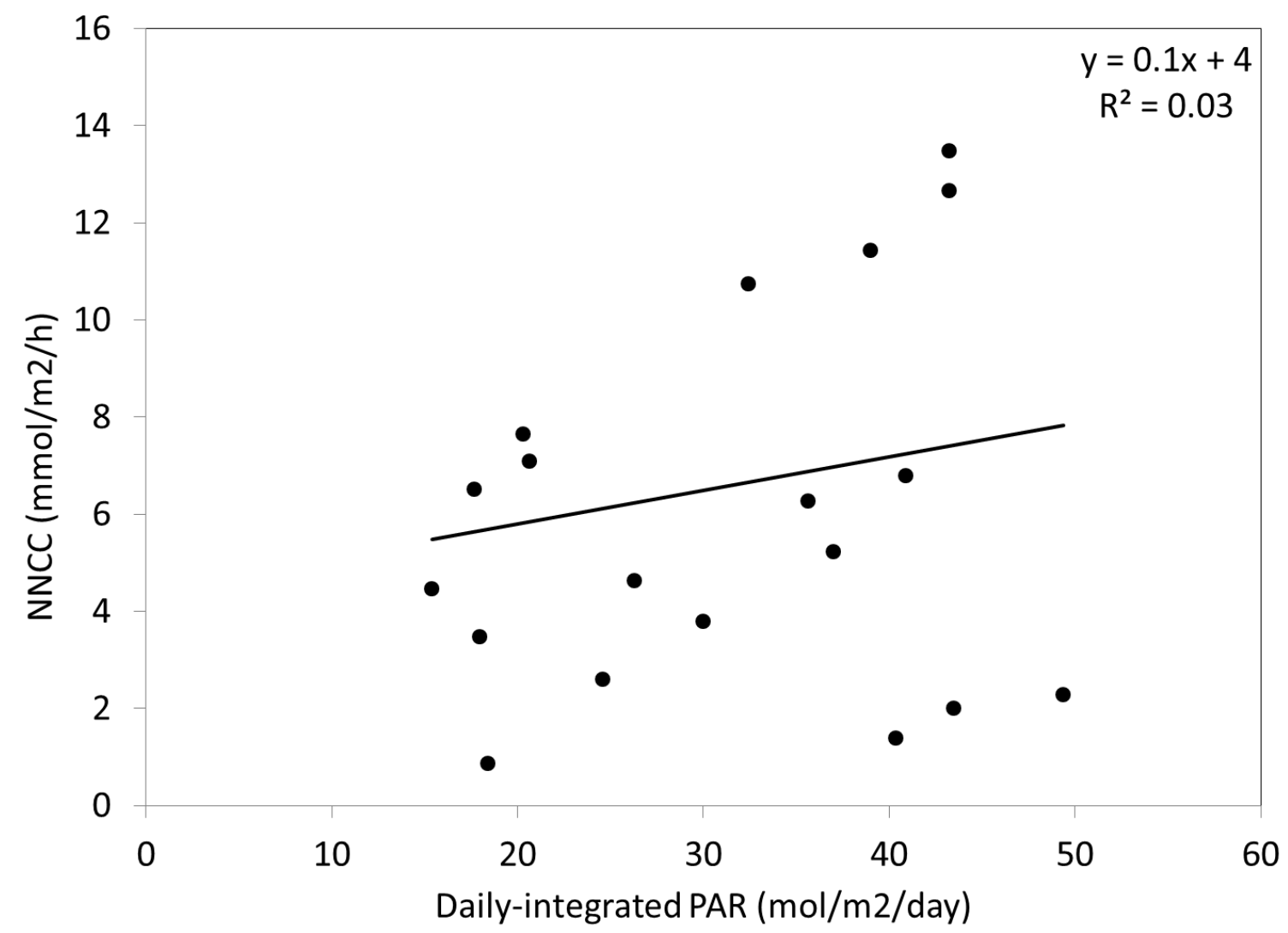

Figure 9 Average NNCC for each study versus daily-integrated PAR $\left(\mathrm{E} \mathrm{m}^{-2} \mathrm{~d}^{-1}\right)$ for each study $(\mathrm{p}=0.5)$. Future field studies should systematically measure PAR in order to thoroughly test the global scale dependence of NNCC on PAR. 


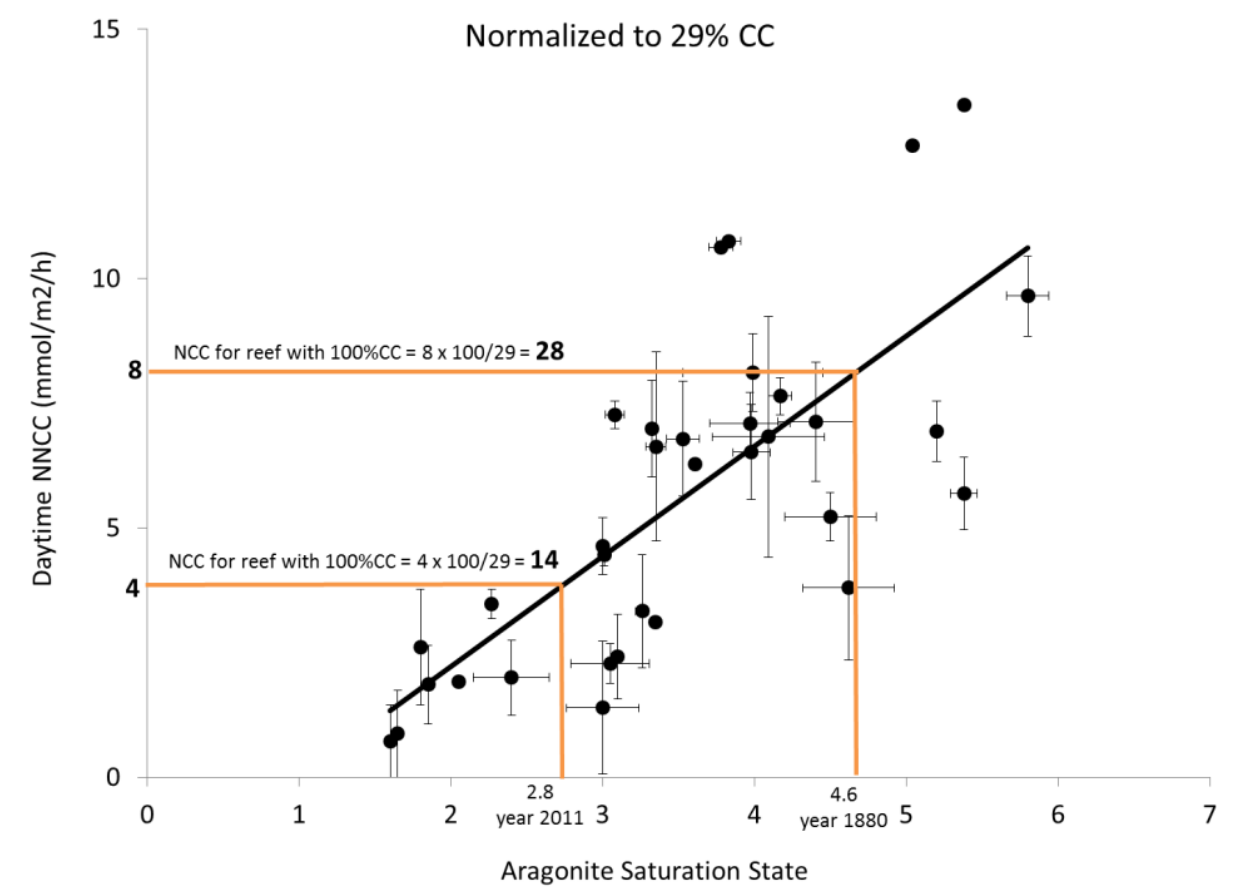

(a)

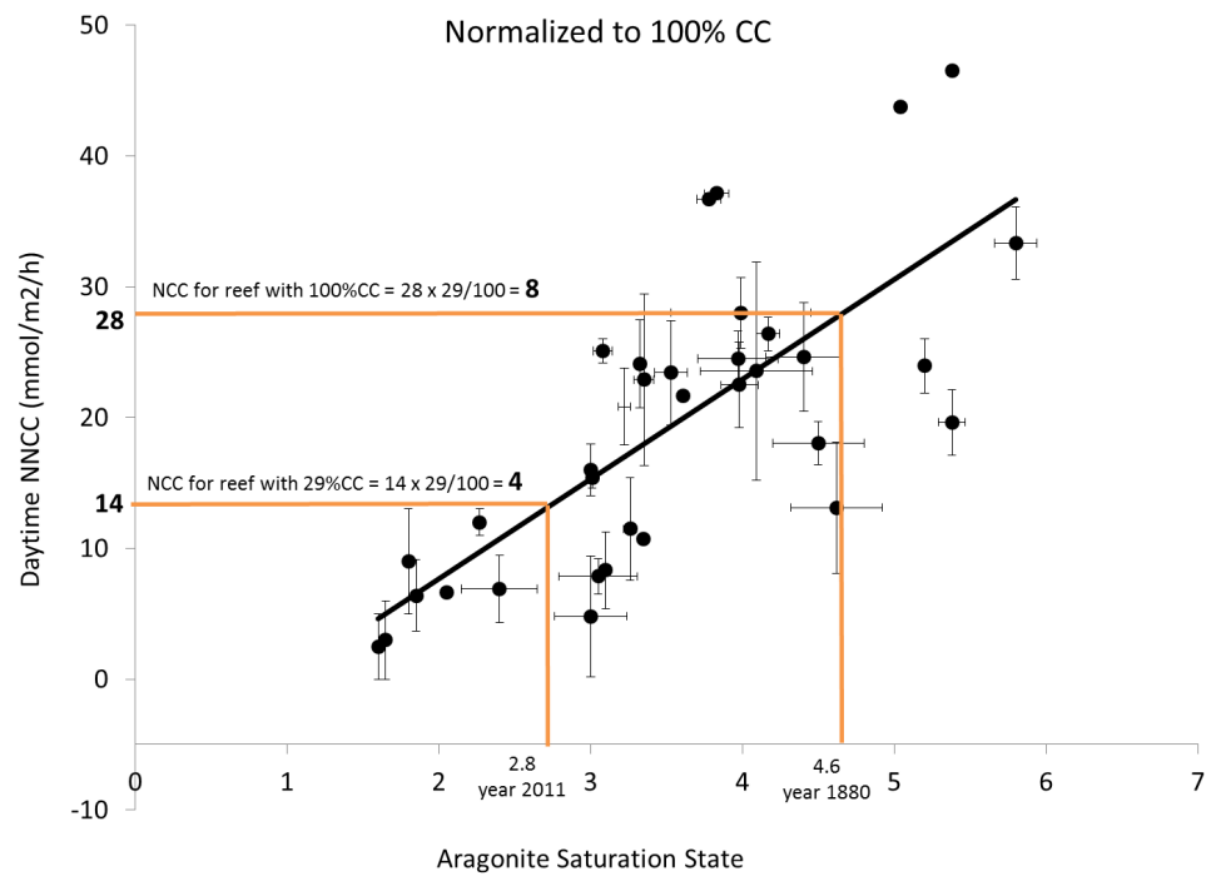

(b)

Figure 10 a and b Average NCC normalized to (a) $29 \%$ CC and (b) $100 \%$ CC. Plots are similar to Figure 6 with outliers and color coding removed for clarity. Orange guidelines indicated how estimates of past and future $\Omega_{\mathrm{a}}$ can be used to predict changes in NCC. Predictions of absolute values of NCC (bold) and percent changes in NCC (50\% from 1880 to 2100) are independent of the value to which the data are normalized. 
Table 1 Summary of data extracted from the 14 studies used in this analysis. \%CC is percent calcifier cover, CCA is crustose coralline algae. N/A for "not available" $\dagger$.

$\dagger$ i.e. Some studies did not report PAR and some studies spanned several seasons such that an average PAR would not be meaningful. 


\begin{tabular}{|c|c|c|c|c|c|c|c|c|c|c|c|c|c|c|c|c|}
\hline 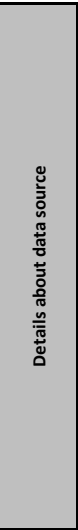 & 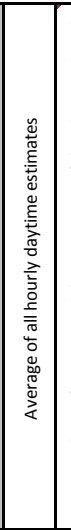 & 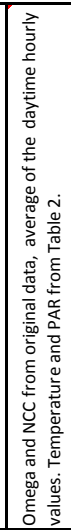 & 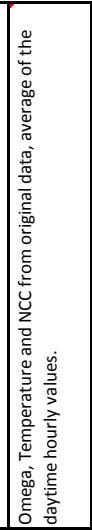 & 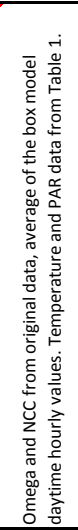 & 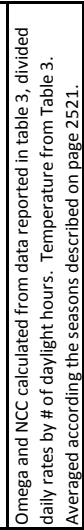 & 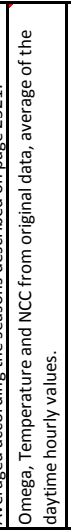 & 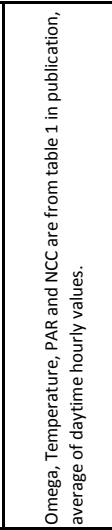 & 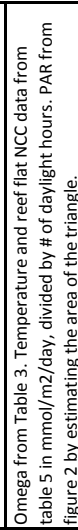 & 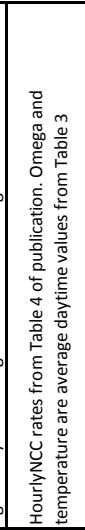 & 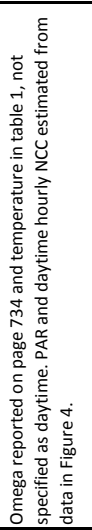 & 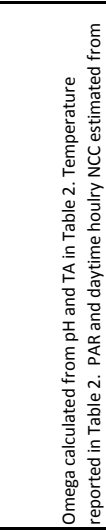 & & 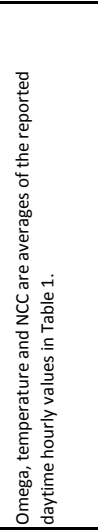 & 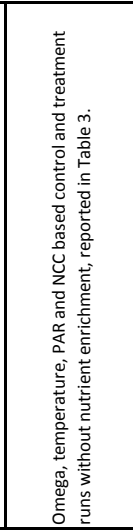 & 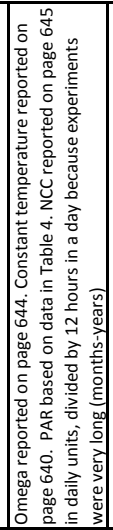 & 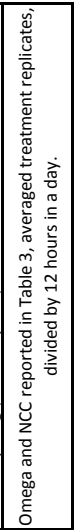 \\
\hline 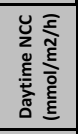 & $\infty=$ & ه & $\circ$ 요 & ติ & ${ }_{+\infty}^{\infty} \underset{\sim}{\sharp}$ & 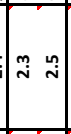 & 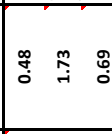 & $\stackrel{9}{\circ}$ & $\stackrel{a}{i} \approx$ & $\stackrel{\mathscr{n}}{m}$ & $\stackrel{n}{\sim}$ & $\stackrel{n}{A}$ & $\begin{array}{ll}\stackrel{O}{0}_{0}^{0} & \stackrel{+}{i}\end{array}$ & o & $\begin{array}{lll}A & m & 0\end{array}$ & $m i$ \\
\hline 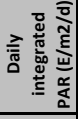 & $\dot{m} \mathrm{~m}$ & 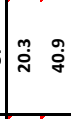 & $\frac{\pi}{z} \frac{\pi}{z}$ & 品 & $\frac{\pi}{2} \frac{\pi}{2}$ & $\stackrel{1}{2}$ & $\mid \begin{array}{ll}\not{g} \\
\dot{g}\end{array}$ & $\frac{\pi}{z} \underset{\tilde{m}}{\mathbb{m}}$ & $\frac{E}{z} \quad \frac{\pi}{z}$ & 递 & $\tilde{\tilde{g}}$ & $\tilde{y}$ & $\frac{s}{z} \quad \frac{\pi}{z}$ & 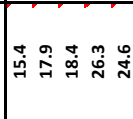 & $\mid \frac{\pi}{z} \frac{\pi}{z}$ & $\frac{s}{z} \frac{\pi}{z}$ \\
\hline 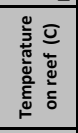 & 品 & $\hat{d}$ & 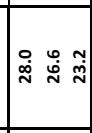 & $\cong \stackrel{M}{\stackrel{M}{0}}$ & $\pi$ ล & $\stackrel{\infty}{i} \underset{i}{i}$ & 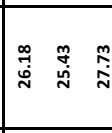 & 趈 & 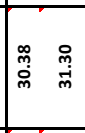 & $\stackrel{m}{i}$ & $\vec{i}$ & $\stackrel{n}{N}$ & $\stackrel{n}{\stackrel{m}{D}} \stackrel{m}{i}$ & 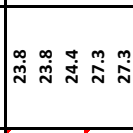 & 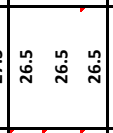 & 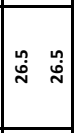 \\
\hline 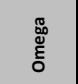 & 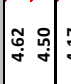 & $f \underset{\sim}{\stackrel{0}{n}}$ & 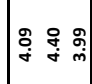 & 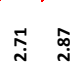 & 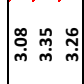 & 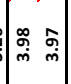 & 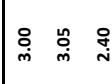 & $\stackrel{\infty}{\infty}$ & 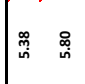 & $\vec{\Gamma}$ & 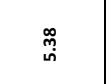 & î & 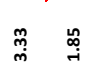 & 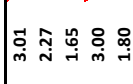 & 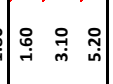 & 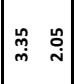 \\
\hline 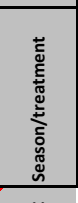 & 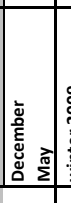 & 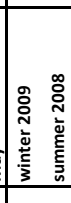 & 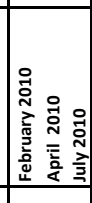 & 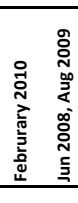 & 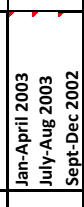 & 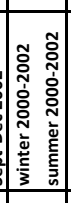 & 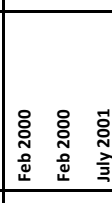 & 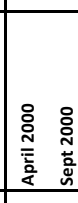 & 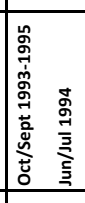 & 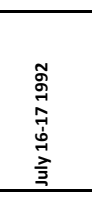 & 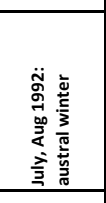 & 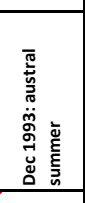 & 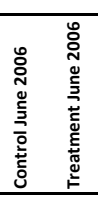 & & 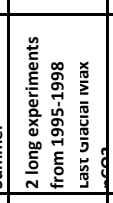 & 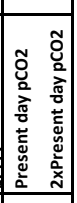 \\
\hline ๕̆ & 55 & $\therefore 8$ & 898 & $\stackrel{\sim}{\sim}$ & $\pi \pi \vec{N}$ & 용요 & $g \approx$ & : & $\ddot{m}$ & $\cong$ & ని & 8 & 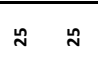 & 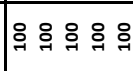 & 8 & 88 \\
\hline 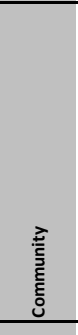 & 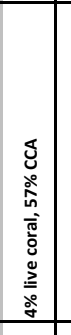 & 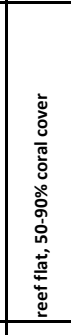 & 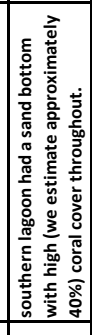 & 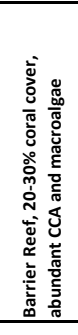 & 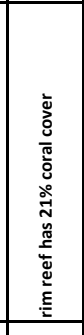 & 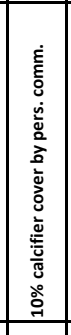 & 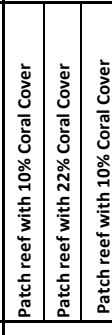 & 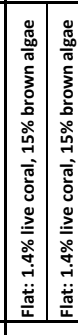 & 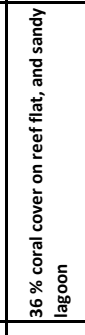 & 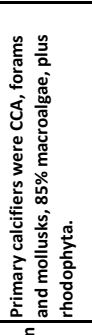 & 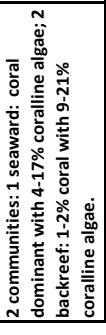 & 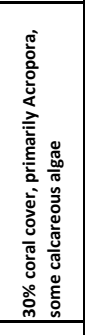 & 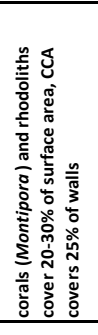 & 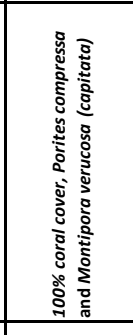 & 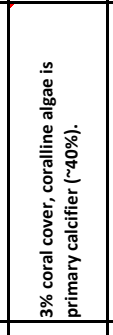 & 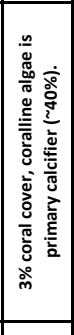 \\
\hline 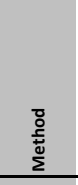 & 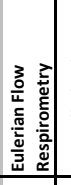 & 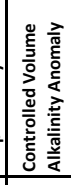 & $\begin{array}{l}\text { 㝴 } \\
\text { 童 }\end{array}$ & 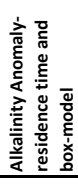 & 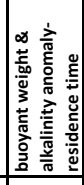 & $\check{\simeq}$ & 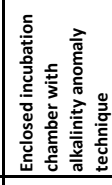 & 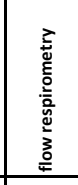 & 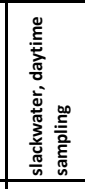 & 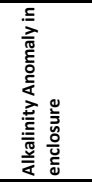 & 3 & & 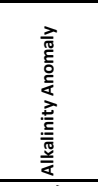 & 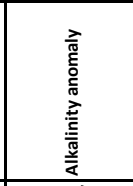 & 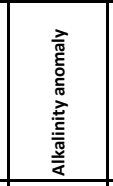 & 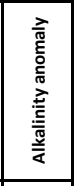 \\
\hline 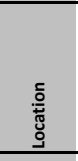 & 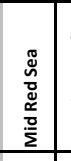 & 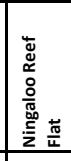 & 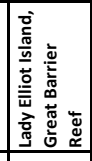 & 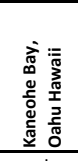 & 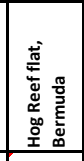 & 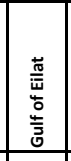 & 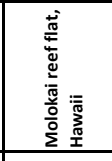 & 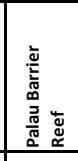 & 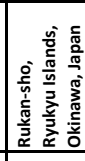 & 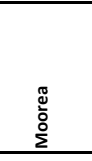 & 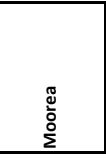 & 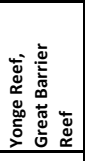 & 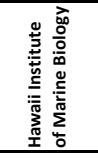 & 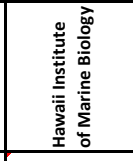 & 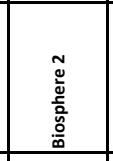 & ฏ \\
\hline 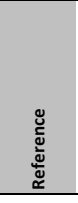 & 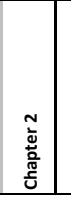 & 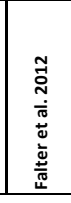 & 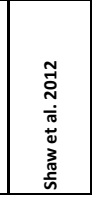 & 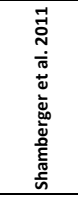 & 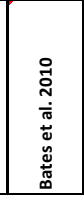 & 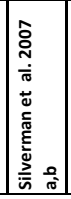 & 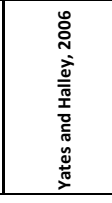 & 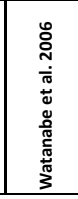 & 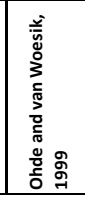 & 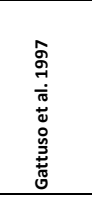 & & & 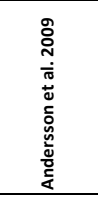 & 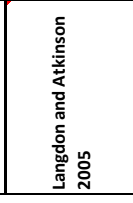 & 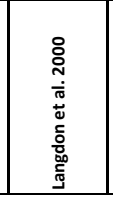 & 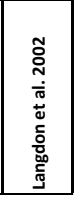 \\
\hline
\end{tabular}


Table 2

Statistics and regression data for correlations between NCC and temperature, daily integrated photosynthetically active radiation (PAR), percent calcifier cover, and $\Omega_{\mathrm{a}}$.

\begin{tabular}{|l|llll|ll|}
\hline \multicolumn{1}{|c|}{ Regression } & \multicolumn{3}{c|}{ Statistics } & \multicolumn{2}{c|}{ Regression data } \\
\hline Global dataset: compiled field and mesocosm data & $\mathrm{n}$ & $\mathrm{r}^{2}$ & $\mathrm{p}$-value & Slope & error \\
\hline NCC versus Temperature & 36 & 0.002 & 0.8 & -0.1 & 0.4 \\
NCC versus Daily Integrated PAR & $20 *$ & 0.02 & 0.6 & 0.1 & 0.1 \\
NCC versus percent calcifier cover & 36 & 0.27 & 0.001 & 0.10 & 0.03 \\
NCC versus $\Omega_{\mathrm{a}}$ & 36 & 0.16 & 0.02 & 2.0 & 0.8 \\
\hline
\end{tabular}

* Not all studies had data for PAR or some mesocosm studies spanned several seasons such that an average PAR would not be meaningful, see Table 1. 


\section{Table 3}

Statistics and regression data for correlations between NNCC and temperature, daily integrated photosynthetically active radiation (PAR), percent calcifier cover, and $\Omega_{\mathrm{a}}$. Regression data for published mesocosm studies, normalized and un-normalized data, are also available for comparison. "Err." is error and "x-int" is $\mathrm{x}$-intercept.

\begin{tabular}{|c|c|c|c|c|c|c|c|c|c|}
\hline \multirow{2}{*}{\begin{tabular}{l} 
Regression \\
\multicolumn{1}{c}{ Global dataset: field and } \\
mesocosm data \\
\end{tabular}} & \multicolumn{3}{|c|}{ Statistics } & \multicolumn{2}{|c|}{$\begin{array}{c}\text { Normalized } \\
\text { to } 29 \% \\
\text { calcifier } \\
\text { cover } \\
\end{array}$} & \multicolumn{2}{|c|}{$\begin{array}{c}\text { Not } \\
\text { normalized }\end{array}$} & \multicolumn{2}{|c|}{$\begin{array}{c}\Omega_{\mathrm{a}} \\
\text { Threshold }\end{array}$} \\
\hline & $\mathrm{n}$ & $r^{2}$ & p-value & $\begin{array}{l}\text { slop } \\
\mathrm{e}\end{array}$ & Err. & slope & Err. & $\mathrm{x}$-int. & Err \\
\hline NNCC vs. temperature & 34 & 0.0005 & 0.9 & 0.03 & 0.26 & \multirow{4}{*}{\multicolumn{2}{|c|}{ See Table 1}} & - & - \\
\hline $\begin{array}{l}\text { NNCC vs. daily integrated } \\
\text { PAR }\end{array}$ & $13^{*}$ & 0.03 & 0.6 & -0.1 & 0.12 & & & - & - \\
\hline $\begin{array}{l}\text { NNCC vs. percent calcifier } \\
\text { cover }\end{array}$ & 34 & 0.07 & 0.1 & $\begin{array}{c}- \\
0.03\end{array}$ & 0.02 & & & - & - \\
\hline NNCC vs. $\Omega_{\mathrm{a}}$ & 34 & 0.30 & 0.001 & 1.8 & 0.5 & & & 0.4 & 1.0 \\
\hline $\begin{array}{l}\text { NNCC vs. } \Omega_{\mathrm{a}} \\
\text { excluding Shamberger et al. } \\
2011\end{array}$ & 32 & 0.62 & $<<0.001$ & 2.1 & 0.3 & & & 1.1 & 0.5 \\
\hline \multicolumn{10}{|l|}{$\begin{array}{l}\text { Mesocosm Studies: daytime } \\
\text { hourly data }\end{array}$} \\
\hline $\begin{array}{l}\text { Langdon et al. } 2000 \\
\text { High resolution data, } \\
\text { weekly timescale } \dagger\end{array}$ & 42 & 0.75 & $<<0.001$ & 1.7 & 0.2 & 2.7 & $\begin{array}{l}0 . \\
3\end{array}$ & 1.7 & 0.3 \\
\hline $\begin{array}{l}\text { Langdon et al. } 2000 \\
\text { Long-term averages for } 3 \\
\text { treatments } \dagger \dagger\end{array}$ & 3 & 0.99 & 0.07 & 1.6 & 0.2 & 2.6 & $\begin{array}{l}0 . \\
3\end{array}$ & 1.5 & 0.4 \\
\hline $\begin{array}{l}\text { Andersson et al. } 2009 \\
\text { Hourly data from } 2 \\
\text { treatments** }\end{array}$ & 12 & 0.70 & 0.001 & 3.3 & 0.7 & 3.4 & $\begin{array}{l}0 . \\
7\end{array}$ & 1.6 & 0.6 \\
\hline $\begin{array}{l}\text { Andersson et al. } 2009 \\
\text { Averages of replicates for } 2 \\
\text { treatments** }\end{array}$ & 2 & - & - & 3.0 & - & 3.0 & - & 1.3 & - \\
\hline $\begin{array}{l}\text { Langdon and Atkinson } 2005 \\
\text { Averages of replicates for } 5 \\
\text { treatments§ }\end{array}$ & 5 & 0.88 & 0.02 & 1.9 & 0.4 & 8 & 2 & 0.9 & 0.6 \\
\hline $\begin{array}{l}\text { Langdon } 2002 \\
\text { Averages of replicates for } 3 \\
\text { treatments }\end{array}$ & 3 & 0.96 & 0.1 & 1.4 & 0.3 & 2.2 & $\begin{array}{l}0 . \\
4\end{array}$ & 1.1 & 0.8 \\
\hline
\end{tabular}

* Not all studies had data for PAR or some mesocosm studies were spanned several seasons such that an average PAR would not be meaningful, see Table S1.

$\dagger$ Weekly data collected over 5 years.

$\dagger \dagger \Omega$ held at 1.6 for 836 days, $\Omega$ held at 3.1 for 497 days and, $\Omega$ held at 5.2 for 56 days

** Data collected at 4 hour intervals over a 24 hour period.

$\S 1.5$ hour incubations repeated over several days for each treatment. Experiments conducted only during mid-day hours when metabolic rates were known to be light saturated.

$\$$ The duration of each experiment was longer than 3 months conducted at $\mathrm{pCO}_{2}$ levels corresponding to present day, $2 x$ present day and of last glacial maximum. 


\section{Supplementary Figures}

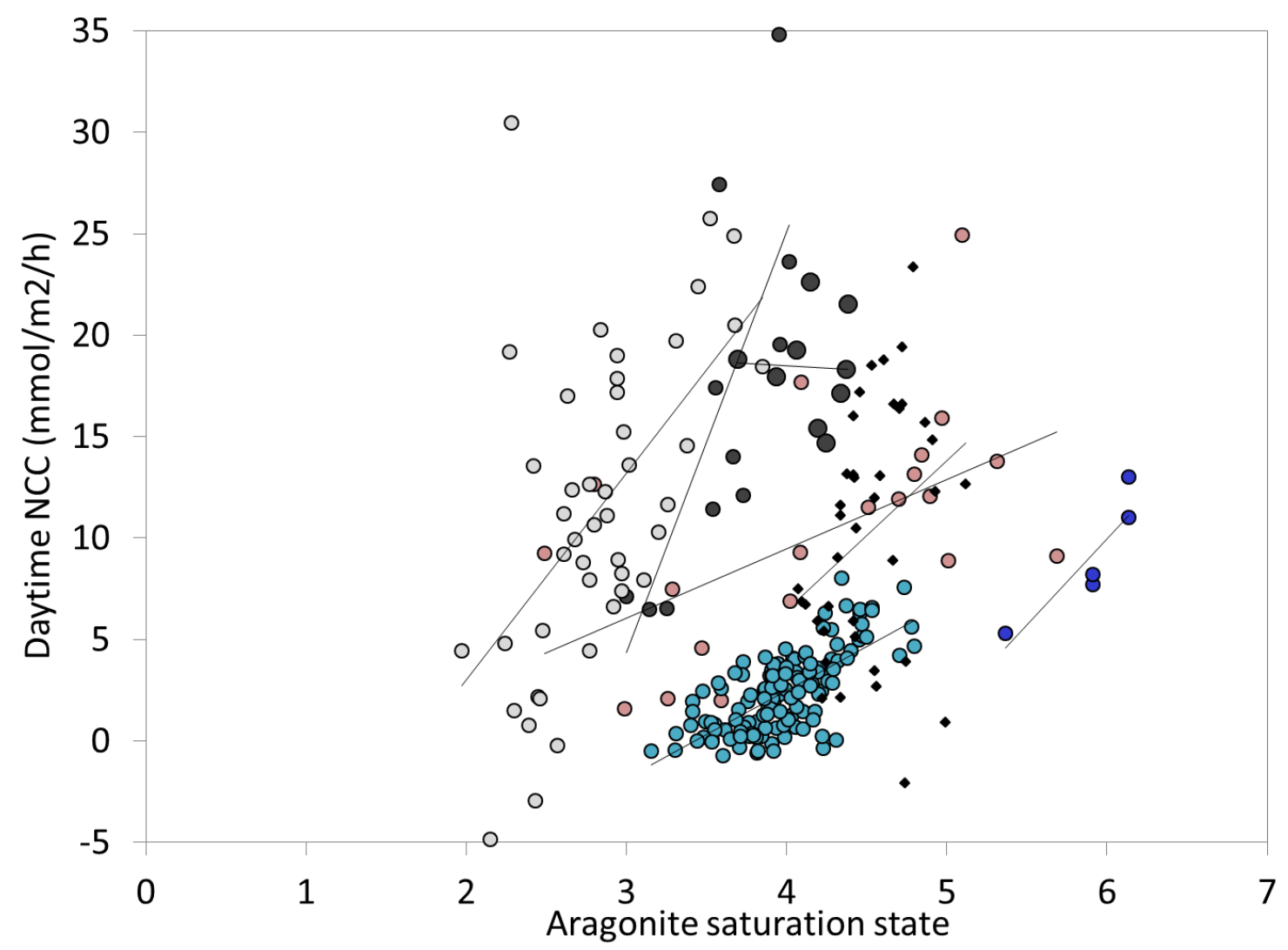

Figure S1 Daytime NCC rate $\left(\mathrm{mmol} \mathrm{m}^{-2} \mathrm{~h}^{-1}\right)$ versus $\Omega_{\mathrm{a}}$ for field studies. Symbols same as in Figure 1. 


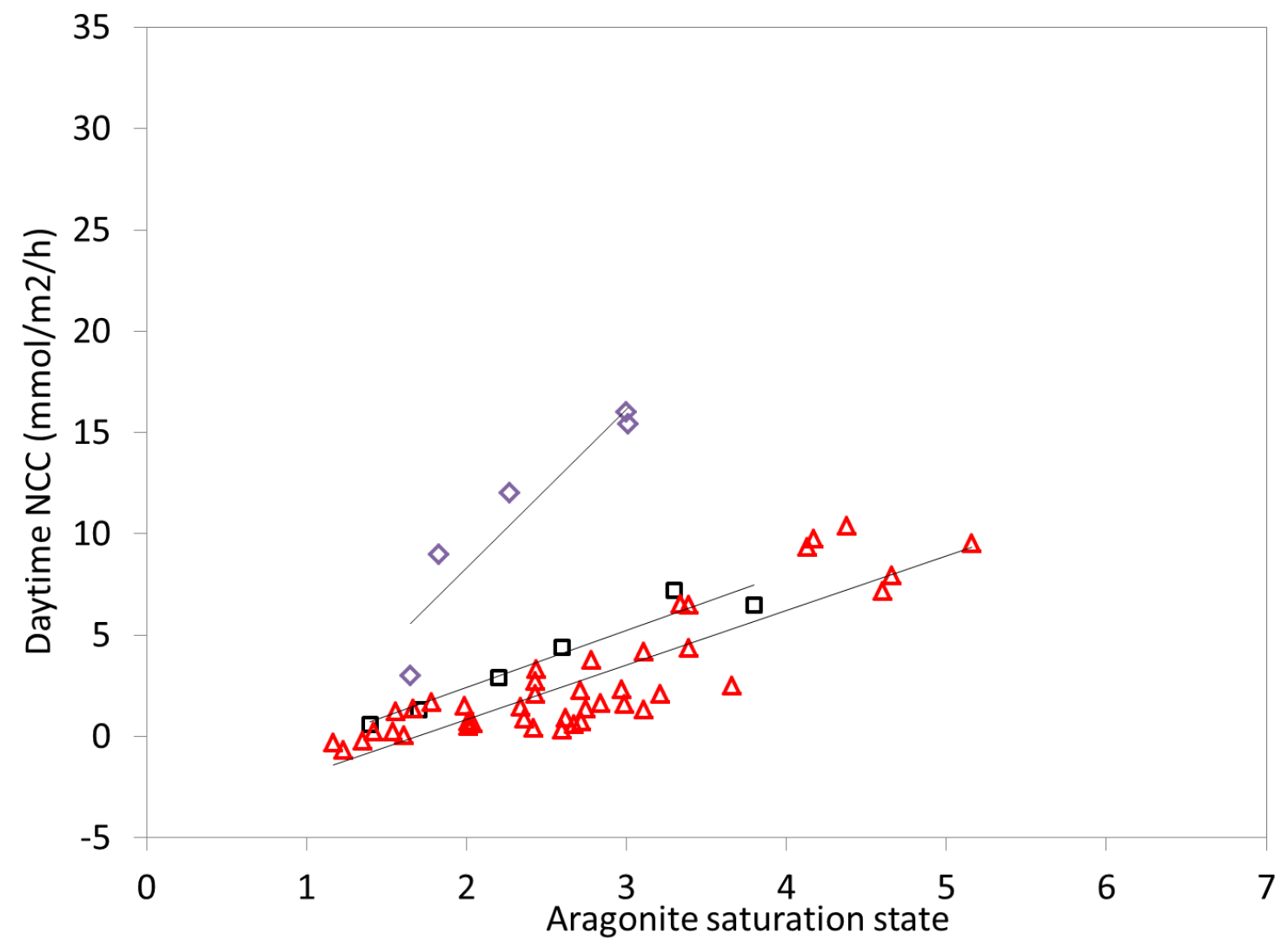

Figure S2 Daytime NCC rate $\left(\mathrm{mmol} \mathrm{m}{ }^{-2} \mathrm{~h}^{-1}\right)$ versus $\Omega_{\mathrm{a}}$ for mesocosm studies. Symbols same as in Figure 1. 


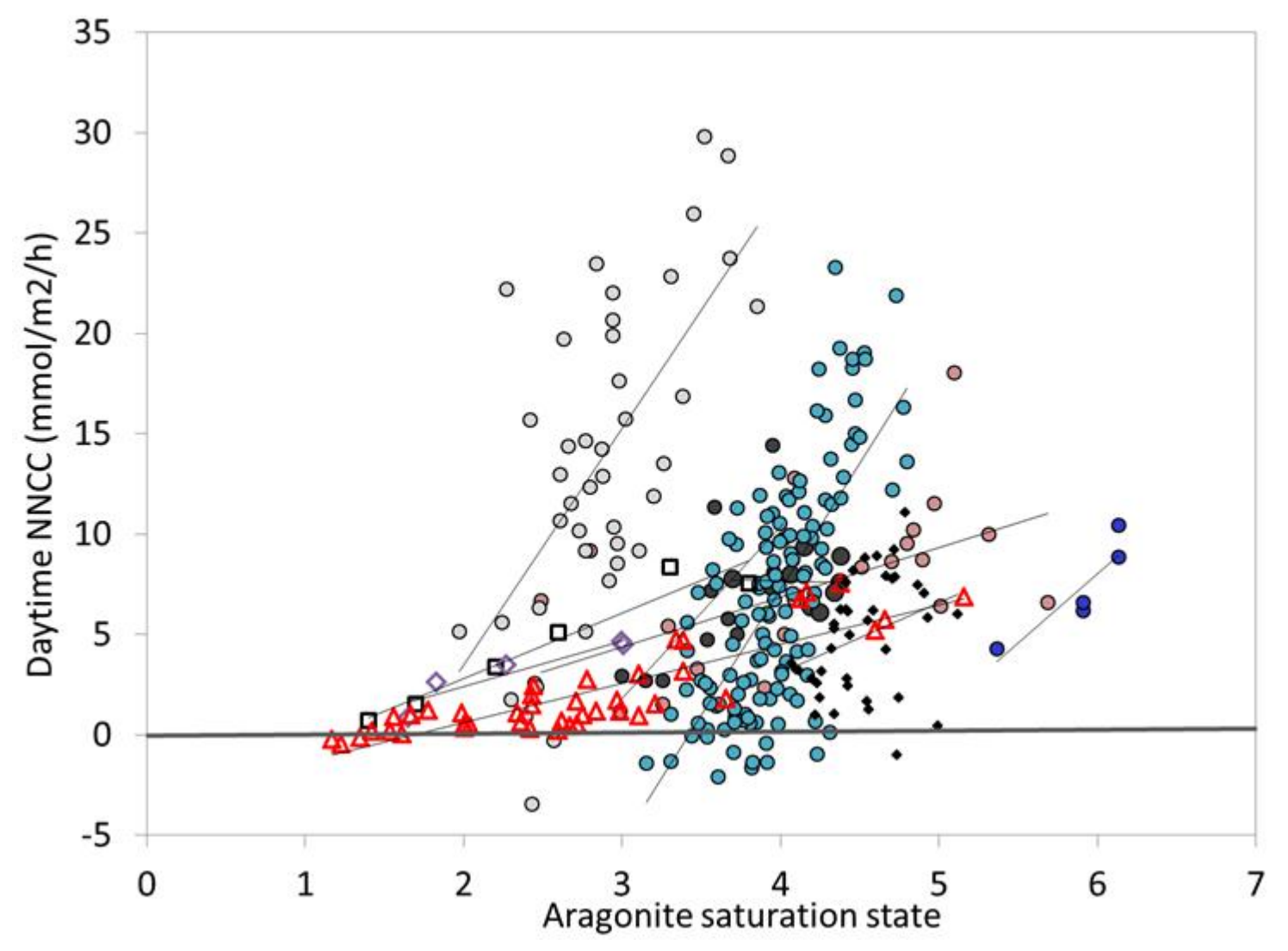

Figure S3 Daytime NNCC rate $\left(\mathrm{mmol} \mathrm{m}^{-2} \mathrm{~h}^{-1}\right)$ versus $\Omega_{\mathrm{a}}$ for mesocosm studies. NCC values have been normalized to the percent calcifier cover (percent coral cover + percent coralline algal cover) for each study site to compute normalized net community calcification (NNCC). See methods. Symbols same as in Figure 1. 


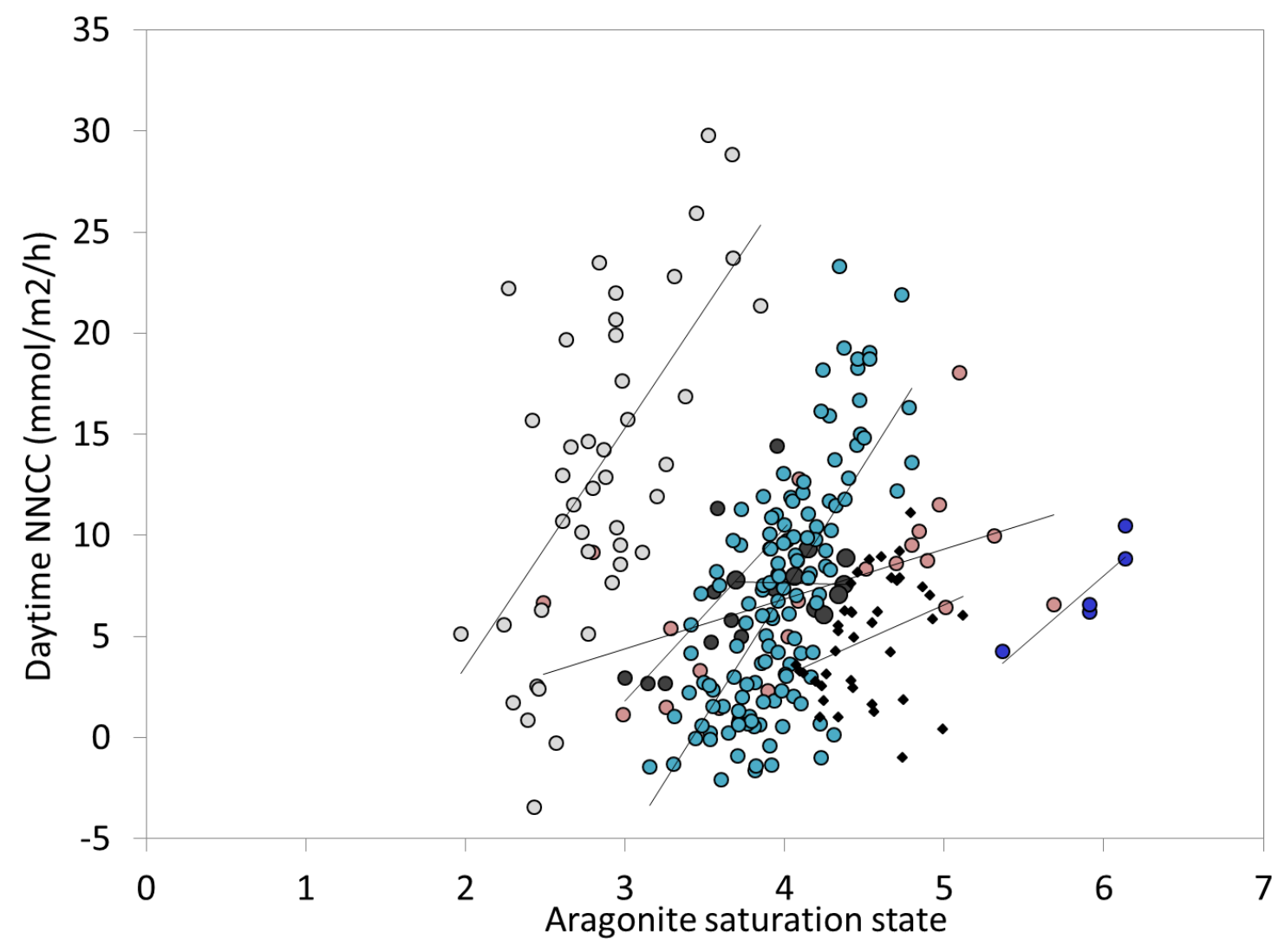

Figure S4 Daytime NNCC rate $\left(\mathrm{mmol} \mathrm{m}^{-2} \mathrm{~h}^{-1}\right)$ versus $\Omega_{\mathrm{a}}$ for field studies. Symbols same as in Figure S3. 


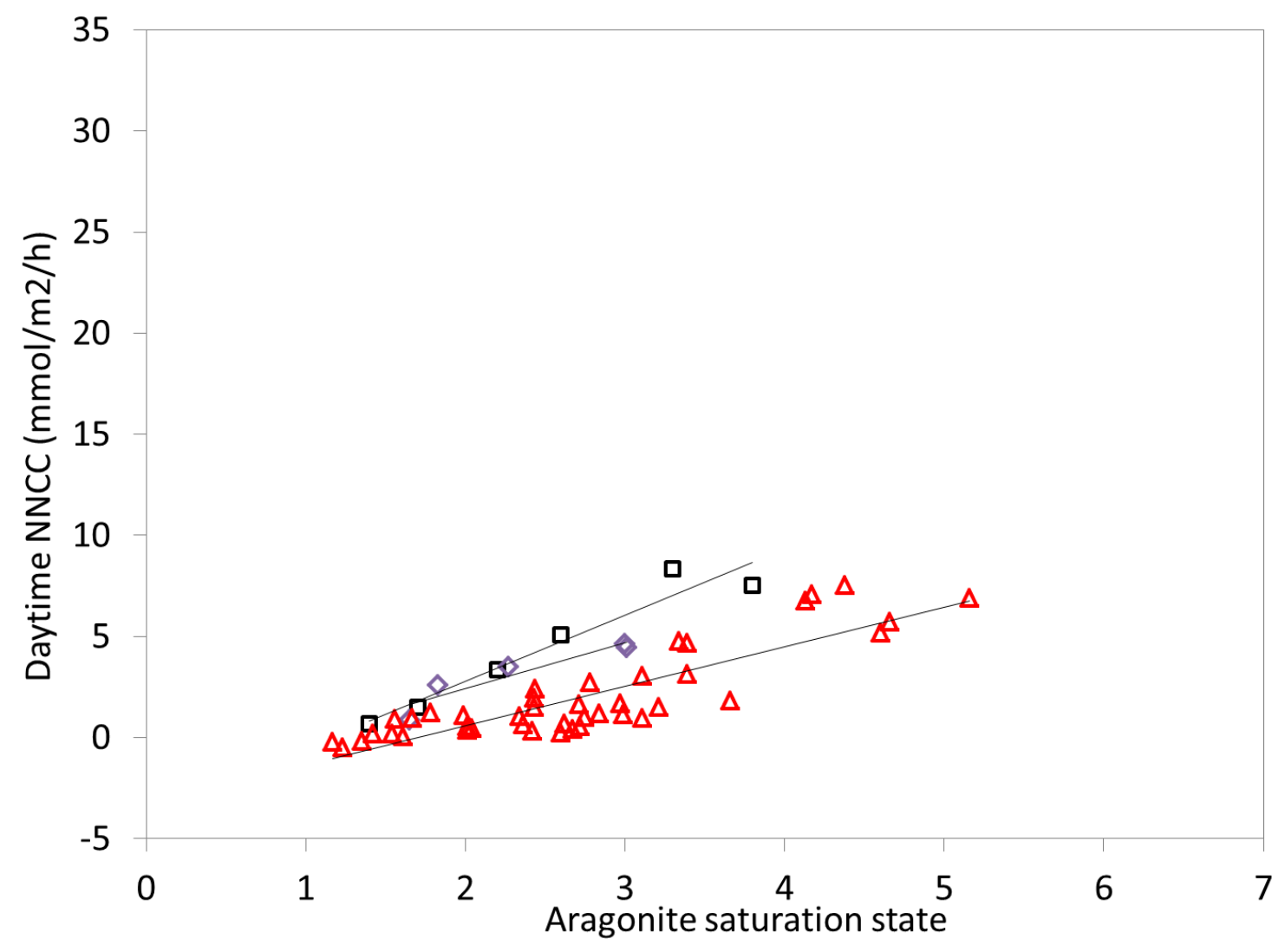

Figure S5 Daytime NNCC rate $\left(\mathrm{mmol} \mathrm{m}^{-2} \mathrm{~h}^{-1}\right)$ versus $\Omega_{\mathrm{a}}$ for mesocosm studies. Symbols same as in Figure S3. 


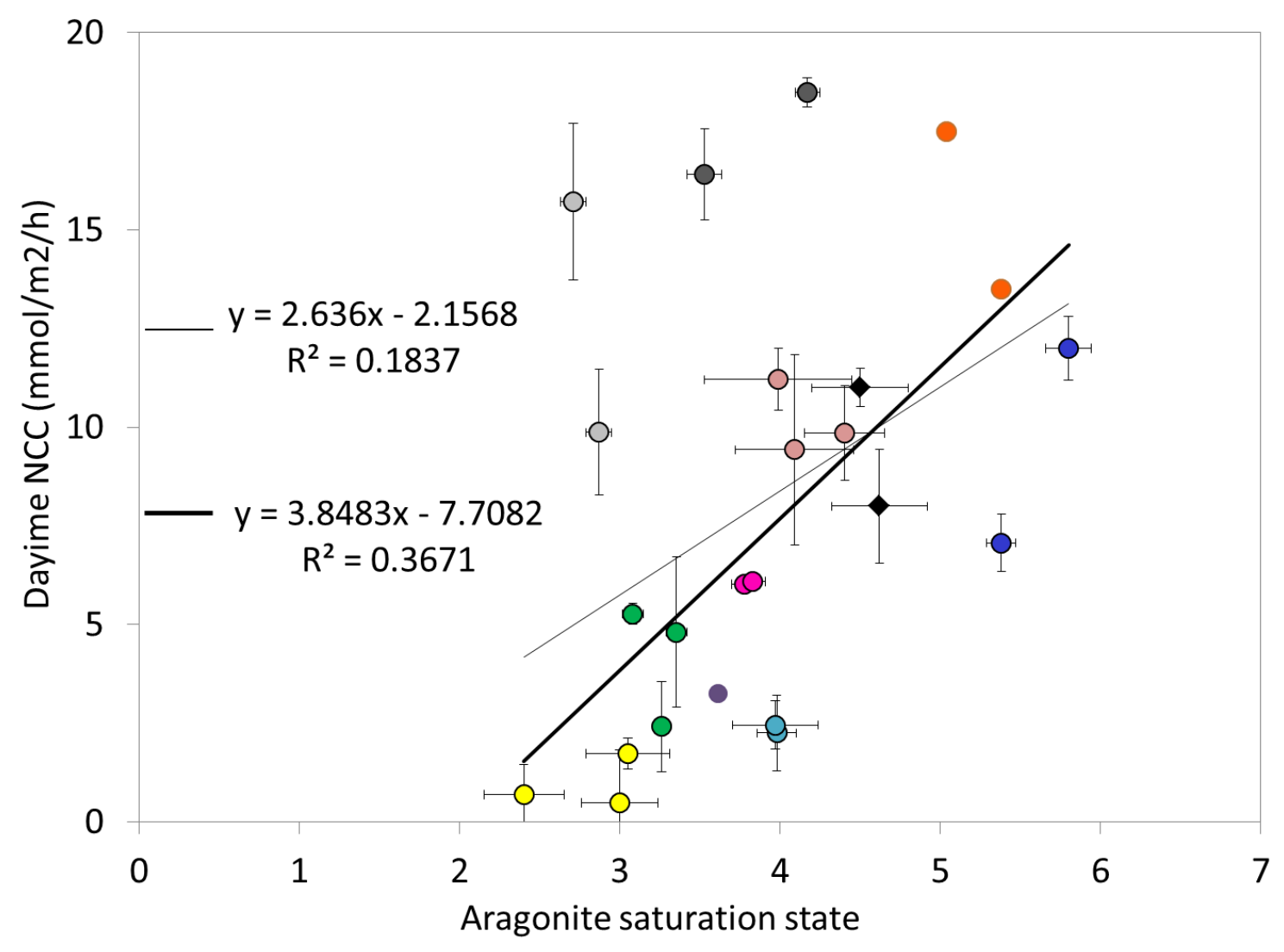

Figure S6 Average daytime NCC values from field studies only, plotted versus $\Omega_{\mathrm{a}}$ before accounting for \%CC at each site. Symbols same as in Figure 5. 


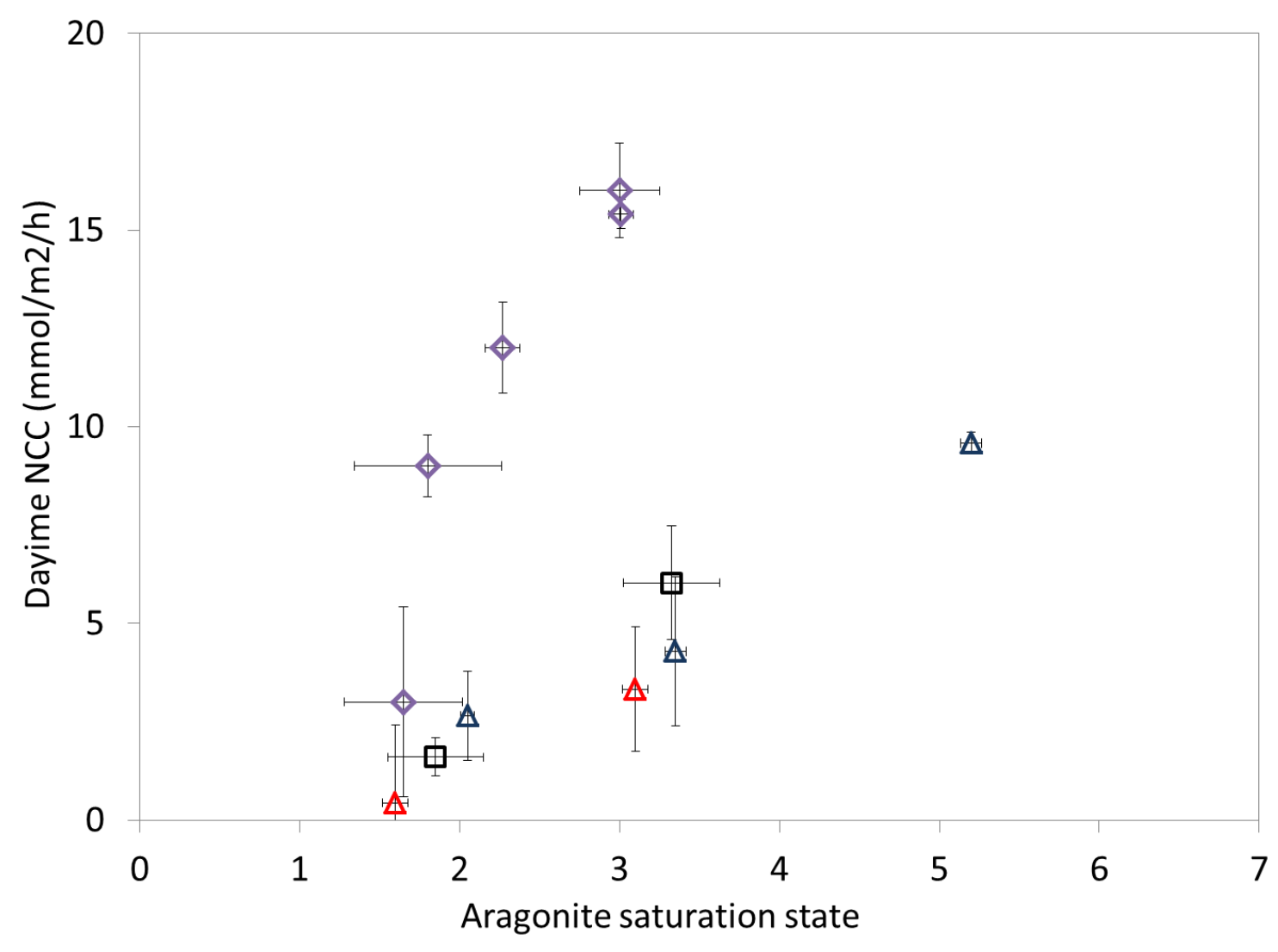

Figure S7 Average daytime NCC values from mesocosm studies only, plotted versus $\boldsymbol{\Omega}_{\mathrm{a}}$ before accounting for \%CC in each mesocosm. Symbols same as in Figure 5. 


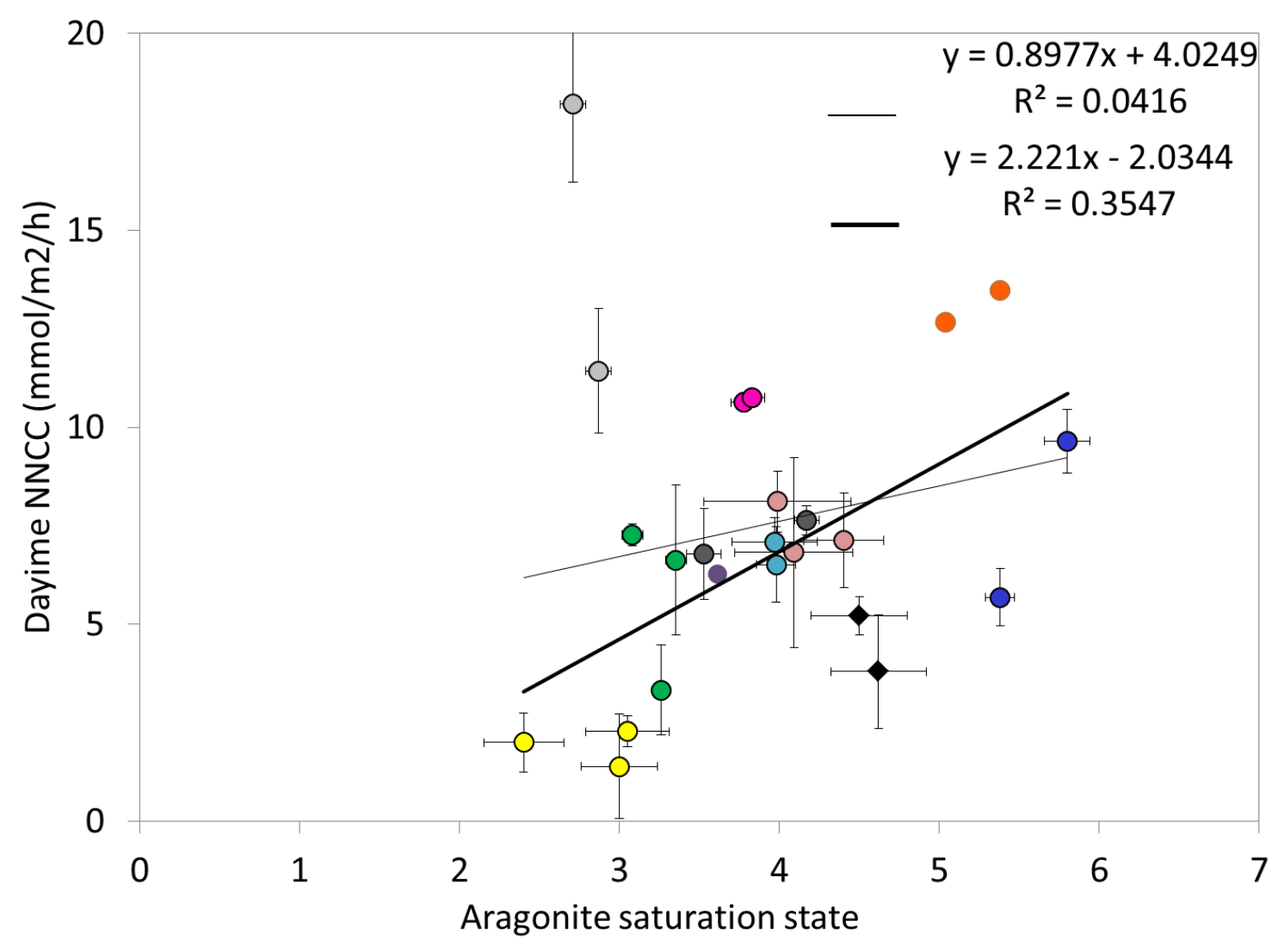

Figure S8 Average daytime NNCC values from field studies only, plotted versus $\Omega_{\mathrm{a}}$. Symbols same as in Figure 5. 


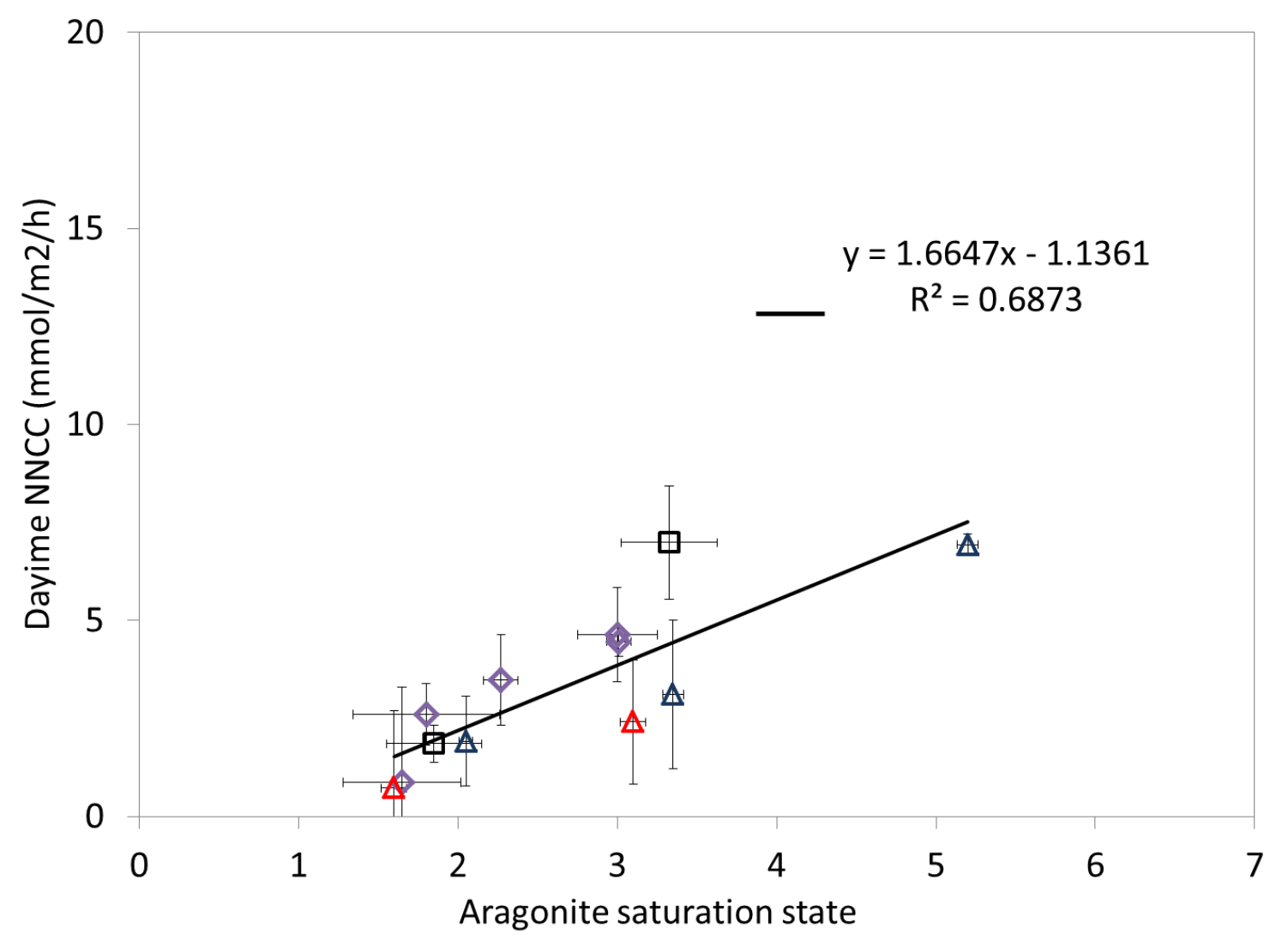

Figure S9 Average daytime NNCC values from mesocosm studies only, plotted versus $\Omega_{\mathrm{a}}$. Symbols same as in Figure 5. 


\section{Chapter 4:}

Decline in net community calcification in the Caribbean region 


\begin{abstract}
Dramatic shifts in live coral cover and community structure have occurred in Caribbean reefs since the 1970's due to over fishing, a Diadema pandemic, disease, hurricane damage, and stresses deriving from coastal development. These shifts have likely influenced the net metabolic processes occurring at Caribbean reefs. However, long-term changes in net community calcification (NCC) and net community production (NCP) in the Caribbean have until now remained unquantified.

We estimated NCC (calcification - dissolution) and NCP (photosynthesis respiration) in summer and winter at Cayo Enrique in Puerto Rico and at Evan's Reef in the Florida Keys using the Lagrangian flow respirometry method. Overall, we estimated daytime hourly NCC and NCP rates ranging from $-17 \mathrm{mmol} \mathrm{CaCO}_{3} \mathrm{~m}^{-2} \mathrm{~h}^{-1}$ to $56 \mathrm{mmol}$ $\mathrm{CaCO}_{3} \mathrm{~m}^{-2} \mathrm{~h}^{-1}$ (mean daytime $\mathrm{NCC}=3$ ) and from to $-70 \mathrm{mmol} \mathrm{C} \mathrm{m}^{-2} \mathrm{~h}^{-1}$ to $46 \mathrm{mmol} \mathrm{C} \mathrm{m}^{-}$ ${ }^{2} \mathrm{~h}^{-1}$ (mean daytime NCP $=15$ ), respectively. The community composition and geomorphology of a Jamaican reef - Discovery Bay - and these two study sites were similar in the past (Kinsey 1982), enabling the comparison of NCC rates through time. Average NCC rates during summer and winter at these two sites are 53-92\% lower than values estimated by Lagrangian flow respirometry on a Jamaican reef in 1980 (Kinsey 1982). NCC rates for each field season were not statistically different from zero. About $43 \%$ of all instantaneous NCC rates are negative. The evidence suggests that both Cayo Enrique and Evan's Reef are undergoing net dissolution in both seasons, and may be well on their way to transitioning into a long-term net state of dissolution. These results agree with a study using the ReefBudget census-based method that demonstrates reduced Caribbean reef carbonate production in conjunction with ecological decline (Perry et al. 2013).
\end{abstract}




\section{Introduction}

Net community calcification (NCC) is the precipitation and accretion of biogenic calcium carbonate minerals by calcifying organisms minus the loss of calcium carbonate by dissolution. NCC must be positive on long timescales (year-to-year) in order for coral reefs to keep up with erosion and sea level rise (Kleypas and Langdon 2006; Erez et al. 2011). Calcification on coral reefs occurs primarily through the activity of corals, coralline algae, foraminifera and mollusks. Dissolution tends to occur within the reef matrix and within sediment pore waters where respiration depresses the mineral saturation state of the fluid microenvironment (Walter et al. 1993; Ku et al. 1999; Tribollet and Golubic 2011; Andersson and Gledhill 2013). The dissolution, erosion and breakdown of coral reefs are controlled by interrelated chemical, biological, and physical processes, including lithification, metabolic dissolution (biocorrosion), mechanical erosion by grazing and boring organisms (bioabrasion), and mechanical destruction by waves and storms (Tribollet and Golubic 2011; Andersson and Gledhill 2013).

The balance of calcification and dissolution can be shifted by forces that change calcification rates or drive shifts in community composition. Over-fishing of herbivorous fishes and increased nutrient concentrations and disease occurrence increase the competitive advantage of algae for reef surface area (Littler and Littler 1984; Smith et al. 2001; Mumby et al. 2006). Prolonged thermal stress decreases calcification rates and can lead to bleaching, coral death and subsequent colonization by algae (Clausen and Roth 1975; Jokiel and Coles 1977; Coles and Jokiel 1978; Lough and Barnes 2000; Baird and Marshall 2002; Mendes and Woodley 2002). Finally, ocean acidification both depresses calcification rates and enhances conditions for dissolution (Marubini and Atkinson 1999; Langdon et al. 2000; Marubini et al. 2001; Langdon and Atkinson 2005; Kleypas and Langdon 2006; Kleypas et al. 2006; Jokiel et al. 2008; Kuffner et al. 2008; Martin and Gattuso 2009).

Coral reefs in the Caribbean region have long been compromised by local stresses but are now confronted with the additional stress of ocean acidification and global warming. Since the mid 1970's scleractinian coral cover has declined by an average of 
80\% across the Caribbean basin (Hughes 1994; Gardner et al. 2003). The effects of fishing pressure, disease, hurricanes, habitat destruction, a massive die-off of Diadema antillerium in the early 1980's, an unprecedented Caribbean-wide bleaching event in 1987 followed by subsequent bleaching events, and increased temperatures and nutrient levels have forced dramatic changes in coral abundance and community structure resulting in shifts from coral-dominated to algal-dominated communities (Vicente 1993; Hughes 1994; Rogers and Beets 2001).

While it may seem obvious that NCC would decline as reefs degrade, it is possible that the relative abundance of corals, algae and bioeroders shift in such a way as to have little or no effect on the magnitude or sign of NCC (Mallela and Perry 2007). Even in the case of evident decline, knowledge of the rates of NCC change is necessary to predict the trajectory and future persistence of coral reefs. In order to understand the linkages between reef metabolism and benthic community, changes in NCC must be quantified, in conjunction with changing community composition.

We estimated NCC using the Lagrangian flow hydrochemical method at two Caribbean sites and we compare our results to those of a recent Caribbean-wide study that employed the ReefBudget census-based method to estimate changes in carbonate production rates (CPR) (Perry et al. 2013). Assuming growth rates based on speciesspecific studies, the census method estimates reef growth rates on an annual timescale which is relevant to the long term persistence of reefs. However, the census method cannot resolve the relative carbonate production rates during specific seasons. In contrast, the hydrochemical method used here tracks changes in alkalinity to estimate NCC on hourly timescales and so can attribute the long-term trends to activity on shorter timescales depending on the temporal resolution of the study. For example, with sufficiently extensive sampling, net diurnal rates can be parsed into daytime and nighttime rates, and annual rates can be examined on a seasonal basis.

The census method has the advantage of estimating the relative contributions of the various carbonate producers and eroders on the reef. However, this involves many assumptions, empirical approximations and extrapolations when local or species-specific 
data are not available (Perry et al. 2012; Perry et al. 2013). This can be problematic because bioerosion rates may vary significantly depending on environmental conditions, competition between bioeroders, the density and hardness of the substrate, and the seasonal growth patterns of the boring agents (Hutchings and Kiene 1986; Andersson and Gledhill 2013). Thus some calcification or dissolution processes may not be accurately quantified or accounted for, including dissolution of carbonate material inside animal gut, dissolution of carbonate material in the sands, or deposition of sands as infill in the carbonate framework and subsequent lithification and cementation of the conglomerate platform (Vecsei 2001; Perry et al. 2012). In contrast, while the hydrochemical method does not account for mechanical erosion and abrasion, it does account for both environmental and metabolically driven dissolution.

We chose to employ the hydrochemical method in this study because this method can monitor changes in NCC in response to seawater chemistry. The instantaneous response of calcification and dissolution rates to changing seawater saturation state cannot be detected by the census method, which assumes a fixed growth rate for each organism and relies on assessments of community composition tied to a longer timescale (Perry et al. 2012; Perry et al. 2013). The growth rate estimates of the census-based method are inherently tied to a longer timescale (annual to decadal). The hydrochemical method can also be used to monitor changes on a longer timescale if repeat measurements are made periodically. Although the hydrochemical and census-based methods are distinctly different, they address the shared question of how community growth has changed over several decades of disturbance and stress. They yield results that are complementary, and together provide the opportunity for continued monitoring of decline in NCC in conjunction with global change.

\section{Methods}

\subsection{Study sites}

NCC and NCP were estimated by Lagrangian flow respirometry at two sites: Cayo Enrique, Puerto Rico (Figure 1) and Evan's Reef, Florida Keys (Figure 2). In August and 
December, 2011, we sampled along the western leg of the fore-reef slope of Cayo Enrique in Puerto Rico. Transects varied in lengths and duration, but covered a common region along the reef slope (white band, Figure 3). The average length was about 180m and the durations of the transects were 1.25 to 2 hours. The slope drops from a shallow (1m) flat colonized primarily by Millipora spp. or 'fire coral', to a sand bottom at about $20 \mathrm{~m}$ depth. We sampled at about 4-5m depth. The slope is a hard-bottom habitat consisting mostly of relict corals, rubble and reef conglomerate that is colonized by Siderastrea siderea, Porites astreoides, gorgonians, crustose coralline algae (CCA), and turf algae (Figure 4).

The benthic community composition at Cayo Enrique was evaluated with four 10m point-intercept transects conducted in March 2009 at 4-5m depth midway along the length of the reef. The estimate of live coral cover (7\%) agrees well with the average of four Atlantic and Gulf Rapid Reef Assessment (AGRRA) surveys (7.3\%) conducted at the same location and on the same day (all unpublished data, Figure 4). The primary corals observed in the AGRRA surveys are Siderastrea siderea (16\%), Porites astreoids (14\%), Diploria strigosa (8\%), and S. radians (4\%). These data also agree with a benthic study conducted at the western end of Cayo Enrique (Moyer et al. 2012) which found the corals present to consist mostly of $S$. siderea, $P$. astreoides, and Montastrea faveolata, and the base substrate to consist primarily of relic massive corals and old reef platform rather than sand. The results of Moyer et al. (2012) align with our own general observations along the transects during this study in 2011.

Cayo Enrique was selected for this Lagrangian study because of the predictable flow of water along the fore-reef from east to west (Gray et al. 2012). Occasionally, the water slows or reverses direction depending on tide and weather, but during the study the flow remained collinear with the reef-slope as indicated by the drifter transect paths and corroborated by current measurements made in prior years using a current meter mounted on PVC plastic with titanium nuts and bolts on the pressure cases (Figures S1 and S2). Cayo Enrique is a convenient site due to its proximity to the University of Puerto Rico at Mayaguiez, and consequently, the reef community has been monitored for decades. 
Because Cayo Enrique is part of the Atlantic Ocean Acidification test-bed (AOAT), environmental data are already available from the Integrated Coral Observing Network (ICON) mooring and the Moored autonomous pCO2 system (MapCO2), and numerous contemporary studies of the local metabolic rates will be available for comparison as they become published (McGillis et al. 2010, Gray et al. 2012). This is the first of these studies to report NCC rates.

We sampled Evan's Reef in February and August of 2012. Evan's Reef is a patch reef $7 \mathrm{~km}$ from the University of Miami Field Station on Broad Key, North Key Largo (Figure 2). We sampled at the reef floor which had an average depth of about $3 \mathrm{~m}$. The directionality of transects (westward or eastward) varied depending on the tide. The transect paths varied in length and duration from 200 to $300 \mathrm{~m}$ and from roughly $30 \mathrm{~min}$ to 2 hours, respectively.

Evan's Reef consists of a hard bottom habitat along the main axis with some accumulation of sand on the hard substrate. The main axis is where the majority of hard corals, soft corals and gorgonians have colonized, with the highest density of corals at the southern end (Figure 5). There is a western tongue of reef that has more sand, and is a soft bottom habitat interspersed with sea grass and hard and soft coral. This mixed habitat also runs along the margins of the entire reef as a transitional zone from the reef to the sea grass beds that surround it. A set of 14 benthic surveys in June and July 2011 indicate that the benthic cover is $26 \%$ rubble, $19 \%$ algae, $18 \%$ hard corals, $13 \%$ gorgonians, and $12 \%$ sand (Figure 6). The hard corals are predominantly S. siderea (45\%), with some P. astreoides (11\%; a large patch occurs in the north east portion of the reef) and Acropora cervicornis (7\%).

\subsection{Determination of Metabolic rates}

At each site, we used the Lagrangian flow respirometry method (Langdon et al. 2010) to quantify NCC and NCP. This involves following a parcel of water with a drifter (Figure 7) and sampling the seawater at the head and tail of the transect path in order to quantify the change in Total Alkalinity (TA), Dissolved Inorganic Carbon (DIC), and dissolved oxygen concentration, represented in this chapter as $\left[\mathrm{O}_{2}\right]$ in umol $\mathrm{L}^{-1}$. A $6920 \mathrm{YSI}$ 
instrument package was attached to the top of the drifter to monitor temperature, salinity, $\mathrm{pH}$ and dissolved oxygen concentration of the water mass as it drifted across the reef. Hobo temperature loggers were also attached to the body of the drifter for additional backup.

The metabolic rates are calculated as follows:

$$
\begin{array}{ll}
N E C=-0.5 \frac{\left(T A_{d}-T A_{u}\right) \rho_{w} h}{\Delta t} & \text { Equation 1 } \\
N C P_{D I C}=\frac{\left(D I C_{d}-D I C_{u}\right) \rho_{w} h}{\Delta t}-N E C-F_{A S G E} & \text { Equation 2 } \\
N C P_{O 2}=\left(\frac{1}{P Q}\right)\left[\frac{\left(\left[O_{2}\right]_{d}-\left[O_{2}\right]_{u}\right) h}{\Delta t}-F_{A S G E}\right] & \text { Equation 3 }
\end{array}
$$

Where subscripts $d$ and $u$ represent downstream and upstream, respectively, $\rho_{\mathrm{w}}$ is the density of the seawater based on its temperature and salinity, $h$ is the depth of the seawater, and $\Delta \mathrm{t}$ is the duration of the transect. $\left[\mathrm{O}_{2}\right]$ has units of $\mu \mathrm{M}$ while TA and DIC are in $\mu \mathrm{mol} \mathrm{kg}{ }^{-1}$. $\mathrm{F}_{\mathrm{ASGE}}$ is the flux of $\mathrm{O}_{2}$ or $\mathrm{CO}_{2}$ due to air-sea gas exchange. However, because $\mathrm{CO}_{2}$ equilibrates slowly with the atmosphere, $\mathrm{F}_{\mathrm{ASGE}}$ for $\mathrm{CO}_{2}$ is negligible (Wanninkhof 1992; Frankignoulle et al. 1996; Sweeney et al. 2007) and is not included in the calculation. $\mathrm{F}_{\mathrm{ASGE}}$ for $\mathrm{O}_{2}$ is the product of the $\left[\mathrm{O}_{2}\right]$ gradient between the air and the seawater and the piston velocity, which is a function of wind speed and salinity according to the Wanninkhof parameterization (Wanninkhof 1992). Wind speeds were measured at the ICON mooring (measured at 6.5 meters and converted to wind speeds at $10 \mathrm{~m}) 1.6 \mathrm{~km}$ south of Cayo Enrique and at the Miami International Airport $44 \mathrm{~km}$ northwest of Broad Key ((NCDC) 2013) for Evan's Reef. NCP measured according to the change in $\left[\mathrm{O}_{2}\right]$ was converted to carbon-based units assuming a constant photosynthetic quotient of $1 \mathrm{~mol} \mathrm{O}_{2} \mathrm{~mol}^{-1} \mathrm{CO}_{2}$. Although, the PQ may shift throughout the day, several studies have shown that it is likely to be near 1 in reef communities, and without further information about variability in this quotient we assume the simplest possibility, that it is constant (Smith 1973; Kinsey 1985; Gattuso et al. 1998a; Atkinson and Falter 2003; Falter et al. 2012; Silverman et al. 2012). 
We chose to use the Lagrangian method because it requires minimal instrumentation. This method involves several assumptions that are discussed and evaluated here.

The Lagrangian method assumes that the drogue follows the water parcel perfectly. However, when employing any drifter, some "slippage" usually occurs in which the drifter and water parcel shift relative to one another. Future studies employing drifters could assess the extent of slippage by marking the water parcel with dye. We did not use dye in our deployments. However, we did identify some instances of a detectable change in salinity over the course of the transect (see appendix 1), which may be a indicate some instances of slippage. It is important to keep in mind that slippage may have still occurred even when no salinity change was observed, because it is possible for the water to be uniform with respect to salinity and heterogeneous with respect to alkalinity. This possibility cannot be assessed with this data set, but the additional source of uncertainty should be kept in consideration when examining the data and error estimates. At best, future studies could survey the vertical and cross-transect gradients in alkalinity if resources allow. At a minimum, vertical and lateral transects of temperature and salinity using instrumentation may provide some information about the extent of error introduced by slippage, especially if an alkalinity-salinity relationship for the area is known.

The Lagrangian method also assumes that there is no mixing of water masses with different "histories", or rather that the surrounding water is homogenous with respect to TA, DIC and [O $\left.\mathrm{O}_{2}\right]$ (Odum 1956; Odum et al. 1959; Rogers 1979). In Puerto Rico, the water is not homogenous cross-wise to the reef slope, because there is a chemical gradient between the open ocean water and the water chemically altered by the reef metabolism. It is possible that water with a different "history" could mix into the tracked water parcel from either side. Water mixing in from the reef flat would result in an overestimate of NCC along the transect path, and water mixing in from the ocean side would result in an underestimate of NCC. We evaluated this possibility by examining the YSI measurements of salinity each transect path. Two transects (20 and 21) conducted at 
Broad Key in August were subject to possible mixing as implicated by an abrupt change in salinity (see Appendix 1). The records of salinity for all other transects either showed constant salinity within the precision of the measurement or a monotonic change that would be associated with slippage and is discussed in the appendix. As with slippage, transects for which no abrupt change in salinity is observed may still be subject to error due to mixing, because that mixing could happen between water parcels with the same salinity but different TA, DIC or $\left[\mathrm{O}_{2}\right]$. Again, this additional source of uncertainty should be kept in consideration when examining the data and error estimates provided in this paper.

We conducted 1-7 transects per day from 31 July to 4 August and 12-17 December, 2011, at Cayo Enrique, and also on 25, 26, and 28 February and 16-21 August, 2012, at Evan's Reef. Sampling at Cayo Enrique was interrupted by Hurricane Irene, ceasing field work operations from late morning Aug 2 through August 3. At Evan's Reef we conducted 2 nighttime transects each on 17 and 18 August, 2012.

$\mathrm{NCP}$ was calculated using the change in either DIC or $\left[\mathrm{O}_{2}\right]$ (Equations 2 and 3). The change in $\left[\mathrm{O}_{2}\right]$ can be measured with a higher sampling density using instrumentation, whereas the change in DIC is most precisely measured using discreet water samples. Also the change in $\left[\mathrm{O}_{2}\right]\left(\sim 5 \mathrm{umol} \mathrm{L}^{-1}\right)$ is larger relative to measurement precision $\left(0.2 \mathrm{umol} \mathrm{L}^{-1}\right)$ than the change in DIC $\left(\sim 8 \mathrm{umol} \mathrm{kg}^{-1}\right)$ is relative to measurement precision (1.5-3.6 umol kg-1). On the other hand, the $\mathrm{O}_{2}$-method requires a correction for air-sea gas exchange which has an uncertainty of up to 30\% (Wanninkhof 1992). This uncertainty derives from uncertainty in the Schmidt number, $\mathrm{pO}_{2}$ estimates, windspeed estimates, and the uncertainty in the windspeed parameterization itself, which does not directly account for the effects of sea state, bubble, surface films. Additionally, the $\mathrm{O}_{2}$ method requires a stoichiometric conversion from $\mathrm{mmol}_{\text {of }} \mathrm{O}_{2}$ to $\mathrm{mmol}$ of $\mathrm{C}$ by way of the photosynthetic quotient. The uncertainty in the photosynthetic quotient introduces error to the estimate of NCP estimated by the $\mathrm{O}_{2}$ method but reported in carbon-based units. In one study at One Tree Island in the Great Barrier Reef PQ was shown to range from 0.45 to 1.58 (Silverman et al. 2012). In contrast, the DIC-method provides a direct 
estimate of NCP in carbon-based units and does not require a correction for air-sea gas exchange which occurs on a much longer timescale than the transect durations (Wanninkhof 1992; Frankignoulle et al. 1996; Sweeney et al. 2007; Silverman et al. 2012; Falter et al. 2013).

The DIC and $\mathrm{O}_{2}$ methods are both valid and have been shown to agree under highly sampled controlled conditions (Langdon et al. 2003). However, it has been very challenging to find close agreement between these two methods in the much more complex field setting (Falter et al. 2012; Silverman et al. 2012). Deviations between results based on these two methods are not yet well understood, but may derive from uncertainty in gas exchange (Silverman et al. 2012). We estimated NCP by both methods during two field seasons (Appendix 2). The discrepancies between the two methods may in fact be an indication of the larger uncertainty in the NCP estimates beyond the analytical. This uncertainty could derive from uncertainty in the gas exchange for $\mathrm{O}_{2}$ or uncertainty in the PQ, which we assumed to be constant.

\subsection{Sample collection and analysis}

Water samples for determination of DIC, TA, salinity, and nutrients were collected from the reef-water interface using a hand-held Niskin sampler (Table 1). The Niskin sampler broke on the night of August 18, 2012 at Broad Key, so samples were collected for the remainder of that field season directly into samples bottles by carefully filling the bottles at the surface. This adds additional error to the estimates of metabolic rates at Broad Key in August, because the estimates require that the water column be well mixed, and because sampling without a Nisking sampler is not ideal. Although care was taken to minimize bubbles and splashing, we believe that this sampling method compromised the discreet bottle samples for $\left[\mathrm{O}_{2}\right]$ analysis, because $\left[\mathrm{O}_{2}\right]$ is very sensitive to gas exchange. DIC can also be compromised by this sampling method, although it is less sensitive to gas exchange than $\left[\mathrm{O}_{2}\right]$. For these reasons, we used the YSI measurements of $\left[\mathrm{O}_{2}\right]$ to estimate NCP at Broad Key in August and do not expect the DIC and $\mathrm{O}_{2}$ based methods to agree well (see Appendix 2 for comparison of YSI and Winkler-based estimates). 
We measured DIC and TA for samples collected at Cayo Enrique in August 2011 using a Marianda VINDTA-3C analysis system in Dr. Daniel McCorkle's lab at Woods Hole Oceanographic Institution. Alkalinity was determined by nonlinear curve fitting of data obtained by open-cell titrations, and DIC concentrations were determined by coulometric analysis. Both measurements were standardized using certified reference materials obtained from Dr. A. Dickson at the Scripps Institution of Oceanography (DIC precision $3.6 \mathrm{umol} \mathrm{kg}{ }^{-1}$ and alkalinity precision $2.9 \mathrm{umol} \mathrm{kg} \mathrm{n}^{-1}=16$ ). Noticing that the changes in TA were very small due to the low coral cover at this site, we ran all samples from remaining field expeditions by open-cell potentiometric titration following the DOE procedure SOP3b (Dickson et al. 2007). We used a custom-built automated Gran titration system (alkalinity precision less than $1 \mathrm{umol} \mathrm{kg}^{-1} \mathrm{n}=128$ ) in Dr. Langdon's lab at The Rosenstiel School of Marine and Atmospheric Science (RSMAS), University of Miami, which analyses small sample volumes such that a single $250 \mathrm{ml}$ bottle sample can be measured multiple times in order to achieve high precision of the measurement (Table 2). Certified reference materials (CRMs) (Dickson et al. 2003) were used to standardize the $\mathrm{HCl}$ titrant. The remaining DIC measurements were made on the Licor analyzer (DIC precision less than 1.5 umol $\mathrm{kg}^{-1} \mathrm{n}=128$ ) in the same lab at RSMAS.

We did not measure $\left[\mathrm{O}_{2}\right]$ at Cayo Enrique in August, so NCP for that field season is estimated using the change in DIC (Equation 2). We did measure $\left[\mathrm{O}_{2}\right]$ during all other field seasons. We measured discrete bottle samples by Winkler titration and collecting in situ measurements using a YSI optical probe calibrated with the bottle samples. The Winkler titrations were conducted using an automated titrator employing amperometric endpoint detection. The values based on Winkler titrations were used to estimate NCP in the winter at both sites. During field sampling in August at Evan's Reef, the discreet water samples for Winkler titrations were compromised because the niskin broke and we were compelled to sample by hand which is not ideal for $\left[\mathrm{O}_{2}\right]$ measurements which are very sensitive to gas exchange, so the changes in $\left[\mathrm{O}_{2}\right]$ were estimated using the YSI optical probe instead. The YSI optical probe was calibrated using the discreet samples that were collected before the niskin broke (Figure S3). The uncertainty for $\left[\mathrm{O}_{2}\right]$ 
measured by the calibrated YSI is $\pm 3 \mathrm{umol} \mathrm{L}^{-1}$ in contrast to the uncertainty of \pm 0.2 umol $\mathrm{L}^{-1}$ for the Winkler titrations, so the productivity values estimated at Broad Key in August are not known with as much certainty as those estimated with discreet samples at Broad Key and Cayo Enrique during the winter months.

$\Omega_{\mathrm{a}}, \mathrm{pH}$ and $\mathrm{pCO}_{2}$ were calculated from the measured TA, DIC, temperature, and salinity (Table 1). The calculation was carried out using the CO2SYS program (Pierrot 2006), applying the carbonate species dissociation constants of (Mehrbach et al. 1973) as refit by (Dickson and Millero 1987), and the aragonite solubility constant of (Mucci 1983). Salinity was measured by salinometer at Woods Hole Oceanographic Institution. Inorganic nutrient concentrations were measured at Oregon State University using a continuous segmented flow system consisting of a Technicon AutoAnalyzer II (SEAL Analytical) and an Alpkem RFA 300 Rapid Flow Analyzer (Alpkem), as described in (Apprill and Rappe 2011). The precisions for nitrite and nitrate+nitrite are $0.02 \mu \mathrm{M}$ and $0.15 \mu \mathrm{M}$, respectively.

\subsection{Additional field sampling}

While conducting field sampling we also measured depth, temperature, and photosynthetically active radiation (PAR) (Table 1). We measured depth using a weighted line. We then adjusted all depths to a neutral tide level, interpolated the adjusted depths, averaged the interpolated depths along each transect path and corrected each average transect depth according to the tide level at the time of the transect. The errors for interpolated and corrected depths are estimated to be about $0.5 \mathrm{~m}$. For the calculations of metabolic rates we used the full estimated depth of the water column over the reef at the time of sampling. We are assuming that the water column is well mixed on the timescale of the transect duration.

Temperature was measured using several instruments. At both sites we measured temperature along the transect path using the YSI sonde and numerous Hobo temperature loggers attached to the drifter (Figure 7). At Cayo Enrique, we also had temperature measurements from the MapCO2 mooring adjacent to the sampling area and the ICON $1.6 \mathrm{~km}$ south of Cayo Enrique (Figure 1). At Evan's Reef, we had additional temperature 
measurements available from a stationary YSI that remained on the reef during our February field visit (Figure 5). PAR was measured at the ICON mooring near Cayo Enrique (Figure 1) and by a PAR sensor placed on the reef flat at Evan's Reef (Figure 5).

\section{Results}

\subsection{Net community calcification}

Both positive and negative values of NCC were estimated during the daytime at each site in both summer and winter, and the range was largest in August at Evan's Reef (Figure 8). We explored numerous possibilities to explain the variability in NCC including time of day, temperature, salinity, $\Omega_{\mathrm{a}}$, wind speed, tidal patterns, and benthic cover beneath the transect path. A complete explanation for the variability was not found. These results are also shown in terms of the change in salinity normalized TA and DIC in propertyproperty plots (Figures S5 - S7). In comparing the slope of the data for each transect to the vectors that correspond to calcification, dissolution, photosynthesis and respiration, it is clear that the system between dominant processes at these sites.

$45 \%$ of the daytime NCC estimates at Cayo Enrique and $41 \%$ of daytime NCC estimates at Evan's Reef were significantly less than zero (student's t-test). Average daytime NCC rates for each field season are $( \pm 1 \sigma)$ :

$$
\begin{aligned}
& 2 \pm 8 \mathrm{mmol} \mathrm{CaCO}_{3} \mathrm{~m}^{-2} \mathrm{~h}^{-1} \text { for Puerto Rico, August 2011; } \\
& 1 \pm 5 \mathrm{mmol} \mathrm{CaCO}_{3} \mathrm{~m}^{-2} \mathrm{~h}^{-1} \text { for Puerto Rico, December 2011; } \\
& 3 \pm 10 \mathrm{mmol} \mathrm{CaCO}_{3} \mathrm{~m}^{-2} \mathrm{~h}^{-1} \text { in the Florida Keys in February 2012; } \\
& 4 \pm 16 \mathrm{mmol} \mathrm{CaCO}_{3} \mathrm{~m}^{-2} \mathrm{~h}^{-1} \text { in the Florida Keys in August } 2012 .
\end{aligned}
$$

Overall, the average daytime NCC rates for each field season are not significantly different from zero (t-test: Two-Sample Assuming Unequal Variances, $\mathrm{p}$-values $=0.5$, 0.3, 0.4, 0.1 for Cayo Enrique in August and December and Evan's Reef in February and August, respectively). 
The flow respirometry method only captures instantaneous rates, so estimating net diurnal rates without nighttime measurements requires assumptions about nighttime dissolution. However, we have three nighttime estimates for Evan's Reef in August 2012, averaging $-13 \pm 11 \mathrm{mmol} \mathrm{CaCO}_{3} \mathrm{~m}^{-2} \mathrm{~h}^{-1}$. For early August, we estimate the diurnal NCC rate as $-85.5 \mathrm{mmol} \mathrm{CaCO}_{3} \mathrm{~m}^{-2} \mathrm{~d}^{-1}$ by multiplying the average daytime $\mathrm{NCC}$ by 13 daylight hours and the average nighttime NCC by 11 hours.

We do not have nighttime rates for any of the field seasons in Cayo Enrique or the winter field season at Evan's Reef. Multiplying mean daytime NCC rates by the number of daylight hours during the field seasons yields the maximum possible diurnal net calcification rate:

$21 \mathrm{mmol} \mathrm{CaCO}_{3} \mathrm{~m}^{-2} \mathrm{~d}^{-1}$ for Puerto Rico, August 2011;

$14 \mathrm{mmol} \mathrm{CaCO}_{3} \mathrm{~m}^{-2} \mathrm{~d}^{-1}$ for Puerto Rico, December 2011;

$29 \mathrm{mmol} \mathrm{CaCO}_{3} \mathrm{~m}^{-2} \mathrm{~d}^{-1}$ in the Florida Keys in February 2012.

These values involve the assumption that neither calcification nor dissolution happen at night. However, our few estimates of nighttime NCC exhibit substantial dissolution. If the diurnal NCC for the first three field seasons were in fact zero or negative, it would require average nighttime dissolution rates of at least:

-2 $\mathrm{mmol} \mathrm{CaCO}_{3} \mathrm{~m}^{-2} \mathrm{~h}^{-1}$ for Puerto Rico, August 2011;

-1.1 $\mathrm{mmol} \mathrm{CaCO}_{3} \mathrm{~m}^{-2} \mathrm{~h}^{-1}$ for Puerto Rico, December 2011;

$-2.3 \mathrm{mmol} \mathrm{CaCO}_{3} \mathrm{~m}^{-2} \mathrm{~h}^{-1}$ in the Florida Keys in February 2012.

Given that we measured nighttime dissolution rates of $-3,-10$ and $-25 \mathrm{mmol}$ $\mathrm{CaCO}_{3} \mathrm{~m}^{-2} \mathrm{~h}^{-1}$ at Evan's Reef in August, these values are plausible. In fact, such dissolution values are well within the range of NCC rates observed at all the sites, even during the day (Figure 8). Given that some net dissolution happens during the day, it is reasonable to expect that the dissolution rates at night would be comparable or even 
larger, suggesting that the reefs in general are experiencing net dissolution on a diurnal timescale.

Further, if we assume that the $-13 \mathrm{mmol} \mathrm{CaCO}_{3} \mathrm{~m}^{-2} \mathrm{~h}^{-1}$ is representative of nighttime dissolution rates on both reefs in both seasons, then both reefs in both seasons would be undergoing substantial net dissolution on a diurnal timescale (Table 3):

$-121 \mathrm{mmol} \mathrm{CaCO}_{3} \mathrm{~m}^{-2} \mathrm{~d}^{-1}$ for Puerto Rico, August 2011;

$-153 \mathrm{mmol} \mathrm{CaCO}_{3} \mathrm{~m}^{-2} \mathrm{~d}^{-1}$ for Puerto Rico, December 2011;

$-132 \mathrm{mmol} \mathrm{CaCO}_{3} \mathrm{~m}^{-2} \mathrm{~d}^{-1}$ in the Florida Keys in February 2012;

$-85 \mathrm{mmol} \mathrm{CaCO}_{3} \mathrm{~m}^{-2} \mathrm{~d}^{-1}$ in the Florida Keys in August 2012.

Even without observations of nighttime NCC estimates at both sites during all field seasons, we can conclude with reasonable confidence that both reefs during both seasons are likely experiencing net dissolution on diurnal timescales.

\subsection{Net community production}

There was considerable variability in NCP, as for NCC (Figure 9). This variability may be an indication of additional uncertainty in our estimates of NCP deriving from slippage and mixing as discussed in the appendix. In the case of $\mathrm{O}_{2}$-based NCP, there is additional uncertainty associated with the estimate of air-sea gas exchange and with the assumption that the PQ is constant and equal to 1. Discrepancies between NCP determined by DIC and $\mathrm{O}_{2}$ may be an indication of the magnitude of uncertainty due to these additional factors (Appendix 2).

Nonetheless, we explored the same possibilities - time of day, temperature, salinity, $\Omega_{\mathrm{a}}$, wind speed, tidal patterns, and benthic cover beneath the transect path - in seeking and explanation for the variability and found no patterns.

With the exception of three NCP rates measured at Cayo Enrique in August, all the daytime hourly NCP rates showed net autotrophy during the day (Figure 9). The average daytime NCP for each field season is (average $\pm 1 \sigma$ ): 
$3 \pm 28 \mathrm{mmol} \mathrm{C} \mathrm{m}^{-2} \mathrm{~h}^{-1}$ for Puerto Rico, August 2011;

$9 \pm 12 \mathrm{mmol} \mathrm{C} \mathrm{m}^{-2} \mathrm{~h}^{-1}$ for Puerto Rico, December 2011;

$20 \pm 12 \mathrm{mmol} \mathrm{C} \mathrm{m}^{-2} \mathrm{~h}^{-1}$ in the Florida Keys in February 2012;

$23 \pm 10 \mathrm{mmol} \mathrm{C} \mathrm{m}^{-2} \mathrm{~h}^{-1}$ in the Florida Keys in August 2012.

As a consequence of three negative NCP rates, the average hourly NCP rates measured at Cayo Enrique in August are not significantly different from zero (t-test, $\mathrm{p}=0.8$ ). All other data sets have average daytime NCP rates significantly greater than zero.

In March 2009, McGillis et al. (2011) estimated NCP on the fore reef on the western end of Cayo Enrique over an eight day diurnal study. Using the boundary layer method, they estimated NCP ranging from -12.3 to $13.7 \mathrm{mmol} \mathrm{O}_{2} \mathrm{~m}^{-2} \mathrm{~h}^{-1}$, and by the SHARQ fixed volume enclosure method they estimated NCP ranging from -11 to 12.9 $\mathrm{mmol} \mathrm{O}_{2} \mathrm{~m}^{-2} \mathrm{~h}^{-1}$ (McGillis et al. 2011). Assuming a PQ of 1, the maximum daytime NCP estimated by McGillis et al. (2011) is in agreement with the maximum daytime NCP measured in this study at Cayo Enrique. Assuming the nighttime estimate of NCP by McGillis et al. (2011), we estimate that photosynthesis and respiration are approximately balanced at Cayo Enrique reef, although it is hard to make any sure conclusion because the error for daytime NCP at Cayo Enrique is so large. This is consistent with the production:respiration ratio of about 1 for the "standard performance" coral/algal flat over extended time (Kinsey 1985) and with observations of numerous previous studies that this ratio is near 1 (Gattuso et al. 1998b; Falter et al. 2001; Atkinson and Falter 2003; Langdon et al. 2003; Falter et al. 2008; Falter et al. 2012; Falter et al. 2013).

The average nighttime NCP of $-22 \pm 6 \mathrm{mmol} \mathrm{C} \mathrm{m}^{-2} \mathrm{~h}^{-1}$ at Evan's Reef is estimated by 4 nighttime transects, two on each of two nights in August (Figure 9). This balances the NCP during the daytime, suggesting that Evan's Reef is balanced between heterotrophy and autotrophy on a diurnal timescale in August. Assuming that the nighttime NCP at Evan's Reef in February is similar to that in August, we observe a balance between heterotrophy and autotrophy in February as well. Again, this is consistent with previous observations that the organic metabolism of a complete reef 
system is essentially balanced (Smith and Marsh 1973; Kinsey 1985; Gattuso et al. 1998b; Atkinson and Falter 2003; Falter et al. 2008; Falter et al. 2012).

\section{Discussion}

\subsection{Selection of baseline values against which to gauge change in NCC}

Baseline NCC measurements at Cayo Enrique and Evan's Reef have never been previously determined. However, hydrochemical estimates of NCC were previously determined at Discovery Bay, Jamaica, in June 1980 (Kinsey 1982). In order to compare the modern NCC rates at Cayo Enrique and Evan's Reef to historical values at Discovery Bay, we must make two assumptions: (1) that historical NCC rates at Discovery Bay are representative of NCC rates at sites with similar communities and environmental conditions, and (2) that the communities and environmental conditions at our own study sites were similar to the community at Discovery Bay. The first assumption is reasonable, because experimental studies have demonstrated that NCC rates are in fact controlled by community composition and environmental conditions (Gattuso et al. 1998b; Langdon et al. 2000; Langdon et al. 2003; Langdon and Atkinson 2005). To support the second assumption we present evidence that the historical communities at the sites in question are comparable.

\subsection{Likeness between former benthic communities at several pertinent Caribbean sites}

Based on observations in the early 1970's, "Jamaican and Puerto Rican reef zones [were] strikingly similar in both species composition and dominant species ([Montastrea] annularis and A. cervicornis)" (Rogers 1979). The likeness between Puerto Rican and Jamaican reefs was described in further detail when Rogers (1979) compared the community at San Cristobal, only $3 \mathrm{~km}$ southwest of Cayo Enrique, to the community at Discovery Bay, Jamaica. In 1975 and 1976, at 4m depth, 68\% of the benthic community at San Cristobal reef was living hard coral cover, and the remainder was coral sand (Rogers 1979). Of the live coral, $45 \%$ was A. cervicornis and $15 \%$ was M. annularis, and gorgonians were abundant (Rogers 1979). Importantly, Rogers (1979) noted that San 
Cristobal reef "resembled the deeper seaward 'mixed zone' (7-15m) described by Goreau and Goreau (1959) for Discovery Bay Reef in Jamaica" - an "annularis-cervicornis" region (Rogers 1979).

Historical descriptions of Cayo Enrique reef slope specifically support the likeness between Cayo Enrique, San Cristobal and Discovery Bay. There was an $A$. palmata zone, which extended to $3 \mathrm{~m}$ depth (Armstrong 1981). Below this the major species on the reef slope were A. cervicornis (51\% cover) to a depth of $5 \mathrm{~m}$ and abundant M. annularis, Diploria sp., and Agaricia agaricites from 5m to 15m (Goenaga and Cintron 1979; Armstrong 1981). This is in close agreement with the annulariscervicornis communities described by Rogers (1979) in reference to both Puerto Rican and Jamaican reefs. This description of the historical reef slope community at Cayo Enrique also directly agrees with the A. palmate-dominated reef slope at Discovery Bay, Jamaica, described by Kinsey (1982). We interpret this as evidence to support the assumption that the former communities at Cayo Enrique reef slope and Discover Bay were sufficiently comparable to warrant comparison of modern NCC rates at Cayo Enrique to historical NCC rates at Discovery Bay, and by extension to estimate the change in NCC at Cayo Enrique over the past three decades.

There are no data specific to the past community composition at Evan's Reef. However, two nearby sites were described in previous years. Ball Buoy Reef, about $4 \mathrm{~km}$ east-southeast of Evan's Reef, shared A. palmata with Discovery Bay as a major species (Kinsey 1982; Porter and Meier 1992). Carysfort Reef, roughly 13 km south of Evan's Reef, was described in 1975 (Dustan and Halas 1987). It shared A. cervicornis, M. annularis and S. sideria with San Cristobal as principle species present (Rogers 1979; Dustan and Halas 1987; Porter and Meier 1992). Carysfort Reef also had A. palmata and Millepora complanata as important species, in common with Jamaican reefs (Rogers 1979; Kinsey 1982; Dustan and Halas 1987; Porter and Meier 1992). This evidence supports the assumption that the historical community at Evan's Reef was comparable to the communities in Puerto Rico and Jamaica. We will therefore also compare the modern NCC rates at Evan's Reef to the historical NCC rates at Discovery Bay. 
We refrain from assessing temporal changes in NCP at these geographically separated locations because there are insufficient data for detailed comparisons of autotrophic community composition between sites. However, we do note that the average NCP rates at Cayo Enrique, $3 \pm 28 \mathrm{mmol} \mathrm{C} \mathrm{m}^{-2} \mathrm{~h}^{-1}$ in August and $9 \pm 12 \mathrm{mmol} \mathrm{C}$ $\mathrm{m}^{-2} \mathrm{~h}^{-1}$ in December 2011, fall within the range estimated by Rogers (1979) at San Cristobal over the annual cycle in 1975 and 1976 by measuring the change in $\left[\mathrm{O}_{2}\right]$ along a fabricated channel:

$$
\begin{aligned}
& \text { Minimum }=0.8 \mathrm{mmol} \mathrm{C} \mathrm{m}^{-2} \mathrm{~h}^{-1} \\
& \text { Maximum }=48 \mathrm{mmol} \mathrm{C} \mathrm{m}^{-2} \mathrm{~h}^{-1} \\
& \text { Mean }=10 \mathrm{mmol} \mathrm{C} \mathrm{m}^{-2} \mathrm{~h}^{-1}
\end{aligned}
$$

\subsection{Comparison of NCC: this study versus Jamaican baseline values} Kinsey (1982) made two overall estimates of NCC at Discovery Bay Reef, Jamaica: one for the outer reef slope (dominated by A. Palmata) and one for the "perimeter zone" between the crest and the sea grass:

$16 \mathrm{mmol} \mathrm{CaCO}_{3} \mathrm{~m}^{-2} \mathrm{~h}^{-1}$ on outer reef slope;

$9.3 \mathrm{mmol} \mathrm{CaCO}_{3} \mathrm{~m}^{-2} \mathrm{~h}^{-1}$ in the perimeter zone.

These values are based on estimates for daytime NCC measured by a Lagrangian hydrochemical methodology (Kinsey 1982). Therefore, they are readily comparable to the daytime estimates determined in this study.

Based on similarity of geomorphological zones, and to further support assumption 2, we compared NCC estimates from the Cayo Enrique reef slope to Kinsey's outer reef slope value, and we compared the NCC estimates from Evan's Reef patch, surrounded by sea grass, to Kinsey's perimeter zone value (Table 3).

We use a Two-Sample t-test, assuming unequal variances, to compare the modern data to the historical averages. The daytime NCC at Cayo Enrique is $91 \%$ and $92 \%$ lower for August $(\mathrm{p}<0.001)$ and December $(\mathrm{p}<<0.001)$, respectively, than Kinsey's value from 1980. The daytime NCC at Evan's Reef is only $73 \%$ and $53 \%$ lower for February ( $\mathrm{p}=0.046)$ and August $(\mathrm{p}=0.09)$ than Kinsey's 1980 value. The latter difference is not significant. This may be due to the assumptions involved in making these comparisons, 
or it may simply indicate that Evan's Reef has experienced a smaller decline in NCC than Cayo Enrique over the past three decades.

Based on a 2-way ANOVA, there is no seasonal effect driving differences between the data sets of NCC at Cayo Enrique and Evan's Reef. However, we would need to sample each site repeatedly over a number of years to be certain about whether or not there are seasonal differences in NCC at each site. Unfortunately, Kinsey (1982) only sampled in June 1980, assuming that this was representative of the entire year. There may in fact have been a seasonal difference in NCC in 1980, but it is not possible to know for certain. Recognizing this, we have more confidence in comparing the June 1980 values to the modern August estimates than to the modern December and February estimates.

Despite uncertainties regarding the exact magnitude of decrease in NCC at our sites, the evidence suggests that there has been an extensive decline. This change in NCC is consistent with the observation that coral cover in the Caribbean reefs has declined by as much as $80 \%$ since the 1970's (Hughes 1994; Gardner et al. 2003), driven by factors including disease outbreaks, coral bleaching, hurricanes, over-fishing, eutrophication, and local anthropogenic impacts (Vicente 1993; Wheaton et al. 2003; Pittman et al. 2010). 4.3 Decline and dissolution: a comparison with findings of Perry et al. (2013) These results that NCC decreased by 53\% and 73\% at Evan's Reef and up to $91 \%$ and 92\% at Cayo Enrique agree with the findings of Perry et al. (2013) - namely that reef growth has declined in concert with declining live coral cover and associated changes in benthic community composition in the Caribbean Region. In their 2010-2012 Caribbeanwide study (19 sites), Perry (2013) found that net carbonate production rates (CPR) were reduced by more than $50 \%$ compared to historical levels, in accord with our estimates.

Perry (2013) also found many reefs were deteriorating rather than accumulating. They found that $37 \%$ of sites were net erosional on an annual basis. Similarly, we found that both of our sites are likely undergoing net dissolution on diurnal timescales in both summer and winter (Table 3). Assuming that the two sampling seasons capture the full range of seasonal variability in NCC, this would translate to net dissolution on an annual timescale (Table 3). 
These findings are consistent with the finding that Caribbean reefs are more prone to bioerosion than reefs elsewhere (Highsmith 1980). Dissolution in the reef matrix and sands may occur when the ambient seawater $\Omega_{\mathrm{a}}$ exceed 1 , due to high $\mathrm{pCO}_{2}$ in the microenvironments from microbial respirations (Walter et al. 1993; Ku et al. 1999; Andersson and Mackenzie 2011). Additionally, dissolution of high-Mg calcite, which is produced by coralline algae can occur at $\Omega_{\mathrm{a}}$ as high as 3.7 (Yamamoto et al. 2011). Dissolution in Cayo Enrique could be happening inside the cavities generated by boring organism (Tribollet and Golubic 2011). These 'bore holes' pepper the carbonate substrate. Dissolution could also be driven by euendoliths, organisms such as microbes, fungi, and algae, that penetrate the carbonate substrate (Radtke et al. 1997; Tribollet and Golubic 2011). Dissolution in Evan's Reef could be happening in the sand and in cavities in the conglomerate matrix and could be driven by respiration by the sea grass roots or burrowing animals (Burdige and Zimmerman 2002; Tribollet and Golubic 2011). Loss by dissolution could be exacerbated by mechanical and physical erosion. Such net loss is detrimental to the maintenance of the reef framework and inhibits reefs from keeping pace with sea level rise. 


\section{Acknowledgements}

We appreciate the hospitality of the University of Puerto Rico at Mayagüez and the Univeristy of Miami at Broad Key. Many thanks to Carolina Mor for her assistance in analyzing samples in the laboratory of Dr. Chris Langdon at RSMAS. We greatly appreciate the assistance of many people in the field, including Chip Young, Ryan Moyer, Melissa Meléndez Oyola, Evan D'Alessandro, Jeff Demott, Jorge Corredor and the students at University of Puerto Rico at Mayagüez. This research was supported by WHOI Ocean Ventures Fund, WHOI Coastal Ocean Institute, MIT Houghton Fund, and MIT Student Research Fund grants to W. Bernstein; NSF OCE0628406 and NOAA's Coral Reef Conservation Program Atlantic Ocean Acidification Test Bed project funding to C. Langdon; and OCE1031288 and WHOI Access to the Sea program funding to K.A.Hughen.

\section{References}

(NCDC) NCDC (2013) Quality controlled local climatological data, hourly observations table, Miami International Airport (12839). National Oceanic and Atmospheric Administration

Andersson A, Mackenzie F (2011) Ocean acidification: setting the record straight. Biogeosciences Discussions 8:6161-6190

Andersson AJ, Gledhill D (2013) Ocean Acidification and Coral Reefs: Effects on Breakdown, Dissolution, and Net Ecosystem Calcification. Annual Review of Marine Science 5:321-348

Apprill A, Rappe MS (2011) Response of the microbial community to coral spawning in lagoon and reef flat environments of Hawaii, USA. Aquatic Microbial Ecology 62:251-266

Armstrong RA (1981) Changes in a Puerto Rican coral reef from 1936-1979 using aerial photoanalysis. Proceedings 4th International Coral Reef Symposium 1:309-315

Atkinson M, Falter J (2003) Coral Reefs. In: Black KaS, G. (ed) Biogeochemistry of marine systems. CRC Press, Boca Raton, Florida,

Baird AH, Marshall PA (2002) Mortality, growth and reproduction in scleractinian corals following bleaching on the Great Barrier Reef. Marine Ecology Progress Series 237:133-141

Burdige DJ, Zimmerman RC (2002) Impact of sea grass density on carbonate dissolution in Bahamian sediments. Limnology and Oceanography 47:1751-1763

Clausen CD, Roth AA (1975) Effect of Temperaturea and Temperature Adaptation on Calcification Rate in Hermatypic Coral PocilloporaDamicornis. Marine Biology 33:93-100

Coles SL, Jokiel PL (1978) Synergistic Effects Of Temperature, Salinity, and Light On Hermatypic Coral Montipora-Verrucosa. Marine Biology 49:187-195

Dickson AG, Millero FJ (1987) A comparison of the equilibrium-constants for the dissociation of carbonic-acid in seawatr media. Deep-Sea Research Part aOceanographic Research Papers 34:1733-1743 
Dickson AG, Afghan JD, Anderson GC (2003) Reference materials for oceanic CO2 analysis: a method for the certification of total alkalinity. Marine Chemistry 80:185-197

Dickson AG, Sabine CL, Christian JR (eds) (2007) Guide to Best Practices for Ocean CO2 Measurements. PICES Special Publication

Dustan P, Halas JC (1987) Changes in the reef-coral community of Carysfort reef, KeyLargo, Florida - 1974 to 1982 Coral Reefs 6:91-106

Erez J, Reynaud S, Silverman J, Schneider K, Allemand D (2011) Coral Calcification Under Ocean Acidification and Global Change

Falter JL, Atkinson MJ, Langdon C (2001) Production-respiration relationships at different timescales within the Biosphere 2 coral reef biome. Limnology and Oceanography 46:1653-1660

Falter JL, Lowe RJ, Atkinson MJ, Cuet P (2012) Seasonal coupling and de-coupling of net calcification rates from coral reef metabolism and carbonate chemistry at Ningaloo Reef, Western Australia. Journal of Geophysical Research-Oceans 117

Falter JL, Lowe RJ, Zhang Z, McCulloch M (2013) Physical and biological controls on the carbonate chemistry of coral reef waters: effects of metabolism, wave forcing, sea level, and geomorphology. Plos One 8:e53303

Falter JL, Lowe RJ, Atkinson MJ, Monismith SG, Schar DW (2008) Continuous measurements of net production over a shallow reef community using a modified Eulerian approach. Journal of Geophysical Research-Oceans 113

Frankignoulle M, Gattuso JP, Biondo R, Bourge I, CopinMontegut G, Pichon M (1996) Carbon fluxes in coral reefs .2. Eulerian study of inorganic carbon dynamics and measurement of air-sea CO2 exchanges. Marine Ecology-Progress Series 145:123-132

Gardner TA, Cote IM, Gill JA, Grant A, Watkinson AR (2003) Long-term region-wide declines in Caribbean corals. Science 301:958-960

Gattuso J-P, Frankignoulle M, Wollast R (1998a) Carbon and carbonate metabolism in coastal aquatic ecosystems. Annual Review of Ecology and Systematics:405-434

Gattuso JP, Frankignoulle M, Wollast R (1998b) Carbon and carbonate metabolism in coastal aquatic ecosystems. Annual Review of Ecology and Systematics 29:405434

Goenaga C, Cintron G (1979) Inventory of the Puerto Rican coral reefs Inventory of the Puerto Rican coral reefs. Office of Coastal Zone Management NOAA, Commonwealth of Puerto Rico 193 pp

Gray SEC, DeGrandpre MD, Langdon C, Corredor JE (2012) Short-term and seasonal $\mathrm{pH}, \mathrm{pCO}(2)$ and saturation state variability in a coral-reef ecosystem. Global Biogeochemical Cycles 26

Highsmith RC (1980) GEOGRAPHIC PATTERNS OF CORAL BIOEROSION - A PRODUCTIVITY HYPOTHESIS. Journal of Experimental Marine Biology and Ecology 46:177-196

Hughes TP (1994) Catastrophies, phoase-shifts, and large-scale degradation of a Caribbean coral-reef. Science 265:1547-1551

Hutchings P, Kiene WE (1986) BIOEROSION OF CORAL REEFS. Oceanus 29:71-71 
Jokiel PL, Coles SL (1977) Effects Of Temperature on Mortality and growth of Hawaiian Reef Corals. Marine Biology 43:201-208

Jokiel PL, Rodgers KS, Kuffner IB, Andersson AJ, Cox EF, Mackenzie FT (2008) Ocean acidification and calcifying reef organisms: a mesocosm investigation. Coral Reefs 27:473-483

Kinsey DW (1982) The Pacific/Atlantic reef growth controversy. Proceedings 4th International Coral Reef Symposium 1:493-498

Kinsey DW (1985) Metabolism, Calcification and Carbon Production. Proceedings 5th International Coral Reef Symposium 4:505-526

Kleypas, Langdon (2006) Coral Reefs and Changing Seawater Carbonate Chemistry. In: Phinney J, Hoegh-Guldberg O, Kleypas J, Skirving W, Strong A (eds) Coral Reefs and Climate Change: Science and Management. American Geophysical Union, pp73-110

Kleypas, Feely, Fabry, Langdon, Sabine, Robbins (2006) Impacts of ocean acidification on coral reefs and other marine calcifiers: a guide for future research

Ku T, Walter L, Coleman M, Blake R, Martini A (1999) Coupling between sulfur recycling and syndepositional carbonate dissolution: evidence from oxygen and sulfur isotope composition of pore water sulfate, South Florida Platform, USA. Geochimica et Cosmochimica Acta 63:2529-2546

Kuffner IB, Andersson AJ, Jokiel PL, Rodgers KS, Mackenzie FT (2008) Decreased abundance of crustose coralline algae due to ocean acidification. Nature Geoscience 1:114-117

Langdon, Gattuso, Andersson (2010) Measurements of calcifi cation and dissolution of benthic organisms and communities. Guide to best practices for ocean acidifi cation research and data reporting Chapter 13:213-232

Langdon C, Atkinson MJ (2005) Effect of elevated pCO(2) on photosynthesis and calcification of corals and interactions with seasonal change in temperature/irradiance and nutrient enrichment. Journal of Geophysical ResearchOceans 110:1-16

Langdon C, Takahashi T, Sweeney C, Chipman D, Goddard J, Marubini F, Aceves H, Barnett H, Atkinson MJ (2000) Effect of calcium carbonate saturation state on the calcification rate of an experimental coral reef. Global Biogeochemical Cycles 14:639-654

Langdon C, Broecker WS, Hammond DE, Glenn E, Fitzsimmons K, Nelson SG, Peng TH, Hajdas I, Bonani G (2003) Effect of elevated CO2 on the community metabolism of an experimental coral reef. Global Biogeochemical Cycles 17

Littler MM, Littler DS (1984) Models of tropical reef biogenesis: the contribution of algae. Progress in phycological research 3:323-364

Lough JM, Barnes DJ (2000) Environmental controls on growth of the massive coral Porites. Journal of Experimental Marine Biology and Ecology 245:225-243

Mallela J, Perry CT (2007) Calcium carbonate budgets for two coral reefs affected by different terrestrial runoff regimes, Rio Bueno, Jamaica. Coral Reefs 26:129-145

Martin S, Gattuso JP (2009) Response of Mediterranean coralline algae to ocean acidification and elevated temperature. Global Change Biology 15:2089-2100 
Marubini F, Atkinson M (1999) Effects of lowered pH and elevated nitrate on coral calcification. Marine Ecology-Progress Series 188:117-121

Marubini F, Barnett H, Langdon C, Atkinson MJ (2001) Dependence of calcification on light and carbonate ion concentration for the hermatypic coral Porites compressa. Marine Ecology Progress Series 220:153-162

McGillis WR, Langdon C, Loose B, Yates K, Corredor J (2011) Productivity of a coral reef using boundary layer and enclosure methods. Geophysical Research Letters 38

Mehrbach C, Culberso.Ch, Hawley JE, R.M. P (1973) Measurement of apparent dissociation-constants of carbonic-acid in seawater at atmospheric-pressure. Limnology and Oceanography 18:897-907

Mendes JM, Woodley JD (2002) Effect of the 1995-1996 bleaching event on polyp tissue depth, growth, reproduction and skeletal band formation in Montastraea annularis. Marine Ecology Progress Series 235:93-102

Mucci A (1983) The solubility of calcite and aragonite in seawater at various salinities, temperatures, and one atmosphere total pressure. American Journal of Science 283:780-799

Mumby PJ, Dahlgren CP, Harborne AR, Kappel CV, Micheli F, Brumbaugh DR, Holmes KE, Mendes JM, Broad K, Sanchirico JN, Buch K, Box S, Stoffle RW, Gill AB (2006) Fishing, trophic cascades, and the process of grazing on coral reefs. Science 311:98-101

Odum HT (1956) Primary production in flowing waters. Limnology and Oceanography $1: 102-117$

Odum HT, Burkholder PR, Rivero J (1959) Measurements of Productivity of Turtle Grass Flats, Reefs, and the Bahia Fosforescente of Southern Puerto Rico.

Publication of the Institute of Marine Science 6:159-171

Perry CT, Edinger EN, Kench PS, Murphy GN, Smithers SG, Steneck RS, Mumby PJ (2012) Estimating rates of biologically driven coral reef framework production and erosion: a new census-based carbonate budget methodology and applications to the reefs of Bonaire. Coral Reefs 31:853-868

Perry CT, Murphy GN, Kench PS, Smithers SG, Edinger EN, Steneck RS, Mumby PJ (2013) Caribbean-wide decline in carbonate production threatens coral reef growth. Nature Communications 4

Pierrot DEL, and D. W. R. Wallace. (2006) MS Excel Program Developed for CO2 System Calculations. ORNL/CDIAC-105a

Pittman SJ, Hile SD, C.F.G. Jeffrey, R. Clark, K. Woody, B.D. Herlach, C. Caldow, M.E. Monaco, Appeldoorn. R (2010) Coral reef ecosystems of Reserva Natural La Parguera (Puerto Rico): Spatial and temporal patterns in fish

and benthic communities (2001-2007) Technical Memorandum NOAA, Silver Spring 202pp

Porter JW, Meier OW (1992) Quantification of loss and change in Floridian reef coral populations. American Zoologist 32:625-640 
Radtke G, Hofmann K, Golubic S (1997) A bibliographic overview of micro-and macroscopic bioerosion. Courier Forschungsinstitut Senckenberg 201:307-340

Rogers CS (1979) Productivity of San-Cristobal Reef, Puerto Rico. Limnology and Oceanography 24:342-349

Rogers CS, Beets J (2001) Degradation of marine ecosystems and decline of fishery resources in marine protected areas in the US Virgin Islands. Environmental Conservation 28:312-322

Silverman J, Kline D, Johnson L, Rivlin T, Schneider K, Erez J, Lazar B, Caldeira K (2012) Carbon turnover rates in the One Tree Island reef: A 40-year perspective. Journal of Geophysical Research: Biogeosciences (2005-2012) 117

Smith JE, Smith CM, Hunter CL (2001) An experimental analysis of the effects of herbivory and nutrient enrichment on benthic community dynamics on a Hawaiian reef. Coral Reefs 19:332-342

Smith SV (1973) CARBON-DIOXIDE DYNAMICS - RECORD OF ORGANIC CARBON PRODUCTION, RESPIRATION AND CALCIFICATION IN ENIWEROK REEF FLAT COMMUNITY. Limnology and Oceanography 18:106-120

Smith SV, Marsh J (1973) Organic carbon production on the windward reef flat of Eniwetok Atoll. Limnol Oceanogr 18:953-961

Sweeney C, Gloor E, Jacobson AR, Key RM, McKinley G, Sarmiento JL, Wanninkhof R (2007) Constraining global air-sea gas exchange for CO2 with recent bomb C-14 measurements. Global Biogeochemical Cycles 21

Tribollet A, Golubic S (2011) Reef Bioerosion: Agents and Processes

Vecsei A (2001) Fore-reef carbonate production: development of a regional census-based method and first estimates. Palaeogeography Palaeoclimatology Palaeoecology 175:185-200

Vicente VP (1993) Structural changes and vulnerability of a coral reef (Cayo Enrique) in La Parguera, Puerto Rico. Global aspects of coral reefs C39-C44

Walter LM, Bischof SA, Patterson WP, Lyons TW, O'Nions R, Gruszczynski M, Sellwood B, Coleman M (1993) Dissolution and recrystallization in modern shelf carbonates: evidence from pore water and solid phase chemistry [and discussion]. Philosophical Transactions of the Royal Society of London Series A: Physical and Engineering Sciences 344:27-36

Wanninkhof R (1992) Relationship between wind-speed and gas-exchange over the ocean. Journal of Geophysical Research-Oceans 97:7373-7382

Wheaton J, Jaap WC, Hackett K, Lybolt M, Callahan MK, Kidney J, Kupfner S, Porter JW, Kosmynin V, Tsokos C, Yanev G (2003) U.S. EPA/FKNMS coral reef monitoring project. In: Keller BD (ed) Sanctuary Science Report 2001: an ecosystem report card. NOAA Florida Keys National Marine Sanctuary, USEPA, State of Florida $111 \mathrm{pp}$

Yamamoto S, Kayanne H, Terai M, Watanabe A, Kato K, Negishi A, Nozaki K (2011) Threshold of carbonate saturation state determined by a CO 2 control experiment. Biogeosciences Discussions 8:8619-8644 


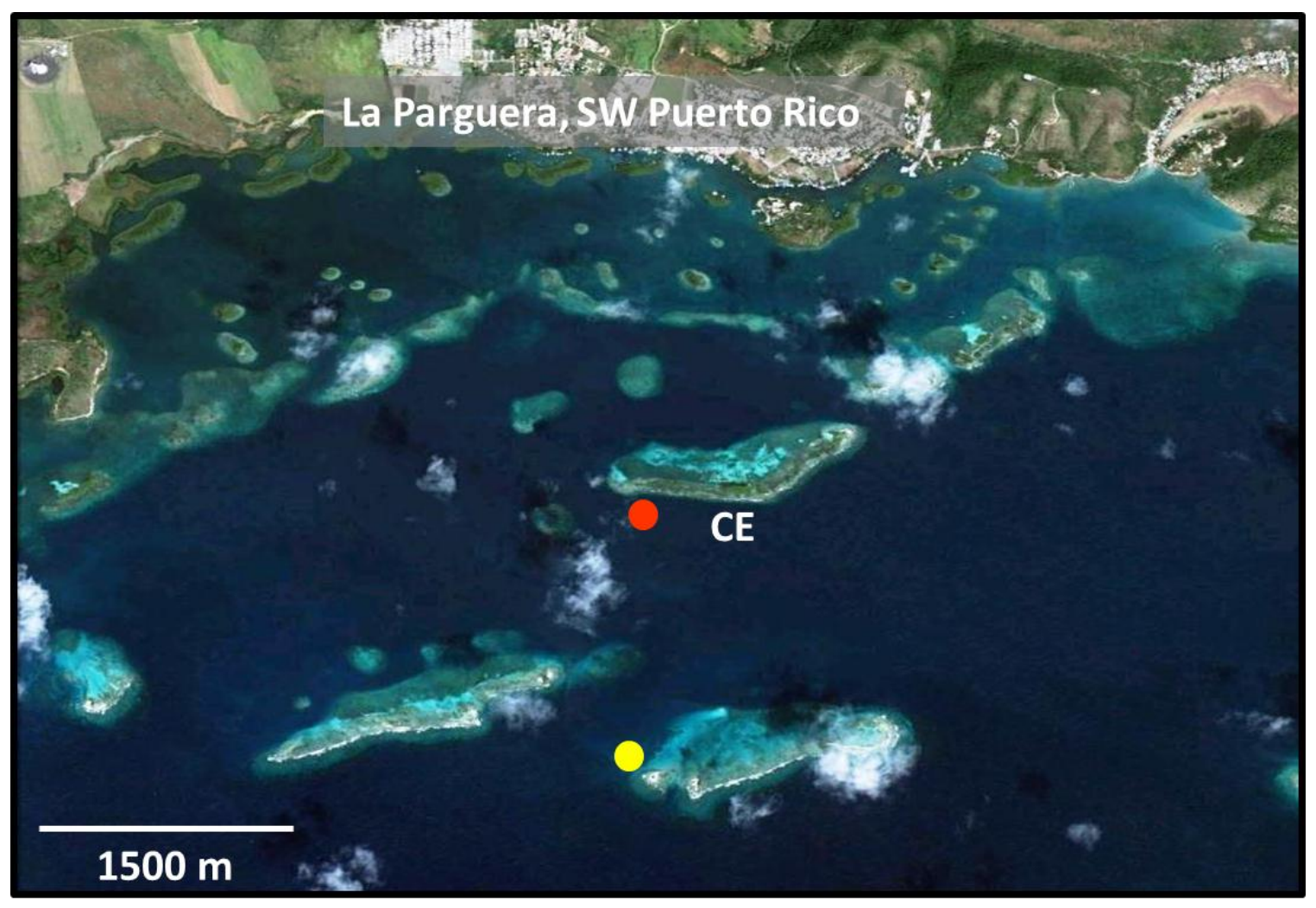

Figure 1 Satellite image of field site in Puerto Rico. Cayo Enrique (CE) is $1.5 \mathrm{~km}$ south of La Parguera on the southwest coast of Puerto Rico. The bay in which Cayo Enrique resides is the location of the Atlantic Ocean Acidification test-bed (AOAT), where moorings have been deployed and numerous methods have been employed to estimate NCC and NCP within a 5 year timespan. The location of the MAPCO2 buoy is marked with a red dot and the location of the ICON mooring is marked with a yellow dot. 


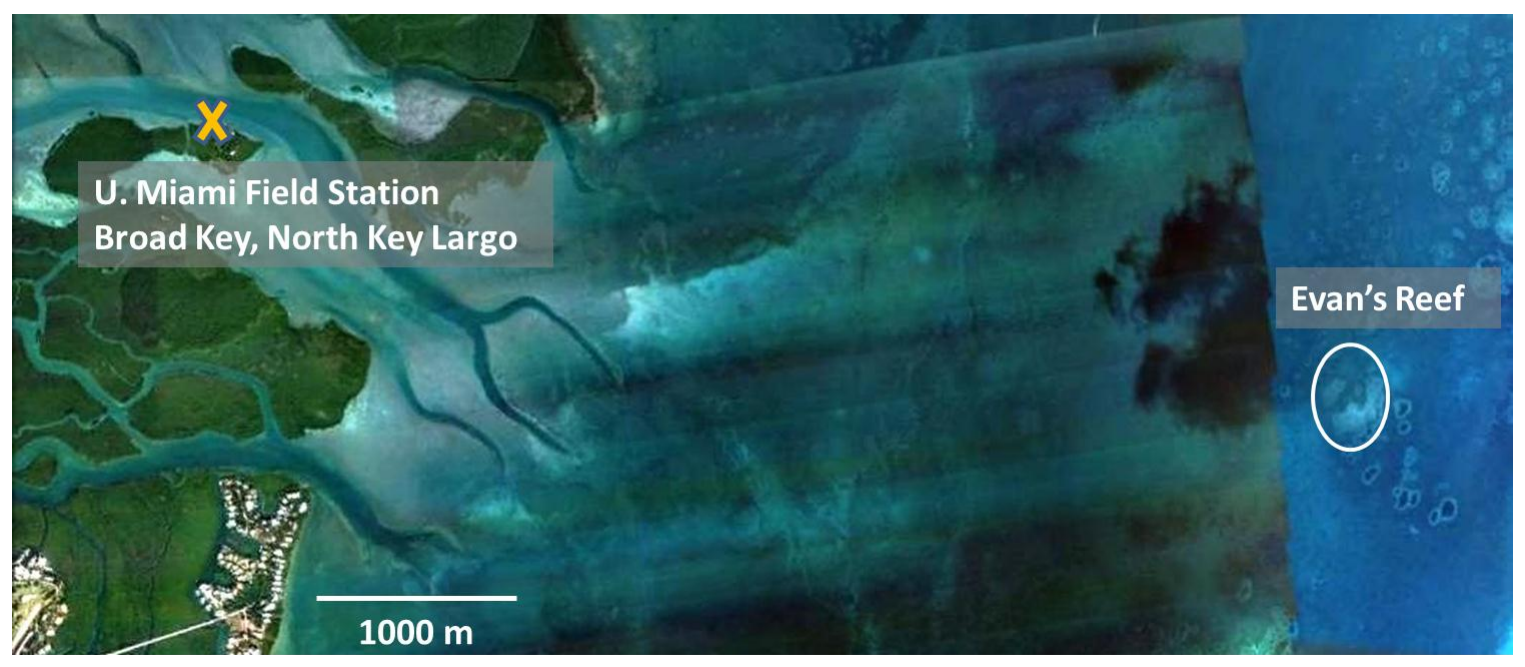

Figure 2 Satellite image of field site at Broad Key. Evan's reef is a patch reef $7 \mathrm{~km}$ east of the University of Miami Field Station on Broad Key, North Key Largo. In this chapter we refer to the site as Broad Key. 


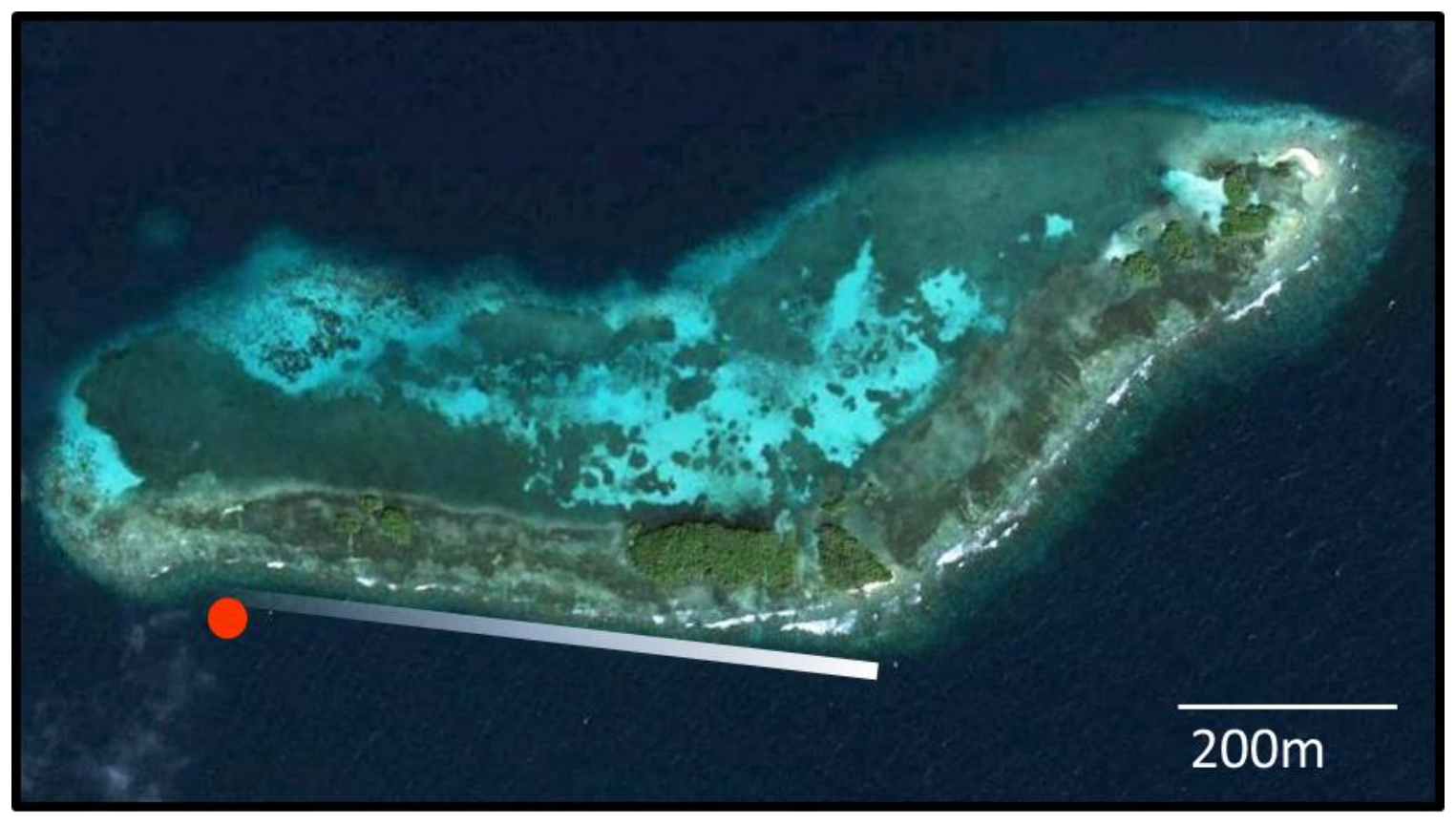

Figure 3 Satellite image of Cayo Enrique. We sampled along the reef slope of Cayo Enrique at about $4 \mathrm{~m}$ depth. The white band marks the sampling region, with the brightest white portion indicating where most transect paths passed, fading into the darker portion where fewer transect paths extended. The location of the MAPCO2 buoy is marked with a red dot.

Most transects began where the band is bright white and moved westward. Two transects began in the middle of this white band and moved eastward. The transect paths varied in length from about $10 \mathrm{~m}$ on two occasions when the water was very still to $350 \mathrm{~m}$ on two occasions when we followed the drifter all the way to the end of the white band. The average length was about $180 \mathrm{~m}$ and the durations of the transects were 1.25 to 2 hours. 


\section{Enrique Benthic Cover \\ Eastern end of Lagrangian Transect Swath}

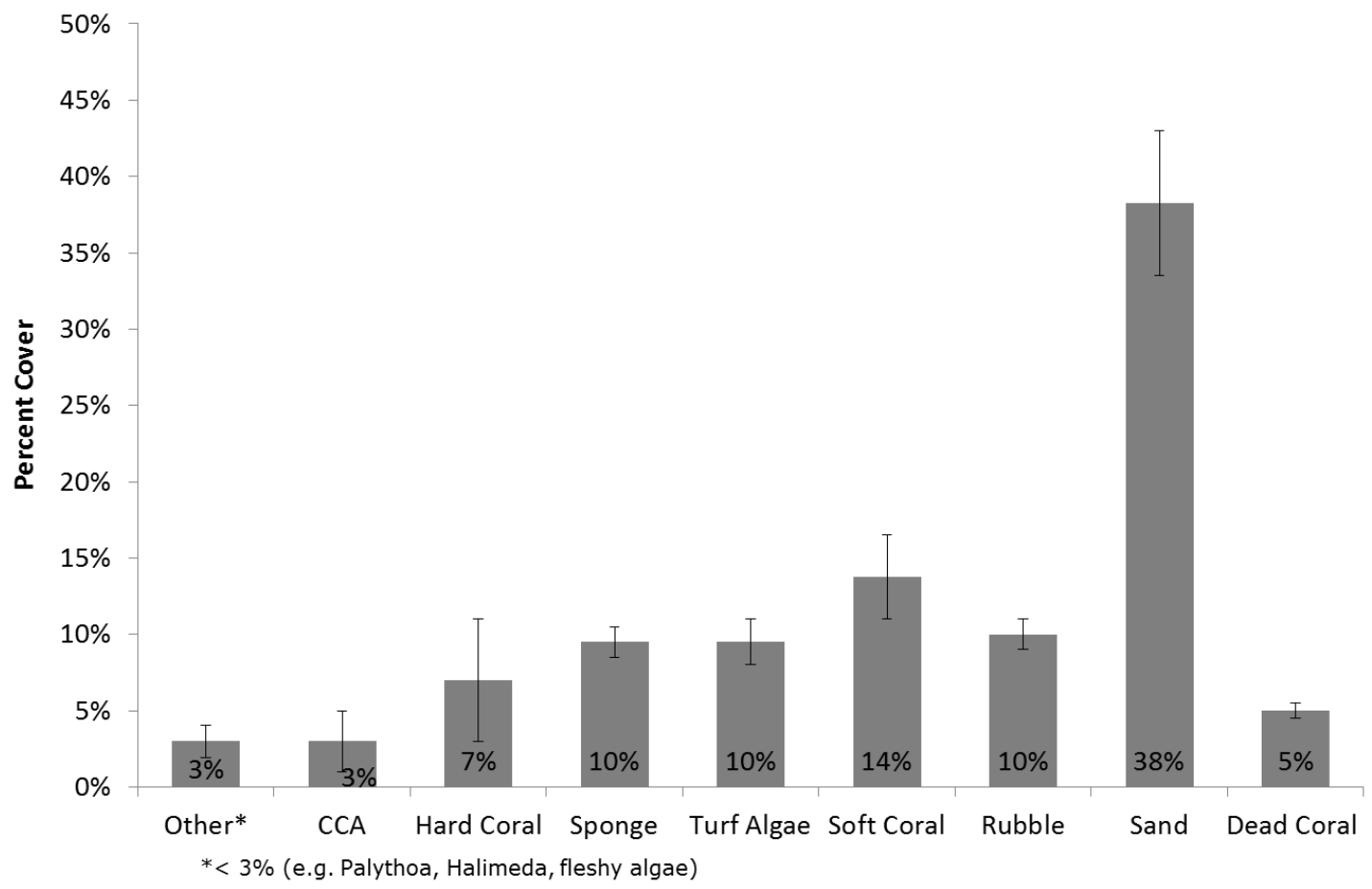

Figure 4 Benthic survey data based on four $10 \mathrm{~m}$ point-intercept transects conducted in March 2009 midway along the length of Cayo Enrique, 4-5m deep. "CCA" is crustose coralline algae. "Soft coral" includes gorgonians and sea pens. Data Collected by Rebecca Albright and Remy Okazaki, courtesy of Chris Langdon. 


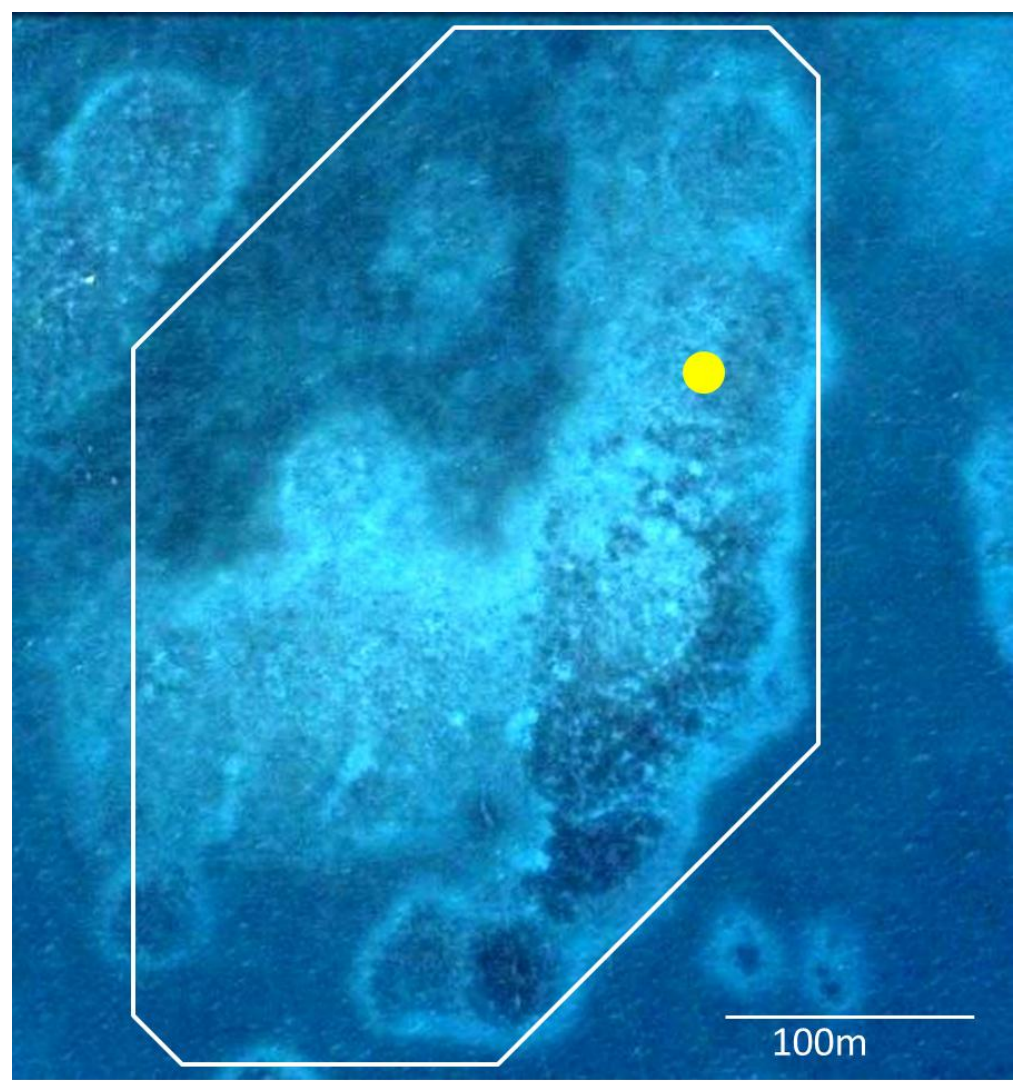

Figure 5 Satellite image of Evan's Reef, a patch reef surrounded by seagrass beds. The transect paths crossed the reef within the region marked by the white polygon. The yellow dot indicates where the stationary YSI in February and the PAR sensor in both seasons were located.

The main axis of the reef, where the densest coral cover occurs is visible as the darker speckled region running from south to north. The lighter region to the west is a mix of sea grass, sand, hard coral and soft coral. The darker portion to the northwest is mostly sea grass with scattered hard corals. A mixed zone of sea grass and coral comprises the transition from the highest density coral zone to the sea grass bed and is visible as a light band circumscribing the reef. 


\section{Evan's Reef Benthic Cover}

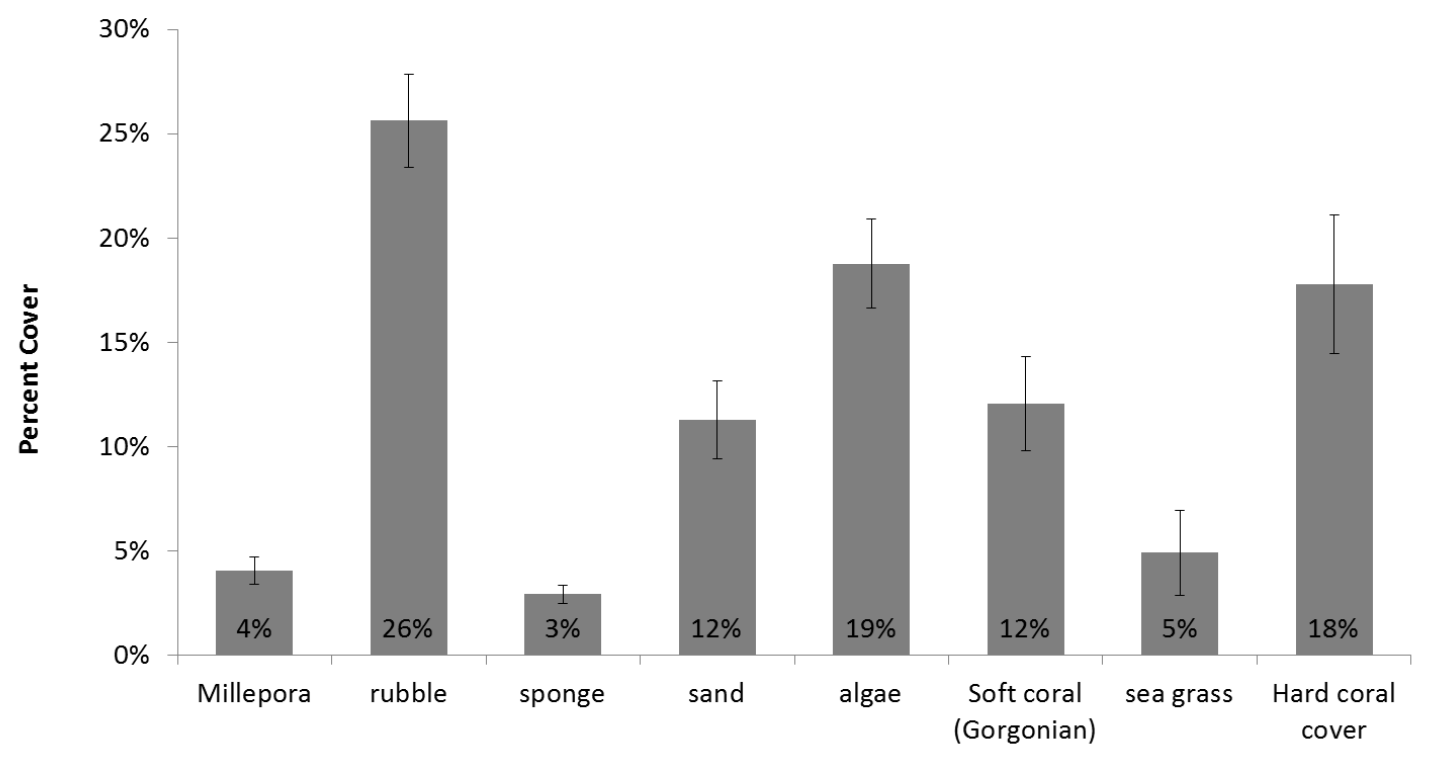

Figure 6 Benthic data based on 14 line-intercept transects conducted in June 2011, courtesy of Chris Langdon. The hard corals are $S$. siderea (45\%), P. astreoides (11\%), Acropora cervicornis (7\%). 


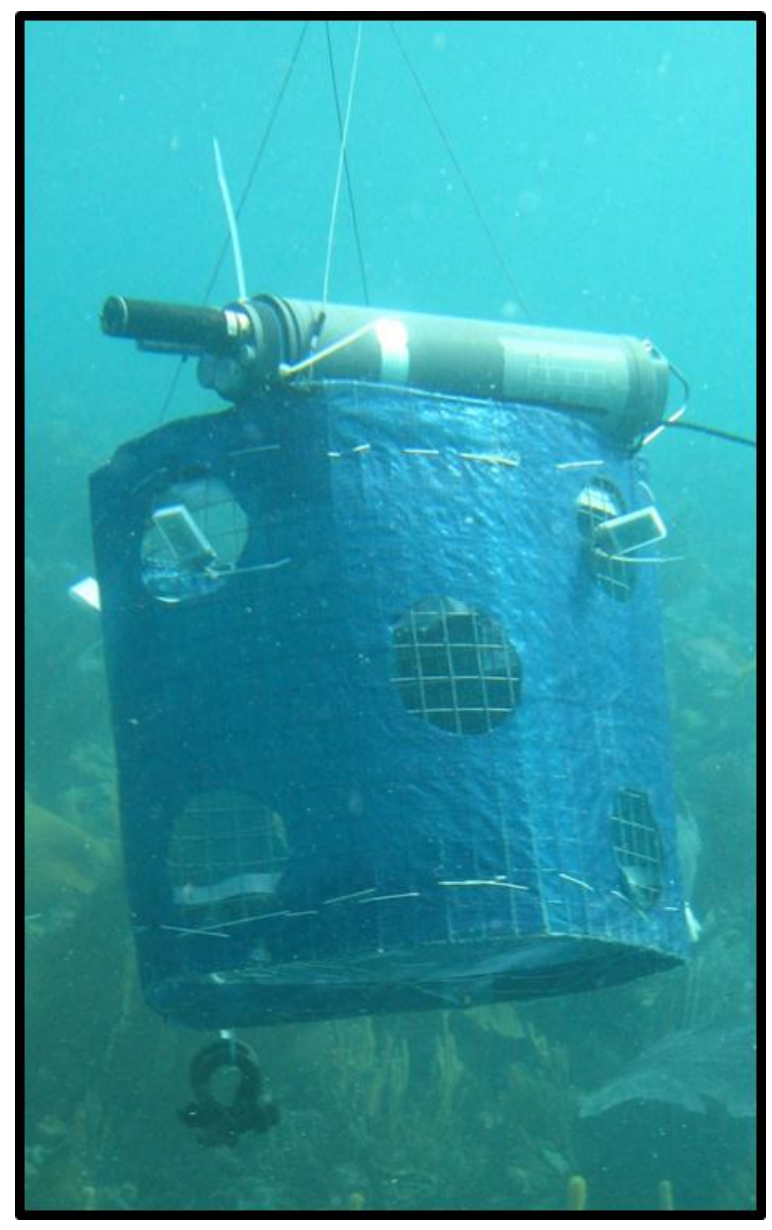

Figure 7 Photograph of the Lagrangian drifter used to track the water mass moving across the reef. It was constructed from chicken mesh, hula hoop, tarp, sail thread, shackles, rope and wire and was weighted with two large shackles. The drifter body was about 1 meter in height and $1 \mathrm{~m}$ in diameter and was suspended from an $8 \mathrm{~cm}$ diameter buoy. A YSI instrument package was attached to the top of the drifter to monitor temperature, salinity, $\mathrm{pH}$ and dissolved oxygen concentration of the water mass as it drifted across the reef. Hobo temperature loggers were also attached to the body of the drifter. 

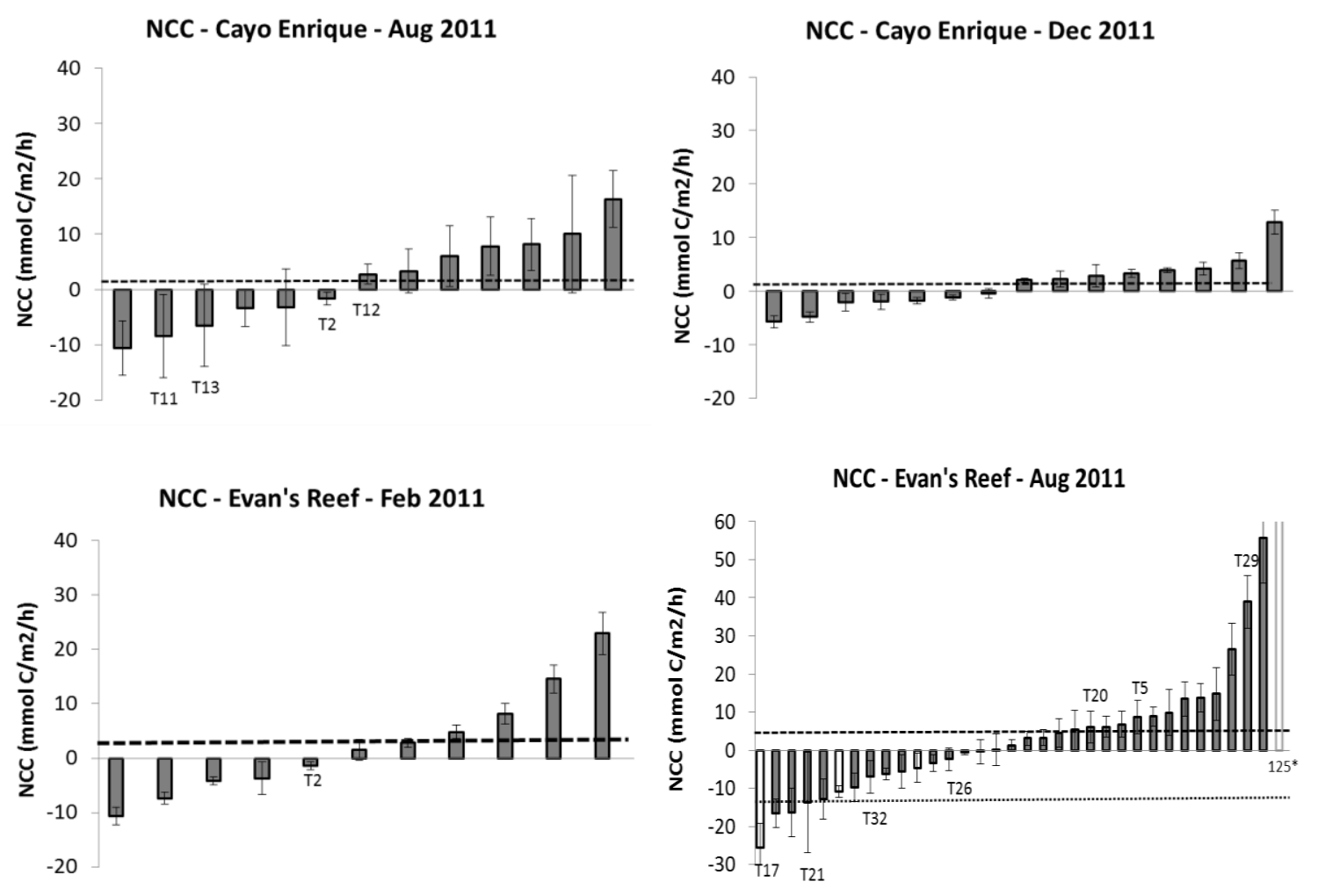

Figure 8 Rank-ordered hourly NCC rates $\left(\mathrm{mmol} \mathrm{C} \mathrm{m}^{-2} \mathrm{~h}^{-1}\right)$ for each field season at each site. Nighttime values measured at Evan's Reef in August 2011 are open bars. Error bars are based on analytical standard error propagated through each calculation. The average daytime rate is marked with a dashed line. The average nighttime rate is marked with a dotted line. The Transects for which there is possible mixing or slippage are labeled. These are discussed in Appendix 2. These results are also presented in transect order and labeled with time of day in order to facilitate inter-comparison (Figure S8).

Note the different range on the vertical axis for Evan's Reef in August 2011. This was to accommodate the larger range in NCC values.

*There is one outlier of $125 \mathrm{mmol} \mathrm{C} \mathrm{m}^{-2} \mathrm{~h}^{-1}$ that was measured at night (open bar). This was excluded from calculations because it is highly unreasonable that the largest NCC rate in the entire dataset would occur at night when it is well understood that NCC is lower at night than during the day This sample may have been compromised due to the added difficulty of sampling at night compounded by the fact that the niskin broke when collecting this sample, so it was the first sample collected by hand without a niskin. The corresponding NCP value is not excluded because it was estimated using the $\mathrm{YSI}_{2}$ data rather than discreet samples. 

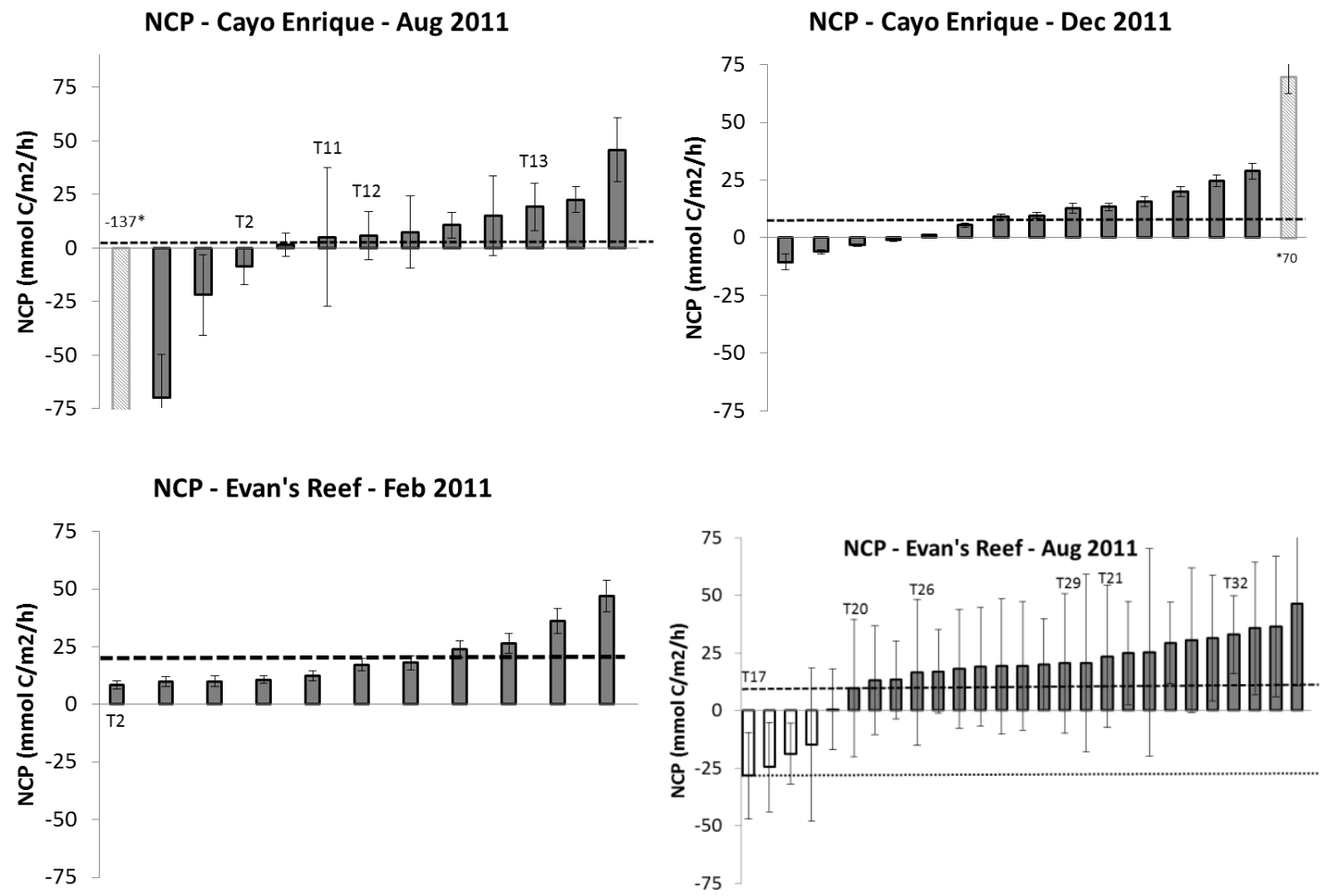

Figure 9 Rank-ordered hourly NCP rates $\left(\mathrm{mmol} \mathrm{C} \mathrm{m}^{-2} \mathrm{~h}^{-1}\right)$ for each field season at each site. Nighttime values measured at Evan's Reef in August 2011 are open bars. Error bars are based on analytical standard error propagated through each calculation. The average daytime rate is marked with a dashed line. The average nighttime rate is marked with a dotted line. The Transects for which there is possible mixing or slippage are labeled. These are discussed in Appendix 2. These results are also presented in transect order and labeled with time of day in order to facilitate inter-comparison (Figure S9).

The average of daytime NCP rates at each site in each season is statistically different from zero in all cases except at Cayo Enrique in August (p-values are 0.8, 0.02, 0.0003, 0.005 for Cayo Enrique August and December and Evan's Reef February and August, respectively).

*There are two outliers: -137 for which we neglected to poison the DIC samples and 70 for which we did not add sufficient reagent in the first $\mathrm{O}_{2}$ sample of the transect. These were excluded from calculations. 


\begin{tabular}{|c|c|c|c|c|c|}
\hline 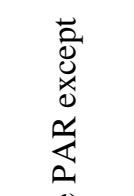 & 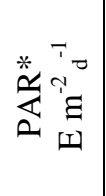 & $\begin{array}{l}\underset{f}{I} \\
\Xi \\
a \\
+1 \\
\nexists \\
\forall\end{array}$ & 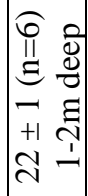 & 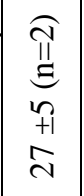 & $\begin{array}{l}\text { In } \\
\stackrel{I}{\Xi} \\
\forall \\
+1 \\
0 \\
0\end{array}$ \\
\hline $\bar{\Xi}$ & $\stackrel{\Xi}{\Xi}$ & & $\mid \begin{array}{ll}1 & 0 \\
0 & 0 \\
0 & 0 \\
0\end{array}$ & $\left|\begin{array}{ll}n & 0 \\
0 & 0 \\
0 & 0 \\
+1\end{array}\right|$ & $\begin{array}{ll}n & 0 \\
0 & 0 \\
0 & 0 \\
0 & +1\end{array}$ \\
\hline 䔍 & $\underset{\delta}{\Sigma} \sum_{z}$ & & $\begin{array}{ll}n & ? \\
0 & 0 \\
0 & +1\end{array}$ & $\left|\begin{array}{cc}n & \infty \\
\hdashline & 0 \\
0 & 0 \\
0 & 0+1\end{array}\right|$ & $\stackrel{ \pm}{ \pm}$ \\
\hline$\cong$ & $\underset{\underline{Z}}{\mathbb{Z}} \sum_{\Xi}$ & & $\mid \begin{array}{ll}\Delta & 0 \\
0 & 0\end{array}$ & 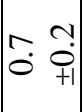 & 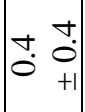 \\
\hline$\dot{0}$ & 的泀 & 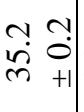 & $\begin{array}{ll}0 & 0 \\
0 & 0 \\
\dot{0} & +1\end{array} \mid$ & $\left|\begin{array}{cc}8 & 0 \\
0 & 0 \\
\dot{0} & 0 \\
n & +1\end{array}\right|$ & 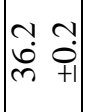 \\
\hline$\Xi$ & $-\begin{array}{c}U \\
0 \\
0 \\
0\end{array}$ & $\begin{array}{ll}0 & + \\
\grave{2} & \vdots \\
\grave{2} & +1\end{array}$ & $\mid$\begin{tabular}{ll}
$\sim$ & $\sim$ \\
\hdashline & 0 \\
\hdashline & +1
\end{tabular} & $\begin{array}{ll}n & \cdots \\
& 0 \\
& +1\end{array}$ & \begin{tabular}{ll}
$n$ & $?$ \\
0 & 0 \\
\hdashline & +1
\end{tabular} \\
\hline$\widetilde{\widetilde{J}}$ & $\bigcup_{\mathscr{2}}^{\top} \Xi$ & $\left|\begin{array}{ll}0 & 0 \\
\multirow{\gamma}{*}{} & +1\end{array}\right|$ & 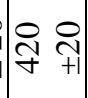 & 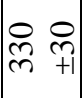 & 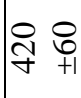 \\
\hline$\pi$ & $\stackrel{\pi}{2}$ & $\begin{array}{cc}c & 1 \\
0 & 0 \\
\infty & 0 \\
\infty & +1\end{array} \mid$ & $\left|\begin{array}{cc}1 & 0 \\
0 & \vdots \\
\infty & +1 \\
0 & +1\end{array}\right|$ & \begin{tabular}{cc}
$\simeq$ & 0 \\
\hdashline & 0 \\
$\infty$ & 0 \\
$\infty+1$
\end{tabular} & $\begin{array}{cc}0 & 0 \\
0 & 0 \\
\infty & 0 \\
\infty & +1\end{array}$ \\
\hline & G & 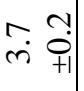 & $\mid \begin{array}{ll}0 & 0 \\
& \mathbf{+ 1}\end{array}$ & $\left|\begin{array}{ll}0 & N \\
\dot{f} & \vdots \\
+1\end{array}\right|$ & $\begin{array}{ll}0 & 0 \\
& \dot{+1}\end{array}$ \\
\hline$\stackrel{\overrightarrow{0}}{\dot{z}}$ & 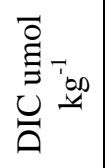 & $\begin{array}{l}= \\
+1 \\
\stackrel{1}{\$} \\
a\end{array}$ & $\begin{array}{l}n \\
n \\
+1 \\
0 \\
\vdots \\
a\end{array}$ & 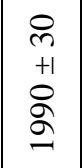 & $\begin{array}{l}m \\
+1 \\
8 \\
8 \\
8\end{array}$ \\
\hline 䍘 & 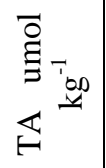 & $\begin{array}{l}0 \\
+1 \\
\stackrel{1}{2} \\
\text { ปे }\end{array}$ & $\begin{array}{l}m \\
+1 \\
+1 \\
0 \\
\\
\text { ה }\end{array}$ & $\begin{array}{l}a \\
+1 \\
\tilde{n} \\
\tilde{v}\end{array}$ & $\begin{array}{l}= \\
+1 \\
0 \\
0 \\
0 \\
0\end{array}$ \\
\hline & $=$ & $\stackrel{\sim}{\sim}$ & i & ป & $\infty$ \\
\hline 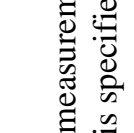 & & 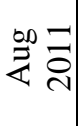 & $\begin{array}{l}\dot{\nu} \\
0\end{array}$ & $\mid \begin{array}{ll}0 & 1 \\
0 & 0 \\
1 & 0\end{array}$ & 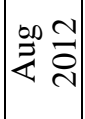 \\
\hline 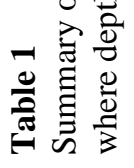 & & 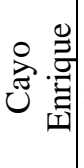 & ¿ & 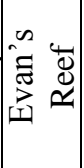 & 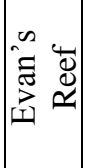 \\
\hline
\end{tabular}


Table 2

The precision of TA and DIC measurements. The number (n) of paired measurements used for determining precision in TA and DIC is also listed. The instrument used to measure each quantity is specified.

\begin{tabular}{lllccc}
\hline Site & Season & Instruments & $\begin{array}{c}\text { TA } \\
\text { umol/kg }\end{array}$ & $\mathrm{n}$ & $\begin{array}{c}\text { DIC } \\
\text { umol/kg }\end{array}$ \\
\hline Cayo Enrique & Aug-11 & VINDTA & 2.86 & 26 & 3.59 \\
Cayo Enrique & Dec-11 & $\begin{array}{l}\text { Gran \& Licor } \\
\text { titrators }\end{array}$ & 0.9 & 30 & 1.5 \\
Evan's Reef & Feb-12 & $\begin{array}{l}\text { Gran \& Licor } \\
\text { titrators }\end{array}$ & 0.82 & 22 & 1.6 \\
Evan's Reef & Aug-12 & $\begin{array}{l}\text { Gran \& Licor } \\
\text { titrators }\end{array}$ & 0.95 & 68 & 0.92
\end{tabular}




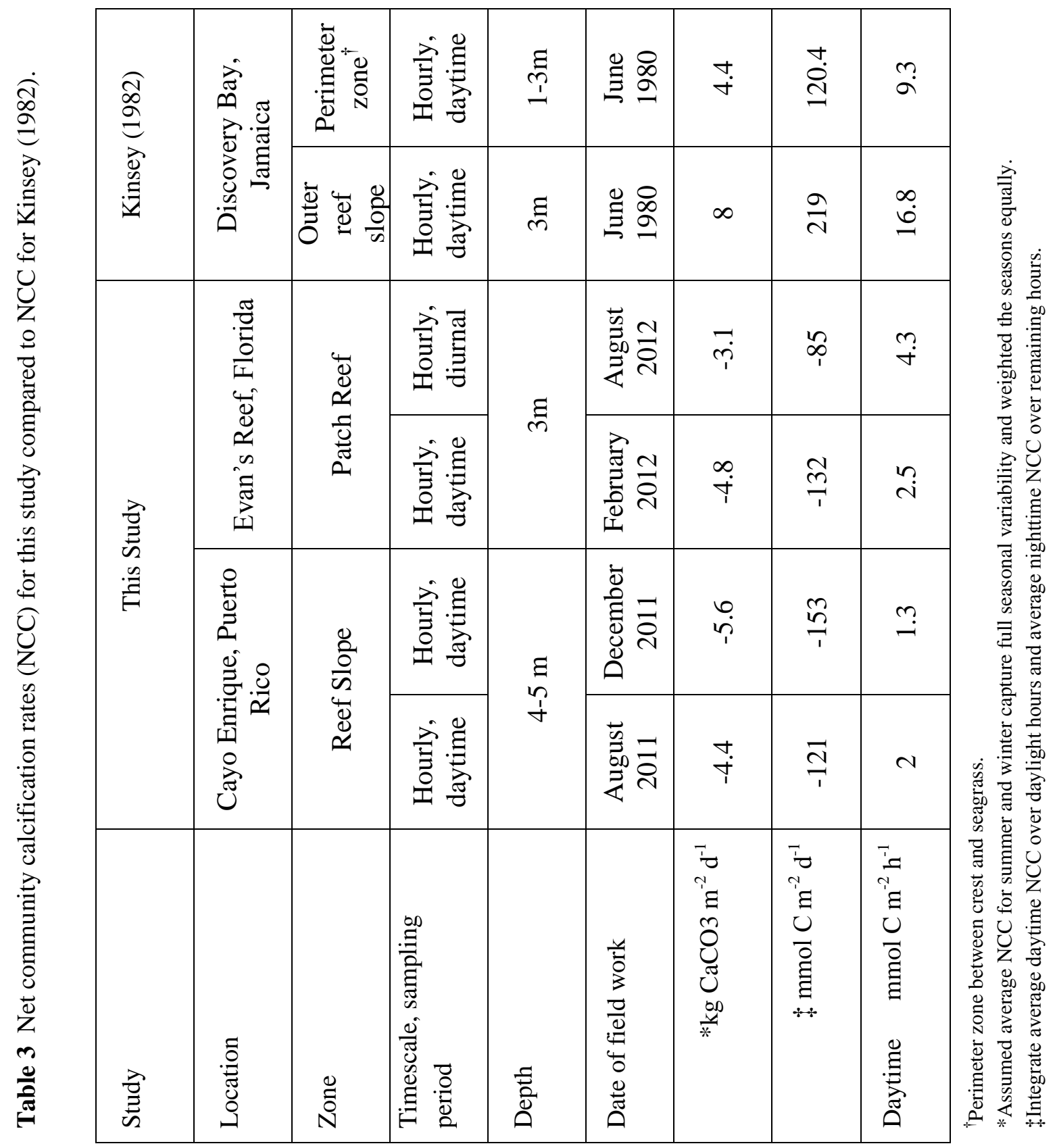




\section{Supplementary Figures}

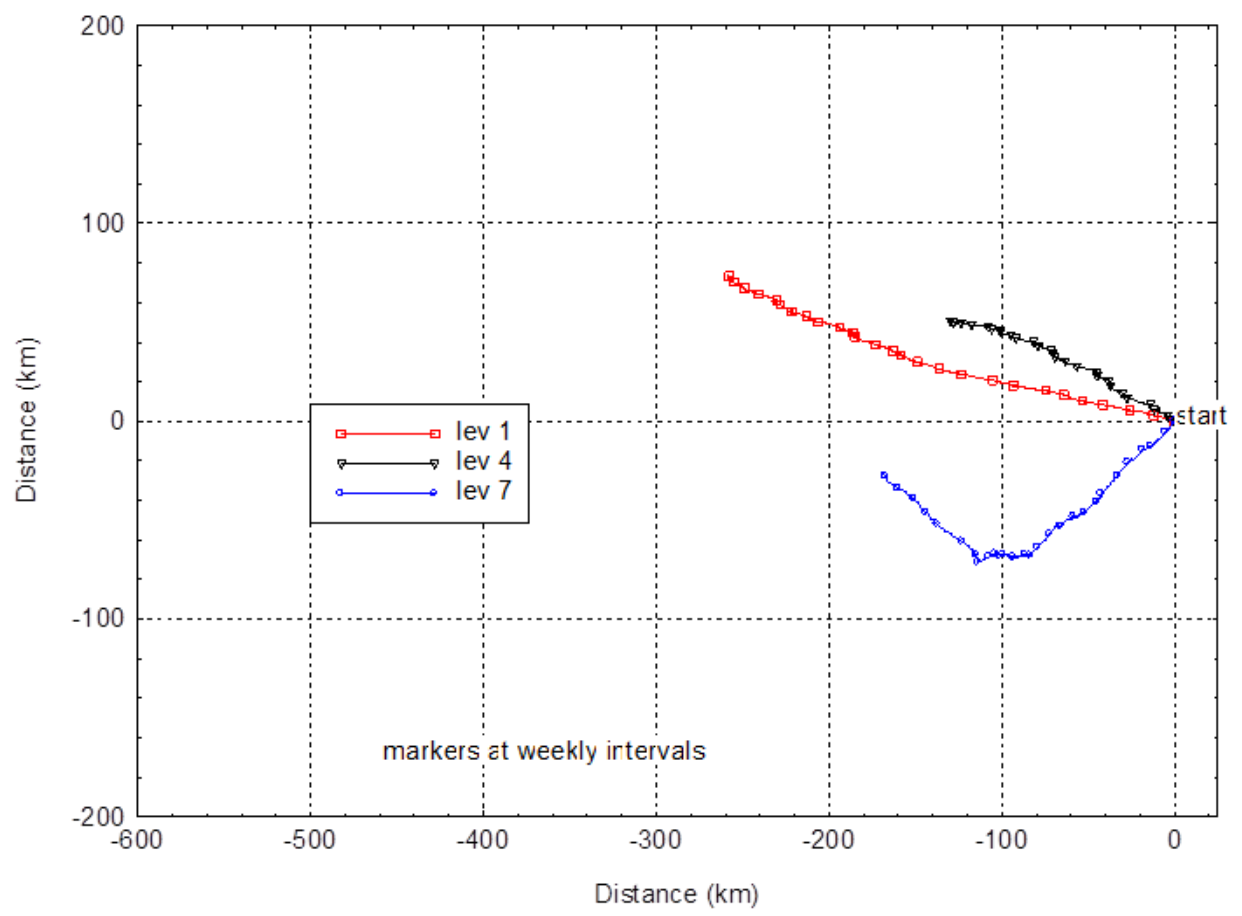

Figure S1 Progressive vectors showing the direction of flow at three depths: level 1 is about $4 \mathrm{~m}$ depth, level 4 is $2.3 \mathrm{~m}$, level 7 is $0.82 \mathrm{~m}$. Data collected July 15, 2009 to Dec 30, 2009 (courtesy of Jorge Capella and Chris Langdon). The flow near the bottom is almost unidirectional. 


\section{Cayo Enrique CO2-02 - West: Transport Rose}

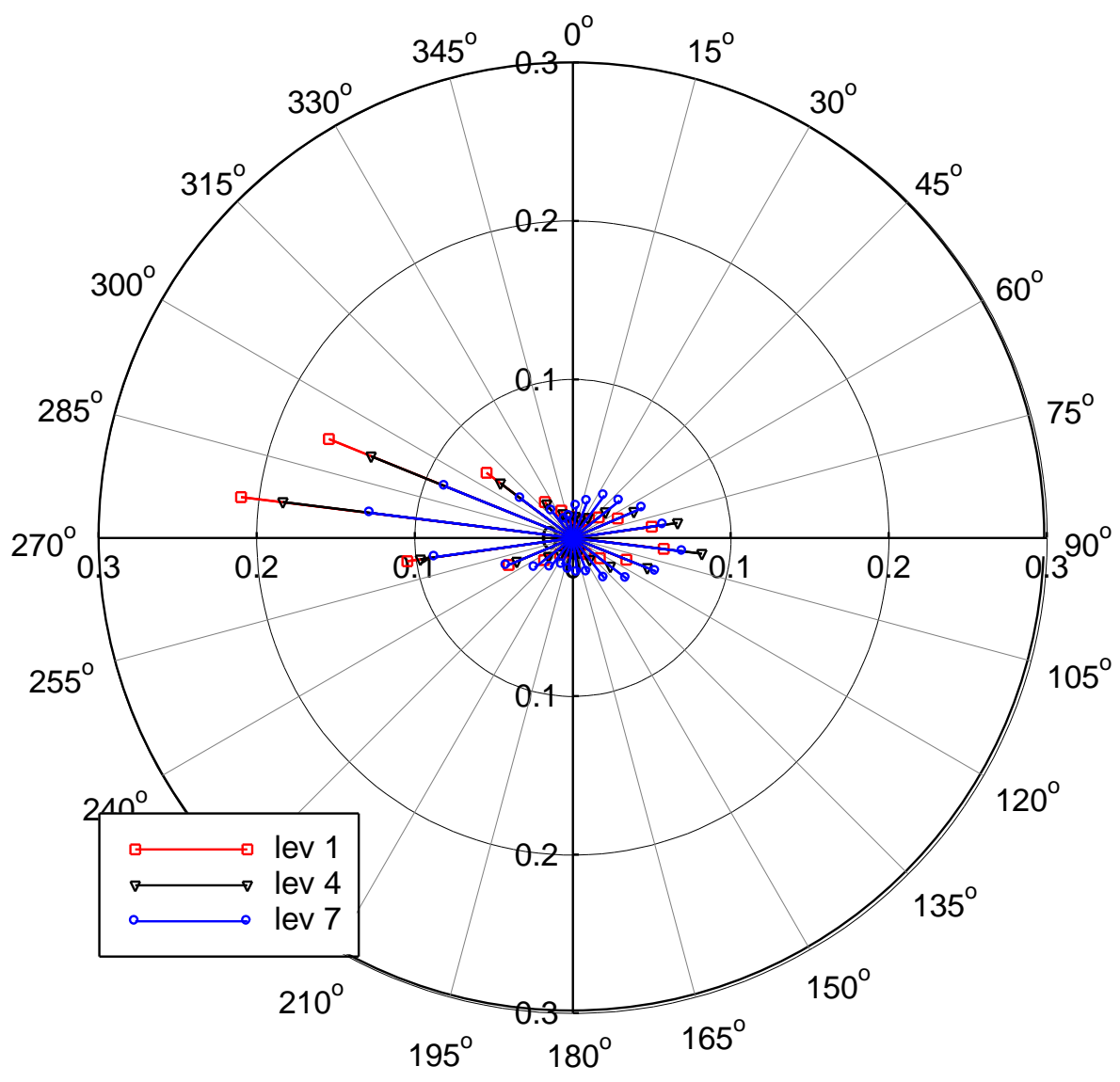

Figure S2 Vectors show the velocity of flow at three depths: level 1 is about $4 \mathrm{~m}$ depth, level 4 is $2.3 \mathrm{~m}$, level 7 is $0.82 \mathrm{~m}$. Data collected July 15, 2009 to Dec 30, 2009 (courtesy of Jorge Capella and Chris Langdon). While the mean flow near the bottom is almost uni-directional, there are moments of slight cross-wise flow that could cause slippage or mixing during a drift transect. 


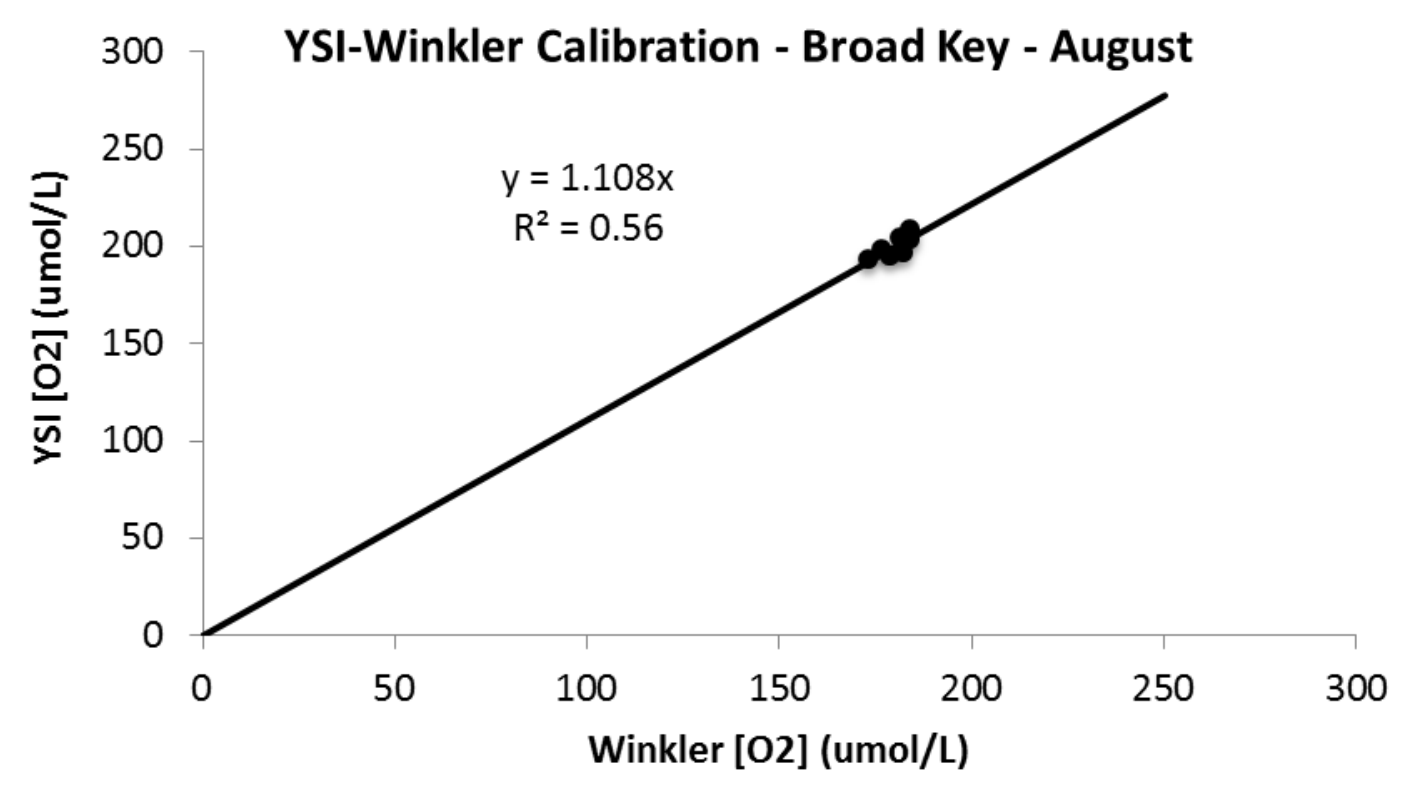

Figure S3 Calibration of the oxygen concentration measured by the YSI against the concentration measured by the Winkler titrations. The manual for the ROX Optical DO sensor recommends a 1-point calibration, unless we have a sample to measure that is truly without any oxygen. 


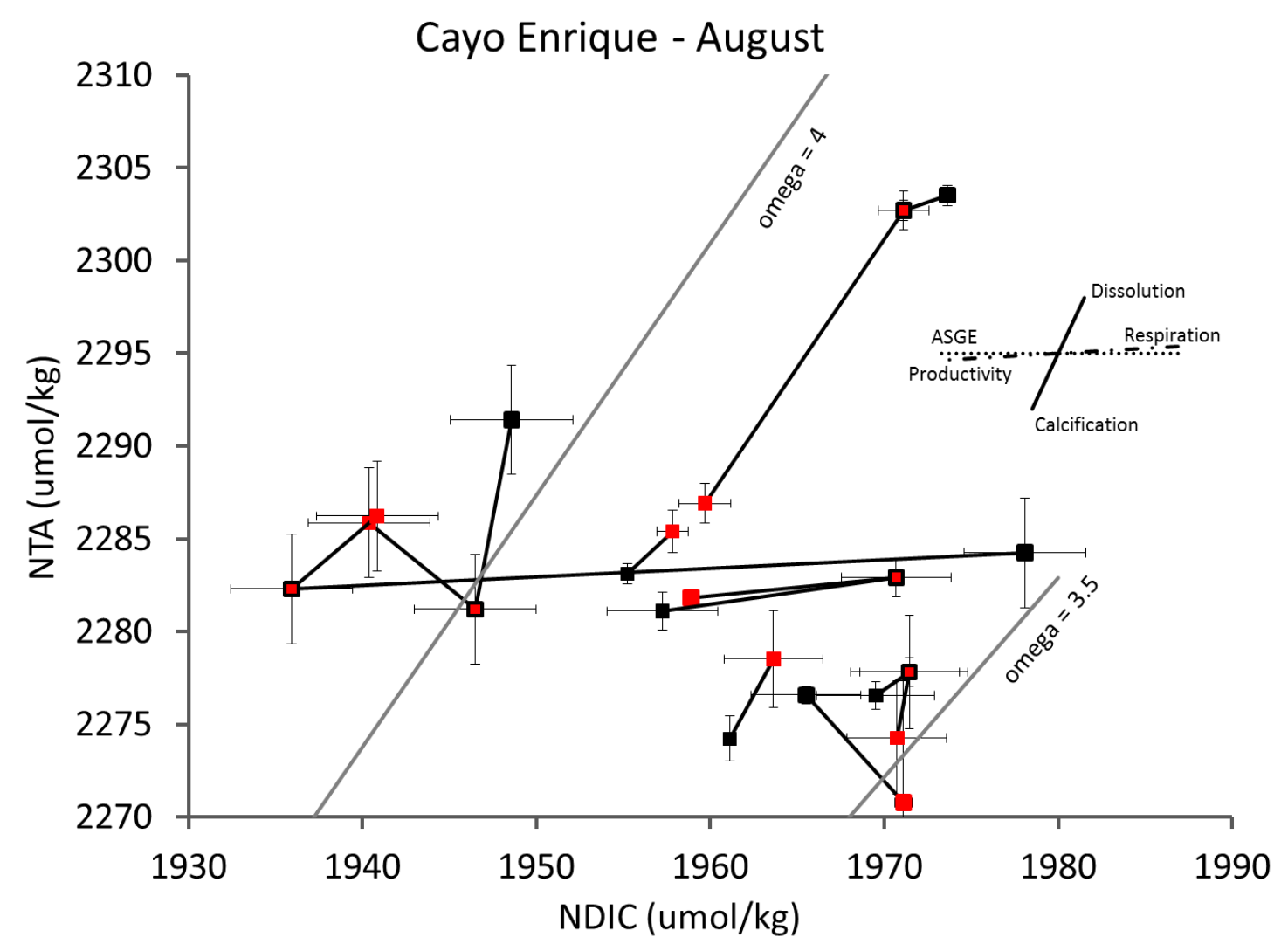

Figure S4 Property-property plot of salinity normalized TA and DIC. The initial composition is shown in red, the final composition is shown in black and any intermediate samples of seawater are represented at a red square with black outline. The direction of lines connecting subsequent samples gives an indication of the dominant processes controlling the carbonate chemistry of the system according to the key in the upper right corner. ASGE is air-sea gas exchange, dotted line. Isopleths for $\Omega_{\mathrm{a}}=4$ and $\Omega_{\mathrm{a}}=3.5$ are plotted in grey and were calculated using CO2sys $(\mathrm{T}=29.58, \mathrm{~S}=35.18)$. 


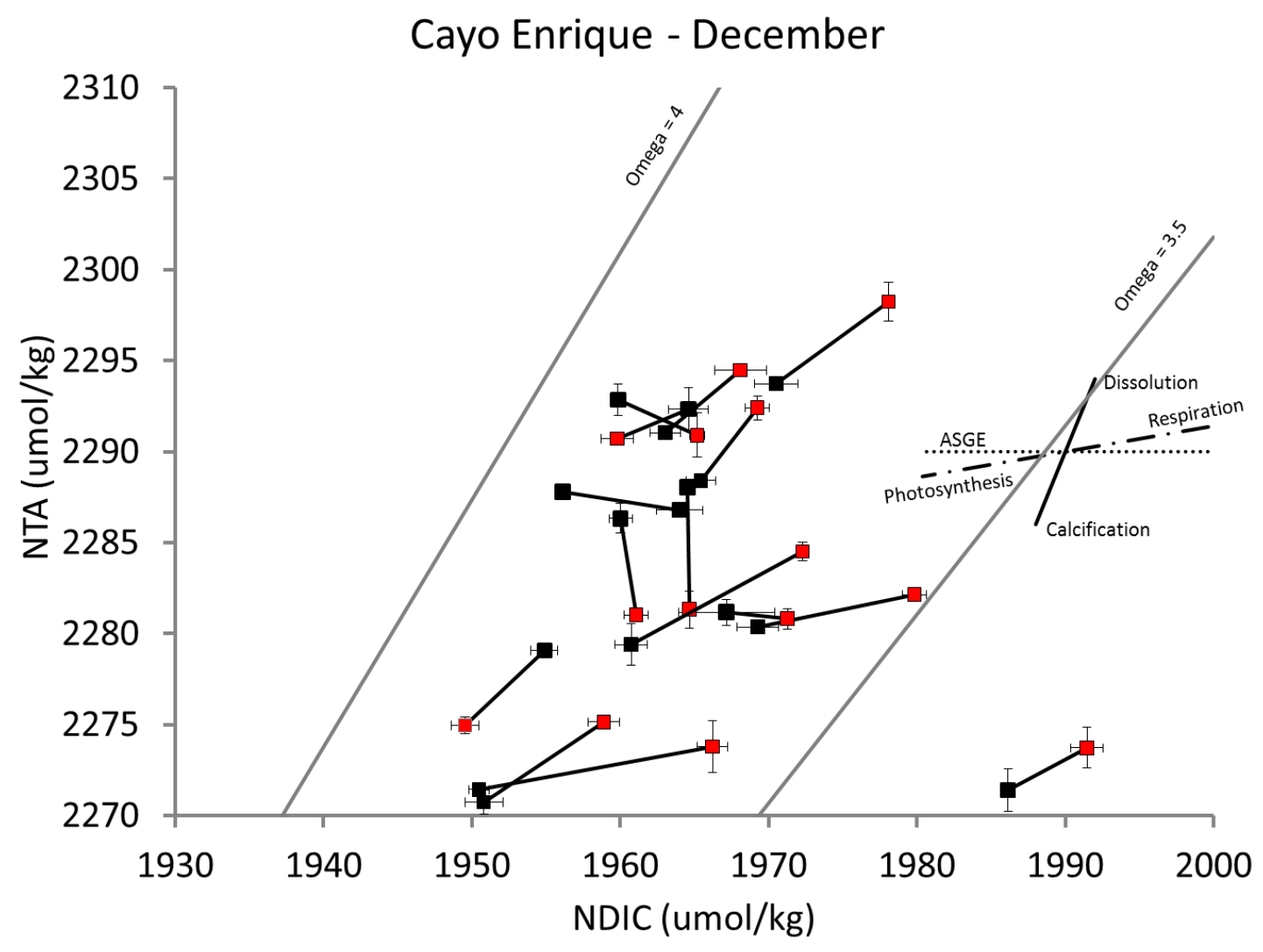

Figure S5 Same as in Figure S4 except isopleths for $\Omega_{\mathrm{a}}=4$ and $\Omega_{\mathrm{a}}=3.5$ were calculated using $\mathrm{CO} 2$ sys at $\mathrm{T}=29.57$ and $\mathrm{S}=35.21$. 


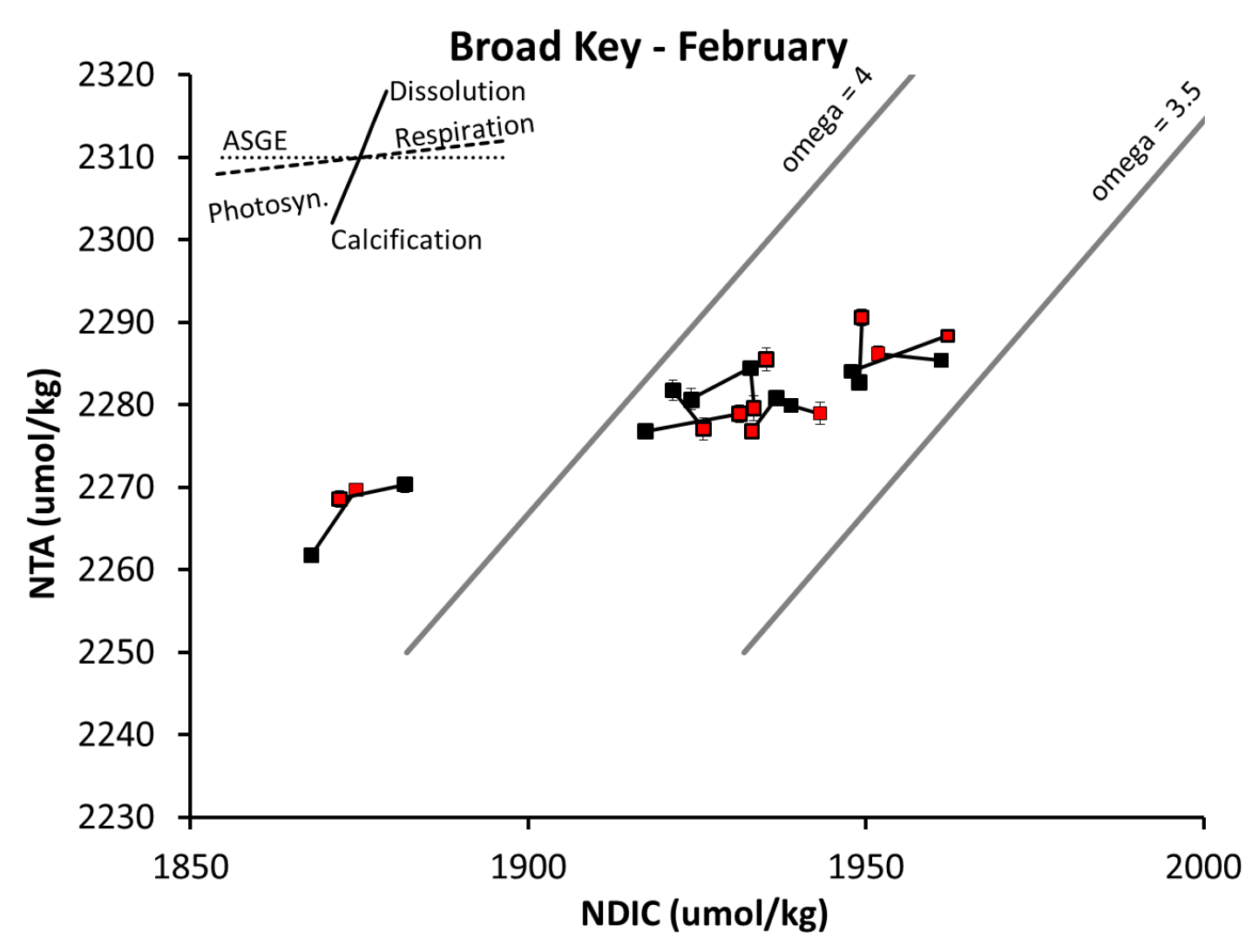

Figure S6 Same as in Figure S4. Note the change in axes from plots for Cayo Enrique to plots for Broad Key. Photosynth. Stands for photosynthesis. Isopleths for $\Omega_{\mathrm{a}}=4$ and $\Omega_{\mathrm{a}}=3.5$ were calculated using CO2sys at $\mathrm{T}=25.25$ and $\mathrm{S}=36.09$, the average values for this data set. 


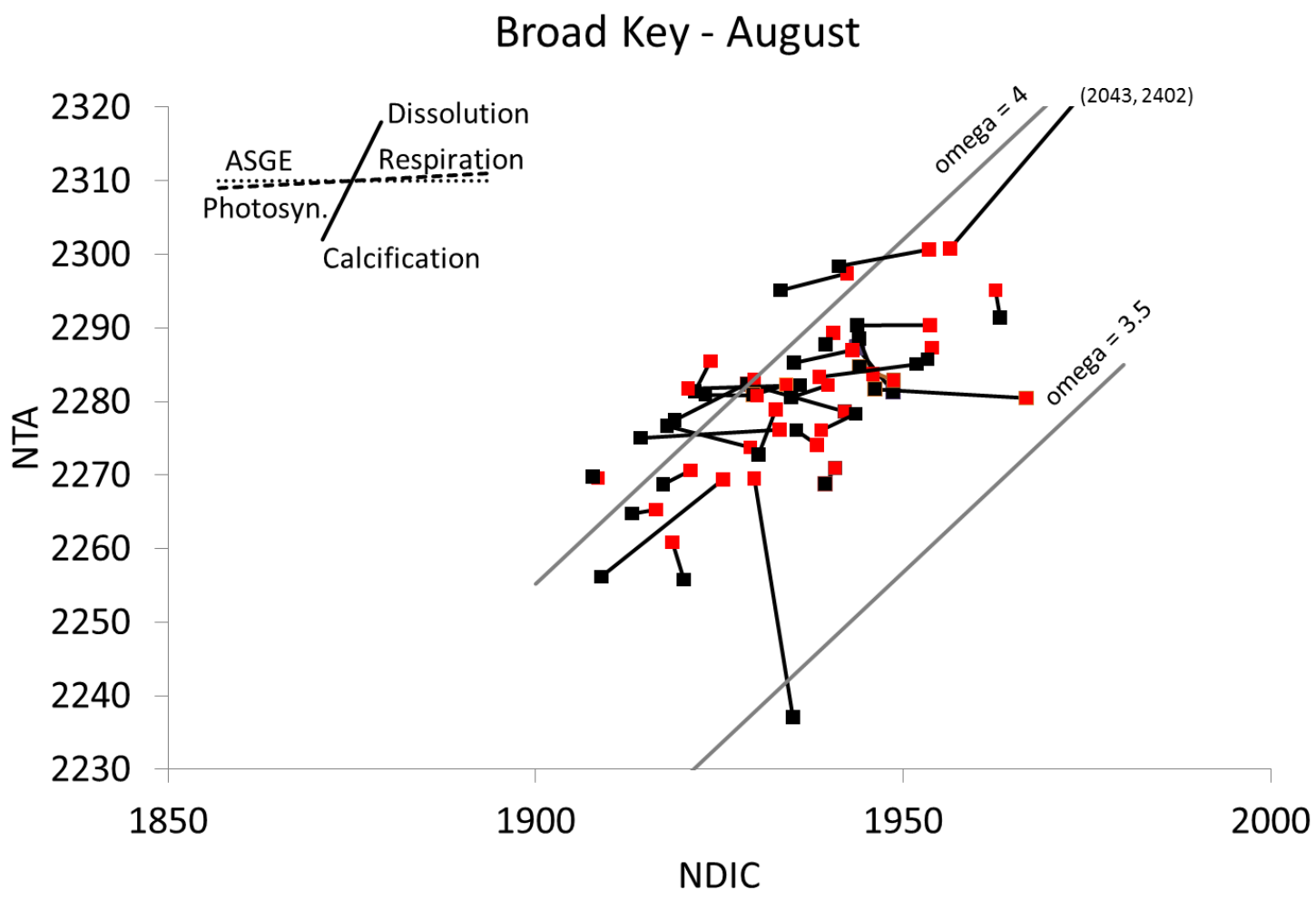

Figure S7 Same as in Figure S4. Note the change in axes from plots for Cayo Enrique to plots for Broad Key. Photosynth. Stands for photosynthesis. Isopleths for $\Omega_{\mathrm{a}}=4$ and $\Omega_{\mathrm{a}}=3.5$ were calculated using $\mathrm{CO} 2$ sys at $\mathrm{T}=30.50$ and $\mathrm{S}=36.15$, the average values for this data set. One transect has a tail-value that plots off the chart at NDIC $=2043$ umol $\mathrm{kg}^{-1}$ and NTA $=2402 \mathrm{umol} \mathrm{kg}$ and the value is indicated on the plot to represent the point that is outside the bounds of the plot. 

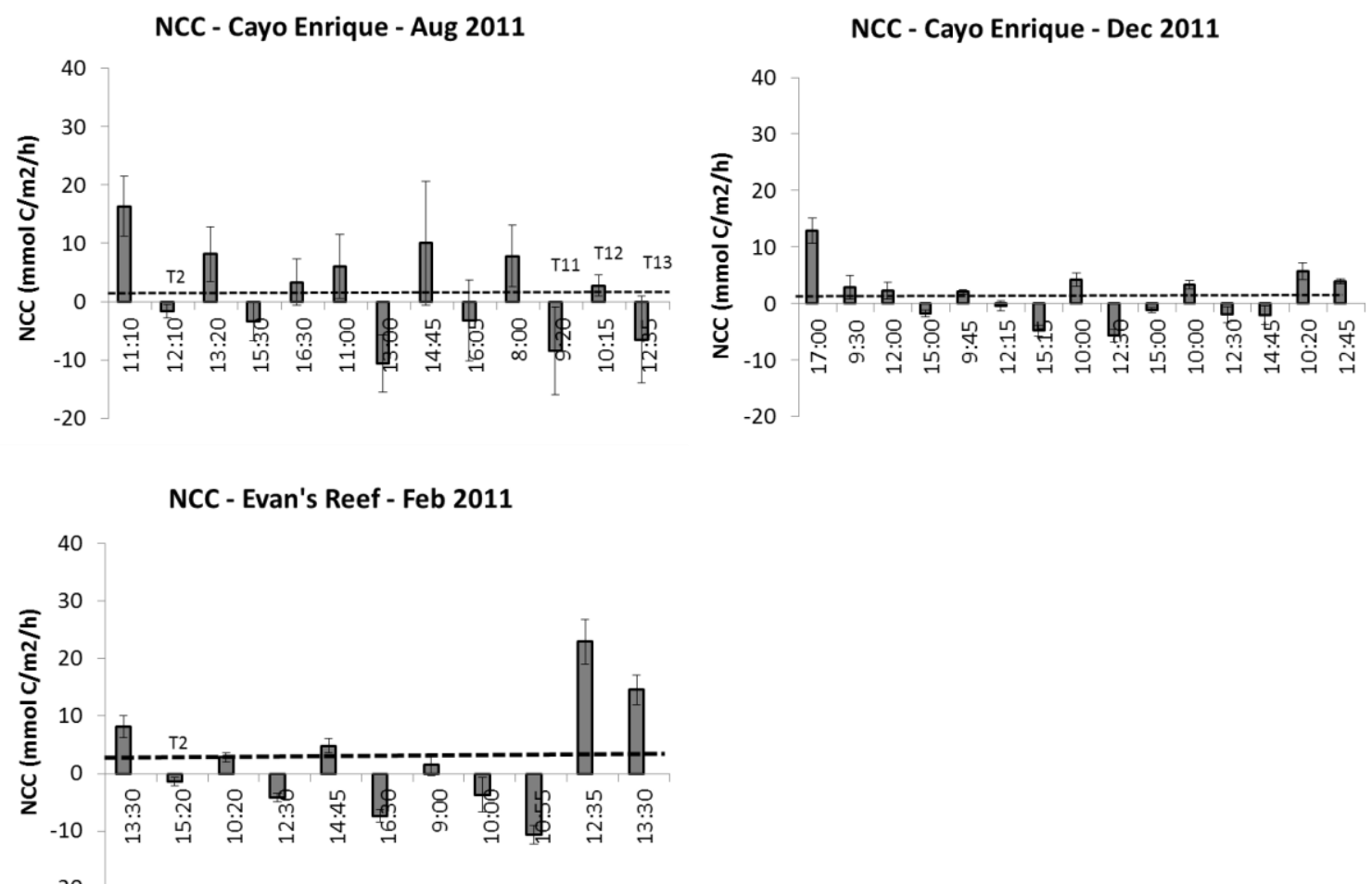

NCC - Evan's Reef - Aug 2011

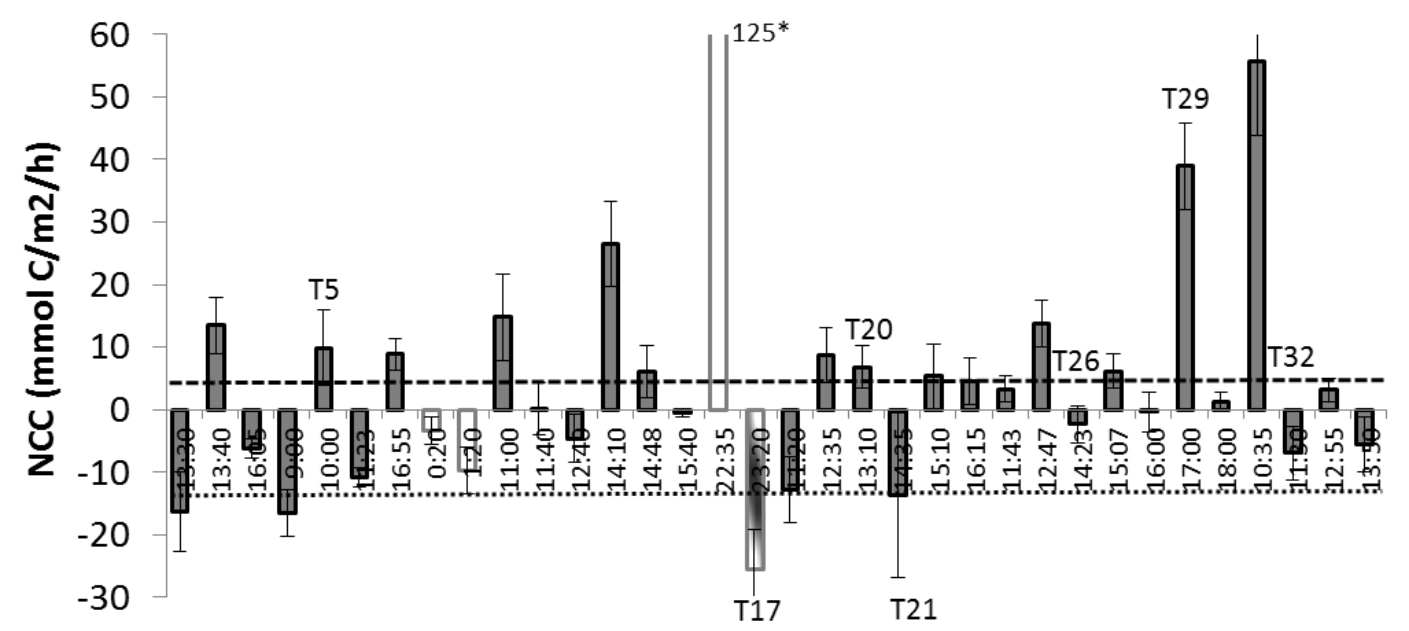

Figure S8 Same results as in Figure 8, but in transect order and labeled with the time of day at which the transect was taken. 

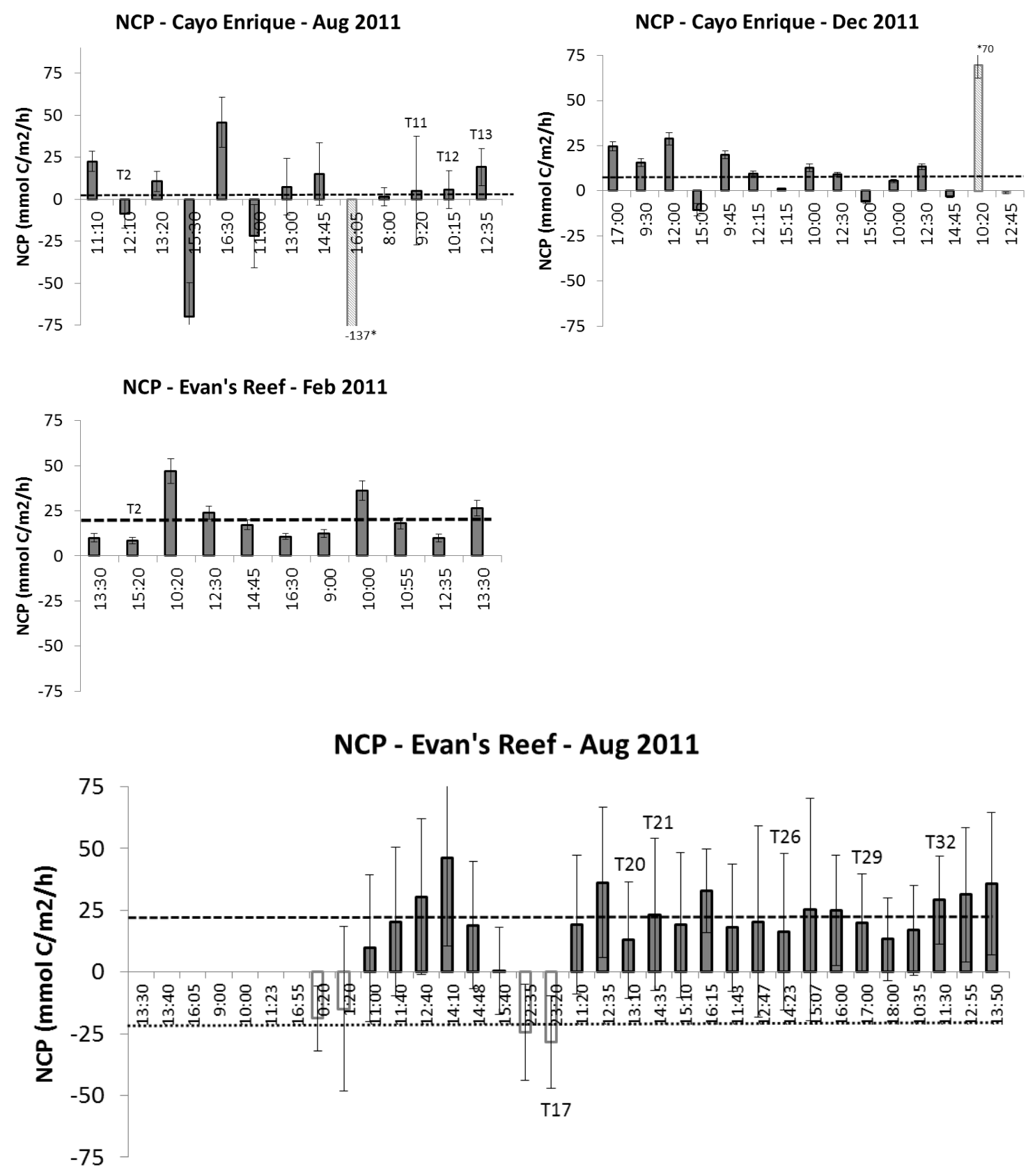

Figure S9 Same results as in Figure 8, but in transect order and labeled with the time of day at which the transect was taken. 


\section{Appendix 1:}

Uncertainties related to the Lagrangian drifter 
The Lagrangian method assumes that the drogue follows the water parcel precisely and accurately. However, when employing a physical drifter rather than a dye marker, some "slippage" can occur in which the drifter and water parcel shift relative to one another. Future studies employing drifters could assess the extent of slippage by marking the water parcel with dye. We did not use dye in our deployments. Another source of error is the possibility of a water parcel with a different history (from the reef flat or from the open ocean) mixing in with the water parcel that the drogue is tracking.

We investigated the possibility and extent of slippage and mixing by examining the salinity over the course of each transect. A detectable change in salinity over the course of the transect may be a positive indication of slippage or mixing with a different water parcel. We evaluated the change in salinity using the discreet bottle samples from the head and tail of each transect and then further investigated the transects suspect of slippage or mixing using YSI data. We discuss this strategy here, and later discuss an additional strategy for investigating mixing.

\section{A1.1 Cayo Enrique - August}

In the data from Cayo Enrique, August, we see that during transect 2 there was either mixing with low salinity water, or a discreet salinity sample was compromised (Figure A1.1). We do not have YSI data to support the decline in salinity observed with discreet samples. This transect was very early in our sampling campaign and we feel that the low salinity is likely due to human error of not rinsing the bottle before filling it.

Normalizing the downstream alkalinity with this salinity exaggerates the change in alkalinity over the transect and yields an NCC value of $-62.25 \mathrm{mmol} \mathrm{m}^{-2} \mathrm{~h}^{-1}$ and an $\mathrm{NCP}$ value of -51.81 . This would mean that the reef is dissolving and respiring extremely fast at noon. We find this to be unlikely. Calculating the NCC and NCP without normalizing TA and DIC to salinity, yields estimates of $-2 \pm 1 \mathrm{mmol} \mathrm{m}^{-2} \mathrm{~h}^{-1}$ and $-9 \pm 9$ mmol m${ }^{-2} \mathrm{~h}^{-1}$ for NCC and NCP, respectively. Alternatively, replacing the compromised salinity value with the average salinity measured that day, yields estimates of $-4 \pm 6$ mmol m $\mathrm{m}^{-2} \mathrm{~h}^{-1}$ and $-10 \pm 11 \mathrm{mmol} \mathrm{m}^{-2} \mathrm{~h}^{-1}$ for NCC and NCP, respectively. We used the 
former estimate which involves the assumption that there is no mixing, slippage or salinity change, and flagged T2.

Looking more closely at the changes in salinity for the other transects from Cayo Enrique, August (Figure A1.2), we observe that three points show relatively large increases in salinity. This could be an indication of slippage or mixing. All three of these transects occurred after the hurricane, so the water may have been more heterogeneous with respect to salinity, TA, and DIC. The YSI data support the observed increase in salinity during T13, but it is unclear whether they show a change in salinity for T11, and T12 (Figure A1.3). The NCC and NCP estimates for these transects should be treated with caution.

\section{A1.2 Cayo Enrique - December}

At Cayo Enrique in December, there were no changes in discreet samples for salinity that were outside the noise of the salinity measurement (0.02psu) (Figure A1.4). The YSI also showed no patterns of change beyond the noise of the measurement $(0.05 \mathrm{psu})$ for transects 1-4 and 11-13. The YSI malfunctioned during transects 5-10 and 14 and 15.

\section{A1.3 Broad Key - February}

We used discreet water samples to evaluated the change in salinity for transects 1-6 at Broad Key in February. Transect 2 shows a change in salinity (-0.05psu) for the discreet samples outside the noise, which is corroborated by a decline in the YSI salinity measurements (-0.04psu) (Figures A1.5 and A1.6). This could be an positive indication of slippage or mixing during transect 2. The measurement for transect 2 should be treated with caution.

There were not sufficient discreet salinity samples to evaluate transects 7-11 at Broad Key in February. The YSI showed no change in salinity beyond the noise of the measurement $(0.05 \mathrm{psu})$ for transects 1 and 3-6. The YSI malfunctioned during transects 7-9. The YSI data for transects 10 and 11 and showed no pattern of change in salinity outside the noise of the measurement $(0.05 \mathrm{psu})$. We assume no slippage for during transects 7-11.

\section{A1.4 Broad Key - August}


We used discreet water samples to evaluate the change in salinity for all transects at Broad Key in August (Figure A1.7). For transects 16 and 18, we suspect that the salinity samples were compromised. The niskin broke just prior to taking samples for transect 16 and there was the added complication of sampling at night. The YSI data do show that the salinity did increase by 0.08 psu over the course of transect 16, pointing toward the possibility of slippage or mixing (Figure A1.8). There is additional possibility of sampling error for the collection of water samples for TA and DIC analysis. We suspect that this occurred because the data lead to an NCC estimate of $125 \mathrm{mmol} \mathrm{m}^{-2} \mathrm{~h}^{-1}$ which is very unlikely to have occurred at night. Therefore, we do not use the estimates of NCC and NCP based on the TA and DIC samples from Transect 16. We use the YSI measurements of $\left[\mathrm{O}_{2}\right]$ to estimate NCP for transect 16.

For transect 18, the discreet samples show anomalously low values for the first pair (34.6psu) and typical values for our site for the second pair (36.2psu). Transect 18 was the first morning transect conducted after the niskin sampler broke. We may have neglected to rinse the salinity bottles of the first sample pair before filling them. Normalizing TA and DIC to this value in the calculation of metabolic rates yields $380 \pm$ $27 \mathrm{mmol} \mathrm{m}^{-2} \mathrm{~h}^{-1}$ for NCC and $664 \pm 50 \mathrm{mmol} \mathrm{m}^{-2} \mathrm{~h}^{-1}$ or NCP. As we did for transect 2 at Cayo Enrique, August, we proceeded with the calculations of NCC and NCP without normalizing TA and DIC for salinity, and find more reasonable values of $-13 \pm 5 \mathrm{mmol}$ $\mathrm{m}^{-2} \mathrm{~h}^{-1}$ and $-4 \pm 20 \mathrm{mmol} \mathrm{m}^{-2} \mathrm{~h}^{-1}$, respectively. We used these estimates which involve the assumption that there is no mixing, slippage or salinity change. This assumption is supported by the observation of no change in salinity over the course of the transect as measured by the YSI (Figure A1.9).

The next largest change in salinity is a decline of 0.22 psu over the course of transect 17 (Figure A1.10). The YSI data also show a change in salinity, but they show an increase of $0.06 \mathrm{psu}$ (Figure A1.11). It is unclear whether or not this value has been compromised by slippage or mixing, so it is flagged and interpreted with caution. Finally, there remain four transects for which changes in salinity estimates with discreet samples suggest possible slippage or mixing (Figure A1.12). These transects are 5 and 
32 for which salinity decreased and transects 26 and 29 for which salinity increased. The decline in salinity of 0.08 psu for transect 5 is smaller than the uncertainty in the change in salinity $(0.09 \mathrm{psu})$ for those discreet samples. There are no YSI data with which to further evaluate changes for transect 5 . The YSI data for transect 32 show a gradual increase of 0.1psu (Figure A1.13) in contrast to the decrease of 0.05psu suggested by the discreet samples. It is unclear whether or not these values have been compromised by slippage or mixing, so they are flagged and interpreted with caution.

As for transect 5, transects 26 and 29 have increases in salinity ( 0.04 psu and 0.05 $\mathrm{psu}$, respectively) that are smaller than the uncertainty of the change ( $0.07 \mathrm{psu})$. The YSI data also show that the salinity may be increasing slightly (Figures A1.14 and A1.15). The change ( $0.03 \mathrm{psu}$ and $0.02 \mathrm{psu}$, respectively), although monotonic (Figures A1.14 and A1.15), are smaller than the noise of the measurement which we estimate at $0.05 \mathrm{psu}$ for this instrument. It is unclear whether or not this value has been compromised by slippage or mixing, so it is flagged and interpreted with caution.

\section{A1.5 Mixing, Broad Key, August}

There are two occasions of possible mixing of water parcels with different "histories", as defined by an abrupt change in salinity larger than the noise of the measurement (Figure A1.16 (a) and (b)). 


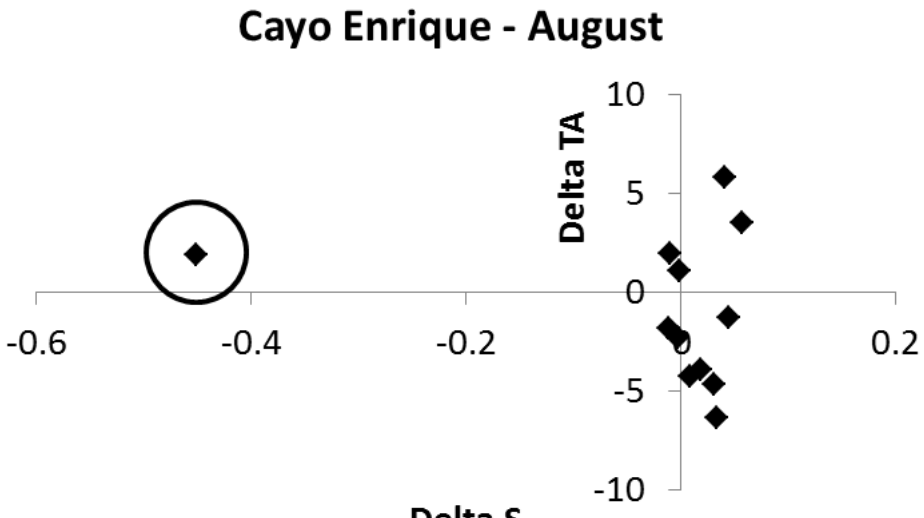

Figure A1.1 Change in salinity and TA over the course of each transect evaluated according to discreet bottle samples. Data point representing the large decline in salinity over transect 2 is circled.

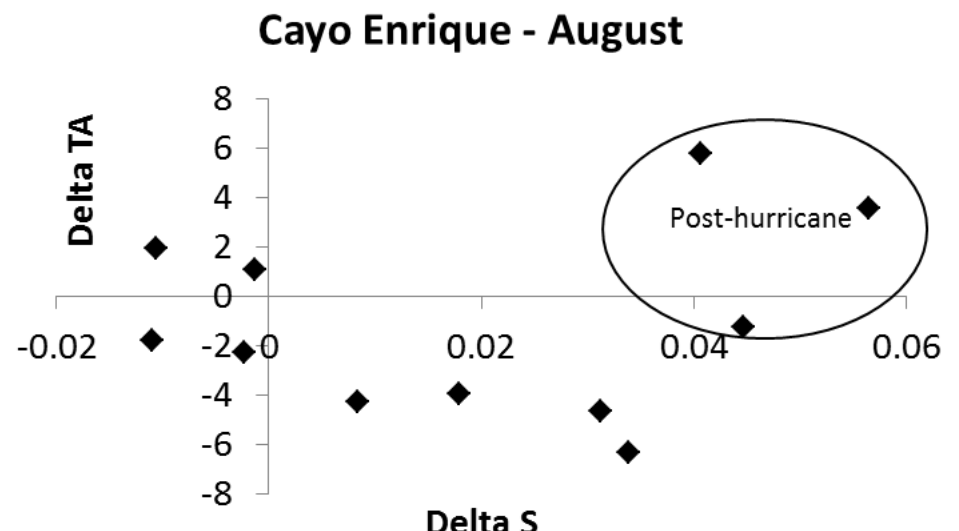

Figure A1.2 Expanded axis for change in salinity and TA over the course of each transect evaluated according to discreet bottle samples. Data points corresponding to transects $11,12,13$ which were conducted on the day following the hurricane are circled. 


\section{Cayo Enrique - 4-Aug: T11-T13}

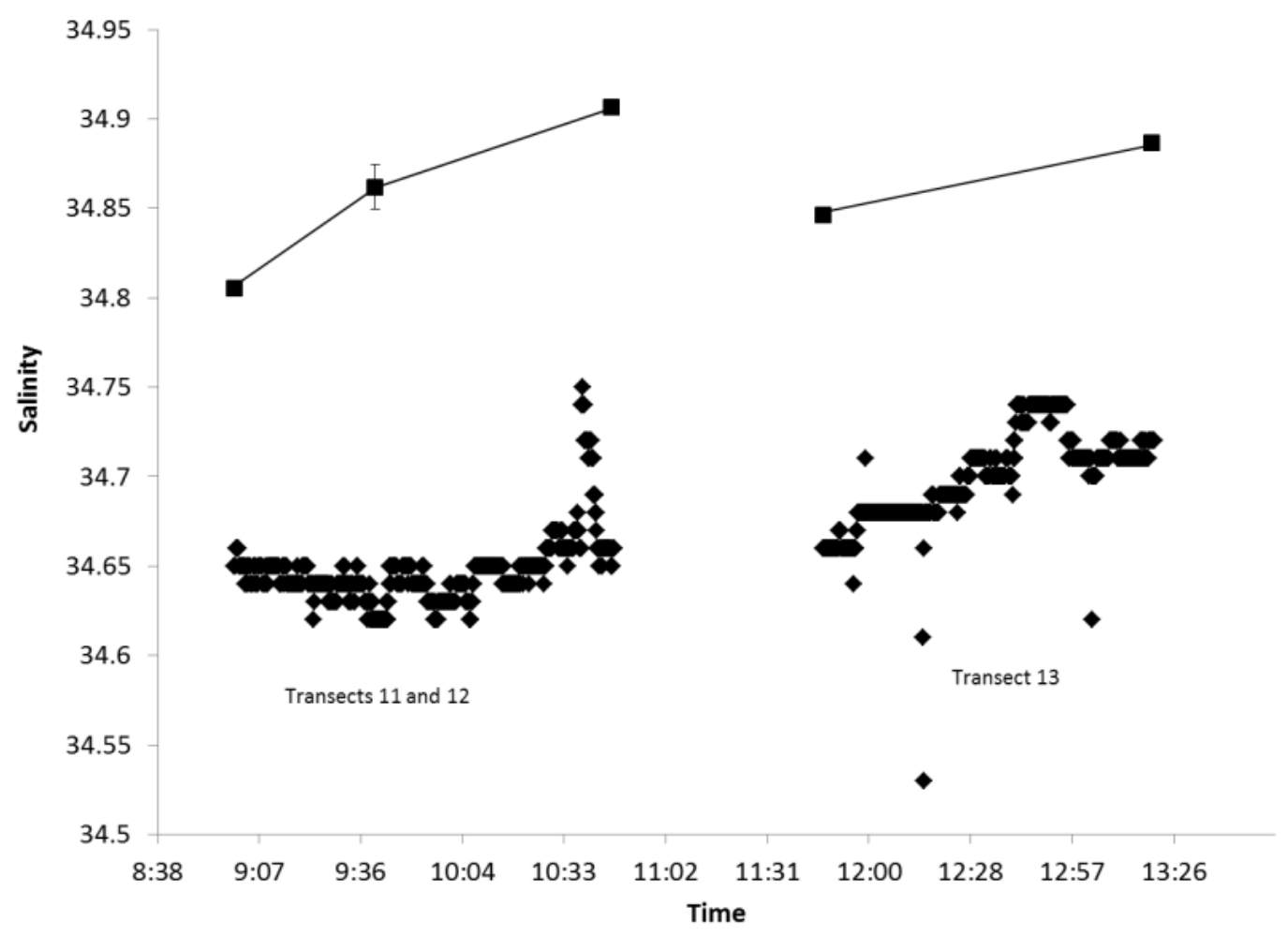

Figure A1.3 Salinity changes in discreet samples (squares) and YSI measurements (diamonds) during transects 11, 12 and 13, all conducted on August 4, the day following the hurricane. 


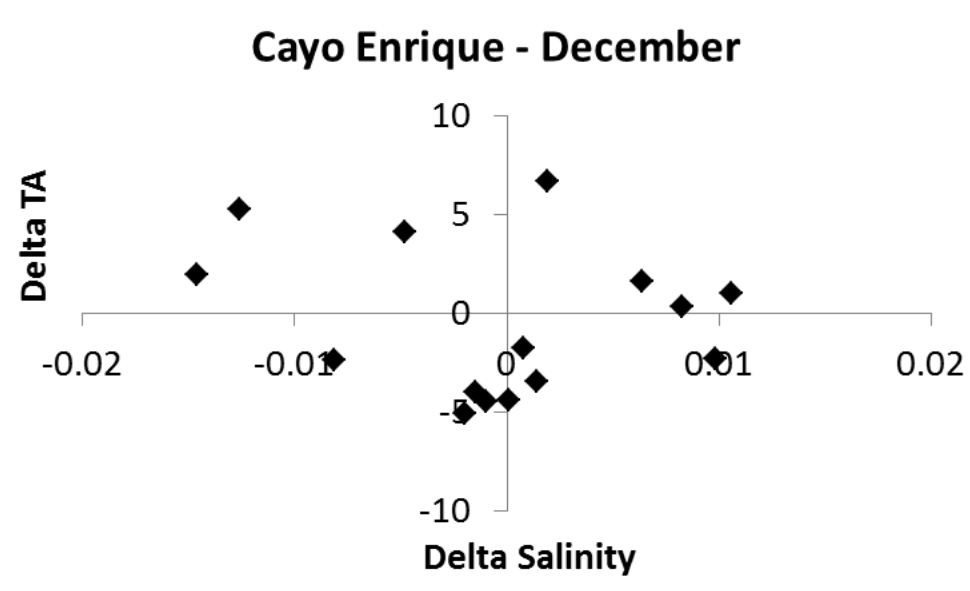

Figure A1.4 Change in salinity and TA over the course of each transect evaluated according to discreet bottle samples. 


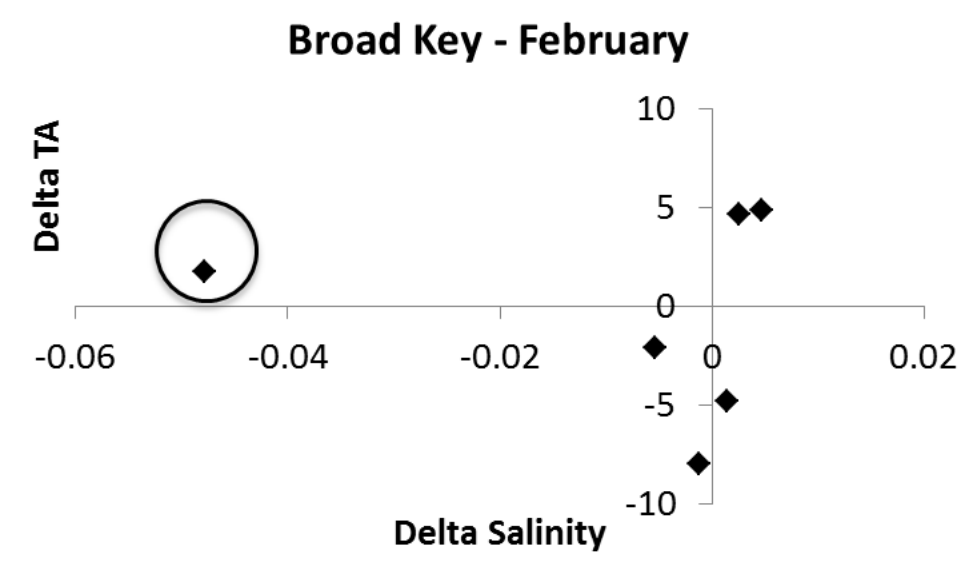

Figure A1.5 Change in salinity and TA over the course of each transect evaluated according to discreet bottle samples. These data represent only transects 1-6. There were not sufficient discreet salinity samples to evaluate transects 7-11.

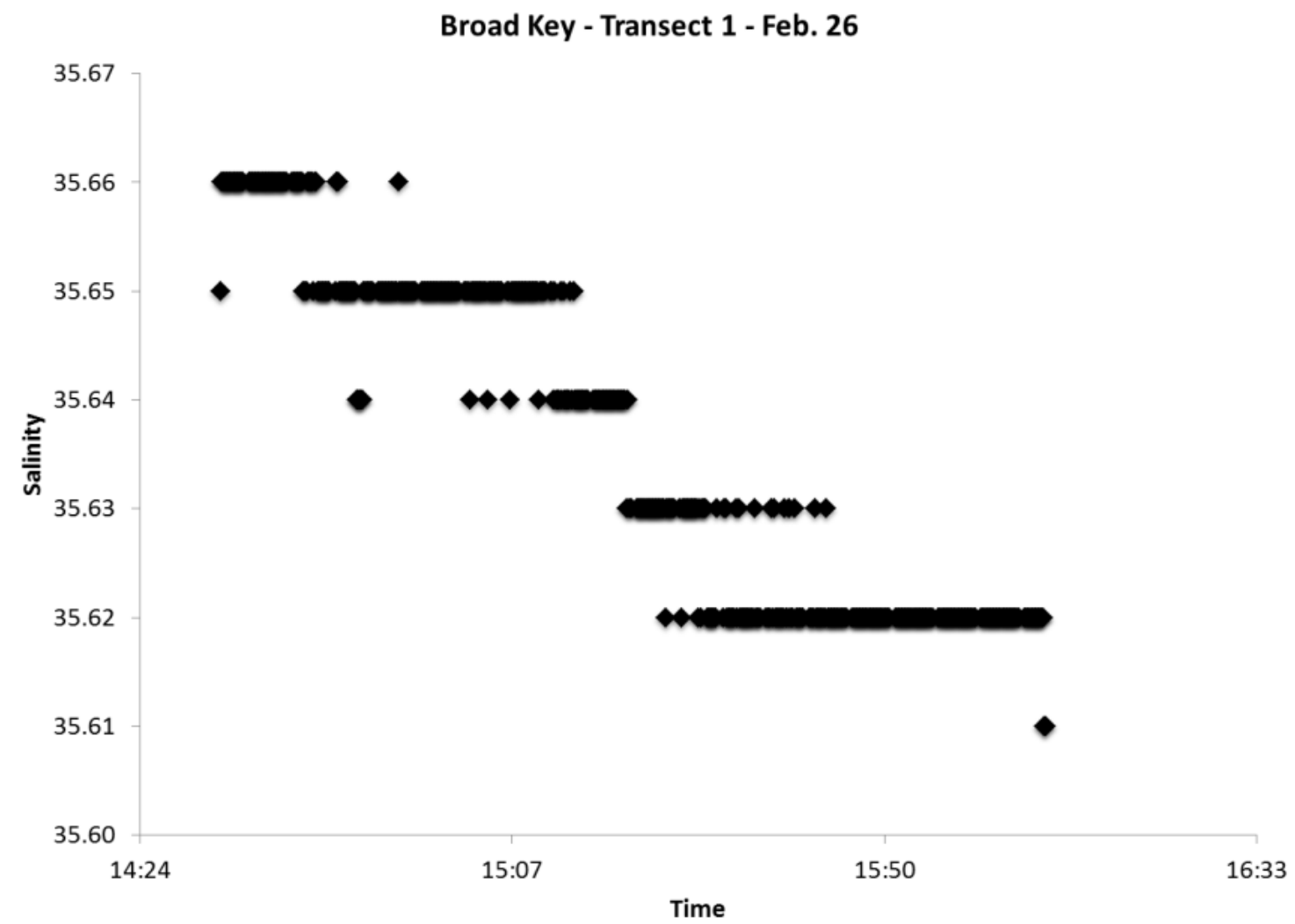

Figure A1.6 The YSI measurements of salinity show a slight decline over the course of the Transect 2 . This could be an indication of slippage. 


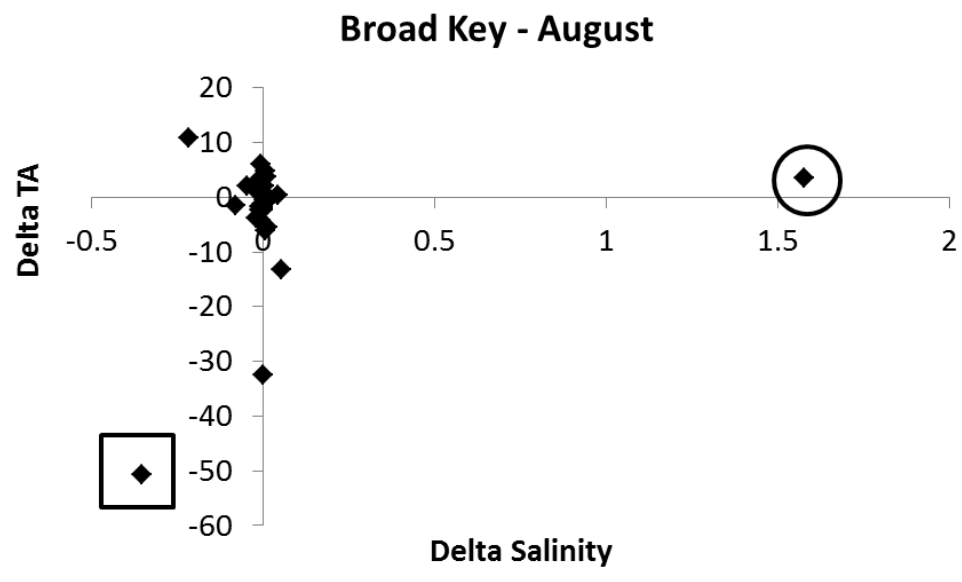

Figure A1.7 Change in salinity and TA over the course of each transect evaluated according to discreet bottle samples. The point inside a square corresponds to transect 16 and the circled point corresponds to transect 18.

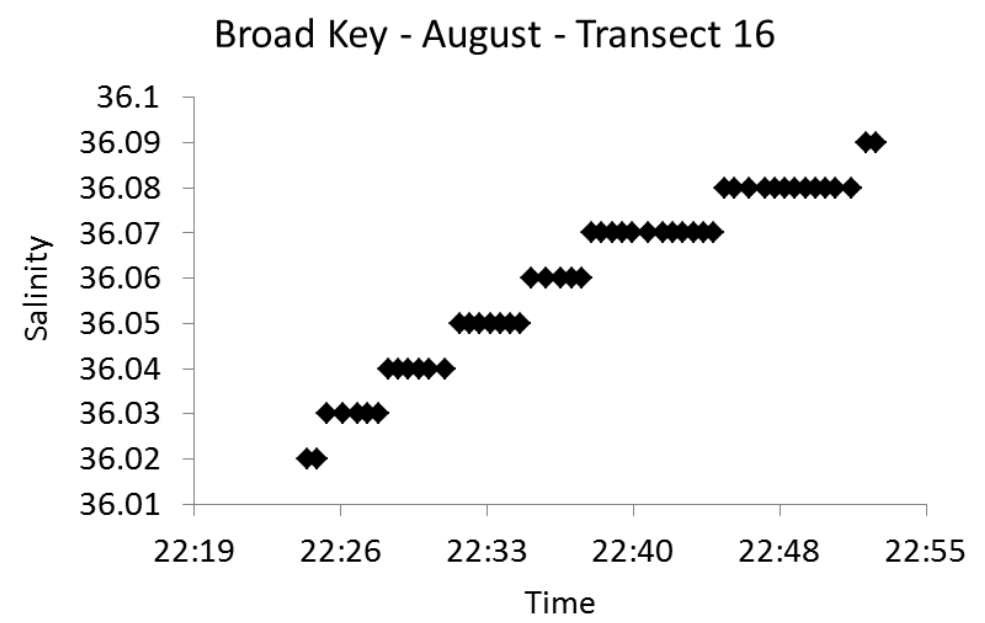

Figure A1.8 The salinity measured by the YSI increases gradually but only slightly relative to the noise of the measurement. 


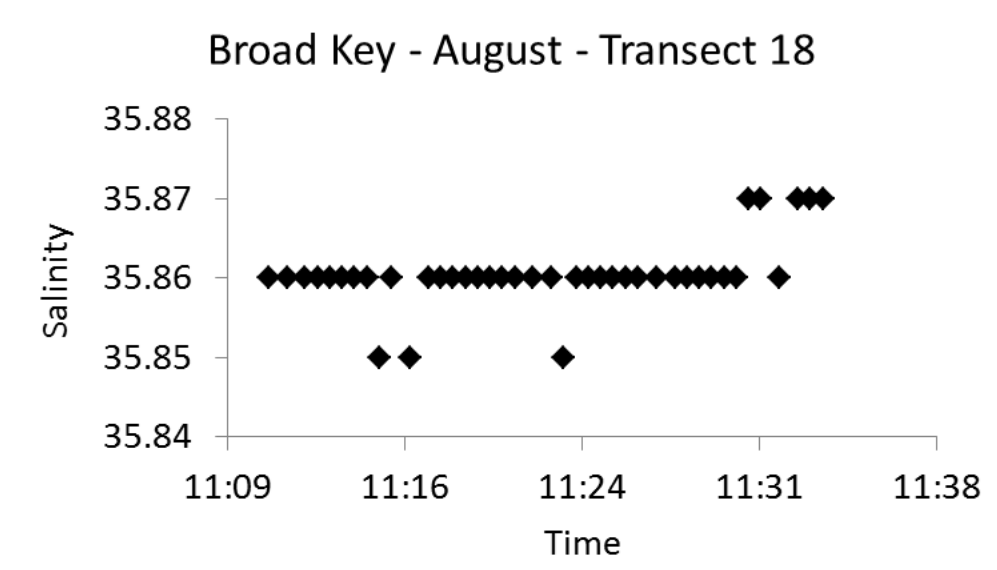

Figure A1.9 The salinity measured by the YSI shows no change outside the noise of the measurement.

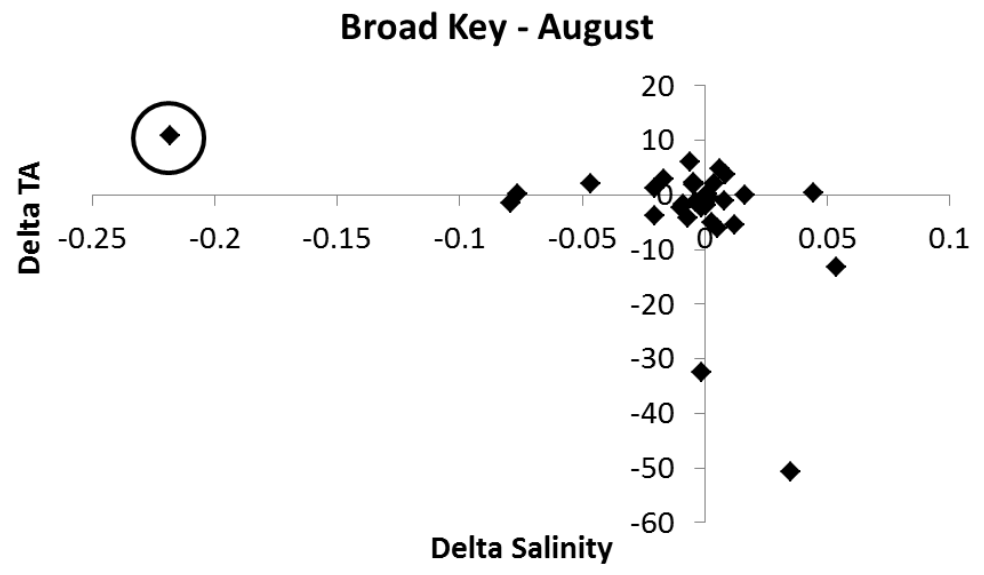

Figure A1.10 Change in salinity and TA over the course of each transect evaluated according to discreet bottle samples. The circled point corresponds to transect 17 for which we suspect that slippage may have occurred. 


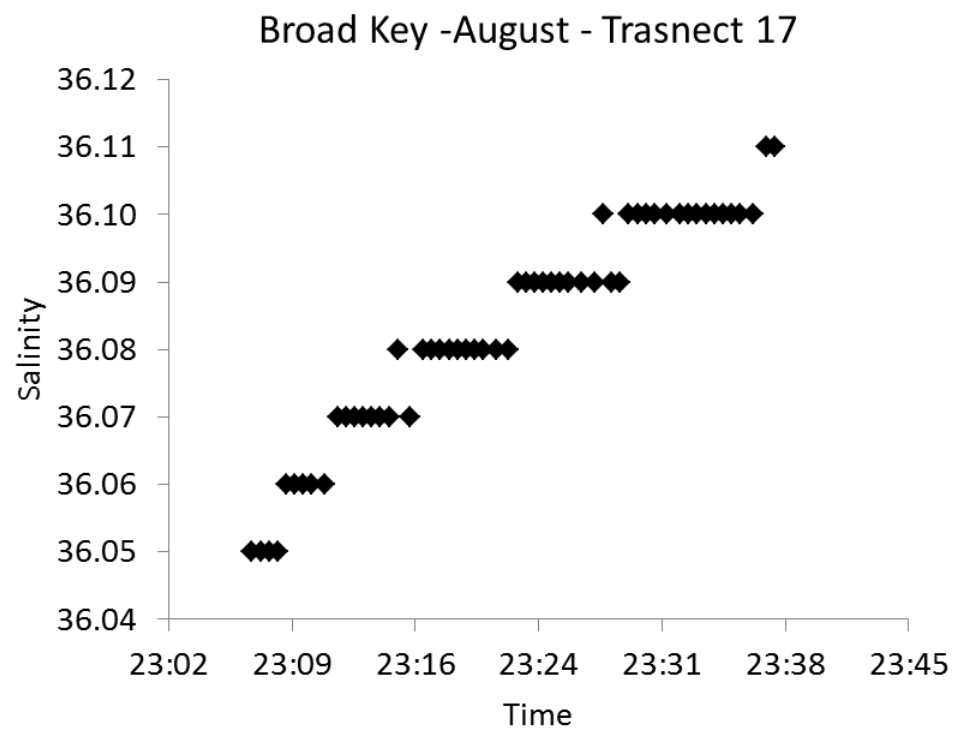

Figure A1.11 The salinity measured by the YSI shows a gradual increase in salinity.

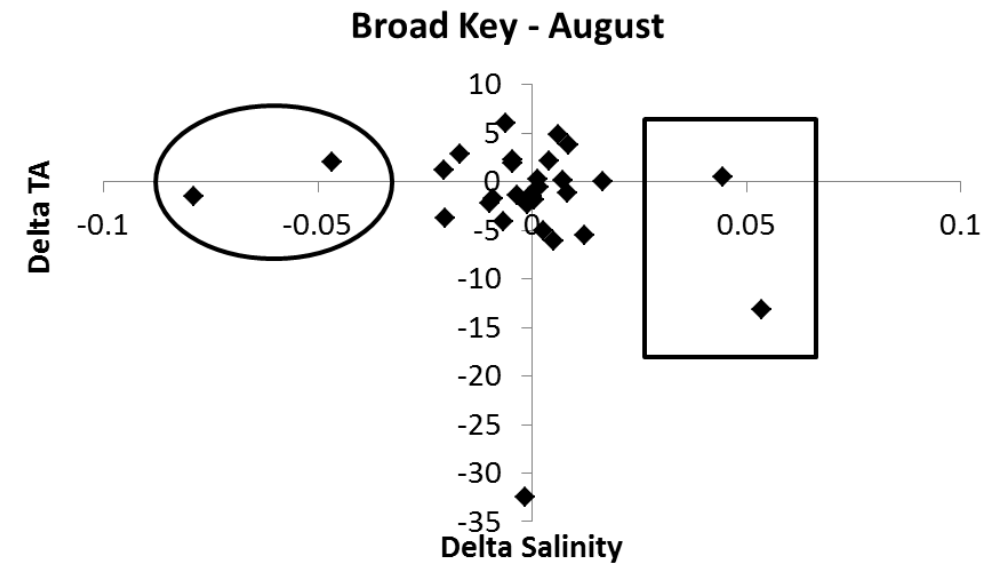

Figure A1.12 Change in salinity and TA over the course of each transect evaluated according to discreet bottle samples. The circled points correspond to transects 5 and 32 for which salinity decreased and the points inside the box correspond to transects 26 , and 29 for which salinity increased. 


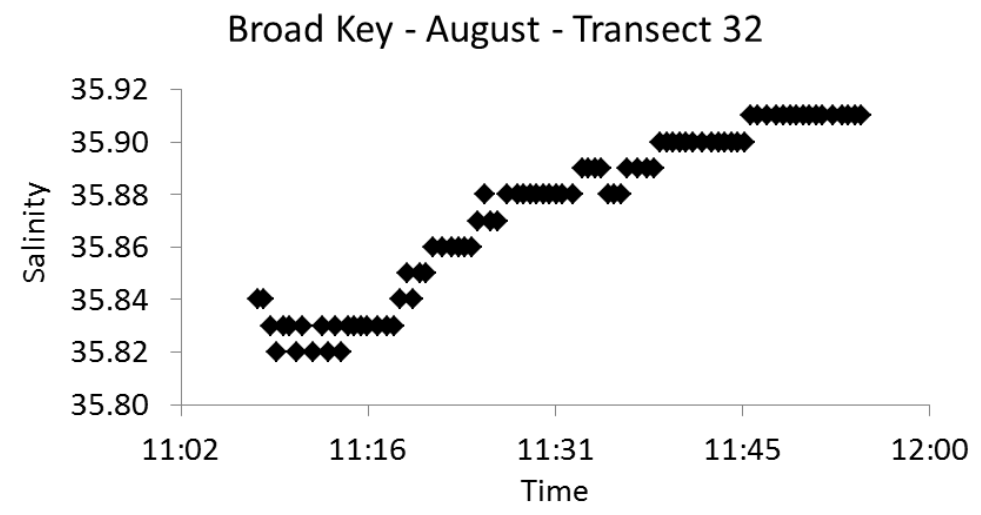

Figure A1.13 The salinity measured by the YSI shows a gradual increase in salinity.

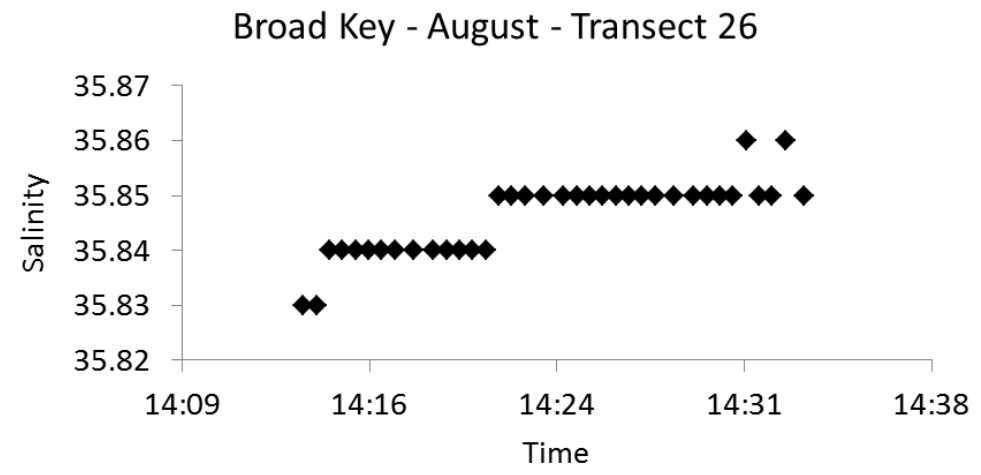

Figure A1.14 The salinity measured by the YSI increases gradually but only slightly relative to the noise of the measurement.

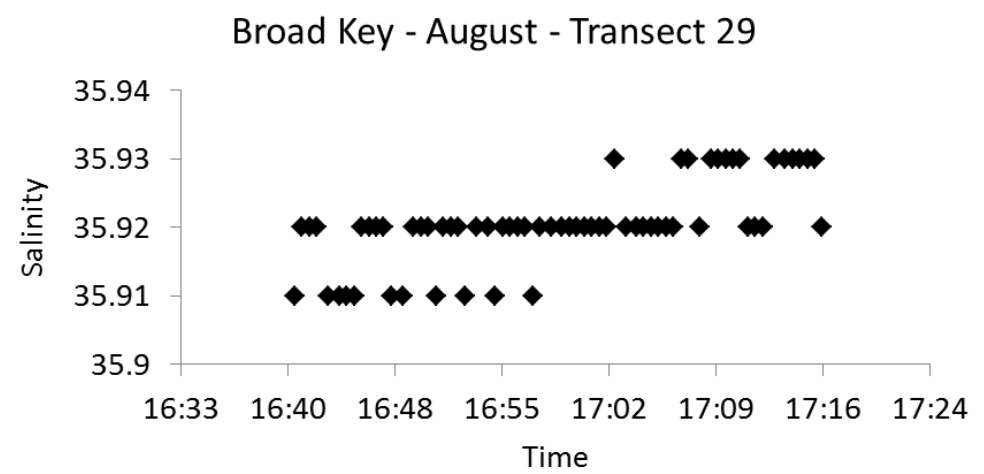

Figure A1.15 The salinity measured by the YSI increases gradually but only slightly relative to the noise of the measurement. 


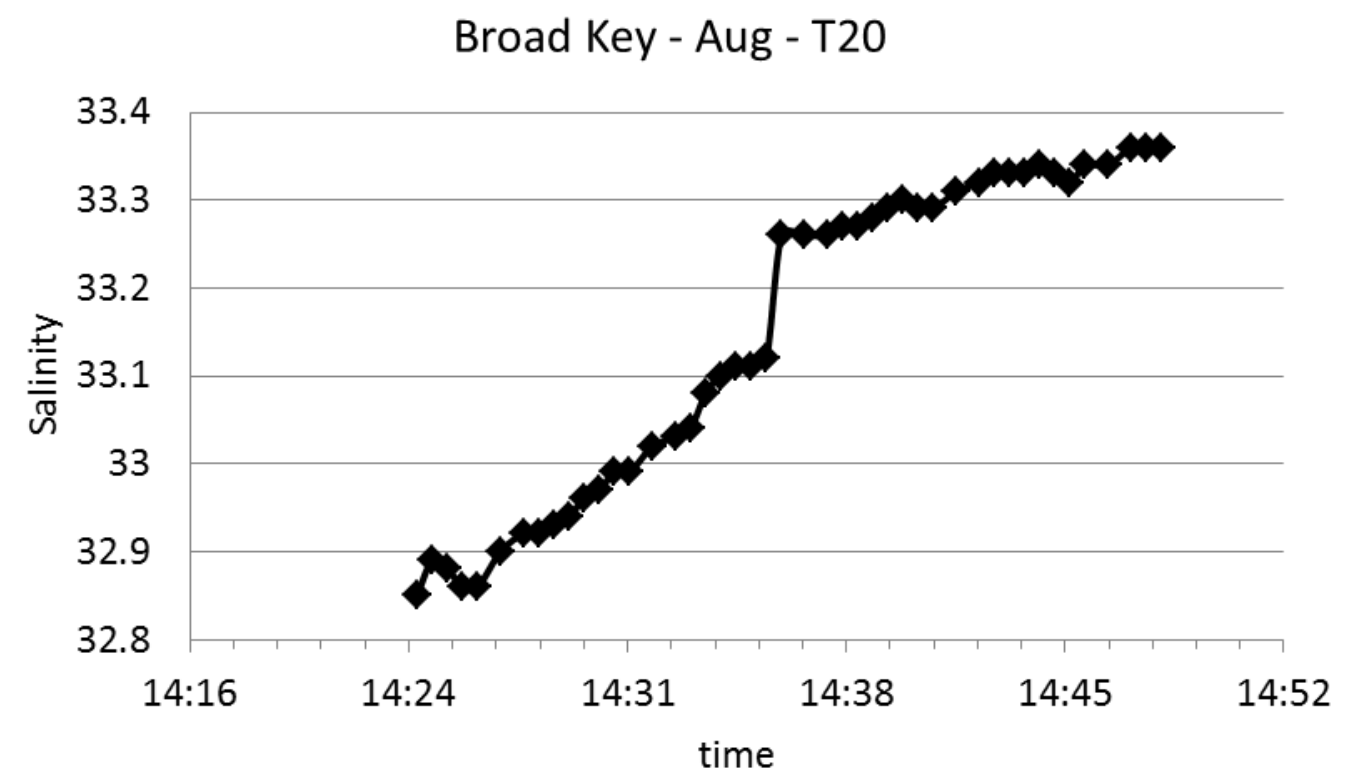

(a)

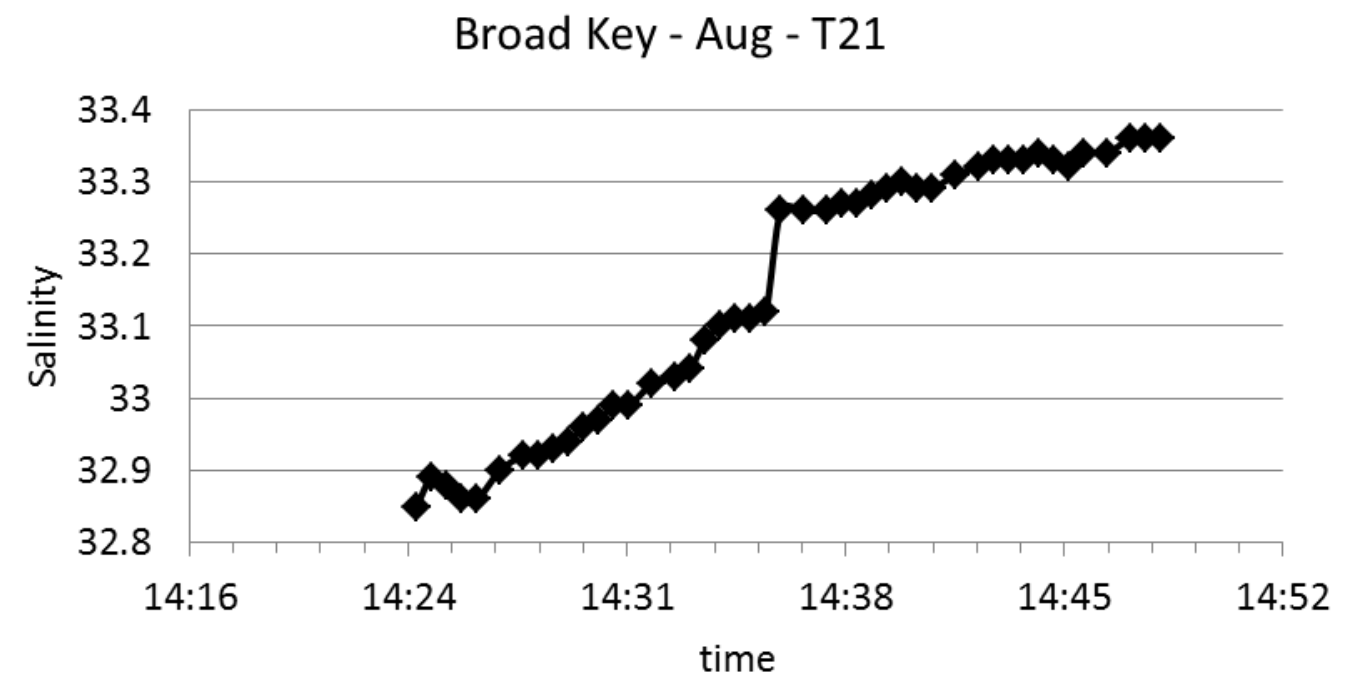

(b)

Figure A1.16 The salinity measured by the YSI shows an abrupt change larger than the noise of the measurement rather than a gradual change throughout the transect. 


\section{Appendix 2:}

Methods for calculating NCP 
NCP was estimated in several ways during this study. In August at Cayo Enrique, we estimated NCP using changes in DIC only because we did not measure $\left[\mathrm{O}_{2}\right]$. In December at Cayo Enrique, we estimate NCP using changes in DIC and $\left[\mathrm{O}_{2}\right]$ as measured with discreet samples. These are compared below. The oxygen probe on the YSI was not working properly in December at Cayo Enrique, so we could not estimate NCP using the YSI $\left[\mathrm{O}_{2}\right]$ data. In February at Broad Key, we estimated NCP by all three methods (DIC, $\left[\mathrm{O}_{2}\right]$-winkler and $\left[\mathrm{O}_{2}\right]$-YSI). Below, we compare the estimates by NCP based on changes in DIC and $\left[\mathrm{O}_{2}\right]$ as measured with discreet samples. We also compare the $\left[\mathrm{O}_{2}\right]$-based estimates of NCP in February at Broad Key determined with data from discreet samples and YSI measurements to support our usage of YSI data for estimating $\mathrm{NCP}$ in August at Broad Key, when the DIC and $\left[\mathrm{O}_{2}\right]$ discreet samples were compromised.

\section{A2.1 Comparison of YSI and Winkler based methods}

In February, we measured $\left[\mathrm{O}_{2}\right]$ by winkler titration and using the $\mathrm{YSI} \mathrm{O}_{2}$-probe. We calibrated the $\mathrm{O}_{2}$-probe using the discreet samples measured by winkler titration. The calibration had a high $\mathrm{r}^{2}$ (Figure A2.1). We then estimated NCP using both measures of $\left[\mathrm{O}_{2}\right]$ and found that they compared very well (Figures A2.2 and A2.3). This is partly due to the fact that the YSI measurements are calibrated with the discreet samples, but is a demonstration of the efficacy of the YSI-based estimates and the validity of comparing winkler-based estimates from one season (February) to YSI-based estimates from another season (August).

\section{A2.2 Comparison of $\mathrm{NCP}$ estimates based on changes in DIC and [ $\left.\mathrm{O}_{2}\right]$}

$\mathrm{NCP}$ was estimated based on the change in DIC and on the change in $\left[\mathrm{O}_{2}\right]$ the winter seasons at Cayo Enrique and Broad Key. Both methods are valid, and have been shown to agree under highly sampled controlled conditions (Langdon et al. 2003). It has been very challenging to find close agreement between these two methods in the much more complex field setting (Falter et al. 2012; Silverman et al. 2012).

We tested the agreement between the two approaches using data collected by both methods at Cayo Enrique and Broad Key in December and February respectively 
(Figures A2.4 and A2.5). If these two methods agreed well the estimates based on these methods would have a 1:1 relationship. Discrepancies between the two methods likely derive from a source of error that impacts one method or impacts both methods differently. This error could be a result of mixing with water that has a different history from the water we are tracking, which could affect both estimates differently. Another source of error could be under or over-estimates of gas exchange for $\mathrm{O}_{2}$. Additionally, the estimates of NCP using the $\mathrm{O}_{2}$ method have been converted to carbon-based units assuming a photosynthetic quotient of 1 . However, it is possible that the PQ actually varies throughout the day or varies spatially over the heterogeneous benthos. Silverman et al. (2012) found PQ to vary from 0.45 to 1.58 with a mean of $0.95 \pm 0.26( \pm 1 \mathrm{SD})$. Because the error for the $\mathrm{O}_{2}$ method is smaller than the error for the DIC method we choose to use the $\mathrm{O}_{2}$ when possible. The strength of the correlations may provide further information about the uncertainty that we have in our estimates of NCP. 


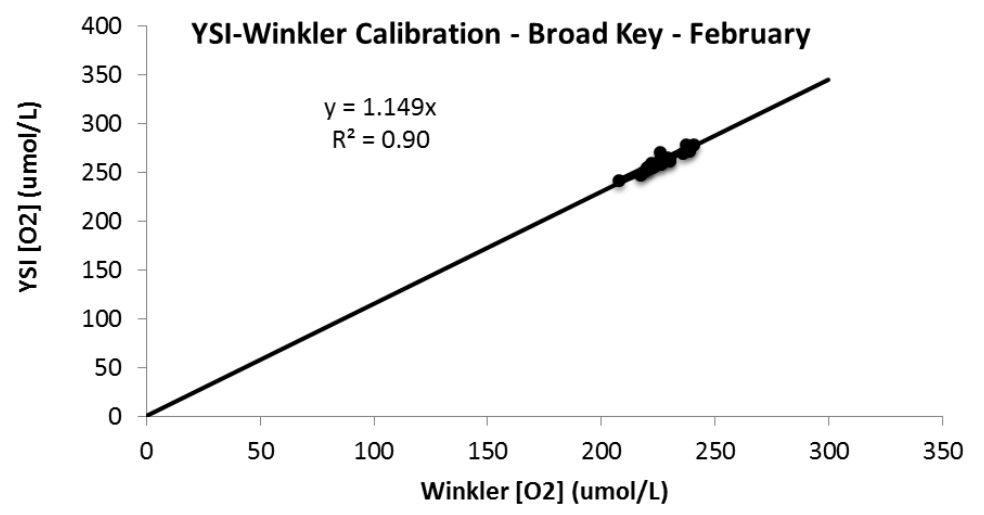

Figure A2.1 Calibration of YSI $\left[\mathrm{O}_{2}\right]$ measurements to $\left[\mathrm{O}_{2}\right]$ measurements of discreet bottle samples measured by Winkler titration. The manual for the ROX Optical DO sensor recommends a 1-point calibration, unless we have a sample to measure that is truly without any oxygen. Here, we essentially determine the best average 1-point calibration. Value in parentheses is standard error of the slope. 


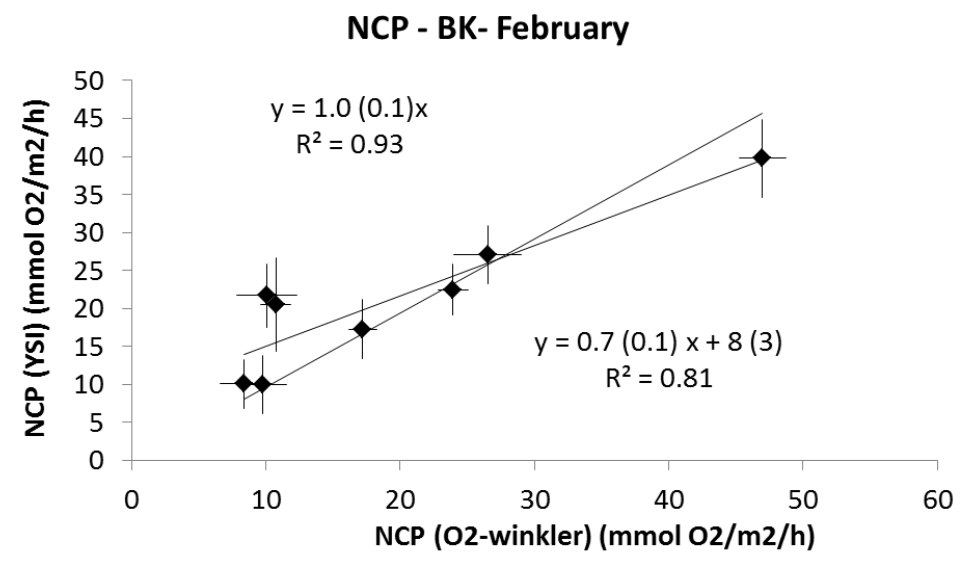

Figure A2.2 The estimates of NCP using YSI data and discreet analyses of $\left[\mathrm{O}_{2}\right]$ by winkler titration agree well. Values in parentheses are standard errors. Both the correlations allowing bias and assuming no bias are shown. Values in parentheses are standard errors of the slope and intercept.

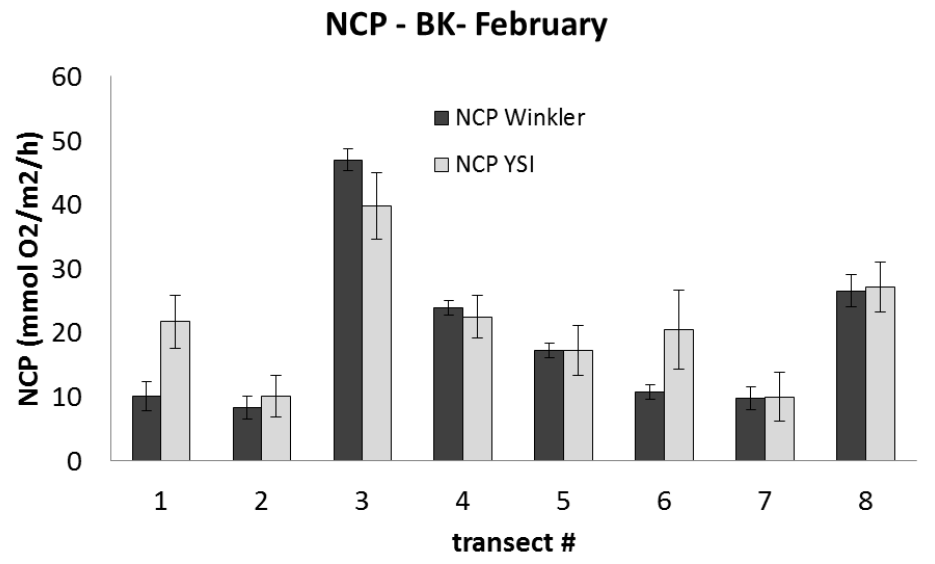

Figure A2.3 The NCP estimates based on the Winkler and YSI measurements of [O2] agree very well. 


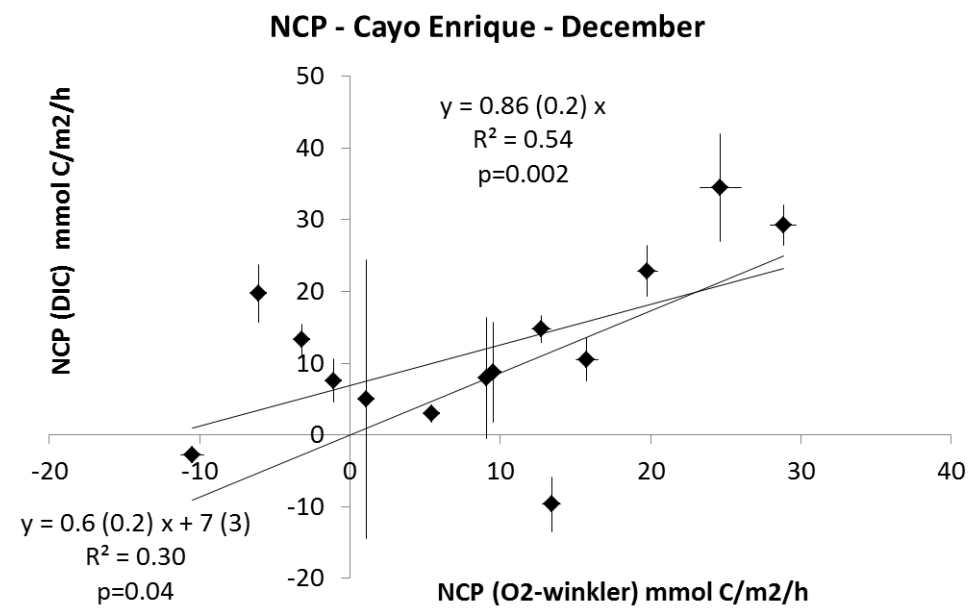

Figure A2.4 Correlations of NCP estimates based on changes in DIC and $\left[\mathrm{O}_{2}\right]$, allowing bias and assuming no bias are shown. Correlations are significant with $p<0.05$. Values in parentheses are standard errors of the slope and intercept.

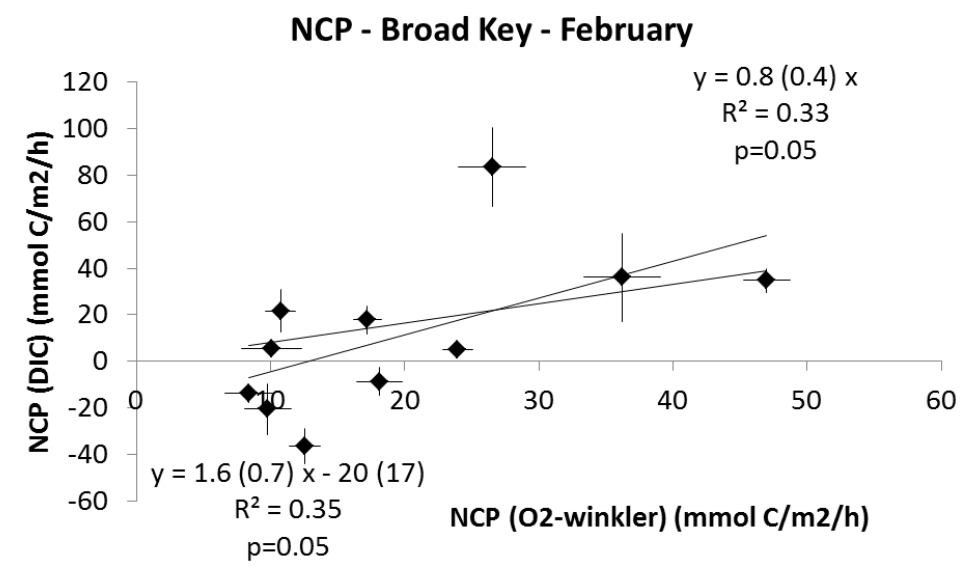

Figure A2.5 Correlations of NCP estimates based on changes in DIC and $\left[\mathrm{O}_{2}\right]$, allowing bias and assuming no bias are shown. Correlations are not significant with $\mathrm{p}>0.05$. Values in parentheses are standard errors of the slope and intercept. 


\section{Chapter 5:}

Conclusions and suggestions for future research 
I investigated net community calcification (NCC) rates on local and global scales to advance our understanding of NCC as a response to environmental changes and as an indication of overall reef health. I quantified the relationship between NCC and aragonite saturation state $\Omega_{\mathrm{a}}$ on local and global scales. I also estimated the magnitude of NCC at both healthy and degraded sites in order to establish baseline values against which future changes can be measured. These values will be useful for quantifying the impacts of ocean acidification, global warming and other environmental changes in the future.

I estimated NCC on a reef flat in the central Red Sea, on a reef slope in Puerto Rico and on a patch reef in the Florida Keys. Average daytime NCC in the Red Sea is $8 \pm 3 \mathrm{mmol} \mathrm{m}^{-2} \mathrm{~h}^{-1}$ in December 2010 and $11 \pm 1 \mathrm{mmol} \mathrm{m}^{-2} \mathrm{~h}^{-1}$ in May 2011. In evaluating the controls on the variability in daytime NCC in the Red Sea, I determined that, although NCC is positively correlated with $\Omega_{\mathrm{a}}$, this correlation is weak and may reflect both the control of $\Omega_{\mathrm{a}}$ on NCC and the confounding effects of organic metabolism on both $\Omega_{\mathrm{a}}$ and NCC (Chapter 2). It is challenging to isolate and quantify the control of $\Omega_{\mathrm{a}}$ on NCC in the field, because light levels and net community production (NCP) exercise such a strong control on NCC. Although high resolution sampling over several years may allow the underlying NCC- $\Omega_{\mathrm{a}}$ relationship to emerge (Langdon et al. 2000), this would require considerable resources and research coordination at a much larger scale than the scope of this thesis project. To circumvent this, I formulated an alternative approach to the problem by utilizing previously published data from around the globe.

This global approach stemmed from the recognition that my model of the controls on NCC assumed that locations with higher $\Omega_{\mathrm{a}}$ would have higher NCC rates than locations with lower $\Omega_{\mathrm{a}}$, after normalizing for calcifier cover. I investigated this notion by assembling a global data set comprised of average daytime hourly NCC, $\Omega_{a}$, temperature, photosynthetically active radiation (PAR), and percent calcifier cover from 15 previously published field and mesocosm studies (including sites from each major ocean basin between $23^{\circ} \mathrm{S}$ and $32^{\circ} \mathrm{N}$ ) (Chapter 3). I found that the NCC, normalized to percent calcifier cover (we used the average percent calcifier cover of $29 \%$, weighting corals and coralline algae equally), correlates strongly with $\Omega_{\mathrm{a}}$, but not with temperature 
or PAR. Moreover, the relationship based on the global dataset agrees within the error of the slope with those from controlled mesocosm experiments also normalized to $29 \%$ calcifier cover (Langdon et al. 2000; Langdon 2002; Langdon and Atkinson 2005; Andersson et al. 2009). This suggests that the NCC- $\Omega_{\mathrm{a}}$ relationship is robust and can be quantified by this global dataset. This analysis could be improved by coordinating field studies to facilitate inter-comparison of the various results (e.g. (Riebesell et al. 2010)). It is especially important to quantify the percent calcifier cover in a thorough manner that is consistent between studies because percent calcifier cover is a key determinant of the NCC observed at any given site. Additionally, targeting research sites that have either high or low mean $\Omega_{\mathrm{a}}$ would expand the range of this relationship. Although there remains room for refinement, the analysis thus far yields a significant result. It implies a sensitivity of about $2.2 \pm 0.4 \mathrm{mmol} \mathrm{m}^{-2} \mathrm{~h}^{-1}$ per unit change $\Omega_{\mathrm{a}}$ for an average reef with $29 \%$ calcifier cover. The sensitivity of a reef with a different percent calcifier cover can be evaluated by scaling the estimated NNCC accordingly (Chapter 3). This relationship also predicts that reefs will transition from net calcification to net dissolution at a $\Omega_{\mathrm{a}}$ of $1.0 \pm 0.6$. This transition point is known as the $\Omega_{\mathrm{a}}$ threshold.

The $\Omega_{\mathrm{a}}$ of surface waters is steadily declining due to ocean acidification. The metabolic activity of the coral reef exerts a strong control on the local reef water carbonate chemistry (Falter et al. 2013) (Chapter 2). The extent to which the reef water $\Omega_{\mathrm{a}}$ differs from the oceanic value on long timescales (months and years) depends on the reef water residence time relative to the metabolic rates. A recent modeling study has improved our understanding of how open ocean and reef water $\Omega_{\mathrm{a}}$ values relate to one another on a small model reef (Falter et al. 2013). Further research is required to investigate the relationship between open ocean and reef water chemistry for diverse reef geometries. The relationship derived here, in Chapter 3, may help in refining these models by serving as a feedback equation between NCC and reef water $\Omega_{\mathrm{a}}$. With improved models of reef carbonate chemistry, we will be poised to use predictions of open ocean carbonate chemistry to predict the reef water $\Omega_{\mathrm{a}}$. 
Without predictions for reef water $\Omega_{\mathrm{a}}$, we use predictions for open ocean $\Omega_{\mathrm{a}}$ to estimate the change in NCC from the pre-industrial until 2100, and assume these represent reef water $\Omega_{\mathrm{a}}$. This assumption is good for reefs that have a short flushing time of 1-2 days (Falter et al. 2013). In 1880, when atmospheric $\mathrm{pCO}_{2}$ was 280ppm, average surface ocean $\Omega_{\mathrm{a}}$ is estimated to have been $4.6 \pm 0.2$ (Kleypas et al. 1999). Average ocean $\Omega_{\mathrm{a}}$ is expected to continue to decline, reaching $2.8 \pm 0.2$ by 2100 (Kleypas et al. 1999). Using the model developed in Chapter $3, N C C=2.2( \pm 0.4) \times \Omega-2( \pm 1)$ (for a reef of $29 \%$ calcifier cover), we predict that NCC rates will decline by $50 \%$ relative to preindustrial rates by the year 2100. A trivial arithmetic exercise shows that the percent decline in NCC for a given change in $\Omega_{\mathrm{a}}$ is the same for reefs of any percent calcifier cover (Chapter 3). This predicted percent decline from 1880 to 2100 is in close agreement with predictions based on mesocosm studies (Langdon et al. 2000; Langdon and Atkinson 2005). Rapidly declining NCC will make it difficult for reefs to accumulate faster than physical, biological and chemical forces erode the reef structure (Hoegh-Guldberg et al. 2007).

The NCC- $\Omega_{\mathrm{a}}$ relationship proposed in Chapter 3 can ultimately be tested and improved as time passes, but only if NCC is monitored regularly as $\Omega_{\mathrm{a}}$ declines with ocean acidification. In order to distinguish changes in NCC due to ocean acidification from changes due to other stressors, care must be taken to monitor changes in other important factors such as calcifier cover, disease levels and temperature. In Chapter 4 of this thesis I estimated modern NCC rates at Cayo Enrique, Puerto Rico and Evan's Reef, Florida. Both of these Caribbean sites have experienced extensive decline over the past four decades due to repeat hurricanes, mass coral bleaching, coral disease, a Diadema pandemic, over-fishing and a variety of other human-induced stressors as the Caribbean islands rapidly developed. I compared these NCC rates to previously published values, and estimate that since 1980 NCC in Puerto Rico declined by more than $90 \%$ and NCC at the Florida Keys site declined by 53 to $73 \%$ (Chapter 4). These changes in NCC are likely linked to changes in the benthic community composition driven by reef degradation. These results agree with the results of a study (Perry et al. 2013) that 
investigated change in net carbonate production rates over several decades by a censusbased method. I also found that both of sites are now likely undergoing net dissolution on diurnal timescales in both summer and winter, in agreement with extensive states of dissolution observed across the Caribbean by Perry et al. (2013). The daytime hourly $\mathrm{NCC}$ at Cayo Enrique and Evan's Reef ranged from $-17 \mathrm{mmol} \mathrm{CaCO}_{3} \mathrm{~m}^{-2} \mathrm{~h}^{-1}$ to $56 \mathrm{mmol}$ $\mathrm{CaCO}_{3} \mathrm{~m}^{-2} \mathrm{~h}^{-1}$ (mean NCC $=3 \mathrm{mmol} \mathrm{CaCO}_{3} \mathrm{~m}^{-2} \mathrm{~h}^{-1}$ ). The estimates determined here will be useful to researchers in the future for continued assessment of changes in reef community growth in the Caribbean Region. As we investigate the consequences of ocean acidification in the future, we must also consider the impacts of other stressors on reef communities. One way to account for this is to carefully monitor changes in benthic community composition. Both Chapters 3 and 4 demonstrate the importance of this key variable, which has until recently been poorly quantified in conjunction with studies of NCC and reef carbonate chemistry.

Net community calcification is a complex construct, as it includes both calcification by many types of organisms and dissolution driven by diverse processes. Because calcification and metabolic dissolution are biologically mediated, the rates of these processes depend on numerous biologically and chemically relevant parameters, including temperature, light, nutritional status and the variable of particular interest in this thesis, $\Omega_{\mathrm{a}}$. These numerous controls on NCC co-vary in the field, and also impact photosynthesis and respiration rates, which in turn influence NCC. For these reasons, it is extremely difficult to isolate, confirm, and quantify the specific control of $\Omega_{\mathrm{a}}$ on NCC in the natural environment. However, it is critical that we do so in order to better understand how ocean acidification will impact NCC in the future. In this thesis, I explored the complexities of the NCC- $\Omega_{\mathrm{a}}$ correlation at the local scale in the Red Sea. I then proposed a global approach for quantifying the underlying relationship at the global scale. Finally, I assessed changes in NCC in the Caribbean Region over the past three decades. Overall, I expect that the general $\mathrm{NCC}-\Omega_{\mathrm{a}}$ relationship proposed here will be useful for modeling the consequences of ocean acidification, and that the estimates of NCC provided here will serve as baseline values against which to measure changes in the future. 


\section{References}

Andersson AJ, Kuffner IB, Mackenzie FT, Jokiel PL, Rodgers KS, Tan A (2009) Net Loss of $\mathrm{CaCO}(3)$ from a subtropical calcifying community due to seawater acidification: mesocosm-scale experimental evidence. Biogeosciences 6:18111823

Falter JL, Lowe RJ, Zhang Z, McCulloch M (2013) Physical and biological controls on the carbonate chemistry of coral reef waters: effects of metabolism, wave forcing, sea level, and geomorphology. Plos One 8:e53303

Hoegh-Guldberg O, Mumby P, Hooten A, Steneck R, Greenfield P, Gomez E, Harvell C, Sale P, Edwards A, Caldeira K (2007) Coral reefs under rapid climate change and ocean acidification. Science 318:1737-1742

Kleypas JA, McManus JW, Menez LAB (1999) Environmental limits to coral reef development: Where do we draw the line? American Zoologist 39:146-159

Langdon C (2002) Review of experimental evidence for effects of CO2 on calcification of reef-builders. Ministry of Environment Indonesian Institute of Sciences, Bali, Indonesia:pp. 1091-1098

Langdon C, Atkinson MJ (2005) Effect of elevated pCO(2) on photosynthesis and calcification of corals and interactions with seasonal change in temperature/irradiance and nutrient enrichment. Journal of Geophysical ResearchOceans 110:1-16

Langdon C, Takahashi T, Sweeney C, Chipman D, Goddard J, Marubini F, Aceves H, Barnett H, Atkinson MJ (2000) Effect of calcium carbonate saturation state on the calcification rate of an experimental coral reef. Global Biogeochemical Cycles 14:639-654

Perry CT, Murphy GN, Kench PS, Smithers SG, Edinger EN, Steneck RS, Mumby PJ (2013) Caribbean-wide decline in carbonate production threatens coral reef growth. Nature Communications 4

Riebesell U, Fabry VJ, Hansson L, Gattuso J-P (2010) Guide to best practices for ocean acidification research and data reporting. Publications Office of the European Union Luxembourg 